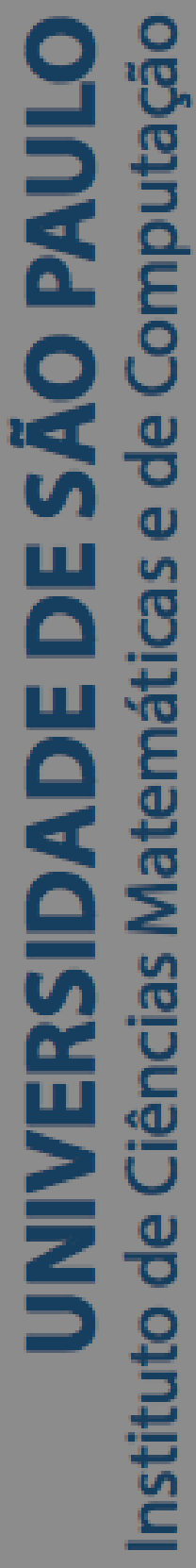

\title{
Similaridade em big data
}

\section{Lúcio Fernandes Dutra Santos}

Tese de Doutorado do Programa de Pós-Graduação em Ciências de Computação e Matemática Computacional (PPG-CCMC) 

Data de Depósito:

Assinatura:

\title{
Lúcio Fernandes Dutra Santos
}

\section{Similaridade em big data}

\author{
Tese apresentada ao Instituto de Ciências \\ Matemáticas e de Computação - ICMC-USP, \\ como parte dos requisitos para obtenção do título \\ de Doutor em Ciências - Ciências de Computação e \\ Matemática Computacional. VERSÃO REVISADA \\ Área de Concentração: Ciências de Computação e \\ Matemática Computacional \\ Orientador: Prof. Dr. Caetano Traina Júnior
}


Ficha catalográfica elaborada pela Biblioteca Prof. Achille Bassi e Seção Técnica de Informática, ICMC/USP, com os dados fornecidos pelo(a) autor(a)

\begin{tabular}{|c|c|}
\hline \multirow[t]{3}{*}{ D237s } & $\begin{array}{l}\text { Dutra Santos, Lúcio Fernandes } \\
\quad \text { Similaridade em big data / Lúcio Fernandes Dutra } \\
\text { Santos; orientador Caetano Traina Júnior. -- São } \\
\text { Carlos, } 2017 \text {. } \\
\quad 146 \text { p. }\end{array}$ \\
\hline & $\begin{array}{l}\text { Tese (Doutorado - Programa de Pós-Graduação em } \\
\text { Ciências de Computação e Matemática Computacional) -- } \\
\text { Instituto de Ciências Matemáticas e de Computação, } \\
\text { Universidade de São Paulo, } 2017 \text {. }\end{array}$ \\
\hline & $\begin{array}{l}\text { 1. Busca por similaridade. } 2 \text {. Diversificação de } \\
\text { resultados. } 3 \text {. Buscas em espaços métricos. } 4 . \\
\text { Ánalise de qualidade de resultados. } 5 \text {. Big data. I. } \\
\text { Traina Júnior, Caetano, orient. II. Título. }\end{array}$ \\
\hline
\end{tabular}




\section{Lúcio Fernandes Dutra Santos}

\section{Similarity in big data}

Doctoral dissertation submitted to the Institute of Mathematics and Computer Sciences - ICMC-USP, in partial fulfillment of the requirements for the degree of the Doctorate Program in Computer Science and Computational Mathematics. FINAL VERSION

Concentration Area: Computer Science and Computational Mathematics

Advisor: Prof. Dr. Caetano Traina Júnior

USP - São Carlos

September 2017 

A minha esposa e filha, com todo o meu amor. 



\section{Agradecimentos}

À Deus.

À minha querida esposa, Ailana, pelo amor, apoio incondicional e paciência que me fortaleceram durantes os momentos mais difíceis. Muito obrigado por acreditar que se pode ser.

À minha linda filha, Bianca, muito obrigado por cada sorriso, carinho e por ser a razão para continuar evoluindo a cada dia.

Ao meu orientador, Prof. Dr. Caetano Traina Júnior, agradeço o apoio e toda confiança que dispensou durante a elaboração deste trabalho, mesmo nos momentos em que tudo parecia caótico. À $\operatorname{Prof}^{a} \operatorname{Dr}^{a}$ Agma Juci Machado Traina, devido aos conselhos, sugestões e pela amizade que sempre me ofereceu durante a realização deste trabalho.

Aos meus pais, pelo carinho, dedicação e ensinamentos em todos os momentos da minha vida. À minha mãe pelo exemplo de que nunca devemos desistir e, por muitas vezes, ter feito dos meus os seus sonhos.

Ao meu grande irmão Elvis, por todo apoio, incentivo, por ser sangue do meu sangue, por ser presente mesmo com toda a distância geográfica.

Aos meus sogros, pela maravilhosa família da qual tenho a graça de pertencer.

Aos grandes amigos que encontrei no GBdI, vocês para sempre farão parte da minha vida, muito obrigado por me receberem, compartilharem sonhos, medos, loucuras, trabalhos, viagens e o mais importante, a amizade dos senhores. Citando um de vocês, "listo-os em ordem alfabética, como tudo deveria ser", Christian Bones, Luiz Olmes, Marcos Bedo e Willian Dener. Só vocês sabem o quão difícil foi escapar da ULA, o valor exato do Lipschitz factor e como três horas de churrasco no Cabañas podem ser revigorantes.

Aos demais amigos que fiz no GBdI, em especial aqueles que tive o prazer de discutir ideias, contar histórias e compartilhar risadas: Alceu, Mônica, Ives, Daniel Chino, Letrícia, Jaqueline, Marcelo e Daniel Kaster. Muito obrigado pela oportunidade de compartilhar tantos momentos com vocês. 
Aos professores Robson Cordeiro, José Fernando Júnior, Elaine Parros, Marcela Xavier, Humberto Razente, Enzo Seraphim e Cristina Dutra pelos ensinamentos, histórias e risadas. Aos funcionários e professores do ICMC-USP.

Ao Instituto Federal do Norte de Minas Gerais (IFNMG) por todo apoio na parte final deste trabalho. Ao Diretor Geral do Campus de Montes Claros, Renato Cota, e o Coordenador de Pesquisa e Extensão, Marcos Aurélio, por reconhecerem a importância da capacitação dos docentes e por, principalmente, fornecerem o apoio disponível ao "novo" colega dos senhores. Aos professores, Laércio, Caribe, Neila, Alberto Miranda, Saulo, Leandro e Fernanda pela receptividade calorosa, amizade e apoio num momento de tantas mudanças e de finalização deste trabalho.

À FAPESP (Fundação de Amparo à Pesquisa do Estado de São Paulo) e ao CNPq (Conselho Nacional de Desenvolvimento Científico e Tecnológico), pelo apoio financeiro à realização deste trabalho. 
"Perfer et obdura, dolor hic tibi proderit olim".

Publius Ovidius Naso 



\section{RESUMO}

DUTRA SANTOS, L. F. Similaridade em big data. 2017. 146p. Tese (Doutorado em Ciências Ciências de Computação e Matemática Computacional) - Instituto de Ciências Matemáticas e de Computação, Universidade de São Paulo, São Carlos - SP, 2017.

Os volumes de dados armazenados em grandes bases de dados aumentam em ritmo sempre crescente, pressionando o desempenho e a flexibilidade dos Sistemas de Gerenciamento de Bases de Dados (SGBDs). Os problemas de se tratar dados em grandes quantidades, escopo, complexidade e distribuição vêm sendo tratados também sob o tema de big data. O aumento da complexidade cria a necessidade de novas formas de busca - representar apenas números e pequenas cadeias de caracteres já não é mais suficiente. Buscas por similaridade vêm se mostrando a maneira por excelência de comparar dados complexos, mas até recentemente elas não estavam disponíveis nos SGBDs. Agora, com o início de sua disponibilidade, está se tornando claro que apenas os operadores de busca por similaridade fundamentais não são suficientes para lidar com grandes volumes de dados. Um dos motivos disso é que "similaridade"' é, usualmente, definida considerando seu significado quando apenas poucos estão envolvidos. Atualmente, o principal foco da literatura em big data é aumentar a eficiência na recuperação dos dados usando paralelismo, existindo poucos estudos sobre a eficácia das respostas obtidas. Esta tese visa propor e desenvolver variações dos operadores de busca por similaridade para torná-los mais adequados para processar big data, apresentando visões mais abrangentes da base de dados, aumentando a eficácia das respostas, porém sem causar impactos consideráveis na eficiência dos algoritmos de busca e viabilizando sua execução escalável sobre grandes volumes de dados. Para alcançar esse objetivo, este trabalho apresenta quatro frentes de contribuições: A primeira consistiu em um modelo de diversificação de resultados que pode ser aplicado usando qualquer critério de comparação e operador de busca por similaridade. A segunda focou em definir técnicas de amostragem e de agrupamento de dados com o modelo de diversificação proposto, acelerando o processo de análise dos conjuntos de resultados. A terceira contribuição desenvolveu métodos de avaliação da qualidade dos conjuntos de resultados diversificados. Por fim, a última frente de contribuição apresentou uma abordagem para integrar os conceitos de mineração visual de dados e buscas por similaridade com diversidade em sistemas de recuperação por conteúdo, aumentando o entendimento de como a propriedade de diversidade pode ser aplicada.

Palavras-chave: Buscas por similaridade, Big data, Análise de qualidade de resultados, Buscas em espaços métricos, Diversificação de resultados. 



\section{ABSTRACT}

DUTRA SANTOS, L. F. Similarity in big data. 2017. 146 p. Tese (Doutorado em Ciências - Ciências de Computação e Matemática Computacional) - Instituto de Ciências Matemáticas e de Computação, Universidade de São Paulo, São Carlos - SP, 2017.

The data being collected and generated nowadays increase not only in volume, but also in complexity, requiring new query operators. Health care centers collecting image exams and remote sensing from satellites and from earth-based stations are examples of application domains where more powerful and flexible operators are required. Storing, retrieving and analyzing data that are huge in volume, structure, complexity and distribution are now being referred to as big data. Representing and querying big data using only the traditional scalar data types are not enough anymore. Similarity queries are the most pursued resources to retrieve complex data, but until recently, they were not available in the Database Management Systems. Now that they are starting to become available, its first uses to develop real systems make it clear that the basic similarity query operators are not enough to meet the requirements of the target applications. The main reason is that similarity is a concept formulated considering only small amounts of data elements. Nowadays, researchers are targeting handling big data mainly using parallel architectures, and only a few studies exist targeting the efficacy of the query answers. This Ph.D. work aims at developing variations for the basic similarity operators to propose better suited similarity operators to handle big data, presenting a holistic vision about the database, increasing the effectiveness of the provided answers, but without causing impact on the efficiency on the searching algorithms. To achieve this goal, four mainly contributions are presented: The first one was a result diversification model that can be applied in any comparison criteria and similarity search operator. The second one focused on defining sampling and grouping techniques with the proposed diversification model aiming at speeding up the analysis task of the result sets. The third contribution concentrated on evaluation methods for measuring the quality of diversified result sets. Finally, the last one defines an approach to integrate the concepts of visual data mining and similarity with diversity searches in content-based retrieval systems, allowing a better understanding of how the diversity property is applied in the query process.

Keywords: Similarity queries, Big data, Analysis of results quality, Similarity search in metric space, Result diversification. 



\section{Lista de Figuras}

1.1 Exemplo de busca por similaridade em um espaço Euclidiano de alta dimensionalidade com alta densidade de dados projetado em duas dimensões . . .

2.1 Representação das formas geométricas geradas pelas funções de distância $L_{1}$, $L_{2}$ e $L_{\infty} \ldots \ldots \ldots \ldots \ldots \ldots \ldots \ldots \ldots \ldots$

2.2 Exemplo de busca por similaridade em um espaço bi-dimensional Euclidiano 13

2.3 Conjunto resultado para a busca aos 5-vizinhos mais próximos diversos. . . . 16

2.4 Conjunto resultado para a busca aos 3-vizinhos distintos mais próximos com exclusão por distância de separação. . . . . . . . . . . . . . . . 17

2.5 Operações de junção por similaridade. . . . . . . . . . . . . . . . . . 18

2.6 Representação da distribuição espacial e estrutura lógica de uma Slim-tree . 19

3.1 Linha do tempo para as abordagens existentes de diversificação de resultados 33

3.2 Interface gráfica do protótipo DivDB . . . . . . . . . . . . . . . 35

3.3 Sequência de resultados do protótipo DivDB . . . . . . . . . . . . . . . 36

3.4 Interface gráfica do protótipo POIKILO . . . . . . . . . . . . . . 37

4.1 Resultado para a busca Q1. (a) Resultado da busca utilizando um operador de busca dos $k$-vizinhos mais próximos. (b) Resultado da busca utilizando a nossa proposta de $k$-vizinhos mais próximos com diversidade. . . . . . . . . . 42

4.2 Intensidade da influência em conjunto de dados representado em um espaço Euclideano bidimensional. . . . . . . . . . . . . . . . . . .

4.3 Construção em três passos do conjunto de resultado para a busca aos $k$ vizinhos diversos mais próximos em um espaço euclideano bidimensional pelo algoritmo $\mathrm{BRID}_{k} \ldots \ldots \ldots \ldots \ldots \ldots$

4.4 Diferença de interpretação dos resultados das buscas por abrangência tradicional e abrangência diversificada para o mesmo elemento central de busca $s_{q}$ com limiar de dissimilaridade máximo $\epsilon \ldots \ldots$. . . . . . . . .

4.5 Exemplo de como a avaliação por sobreposição de conjunto de influência forte detecta a diversidade entre dois elementos no conjunto de resultados. . . . . 
4.6 Resultados para o conjunto de dados Cidades Americanas. . . . . . . . . . . 55

4.7 Resultados para o conjunto de dados Aloi. . . . . . . . . . . . . . . 57

4.8 Resultados para o conjunto de dados Aloi. . . . . . . . . . . . . . 58

4.9 Resultados para o conjunto de dados Carros . . . . . . . . . . . . . . 60

4.10 Resultados para o conjunto de dados Synthetic3D . . . . . . . . . . . 61

4.11 Resultados para o conjunto de dados SynthMultiD . . . . . . . . . . . . 62

5.1 Comparação entre Junções por abrangência e abrangência diversificada. . . .

5.2 Avaliação do desempenho e análise da redução de cardinalidade para o conjunto de dados Aloi. . . . . . . . . . . . . . . . . . . . . . . 71

5.3 Avaliação do desempenho e análise da redução de cardinalidade para o conjunto de dados Proteins. . . . . . . . . . . . . . . . . . . . . . . . . . .

5.4 Avaliação de escalabilidade em relação a cardinalidade e dimensionalidade dos conjuntos de dados. . . . . . . . . . . . . . . . . . . . .

6.1 Visão geral da plataforma de avaliação . . . . . . . . . . . . . . . . .

6.2 Representação dos diferentes conjuntos de candidatos gerados na fase de filtragem de candidatos pelas técnicas propostas. . . . . . . . . . . . . .

6.3 Tempo de execução da fase de computação de diversidade no conjunto de dados U.S Cities. . . . . . . . . . . . . . . . . . . . . . . .

6.4 Tempo de execução da fase de computação de diversidade no conjunto de dados Aloi. . . . . . . . . . . . . . . . . . .

6.5 Tempo total de execução total para diversificação de resultados. Fase de filtragem de candidatos + fase de computação de diversidade. . . . . . . . . .

6.6 Qualidade de diversificação dos algoritmos para as estratégias de filtragem de candidatos quando a preferência de diversidade $(\lambda)$ é incrementada no conjunto de dados U.S Cities.

6.7 Qualidade de diversificação dos algoritmos para as estratégias de filtragem de candidatos quando a preferência de diversidade $(\lambda)$ é incrementada no conjunto de dados Aloi. . . . . . . . . . . . . . . . . . . . . .

7.1 Seleção dos elementos para uma busca por similaridade em um espaço Euclideano de duas dimensões.

7.2 Resultados para uma busca sobre o conjunto de dados MRIBalan utilizando a técnica ReGI. . . . . . . . . . . . . . . . . . .

7.3 Tempo de execução para os conjuntos de dados (a) MRIBalan e (b) ImageCLEFmed para $k$ variando de 3 até $11 \ldots \ldots . . \ldots$

7.4 Tempo de execução para $k$ variando de 5 até 25 nos conjuntos: (a) Aloi , (b) Colors, (c) Faces, e (d) Nasa. 
7.5 Benefício Relativo para (a) $k=5$ e (b) $k=10 \ldots \ldots \ldots$. . . . . . . 96

7.6 Relação entre a quantidade de elementos retornados e representativos nos resultados do conjunto de dados MRIBalan. . . . . . . . . . . . . . . .

7.7 Relação entre a quantidade de elementos retornados e representativos nos resultados dos conjuntos de dados Aloi, Colors e Faces. . . . . . . . . . . . .

8.1 Mapeamento do espaço de resposta. . . . . . . . . . . . . . . . . 103

8.2 Avaliação de qualidade do $D i F_{M}$ no espaço de resposta. . . . . . . . . . . . . 106

8.3 Método $D_{M}$. (a) Conjuntos de resultados dissimilares $\left(D_{M}=0.8\right)$. (b) Conjuntos de resultados similares (iguais) $\left(D_{M}=0.0\right) \ldots \ldots \ldots$

8.4 Método $D E_{M}$. (a) Conjuntos de resultados com $D E_{M}=5$. (b) Conjuntos de resultados com $D E_{M}=3$.

8.5 Comparação dos cinco métodos de avaliação de diversificação sobre o conjunto de dados U.S Cities variando a preferência de diversidade. . . . . . . . . . .

8.6 Comparação dos cinco métodos de avaliação de diversificação sobre o conjunto de dados Aloi variando a preferência de diversidade. . . . . . . . . . . . . . . 113

8.7 Comparação dos cinco métodos de avaliação de diversificação sobre o conjunto de dados Nasa variando a preferência de diversidade. . . . . . . . . . . . . .

8.8 Comparação dos cinco métodos de avaliação de diversificação sobre o conjunto de dados Faces variando a preferência de diversidade. . . . . . . . . . . . .

8.9 Gráficos em Radar para análise das características de diversidade no conjunto de dados Nasa. . . . . . . . . . . . . . . . . . . . . . . . . 116

8.10 Gráficos em Radar para análise das características de diversidade no conjunto de dados Faces. . . . . . . . . . . . . . . . . . . . . . . . 117

9.1 Pipeline do método DiVI.

9.2 Exemplos de manipulação de instâncias na projeção inicial no módulo de MVD.123

9.3 Técnicas de visualização e interação utilizadas na projeção final. . . . . . . . . 124

9.4 Interface do Protótipo VikS. . . . . . . . . . . . . . . . . . . . . . . 125

9.5 Resultados (apenas similaridade) para o conjunto de dados Corel no espaço n-dimensional (características extraídas) com o módulo de MVD ativado. . .

9.6 Projeção final gerada para o conjunto de dados Corel com os resultados de ambos os espaços $n$-dimensional e o de distorção do usuário.

9.7 Resultado para uma busca com $40 \%$ de Diversidade no conjunto de dados Corel utilizando as modificações armazenadas na base de dados de característica personalizadas. . . . . . . . . . . . . . . . . . . . 



\section{Lista de Tabelas}

3.1 Aspectos dos algoritmos de diversidade baseada em conteúdo que devem ser considerados para a definição de um modelo e de algoritmos de diversidade apropriados para tratar big data. . . . . . . . . . . . . . . . . 40

4.1 Buscas por similaridade fundamentais e com diversidade e seus respectivos critérios de comparação. . . . . . . . . . . . . . . . . . . . 46

4.2 Estatísticas dos conjuntos de dados . . . . . . . . . . . . . . 54

5.1 Configuração dos experimentos . . . . . . . . . . . . . . . 70

7.1 Estatísticas dos conjuntos de dados . . . . . . . . . . . . . . . 92

8.1 Estatísticas dos conjuntos de dados avaliados . . . . . . . . . . . . 109 



\section{Lista de Algoritmos}

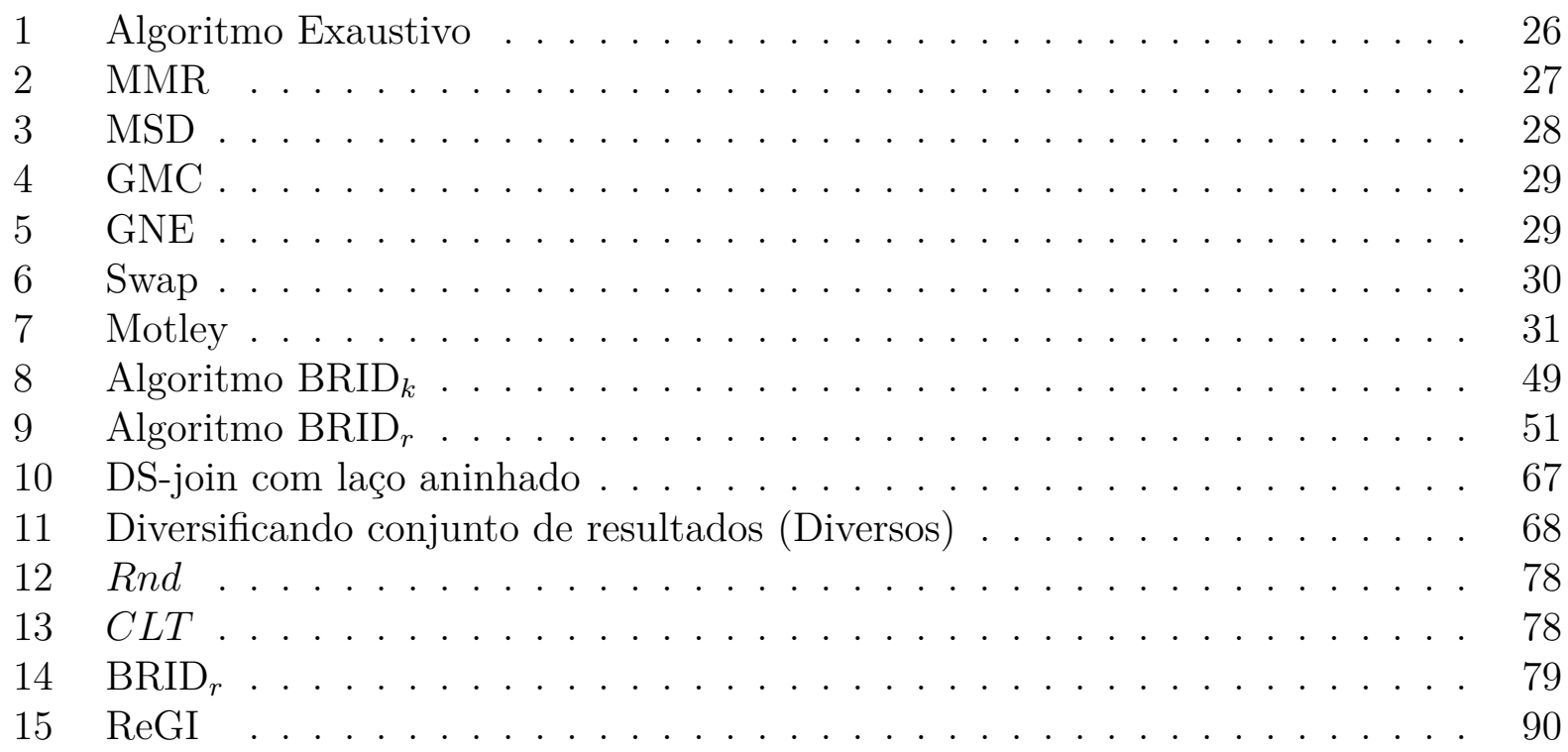





\section{Abreviaturas e Siglas}

\begin{tabular}{|c|c|}
\hline SGBDs & - Sistemas de Gerenciamento de Bases de Dados \\
\hline RI & - Relações de Identidade \\
\hline $\mathrm{RO}$ & - Relação de Ordem \\
\hline$T B I R$ & - Tag-Based Image Retrieval \\
\hline$C B I R$ & - Content-Based Image Retrieval \\
\hline SGBDR & - Sistemas de Gerenciamento de Bases de Dados Relacionais \\
\hline RDI & - Result Diversification based on Influence \\
\hline BRID & - Better Results With Influence Diversification \\
\hline DiVI & - Diversity and Visually-Interactive \\
\hline MAMs & - Método de Acesso Métrico \\
\hline VP-tree & - Vantage Point tree \\
\hline MVP-tree & - Multi-Vantage Point tree \\
\hline$S Q L$ & - Structured Query Language \\
\hline MMR & - Maximal Marginal Relevance \\
\hline MSD & - Max-Sum Diversification \\
\hline GMC & - Greedy Marginal Contribution \\
\hline GNE & - Greedy Randomized with Neighborhood Expansion \\
\hline mmc & - maximum marginal contribution \\
\hline$G R A S P$ & - Greedy Randomizer Adaptive Search Procedure \\
\hline $\mathrm{RCL}$ & - Restricted Candidate List \\
\hline FM & - First-Match \\
\hline $\mathrm{CM}$ & - Centroid-Match \\
\hline$S S S D$ & - Sparse Spatial Selection Diversification \\
\hline$S S S$ & - Spatial Selection Diversification \\
\hline DisC & - Dissimilar and Covering diversity \\
\hline$N D C G$ & - Normalized Discounted Cumulative Gain \\
\hline$M R R$ & - Mean Reciprocal Rank \\
\hline$M A P$ & - Mean Average Precision \\
\hline IR & - Information Retrieval \\
\hline$N D C G-I A$ & - Intent-Aware Normalized Discounted Cumulative Gain \\
\hline $\mathrm{RB}$ & - Relative Benefit \\
\hline POIKILO & - diversos (do grego " $\pi о \iota \kappa \iota \lambda o^{\prime}$ ) \\
\hline
\end{tabular}




\begin{tabular}{|c|c|c|}
\hline MVD & - & Mineração Visual de Dados \\
\hline LAMP & - & Local Affine Multidimensional Projection \\
\hline PEx-Image & - & Projection Explorer System for Images \\
\hline $\mathrm{BRID}_{k}$ & - & Better Results with Influence Diversification to $k-N D N q$ \\
\hline $\mathrm{BRID}_{r}$ & - & Better Results with Influence Diversification to $R D q$ \\
\hline OEM & - & Overlap Evaluation Method \\
\hline DS-Join & - & Diversified Similarity Join \\
\hline$D i F_{M}$ & - & Dissimilarity Feature method \\
\hline$D_{M}$ & - & Dissimilarity Method \\
\hline$D E_{M}$ & - & Dissimilarity Error \\
\hline AvgDivDist & - & Average Diversity Distance \\
\hline AvgSimDist & - & Average Similarity Distance \\
\hline SDDivDist & - & Standard Deviation of Diversity Distance \\
\hline SDSimDist & - & Standard Deviation of Similarity Distance \\
\hline MinDist & - & Minimum Distance \\
\hline MaxDist & - & Maximum Distance \\
\hline $\operatorname{Re} G I$ & - & Relative Grouping based on Influence \\
\hline $\mathrm{CB}$ & - & Context-Boundary \\
\hline LMC & - & Limite Máximo de Contexto \\
\hline $\mathrm{PC}$ & - & Pontos de controle \\
\hline FEM & - & Feature Extractor Module \\
\hline VikS & - & Visually Interactive $k$ Diverse Neighbor System \\
\hline CAD & - & Computer-Aided Diagnosis \\
\hline
\end{tabular}




\section{Símbolos}

\begin{tabular}{|c|c|c|}
\hline$R q$ & - & Similarity range query \\
\hline$k-N N q$ & - & k-nearest neighbor query \\
\hline$k-N D N q$ & - & k-nearest diverse neighbors query \\
\hline$M D P$ & - & Maximum Diversity Problem \\
\hline$k-D N N q$ & - & k-distinct nearest neighbor query \\
\hline$\stackrel{R q}{\bowtie}$ & - & Range join \\
\hline$\stackrel{k-N N q}{\bowtie}$ & - & k-nearest neighbors join \\
\hline$\stackrel{{ }^{k-C N q}}{{ }^{-}}$ & - & k-closest neighbors join \\
\hline$R D q$ & - & Range Diverse query \\
\hline $\operatorname{RngDiv}\left(\delta, \epsilon_{q}\right)$ & - & Diversified Similarity Join \\
\hline$n$ & & Número de elementos num conjunto de dados \\
\hline$s_{q}$ & & Elemento central da busca \\
\hline$S$ & - & Conjunto de dados \\
\hline $\mathbb{S}$ & - & Domínio de dados dos elementos válidos \\
\hline$\delta$ & - & Função de distância \\
\hline $\mathbb{R}^{+}$ & - & Domínio dos números reais positivos \\
\hline$s_{i}$ & & Elemento $i$ \\
\hline$\epsilon_{q}$ & - & Raio de busca ou grau de dissimilaridade máximo \\
\hline$k$ & - & Número de elementos a serem retornados na busca aos $k$-vizinhos mais próximos \\
\hline$E$ & - & Dimensão \\
\hline$\epsilon$ & - & Distância a partir de um elemento de busca \\
\hline$L_{p}$ & & Funções de distância da família Minkowski \\
\hline$L_{e d i t}$ & & Função de distância de Levenshtein \\
\hline$Q$ & & Conjunto de elementos de busca \\
\hline$\delta_{\text {agg }}$ & & Função de agregação de similaridade entre elementos \\
\hline$g$ & & Fator de ajuste (grip factor) de agregação \\
\hline$w_{q}$ & & Fator de peso de agregação \\
\hline$\delta_{\text {sim }}^{4}$ & & Função de distância para o cálculo de similaridade dos elementos \\
\hline$\delta_{d i v}$ & & Função de distância para o cálculo de diversidade dos elementos \\
\hline$R$ & & Conjunto de resultado retornados \\
\hline$\lambda$ & & Preferência de diversidade \\
\hline$\phi$ & - & Distância de separação entre os elementos \\
\hline
\end{tabular}




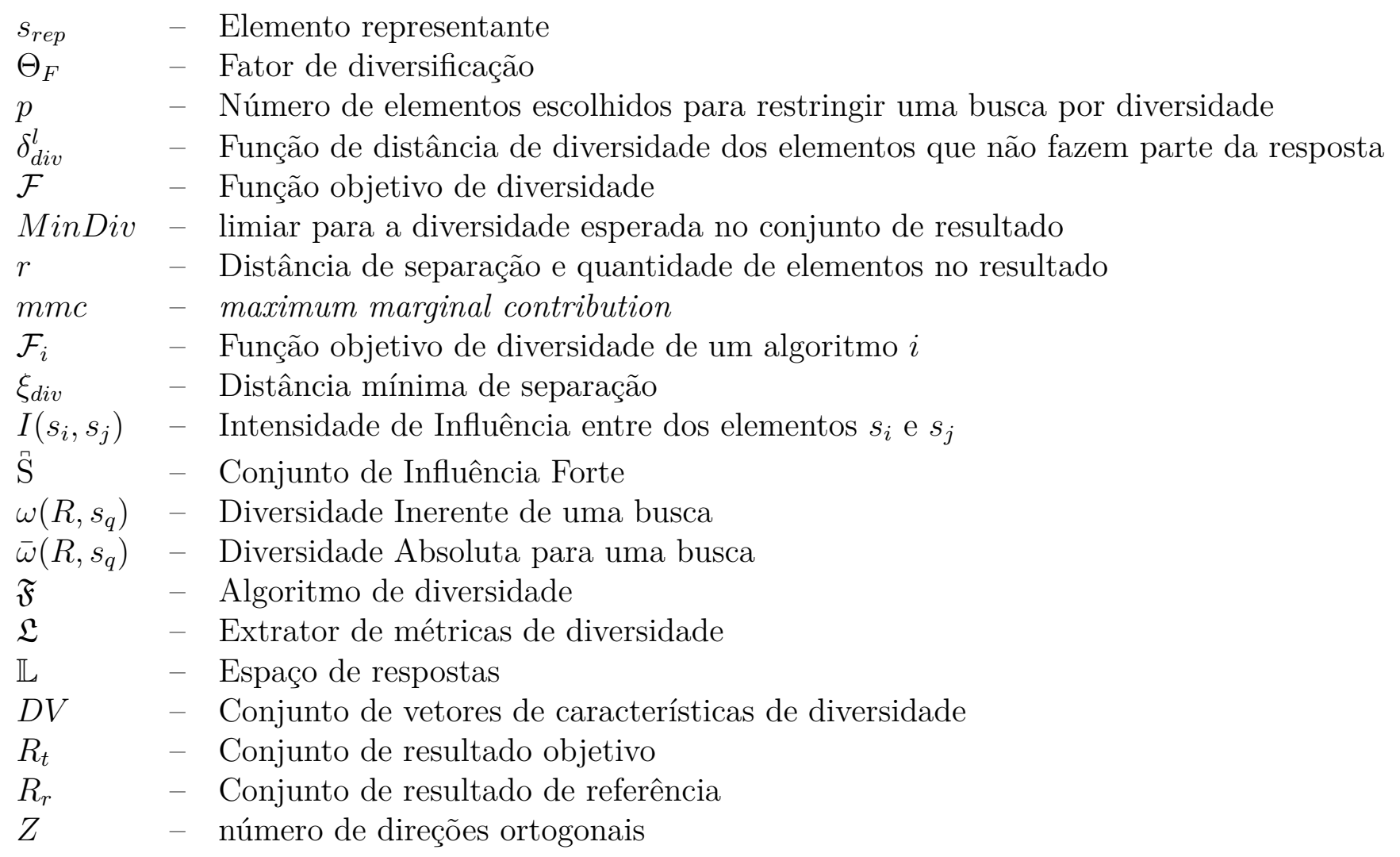




\section{Sumário}

Lista de Figuras

Lista de Tabelas

Lista de Algoritmos

XXIII

Abreviaturas e Siglas

XXV

Símbolos

XXVII

1 Introdução 1

1.1 Motivação . . . . . . . . . . . . . . . . . . . . . 3

1.2 Objetivos e Contribuições . . . . . . . . . . . . . . 5

1.3 Organização do documento . . . . . . . . . . . . . . . . . . 7

2 Buscas por Similaridade $\quad 9$

2.1 Medidas de Similaridade . . . . . . . . . . . . . . . . . . 9

2.2 Tipos de Buscas por Similaridade . . . . . . . . . . . . . . . . . . . . 12

2.2.1 Busca por Abrangência . . . . . . . . . . . . . . . 12

2.2.2 Busca aos $k$-Vizinhos Mais Próximos . . . . . . . . . . . . . . 13

2.2.3 Variações dos Tipos Básicos de Buscas por Similaridade . . . . . . . 13

2.2.3.1 Busca aos $k$-Vizinhos Diversos Mais Próximos . . . . . . 14

2.2.3.2 Busca aos k-Vizinhos Distintos Mais Próximos . . . . . . . 16

2.2.4 Junções por Similaridade . . . . . . . . . . . . . . . . . . 17

2.3 Métodos de Acesso Métrico _ . . . . . . . . . . . . . . . . . . . . . 18

2.4 Considerações Finais . . . . . . . . . . . . . . . . . . . . . 20 
3 Big Data e Diversificação de Resultados $\quad 21$

3.1 A definição de big data . . . . . . . . . . . . . . . . . . . . . . . . . 22

3.2 Arquitetura e Soluções para big data . . . . . . . . . . . . . . . . . . . . 22

3.3 Estratégias para Diversificação de Resultados . . . . . . . . . . . . . . . . 24

3.3.1 Diversidade Baseada em Atributo . . . . . . . . . . . . . . . . 24

3.3.2 Diversidade Baseada em Conteúdo . . . . . . . . . . . . . . . 25

3.3.3 Diversidade baseada em distância de separação . . . . . . . . . . . . 30

3.4 Métodos de Avaliação de Resultados com Diversidade . . . . . . . . . . . . . 32

3.5 Protótipos para Otimização e Avaliação de Resultados com Diversidade . . . 35

3.6 Mineração Visual de Dados . . . . . . . . . . . . . . . . . . 37

3.7 Considerações Finais . . . . . . . . . . . . . . . . . . . . . . . . . . . . 39

4 Diversificação de Resultados baseada em Influência 41

4.1 O Modelo de Diversificação de Resultados baseado em Influência . . . . . . . 43

4.2 A técnica BRID . . . . . . . . . . . . . . . . . . . . . 47

4.2 .1 Busca aos $k$-Vizinhos Diversos mais Próximos . . . . . . . . . . . 48

4.2 .2 Busca por Abrangência Diversificada . . . . . . . . . . . . . . . 49

4.3 Método de Avaliação por Sobreposição de Influência . . . . . . . . . . . . . . 52

4.4 Experimentos . . . . . . . . . . . . . . . . . . . 53

4.4.1 Conjunto de Dados e Descrição dos Experimentos . . . . . . . . . . . 53

4.4.2 Avaliação de Desempenho e Qualidade de Diversificação . . . . . . . . 55

4.4.3 Experimento com as buscas por abrangência diversificada . . . . . . . 59

4.4.4 Experimentos de Escalabilidade . . . . . . . . . . . . . . . 60

4.5 Considerações Finais . . . . . . . . . . . . . . . . . . . . . 62

5 Junção Diversificada $\quad 63$

5.1 Junções por Similaridade Diversificada . . . . . . . . . . . . . . . . . . 65

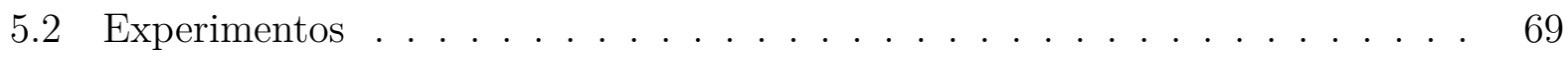

5.2 .1 Conjuntos de Dados . . . . . . . . . . . . . . . . . 69

5.2.2 Avaliação de Desempenho e da Cardinalidade do Conjunto de Resultados 70

5.2.3 Experimentos de Escalabidade . . . . . . . . . . . . . . . . . . 72

5.3 Considerações Finais . . . . . . . . . . . . . . . . . . . . . . . 73 
6 Otimização da Diversificação por meio de Técnicas de Amostragem 75

6.1 Plataforma de Avaliação . . . . . . . . . . . . . . . . . . . . 76

6.2 Técnicas para melhorar a fase de Filtragem de Candidatos . . . . . . . . . . 77

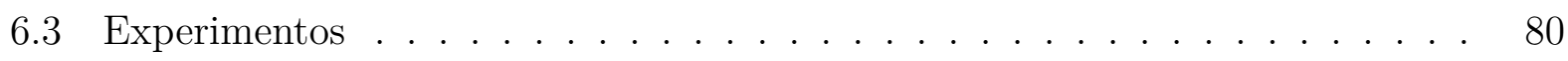

6.3.1 Conjuntos de Dados . . . . . . . . . . . . . . 81

6.3 .2 Avaliação de Desempenho . . . . . . . . . . . . . . . . . . . 81

6.3.3 Avaliação de Qualidade de Diversificação . . . . . . . . . . . . . . . . 84

6.4 Considerações Finais . . . . . . . . . . . . . . . . . . . . . . 85

7 Agrupamento Relativo baseado em Influência $\quad 87$

7.1 ReGI: Agrupamento relativo baseado em Influência . . . . . . . . . . . . . . 89

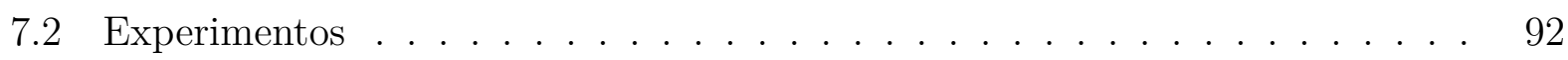

7.2 .1 Estudo de Caso . . . . . . . . . . . . . . . . . . . . . 93

7.2.2 Avaliação de Desempenho . . . . . . . . . . . . . . . . 94

7.2 .3 Avaliação de Qualidade . . . . . . . . . . . . . . . . 96

7.2 .4 Avaliação de Recuperação de Informação . . . . . . . . . . . . . . . . 97

7.3 Considerações Finais . . . . . . . . . . . . . . . . . . . . . . 98

8 Avaliando a Diversificação de Resultados $\quad 101$

8.1 Avaliação de Diversidade . . . . . . . . . . . . . . . . . . 102

8.1 .1 O Vetor de Características de Diversidade . . . . . . . . . . . . . 103

8.1 .2 Método de Avaliação de Diversificação . . . . . . . . . . . . . . 105

8.1.2.1 Método de Dissimilaridade de Características $\left(D i F_{M}\right)$. . . 105

8.1.2.2 Método de Avaliação de Dissimilaridade $\left(D_{M}\right)$. . . . . . 106

8.1.2.3 Método de Avaliação do Erro de Dissimilaridade $\left(D E_{M}\right)$. . 107

8.2 Experimentos . . . . . . . . . . . . . . . . . 108

8.2.1 Comparação de Métodos de Avaliação de Diversificação . . . . . . . . 110

8.2.2 Análise de Características de Diversidade . . . . . . . . . . . . 115

8.3 Considerações Finais . . . . . . . . . . . . . . . . . . . . . 117

9 O Método DiVI e o Protótipo VikS 119

9.1 O Método DiVI . . . . . . . . . . . . . . . . . . . 120

9.2 O protótipo VikS . . . . . . . . . . . . . . . . . . 123 
9.3 Experimentos . . . . . . . . . . . . . . . . . . . . 126

9.4 Considerações Finais . . . . . . . . . . . . . . . . . . . . . . . . . 128

10 Conclusão $\quad 129$

10.1 Principais Contribuições . . . . . . . . . . . . . . . . . . . 130

10.2 Contribuições Complementares . . . . . . . . . . . . . . . . . . 131

10.3 Publicações . . . . . . . . . . . . . . . . . . . . . . . 132

10.4 Trabalhos Futuros . . . . . . . . . . . . . . . . . . . . . 134

$\begin{array}{ll}\text { Referências Bibliográficas } & 137\end{array}$ 


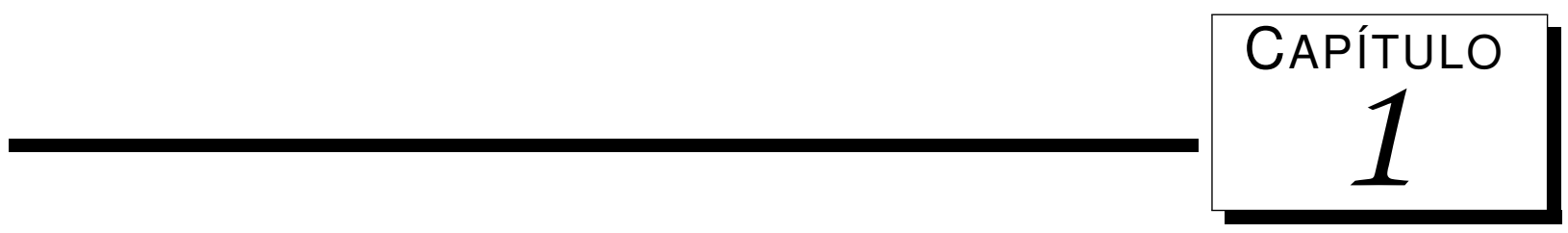

\section{Introdução}

Os Sistemas de Gerenciamento de Bases de Dados (SGBDs) foram criados visando o armazenamento e a recuperação de grandes quantidades de dados, garantindo que sua recuperação seja eficiente, sempre fornecendo respostas exatas às buscas. Estes sistemas, tradicionalmente, suportam apenas números e pequenas cadeias de caracteres, conhecidos como "dados escalares". Com a evolução das aplicações, vem se tornando necessário armazenar, organizar e recuperar dados mais complexos, por exemplo, informações geo-referenciadas, dados vetoriais, dados multimídia (imagens, áudio e vídeo), séries temporais, grafos, sequências de proteínas, genericamente chamados de "dados complexos". Além disso, o ritmo de produção de dados também vem aumentando bastante. Com isso, novas aplicações de SGBDs tais como em ferramentas de apoio ao diagnóstico médico por imagens, coleta de dados de sensores remotos de estações meteorológicas, sistemas governamentais para análise de transações a partir de notas fiscais, ambientes de redes sociais, sistemas de análises científicas, dentre outros, desafiam tanto a eficiência quanto a eficácia dos operadores de busca dos SGBDs.

A quantidade de dados imensa tanto em escala, quanto em complexidade, escopo, distribuição e/ou heterogeneidade produzidos por tais sistemas vem sendo referenciada como big data (CUZZOCREA; SONG; DAVIS, 2011; WANG et al., 2016; LIU; DUBE; GRAY, 2014; MOISE et al., 2013). Desse modo, é cada vez mais necessário desenvolver novas técnicas para tratar de maneira eficiente e eficaz tipos de dados complexos armazenados em escalas que vão à ordem dos milhares de Petabytes - um petabyte $(\mathrm{PB})$ é $2^{50}$ bytes, o que corresponde à ordem de grandeza de $10^{15}$ bytes.

Os Sistemas Gerenciadores de Bases de Dados Relacionais (SGBDR) oferecem recursos para executar buscas usando Relações de Identidade (RI - representadas pelos operadores de comparação $=\mathrm{e} \neq$ ) e Relações de Ordem $(\mathrm{RO}$ - representadas pelos operadores de comparação $<, \leq,>$ e $\geq$ ), propriedades que são atendidas pelos domínios de dados escalares tradicionais. Porém, buscas por igualdade são de pouca serventia para dados complexos, pois é raro existirem elementos exatamente iguais. Além disso, usualmente, os dados complexos são representados em domínios que não atendem às propriedades de $\mathrm{RO}$, impedindo o uso dos respectivos comparadores. 
Na maioria das vezes, a busca em coleções de dados complexos não é feita comparando diretamente os elementos originais, mas usando atributos (características) que descrevem/representam o elemento complexo. Tipicamente, existem duas técnicas para associar atributos aos elementos complexos. A primeira é chamada "Recuperação por Contexto", por exemplo, Recuperação de Imagens por Contexto (TBIR na sigla em inglês - Tag-Based Image Retrieval). Essa técnica se baseia em associar outros atributos a cada elemento complexo, em geral de tipo textual, cujos valores são obtidos externamente (contexto) ao elemento complexo (WU, 2012). Exemplos dessa técnica são a associação de descrições e palavras-chave feitas por pessoas às imagens, tais como laudos em imagens de exames médicos, e a associação automática de textos próximos às imagens em páginas da web. A segunda técnica é chamada de "Recuperação por Conteúdo", como por exemplo em Recuperação de Imagens por Conteúdo (CBIR na sigla em inglês - Content-Based Image Retrieval) (SANTOS et al., 2014; WELTER et al., 2012; CARVALHO et al., 2015; KARIM; HARRIS; ARIF, 2016; NEVEOL et al., 2009). A técnica CBIR corresponde à associação de atributos obtidos a partir do próprio elemento complexo, extraídos automaticamente por algoritmos de processamento não supervisionados.

Na recuperação por conteúdo, as comparações são executadas usando os vetores de características correspondentes em lugar dos elementos complexos propriamente ditos. A comparação é feita por uma "Função de Distância" que quantifica quão "próximos" ou "similares" dois elementos são, habilitando a representação de buscas baseadas na similaridade dos elementos. Além disso, as funções de distância devem garantir propriedades para a construção de estruturas de dados capazes de agilizar o processo de busca no lugar das propriedades baseadas em RO e RI (VENKATESWARAN et al., 2008; ZEZULA et al., 2006). Para ser usada em SGBDs, a função de distância é considerada uma "caixa preta", geralmente definida por um especialista no domínio da aplicação.

Com a necessidade do suporte a dados multimídia em SGBDs, os operadores de busca baseados em operadores de comparação por similaridade vêm despertando interesse crescente, principalmente para a recuperação por conteúdo (BUDIKOVA; BATKO; ZEZULA, 2012; LIU; SHEN; WANG, 2016; ZHANG et al., 2014; SILVA et al., 2013a; GUI et al., 2017). A recuperação dos dados armazenados numa base de dados é feita pelos chamados operadores de busca, dos quais são exemplos os operadores de seleção, projeção, junção e agrupamento. É importante ressaltar que o termo "operador relacional" sempre se refere a um operador de busca e não aos operadores de comparação, dos quais são exemplos, as comparações por igualdade, por relações de ordem e por similaridade. Três dos operadores de busca relacionais, os operadores de seleção, junção e agrupamento, usam operadores de comparação para escolher dentre os dados procurados. A literatura frequentemente lista dois operadores de comparação por similaridade como fundamentais: os que expressam as comparações por abrangência e as comparações por $k$-vizinhos mais próximos (KORN et al., 1996; CHAKRABARTI et al., 2004; SILVA et al., 2013a; SANTOS et al., 2013; CARVALHO et al., 2016).

Contudo, a partir da disponibilidade desses operadores em SGBDRs e de sua aplicação em casos reais sobre bases com grande volume de dados, tem se constatado que os dois critérios de comparação por similaridade fundamentais e os operadores de busca neles baseados não são adequados, ou suficientes, para atender às necessidades de manipulação de dados complexos (CARVALHO et al., 2015; PLANT; SCHAEFER, 2012; HONG; ZHU, 2013; GUI et al., 2017; CARVALHO et al., 2016; KARIM; HARRIS; ARIF, 2016). Além do fato há muito tempo reconhecido de que o processamento de buscas por similaridade é oneroso em termos 
computacionais devido a natureza da busca, os operadores fundamentais são pouco expressivos em situações reais, sendo necessário realizar a composição com outros em uma mesma busca e, em muitos casos, obrigando na reformulação da mesma, o que é feito de maneira nem sempre intuitiva para os usuários (CHEN; LI, 2007; ANGEL; KOUDAS, 2011). Por fim, a quantidade de elementos no conjunto de resultados tende a ser grande, requisitando maior esforço de análise manual dos resultados das buscas ou a utilização de algoritmos de pós-processamento para sumarizar os resultados (CARVALHO et al., 2015).

Todos os problemas citados são agravados com o aumento da densidade dos dados, principalmente pelo aumento da capacidade de geração e armazenamento por parte das aplicações que utilizam os SGBD. Para contornar esses problemas é necessário identificar características específicas da distribuição dos dados e desenvolver operadores mais expressivos, que possam incorporar recursos para explorar a quantidade de informação disponível no enorme volume de dados. Assim, será possível retornar não apenas elementos tão similares entre si que sejam considerados equivalentes, mas também apresentar elementos que forneçam uma visão abrangente da base de dados no conjunto de resultado.

\subsection{Motivação}

As buscas por similaridade são muito importantes para a análise e recuperação de dados complexos em SGBDs, mas os recursos que estão começando a se tornar disponíveis e utilizados em bases com grande volumes de dados vêm revelando que os dois operadores de comparação por similaridade fundamentais e os operadores de busca neles baseados não são adequados, ou suficientes, para atender às necessidades de manipulação de dados complexos (ANGEL; KOUDAS, 2011; KASTER et al., 2011; GUI et al., 2017; CARVALHO et al., 2016; CARVALHO et al., 2015; HONG; ZHU, 2013; PLANT; SCHAEFER, 2012; KARIM; HARRIS; ARIF, 2016). Com isso, existe hoje uma tendência mundial em estudar tanto outros critérios de comparação por similaridade quanto operadores de busca por similaridade mais elaborados, que sejam mais adequados ao processamento e análise de grande volumes de dados. Dentre os critérios de comparação para busca por similaridade que vêm sendo estudados, pode-se citar o critério baseado em $k$-vizinhos reversos mais próximos (YAO; LI; KUMAR, 2009; CHEEMA et al., 2010; LU; LU; CONG, 2011; SURATANEE; PLAIMAS, 2014; EMRICH et al., 2015) e critérios de diversidade (VIEIRA et al., 2011a; SANTOS; MACDONALD; OUNIS, 2015; CATALLO et al., 2013; KHAN; DROSOU; SHARAF, 2013; DOU et al., 2011; FRATERNALI; MARTINENGHI; TAGLIASACCHI, 2012; DROSOU; PITOURA, 2015; AMAGATA; HARA, 2016). Dentre os operadores de busca por similaridade que vêm sendo estudados, pode-se citar operadores de junção por similaridade (SILVA; REED, 2012; SILVA et al., 2013a; LIU; SHEN; WANG, 2016; CHEN et al., 2017; ZHANG et al., 2014; CARVALHO et al., 2016), operadores skyline (ISLAM; LIU; ZHOU, 2014; ZHANG et al., 2013; SAFAR; EL-AMIN; TANIAR, 2011; LI; YAN; LEMIRE, 2016; DING et al., 2012), e operadores de buscas envolvendo mais de um centro de busca (SILVA; AREF; ALI, 2009; DENG et al., 2009; HUANG, 2017; TEODORO et al., 2011; LI et al., 2011; RAZENTE et al., 2008). Para cada nova técnica, também são desenvolvidos novos algoritmos que permitem executá-los de maneira mais eficiente, apoiando assim o desenvolvimento de ferramentas de análise e de novos recursos para os domínios de aplicações que precisam recuperar dados complexos. 


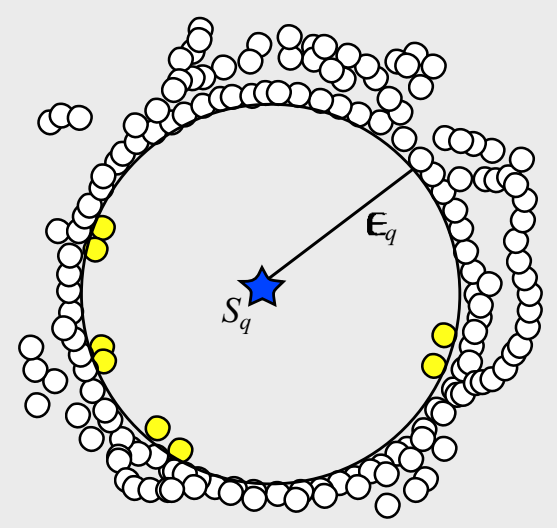

(a)

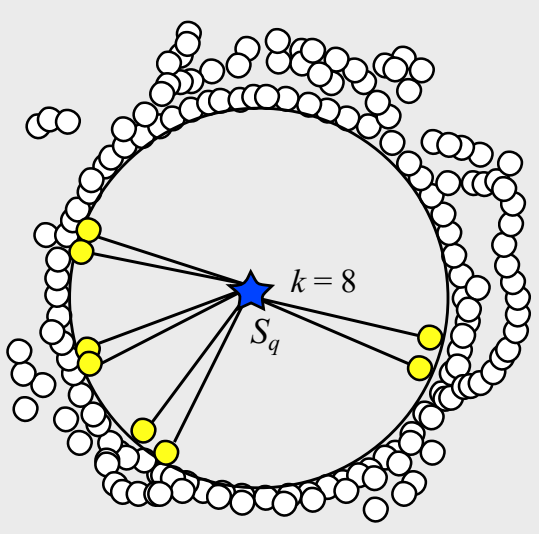

(b)

Figura 1.1: Exemplo de busca por similaridade em um espaço Euclidiano de alta dimensionalidade com alta densidade de dados projetado em duas dimensões. (a) Busca por abrangência e (b) Busca aos $k$-vizinhos mais próximos.

No entanto, tais critérios de comparação e operadores de busca, embora mais expressivos, não têm ainda sido suficientes para atender às particularidades que trabalhar com big data requer, e em parte isso acontece porque na literatura ainda não existe uma distinção bem definida entre os critérios de comparação e os operadores de busca por similaridade. Com isso, existe uma dicotomia entre os trabalhos que buscam aumentar a eficiência necessária para tratar big data e os que buscam atender a novos operadores mais adequados para tratar big data. Por um lado, a criação de novos operadores de busca proporciona a inclusão de novas funcionalidades, algumas visando o tratamento de grandes volumes de dados, mas que extraem informação distinta dos demais operadores já existentes, e portanto não suprem a necessidade de obter a informação provida pelos operadores básicos de maneira escalável para grandes volumes de dados. Por outro, os novos critérios de comparação disponíveis na literatura não levam em conta o volume de dados e a grande maioria não é escalável. Por exemplo, os trabalhos existentes sobre outros critérios de comparação por similaridade ( $k$-vizinhos reversos mais próximos e diversidade) fornecem operadores de busca baseados em algoritmos polinomiais de ordem elevada ou mesmo $n p$-completos, portanto inviáveis para tratar big data. Por outro lado, os trabalhos recentes em big data têm o foco principalmente na eficiência e buscam aprimorar o desempenho da indexação e recuperação, em geral trabalhando com arquiteturas paralelas (BORKAR; CAREY; LI, 2012; PAPADIMITRIOU; SUN, 2008; MOISE et al., 2013; FEGARAS; LI; GUPTA, 2012; SCHADT et al., 2010; VERNICA; CAREY; LI, 2010; SILVA; REED, 2012; HALL et al., 2013; LIU; DUBE; GRAY, 2014; WANG et al., 2016), mas sem abordar a raiz do problema, que é o aumento da densidade do espaço de busca. De fato, apesar do rápido crescimento do volume de dados, o modelo de busca por similaridade utilizado sempre tem permanecido o mesmo, isto é, utilizam-se sempre os mesmos operadores fundamentais que consideram os dados em espaços "esparsos" (SKOPAL et al., 2009).

Um outro problema é que, conforme o espaço vai sendo continuamente preenchido com novos dados, ele tende a ficar tão "denso" que os elementos acabam sendo muito similares a muitos outros. A elevada dimensionalidade dos dados também contribui para aumentar a similaridade entre os elementos, pois um efeito da maldição da alta dimensionalidade é a redução 
da diferença entre as similaridades, ou seja, as distâncias entre o elemento mais próximo e o mais distante de cada centro ficam cada vez mais parecidas (KATAYAMA; SATOH, 2001). Assim, é comum que elementos de uma classe sejam considerados muito similares aos de outra classe, pois os agrupamentos (cluster) de dados praticamente não possuem uma "borda" nesse espaço. Por exemplo, a Figura 1.1 ilustra um espaço Euclidiano de alta dimensionalidade com alta densidade de dados projetado em duas dimensões, mostrando-se a distância dos elementos a um elemento central de busca. A Figura 1.1(a) mostra um exemplo de busca por abrangência e a Figura 1.1(b) mostra um exemplo de busca aos $k$-vizinhos mais próximos com $k=8$, ambas centradas no elemento $s_{q}$. Se cada ponto representar uma imagem no espaço de similaridade, com o aumento da densidade possivelmente os elementos escolhidos ou serão imagens muito similares à imagem central de busca ou na resposta irão existir pares de imagens que são muito similares entre si, e assim provavelmente a inclusão da maioria desses elementos na resposta não agrega utilidade ao usuário. Além disso, com o aumento da dimensionalidade e o consequente "esmagamento" do espaço de distâncias, pequenas variações do elemento de busca podem trazer respostas completamente diferentes. No entanto, apesar da densidade ser sempre alta, continuam a existir variações de densidade. Assim, é necessário desenvolver técnicas que possam obter resultados mesmo tratando de espaços que apresentam alta dimensionalidade e densidade em todo o espaço onde os dados estão distribuídos, desconsiderando elementos muito similares.

\subsection{Objetivos e Contribuições}

Um dos principais diferenciais deste projeto de doutorado em relação aos trabalhos existentes na literatura é o objetivo de melhorar a eficácia (qualidade do resultado da busca) dos operadores em espaços de alta dimensionalidade e densidade de dados, sem causar impactos significativos na eficiência. Dessa maneira, o objetivo geral deste projeto de doutorado foi propor variações dos operadores de busca por similaridade que atendam às necessidades advindas de se trabalhar com big data, bem como os respectivos algoritmos para executá-los de maneira eficiente, definindo operações mais expressivas, que atendam melhor às necessidades dos aplicativos de busca por conteúdo de imagens por similaridade quando o volume dos dados a serem pesquisados é muito grande. Assim, o objetivo específico para o Projeto de Doutorado consistiu em caracterizar um novo "Modelo de Similaridade para big data" analisando como e quais devem ser os critérios de comparação adequados para comparação por similaridade em big data bem como quais e como devem ser os operadores de busca relacional por similaridade. Visando alcançar esse objetivo, a tese explorada neste trabalho é sucintamente descrita conforme segue:

"Num ambiente de big data, não é possível tratar todos os elementos do conjunto de dados para fornecer respostas às buscas formuladas pelos usuários, sendo importante realizar a escolha de alguns elementos (amostragem) para possibilitar uma visão mais abrangente do conjunto de dados. Embora a propriedade de diversidade possua restrições (custo computacional e ajustes de parâmetros) para sua utilização é possível integrá-la aos operadores relacionais (seleção e junção) sem a dependência de ajuste de parâmetros e implementá-la de maneira eficiente e que possa melhorar a qualidade das respostas fornecidas sobre conjuntos de dados volumosos."

As principais contribuições desta tese foram obtidas a partir de quatro frentes de trabalho. A primeira frente compreendeu a definição de um modelo de diversificação de resultados de bus- 
cas por similaridade, chamado de Diversificação de Resultados baseado em Influência (Result Diversification based on Influence - RDI), que realiza uma estimativa automática sobre qual deve ser o tamanho mínimo para a distância de separação entre os elementos na resposta, que é definida adaptativamente, isto é, a medida que os elementos incluídos na resposta ficam cada vez mais distantes do elemento central de busca, a distância mínima exigida entre os elementos também aumenta, imitando a percepção intuitiva de que dois elementos distintos parecem mais similares um do outro à medida que se afastam do observador em questão. O modelo RDI possui as seguintes características: independência de parâmetros, de domínio de dados e do operador de busca. Assim, a propriedade de diversidade foi definida como um critério de comparação transparente aos operadores de busca, definindo um modelo de similaridade para grandes volumes de dados. Além disso, foi definida uma técnica para implementar o modelo RDI nos critérios de comparação aos $k$-vizinhos mais próximos e por abrangência, chamada de Melhores Resultados com Diversificação baseada em Influência (Better Results with Influence Diversification - BRID). Ainda nessa frente de trabalho, a técnica BRID possibilitou a implementação da diversidade nos operadores de busca de seleção e junção por similaridade, mostrando que o modelo RDI é consistente e genérico o suficiente para ser utilizado em operadores de busca unários e binários.

A segunda frente de trabalho concentrou-se na aplicação do modelo RDI em outros modelos de diversificação, especificamente definindo uma técnica de amostragem de conjuntos de dados, resultando em um conjunto de candidatos de menor cardinalidade capaz de reduzir os custos de execução dos algoritmos de diversificação existentes sem comprometer a qualidade final da resposta. Ainda nesta frente de trabalho, o modelo RDI também foi utilizado para definir uma técnica de agrupamentos de dados relativo ao elemento central de busca, possibilitando que usuários visualizem e naveguem iterativamente pelos grupos de elementos muitos similares, começando por um elemento representativo, o que acelera o processo de análise de um espaço de busca.

Quando a busca não tem uma definição do que deve ser a resposta exata, tal como "os $k$ elementos mais próximos", mas acrescenta uma flexibilização tal como "que tenham diversidade entre si", é importante ter um critério para comparar alternativas. A terceira frente de trabalho focou em definir um conjunto de métodos para medir a precisão dos algoritmos de diversificação de resultados, com base no uso de várias análises estatísticas obtidas de diferentes estratégias para medir a diversidade de conjuntos de resultados. Foram apresentados três novos métodos de avaliação de diversidade, sendo que dois deles comparam conjuntos de resultados utilizando apenas os elementos e a relação de distância entre os conjuntos avaliados. O terceiro método utiliza a definição proposta para um "espaço de respostas", no qual cada elemento é uma possível solução de busca. Tal espaço permite a comparação de buscas e a definição de propriedades que permitem desenvolver diretrizes para escolher qual é o algoritmo de buscas por similaridade com diversidade mais adequado para um dado conjunto de dados. Por fim, também foi apresentado um método de avaliação de diversidade com base no conceito RDI, recuperando a qualidade da resposta baseando-se no grau de sobreposição de influência dos elementos.

A última frente de trabalho teve por objetivo a definição de uma abordagem para integrar os conceitos de diversidade e mineração visual de dados nos sistemas de recuperação baseado em conteúdo de imagens (CBIR). O método visualmente interativo e de diversidade (Diversity and Visually-Interactive - DiVI) emprega projeções multidimensionais para visualização do espaço de busca com base nas características extraídas das imagens do conjunto de dados. Visualizações são utilizadas para a apresentação dos resultados, aumentando o 
entendimento sobre como são selecionados os elementos, incluindo como a diversidade é empregada na resposta. Além disso, o método possibilita modificar a posição dos elementos de acordo com o interesse do usuário, aumentando a participação no processo de recuperação. Nesta linha, foi desenvolvido um protótipo de sistema de recuperação por conteúdo de imagens, VikS (Visually Interactive $k$ Diverse Neighbor System) que implementa o método DiVI e os algoritmos existentes de diversidade para aumentar o entendimento do processo de recuperação de respostas diversificadas.

As diversas contribuições propostas neste trabalho de doutorado permitiram avançar o estado-da-arte de diversificação de resultados na área de base de dados, apresentando uma base teórica, métodos de avaliação, algoritmos e um protótipo de sistema de recuperação por conteúdo. As propostas visaram apresentar um modelo de similaridade, identificando o critério de comparação de diversidade e operadores de busca para lidar com grandes volumes de dados, alta dimensionalidade e densidade de dados. Com isso, é possível um analista ter uma visão abrangente do conjunto de dados, usando as respostas das buscas por similaridade.

\subsection{Organização do documento}

Além deste capítulo introdutório, o restante da tese está organizado como segue.

- O Capítulo 2 apresenta os conceitos relacionados a buscas por similaridade, ilustrando os tipos básicos e suas variações. Além disso, ele comenta rapidamente como é feita a recuperação eficiente de dados comparados por similaridade.

- O Capítulo 3 apresenta os conceitos relacionados com big data e as estratégias para melhorar a qualidade dos resultados de buscas por similaridade em grandes volumes de dados por meio da diversificação de resultados.

- O Capítulo 4 descreve uma das atividades correspondentes à primeira frente de trabalho empreendida nesta tese. Nele apresenta-se um modelo de diversificação de resultados que realiza uma estimativa automática sobre qual deve ser o tamanho mínimo para a distância de separação entre os elementos na resposta, sem requisitar nenhum ajuste de parâmetro ou qualquer tipo de conhecimento prévio sobre o conjunto de dados, chamado de modelo de diversificação baseado em influência. Além disso, o modelo define a propriedade de diversidade de maneira transparente aos operadores de busca por similaridade, possibilitando melhorar a relevância dos resultados em grandes volumes de dados.

- O Capítulo 5 descreve a última atividade referente à primeira frente de trabalho desta tese, apresentando o conceito de junção diversificada, uma operação binária que recebe dois conjuntos de dados como entrada e combina os elementos atendendo o critério de similaridade, porém garantindo também uma resposta diversificada com menor cardinalidade.

- O Capítulo 6 descreve uma das atividades referentes à segunda frente de trabalho desta tese. Nele apresenta-se como o modelo de diversificação baseado em influência pode ser utilizado para realizar a amostragem de um conjunto de resultados, com o intuito de aprimorar o desempenho de algoritmos de diversidade baseado em otimização combinatória. Foi definida uma plataforma de avaliação para os principais algoritmos 
de diversificação de resultados para verificar o impacto da substituição da estratégia dos $k$-vizinhos mais próximos na fase de filtragem de candidatos.

- O Capítulo 7 apresenta a última atividade desenvolvida à segunda frente de trabalho realizada na tese. Nele descreve-se uma técnica de agrupamento relativo baseada em influência para agrupar elementos muito similares se baseando no elemento central de busca, com melhor capacidade, numa seção interativa, de recuperar mais informações desde a primeira busca submetida ao sistema.

- O Capítulo 8 apresenta as atividades correspondentes à terceira frente de trabalho empreendida nesta tese. Nele descreve-se um novo conjunto de métodos para medir a precisão dos algoritmos de diversificação de resultados, com base no uso de várias análises estatísticas obtidas de diferentes estratégias para medir a diversidade de conjuntos de resultados.

- O Capítulo 9 descreve as atividades referentes à quarta frente de trabalho empreendida nesta tese. Nele apresenta-se um método de integração dos conceitos de mineração visual de dados e buscas por similaridade com diversidade, chamado de DiVI (Diversity and Visually-Interactive). Seu objetivo é aumentar as informações disponíveis sobre como a propriedade de diversidade é aplicada para obter os conjuntos de resultados. Além disso, é apresentado um protótipo que implementa DiVI para avaliação de buscas em conjuntos de dados de imagens.

- Finalmente, o Capítulo 10 traz as conclusões do trabalho, incluindo referências às publicações geradas durante os trabalhos desenvolvidos e as propostas de trabalhos futuros. 


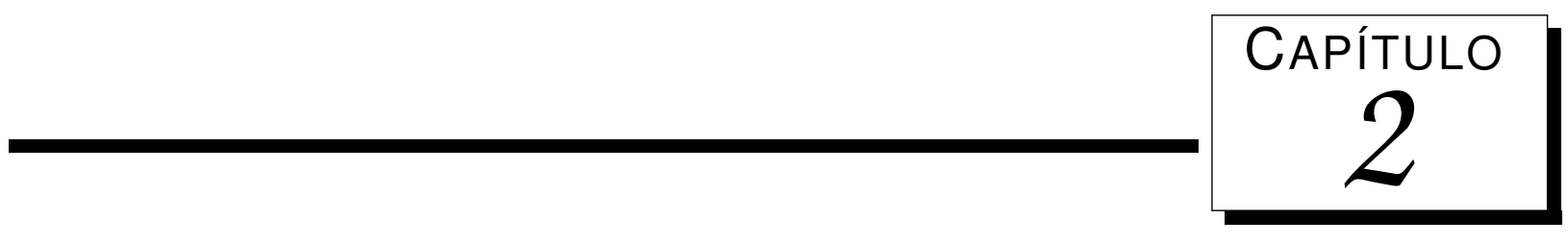

\section{Buscas por Similaridade}

Os Sistemas de Gerenciamento de Bases de Dados (SGBDs) foram criados para o armazenamento e recuperação de grandes quantidades de dados. Desde sua definição, tais sistemas tradicionalmente suportam apenas números e pequenas cadeias de caracteres. Com a evolução das aplicações, vem se tornando necessário armazenar, organizar e recuperar dados mais complexos, como exemplo, informações geo-referenciadas, dados vetoriais, dados multimídia (imagens, áudio e vídeo) e séries temporais. Contudo, as buscas por igualdade ou envolvendo a relação de ordem dos elementos não se aplicam, ou possuem pouco valor semântico para dados complexos. Para esse tipo de dados é mais relevante buscar por elementos que sejam mais "parecidos" ou mais "distintos" de acordo com algum critério de comparação por similaridade.

Neste contexto, este capítulo apresenta os conceitos envolvidos e os principais tipos de operadores de busca por similaridade para dados complexos, tratando esses conceitos dentro do contexto de um ambiente de execução de consultas baseado no Modelo Relacional. A Seção 2.1 apresenta conceitos de medidas de similaridade. A Seção 2.2 apresenta os principais tipos de operadores de busca por similaridade e suas variantes. A Seção 2.3 apresenta alguns dos principais métodos de indexação para tornar a recuperação de imagens representadas em espaços métricos mais eficiente. As considerações finais do capítulo são apresentadas na Seção 2.4.

\subsection{Medidas de Similaridade}

Para que um sistema possa responder a buscas por similaridade e retornar os elementos que mais se assemelham a um dado elemento de busca, é necessário quantificar o quão dissimilares são os elementos envolvidos na busca. Considere que $S=\left\{s_{1}, s_{2}, \ldots s_{n}\right\}$ seja um conjunto de dados com $n$ elementos amostrados de um domínio de dados $\mathbb{S}$. Os elementos $s_{i}$ são representações sucintas dos elementos de interesse (no caso deste projeto, as imagens), chamadas vetores de características. A representação das imagens por características se faz necessária, pois a comparação pixel a pixel entre duas imagens praticamente não possui valor semântico que corresponda à percepção humana. Desta forma, a semântica da imagem é descrita por 
meio de medidas em geral numéricas que capturam alguma propriedade visual da imagem, como exemplo, cor, forma ou textura. As características são obtidas automaticamente por algoritmos de processamento não supervisionados aplicados aos elementos complexos.

Uma função de distância $\delta$ é definida para calcular a distância entre dois elementos e retornar um valor real positivo. Por convenção, adota-se que quanto mais similares dois elementos são entre si, menor o valor dessa função. Como as propriedades da relação de ordem não podem ser utilizadas para a construção de estruturas de dados que agilizem buscas por similaridade, é interessante então representar os dados em algum espaço que possua propriedades úteis para isso. A teoria dos espaços métricos tem sido utilizada para definir estruturas de dados para tornar o acesso e a comparação dos elementos mais eficiente nas buscas por similaridade (VENKATESWARAN et al., 2008; ZEZULA et al., 2006). Formalmente, um espaço métrico é definido conforme apresentado na Definição 1.

Definição 1. Espaço métrico. Seja $\langle\mathbb{S}, \delta\rangle$ um par, onde $\mathbb{S}$ é o conjunto de todos os elementos que atendem aos requisitos do espaço (também chamado de domínio de dados), e $\delta: \mathbb{S} \times \mathbb{S} \rightarrow \mathbb{R}^{+}$é uma função de distância, chamada também de métrica, que atende às três seguintes propriedades (LIMA L. ELON, 1993):

- simetria: $\delta\left(s_{1}, s_{2}\right)=\delta\left(s_{2}, s_{1}\right)$;

- não-negatividade: $0<\delta\left(s_{1}, s_{2}\right)<\infty$ se $s_{1} \neq s_{2} \operatorname{com} \delta\left(s_{1}, s_{1}\right)=0$; e

- desigualdade triangular: $\delta\left(s_{1}, s_{2}\right) \leq \delta\left(s_{1}, s_{3}\right)+\delta\left(s_{3}, s_{2}\right), \forall s_{1}, s_{2}, s_{3} \in \mathbb{S}$.

Em geral, as funções de distância $\delta$ são definidas para aplicações específicas ou para domínios específicos de aplicação. Por isso, uma função de distância é normalmente definida por um especialista da aplicação ou do domínio de dados. Por exemplo, a comparação de imagens requer conhecimento especializado em processamento de imagens, e se a aplicação for mais específica, como a análise de imagens de radiografia de pulmão, então além do domínio de imagens, é necessário o conhecimento das particularidades das imagens radiográficas de pulmão. Porém, a definição dessas funções não se restringe a um tipo de busca. Existe uma grande variedade de funções de distância relatadas na literatura (WILSON; MARTINEZ, 1997). As mais utilizadas são as funções de distância da família Minkowski (BEYER et al., 1999), conhecidas também como família $L_{p}$ de distâncias, e são empregadas em espaços multidimensionais. É possível utilizar a família $L_{p}$ de distâncias para comparar dados de dimensão fixa. Suponha que $s_{1}=\left\{s_{1_{1}}, s_{1_{2}}, \ldots, s_{1_{E}}\right\}$ e $s_{2}=\left\{s_{2_{1}}, s_{2_{2}}, \ldots, s_{2_{E}}\right\}$ são dois elementos de um espaço multidimensional de dimensão $E$. A família $L_{p}$ de distâncias é definida como:

$$
L_{p}\left(s_{1}, s_{2}\right)=\left(\sum_{i=1}^{E}\left|s_{1_{i}}-s_{2_{i}}\right|^{p}\right)^{1 / p}
$$

Os membros da família $L_{p}$ mais conhecidos são representados matematicamente pelas funções de distância:

- Manhattan: $L_{1}\left(s_{1}, s_{2}\right)=\sum_{i=1}^{E}\left|s_{1_{i}}-s_{2_{i}}\right|$

- Euclidiana: $L_{2}\left(s_{1}, s_{2}\right)=\left(\sum_{i=1}^{E}\left|s_{1_{i}}-s_{2_{i}}\right|^{2}\right)^{1 / 2}$ 
- Chebychev: $L_{\infty}\left(s_{1}, s_{2}\right)=\max _{i=1}^{E}\left|s_{1_{i}}-s_{2_{i}}\right|$

A função de distância $L_{1}$, também conhecida como Manhattan, corresponde ao somatório do módulo das diferenças entre as dimensões dos elementos. Nesse caso, o conjunto de pontos equidistantes a uma distância $\epsilon$ do centro forma um losango, como representado na Figura 2.1 (a). A função de distância $L_{2}$, mais conhecida como distância Euclidiana, corresponde à função usual para distância entre vetores. O conjunto de pontos à mesma distância de um centro segundo a distância $L_{2}$ forma uma circunferência, conforme mostrado na Figura 2.1 (b). Considerando o limite da Equação (2.1) quando $p$ tende ao infinito, obtém-se a função de distância $L_{\infty}$, também conhecida como Chebychev, na qual o conjunto de pontos a distância de um centro forma um quadrado, como representado na Figura 2.1 (c). Por fim, a Figura 2.1 (d) apresenta as formas geométricas em relação aos pontos equidistantes à distância $\epsilon$ a partir do mesmo elemento central de busca $s_{q}$ para os três membros da família $L_{p}$ mencionados.

As funções de distância da família $L_{p}$ são exemplos de função cujo conjunto de valores retornados (contradomínio) é infinito ou um conjunto muito grande. Contudo, existem outras funções de distância cujo contradomínio é relativamente pequeno, tal como exemplo a função de distância de Levenshtein (LEVENSHTEIN, 1966), conhecida também como $L_{e d i t}$ ou distância de edição.

A função $L_{\text {edit }}$ é comumente utilizada para avaliar a similaridade entre duas cadeias de caracteres. A similaridade é calculada como o menor número de operações de edições elementares (inserções, remoções e substituições de caracteres) necessário para transformar uma cadeia de caracteres $c_{1}$ numa outra cadeia $c_{2}$. Uma generalização dessa métrica altera o cálculo definindo custos diferentes (pesos) para cada tipo de operação de edição elementar e também permite definir custos diferentes para cada par de caracteres (ZEZULA et al., 2006).

Apesar dessa generalização alterar o resultado final do cálculo da função de distância, uma característica da função de distância de Levenshtein e de suas derivações é que o menor valor do cálculo é zero e no máximo metade do quadrado do número de letras do alfabeto (no caso do alfabeto latino ela é no máximo $25 * 24 / 2=276$ ). Portanto, a capacidade de discriminação oferecida pela função de distância tende a ser pequena.

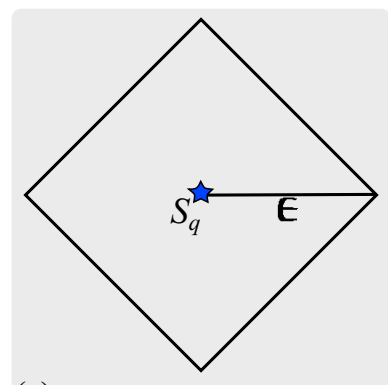

(a)

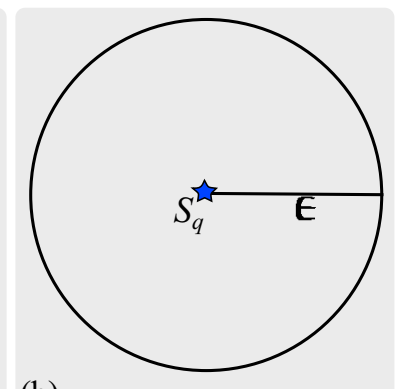

(b)

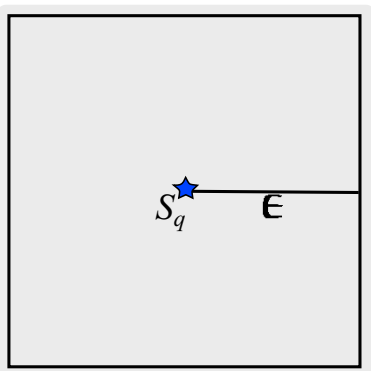

(c)

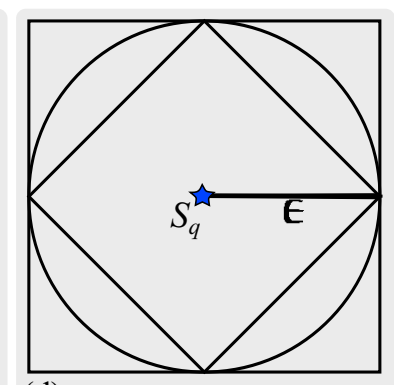

(d)

Figura 2.1: Representação das formas geométricas geradas pelas funções de distância (a) $L_{1}$, (b) $L_{2}$ e (c) $L_{\infty}$ para os pontos equidistantes à distância $\epsilon$ a partir do elemento central $s_{q}$. 


\subsection{Tipos de Buscas por Similaridade}

Um operador de busca por similaridade básico recupera os elementos que atendem a um determinado critério de similaridade, expresso com referência a um elemento do domínio de dados $s_{q} \in \mathbb{S}$, chamado de "elemento central de busca" (HU; LEE, 2006), e em relação a uma função de distância. Em geral, existem dois critérios de seleção por similaridade fundamentais: os que expressam as buscas por abrangência ("similarity range queries" - Rq) e os que expressam as buscas aos $k$-vizinhos mais próximos (" $k$-nearest neighbor queries" $-k$ - $N N q$ ) (KORN et al., 1996; CHAKRABARTI et al., 2004; ZEZULA et al., 2006). Além desses critérios fundamentais, existem outros tipos de buscas por similaridade, principalmente as junções por similaridade (JACOX; SAMET, 2007; XIAO et al., 2009; SILVA; AREF; ALI, 2010; YAO; LI; KUMAR, 2010), as buscas por similaridade agregada (RAZENTE et al., 2008; PAPADIAS et al., 2004; DENG et al., 2009), a busca aos $k$-vizinhos mais próximos reversos (KORN; MUTHUKRISHNAN, 2000; TAO; YIU; MAMOULIS, 2006; YAO; LI; KUMAR, 2009) e as buscas por similaridade com diversidade (CARBONELL; GOLDSTEIN, 1998; SKOPAL et al., 2009; VIEIRA et al., 2011a; DROSOU; PITOURA, 2012; AMAGATA; HARA, 2016). A seguir, esses tipos de buscas são apresentados.

\subsubsection{Busca por Abrangência}

Uma busca por abrangência (similarity range query) recupera todos os elementos da base de dados que diferem do elemento central de busca por, no máximo, o limiar de dissimilaridade indicado. A Definição 2 formaliza este conceito.

Definição 2. Busca por abrangência - $R q$ : Seja $\mathbb{S}$ um domínio de dados, $S \in \mathbb{S}$ um conjunto de elementos, $\delta$ uma função de distância e $\epsilon_{q}$ um limiar de dissimilaridade. Uma busca por abrangência com elemento central de busca $s_{q} \in \mathbb{S}$ é dada por:

$$
R q\left(s_{q}, \epsilon_{q}, S, \delta\right)=\left\{s_{i} \mid s_{i} \in S, \delta\left(s_{i}, s_{q}\right) \leq \epsilon_{q}\right\}
$$

A Figura 2.2 (a) mostra um exemplo de busca por abrangência centrada no elemento $s_{q}$ com raio $\epsilon_{q}$ num espaço bi-dimensional com função de distância Euclidiana. Um exemplo de busca por abrangência em uma base de imagens é "Selecione as imagens que difiram desta imagem $s_{q}$ dada por até 10 unidades", sendo que unidade de distância depende da maneira como a função de dissimilaridade foi definida.

É importante notar que o elemento $s_{q}$ não precisa fazer parte da coleção de elementos que serão consultados, porém ele deve pertencer domínio métrico $\mathbb{S}$ de onde o conjunto de dados $S$ é amostrado. A busca por abrangência reversa (reversed range query) é uma operação complementar da busca por abrangência, isto é, ela retorna todos os elementos da base de dados que estão fora do limiar de dissimilaridade $\left(\epsilon_{q}\right)$. A busca pontual (point query) corresponde ao critério de comparação por abrangência com limiar de dissimilaridade definido como $\epsilon_{q}=0$. A principal motivação nesta busca é identificar se o elemento central de busca está armazenado na base de dados. 


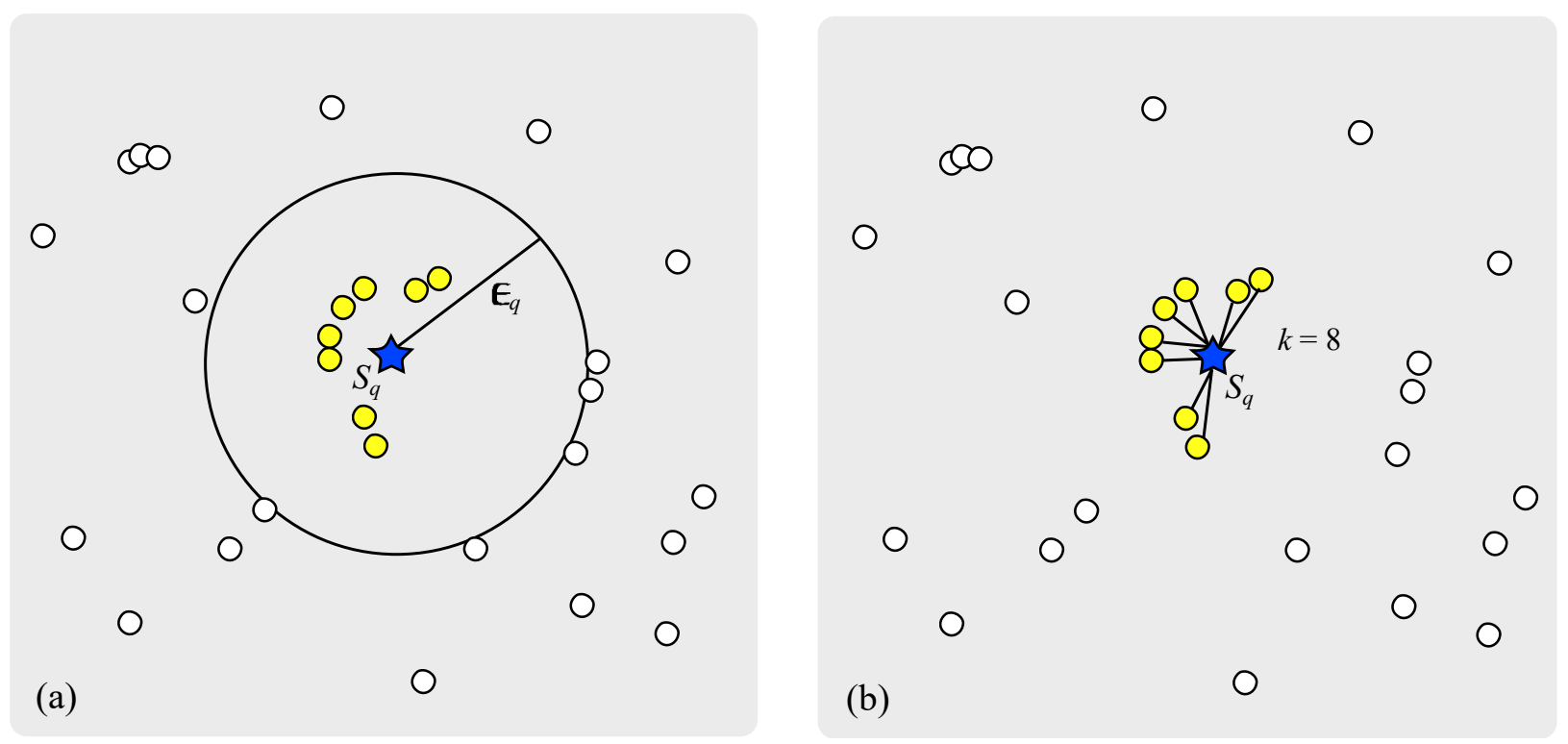

Figura 2.2: Exemplo de busca por similaridade em um espaço bi-dimensional Euclidiano. (a) Busca por abrangência. (b) Busca aos $k$-vizinhos mais próximos.

\subsubsection{Busca aos $k$-Vizinhos Mais Próximos}

Uma busca aos $k$-vizinhos mais próximos ( $k$-nearest neighbors query) tem por objetivo retornar os $k$ elementos mais próximos do elemento central de busca. A Definição 3 formaliza esta busca.

Definição 3. Busca aos $k$-vizinhos mais próximos - $k$ - $N N q$ : Seja $\mathbb{S}$ um domínio de dados, $S \in \mathbb{S}$ um conjunto de elementos, $\delta$ uma função de distância e um inteiro $k \geq 1$. Então, o resultado de uma busca aos $k$-vizinhos mais próximos com elemento central de busca $s_{q} \in \mathbb{S}$ é dado por:

$$
k-N N q\left(s_{q}, k, S, \delta\right)=A=\left\{s_{j}\left|s_{j} \in S, \forall s_{i} \in S-A: \delta\left(s_{q}, s_{j}\right) \leq \delta\left(s_{q}, s_{i}\right),\right| A \mid=k\right\} .
$$

Um exemplo de busca aos $k$-vizinhos mais próximos em uma base de imagens é "Selecione as 10 imagens mais similares a esta imagem $s_{q}$ dada". A Figura 2.2 (b) ilustra uma busca aos $k$ vizinhos mais próximos em um domínio bi-dimensional empregando uma função de distância Euclidiana com número de elementos $k=8$. É importante notar que podem ocorrer empates no $k$-ésimo elemento, isto é, pode haver mais de um elemento encontrado à distância máxima. Assim é possível tratar esse empate de duas formas: a primeira é escolher aleatoriamente um dos elementos à distância máxima, desprezando-se os demais e retornando exatamente o número $k$ de elementos solicitado (ARANTES et al., 2004) e a segunda é incluir todos os elementos à distância máxima na resposta, retornando mais do que $k$ elementos solicitados (ARANTES et al., 2003).

\subsubsection{Variações dos Tipos Básicos de Buscas por Similaridade}

Além dos dois tipos básicos de buscas apresentados, também foram propostas outros operadores de busca por similaridade, alguns dos quais estão descritos nesta subseção. Descrevem-se inicialmente as variações para os operadores de seleção por similaridade, e na próxima seção 
as junções por similaridade. Quanto a operadores de agrupamento por similaridade, existe apenas a proposta de um grupo de pesquisa, relatada em (SILVA; AREF; ALI, 2009; SILVA et al., 2013b; SILVA; AREF; ALI, 2009; TANG et al., 2016; SILVA et al., 2013a). No entanto, esse grupo define operadores de agrupamento que não estão vinculados a predicados de comparação por similaridade, além de serem específicos a dados bidimensionais com função de distância Euclidiana(SILVA et al., 2013b; SILVA; AREF; ALI, 2009). A versão mais recente definida por Tang et al. (2016) pode ser aplicada a dados multidimensionais, porém as operações de agrupamento não estão relacionadas às variações dos operadores de seleção por similaridade nem a de junção por similaridade. Assim, apesar destes relatos de trabalhos com agrupamento por similaridade, os mesmos não serão apresentados neste trabalho de doutorado devido aos estudos não abordarem de maneira consistente como os critérios de comparação por similaridade são usados nesses operadores de busca.

\subsubsection{Busca aos $k$-Vizinhos Diversos Mais Próximos}

A busca aos $k$-vizinhos diversos mais próximos (k-nearest diverse neighbors query), representada como $k-N D N q$, é uma extensão da busca $k-N N q$ que considera o relacionamento entre os elementos presentes em um conjunto de resultado, aumentando a diversidade do resultado. Essa variante é adequada para grandes volumes de dados, pois como foi visto no capítulo anterior, com o aumento da densidade do conjunto de dados, cada elemento tende a ser muito similar à outros do conjunto resultado. O problema de elementos similares entre si em conjuntos de resultado é a redução da utilidade do resultado, pois, é necessário requisitar a análise de vários elementos por parte do usuário que, por sua vez, precisa reformular e ajustar a busca com muita frequência(ANGEL; KOUDAS, 2011).

Uma busca aos $k$-vizinhos diversos mais próximos retorna os $k$ elementos mais próximos do elemento central de busca, e que são ao mesmo tempo diversos entre si, considerando uma medida de similaridade e outra de diversidade. A medida de similaridade é representada pela função de distância $\delta_{\text {sim }}$ e considera o quanto os elementos são similares em relação ao elemento central de busca, definindo o conjunto de elementos $k$-similares (Definição 4 ). Assim, quanto maior a similaridade entre os elementos e o centro de busca, maior o valor atribuído ao conjunto $k$-similar. A medida de diversidade é representada pela função de distância $\delta_{d i v}$ que pode ou não ser a mesma função que mede a similaridade. Ela considera a diversidade entre os elementos no conjunto de resultado, definindo o conjunto de elementos $k$-diversos (Definição 5). Assim, quanto maior a dissimilaridade entre os elementos, maior o valor atribuído ao conjunto $k$-diverso. Desse modo, o problema de diversificação se resume em encontrar um conjunto de resultado $R$, em que cada elemento é tanto similar ao elemento central de busca $s_{q}$ com relação a $\delta_{\text {sim }}$, quanto dissimilar aos elementos pertencentes a $R$ em relação a $\delta_{\text {div }}$, maximizando uma função objetivo de critério duplo.Esse conceito é formalizado a seguir.

Definição 4. Conjunto dos elementos $k$-similares: Seja $\mathbb{S}$ um domínio de dados, $S \in \mathbb{S}$ um conjunto de elementos, $R \subseteq S$ um conjunto de resultado com $k$ elementos. Então, o conjunto dos elementos $k$-similares ao elemento central de busca $s_{q} \in \mathbb{S}$ é dado por: 


$$
\begin{gathered}
R=\underset{S^{\prime} \subseteq S, k=\left|S^{\prime}\right|}{\operatorname{argmax}} \operatorname{Sim}\left(s_{q}, S^{\prime}\right) \\
\text { onde } \operatorname{Sim}\left(s_{q}, S^{\prime}\right)=\sum_{i=1}^{k} \delta_{\text {sim }}\left(s_{q}, s_{i}\right) .
\end{gathered}
$$

Definição 5. Conjunto dos elementos $k$-diversos: Seja $\mathbb{S}$ um domínio de dados, $S \in \mathbb{S}$ um conjunto de elementos, $R \subseteq S$ um conjunto de resultado com $k$ elementos. Então, o conjunto dos elementos $k$-diversos entre si é dado por:

$$
\begin{aligned}
R & =\underset{S^{\prime} \subseteq S, k=\left|S^{\prime}\right|}{\operatorname{argmax}} \operatorname{Div}\left(S^{\prime}\right) \\
\text { onde Div }\left(S^{\prime}\right) & =\sum_{i=1}^{k-1} \sum_{j=i+1}^{k} \delta_{\text {div }}\left(s_{i}, s_{j}\right), s_{i}, s_{j} \in S^{\prime} .
\end{aligned}
$$

A Equação (2.6) é um exemplo de função objetivo, definida por Vieira et al. (2011a). O parâmetro de preferência de diversidade $(\lambda)$ representa o limiar de compromisso entre a similaridade e a diversidade no intervalo $[0,1]$. Quando $\lambda=0$, o problema se resume em encontrar os $k$-vizinhos mais próximos. Porém para $\lambda>0$, o problema é NP-Difícil (AGRAWAL et al., 2009). A formulação do problema dessa maneira é denominada problema da diversidade máxima (Maximum Diversity Problem - MDP) e consiste em selecionar um conjunto ótimo de $k$ elementos diversos entre si em um conjunto de dados .

$$
\mathcal{F}\left(s_{q}, S^{\prime}\right)=(k-1)(1-\lambda) \cdot \operatorname{Sim}\left(s_{q}, S^{\prime}\right)+2 \lambda \cdot \operatorname{Div}\left(S^{\prime}\right) .
$$

Um exemplo de busca aos $k$ vizinhos diversos mais próximos em uma base de imagens é "Selecione as 10 imagens mais similares à imagem $s_{q}$ considerando uma preferência de diversidade de 70\%". É possível perceber que os conceitos de similaridade e diversidade competem entre si, e o usuário precisa definir explicitamente qual é a sua prioridade na busca. No exemplo é considerado 30\% de similaridade ao elemento de busca e $70 \%$ de dissimilaridade (diversidade) entre os elementos na função objetivo.

A Figura 2.3 ilustra uma busca por similaridade com diversidade em um espaço Euclidiano bi-dimensional para um elemento central de busca $s_{q}$, com $k=5$ e variando a preferência de diversidade $(\lambda)$. A Figura 2.3 (a) ilustra que ao não considerar a medida de diversidade $(\lambda=0)$, a resposta para a busca se reduz a encontrar os vizinhos mais próximos de $s_{q}$, pois não é considerado o relacionamento (distância) entre os elementos no conjunto de resultado. A Figura 2.3 (b) ilustra como a definição de diversidade moderada $(\lambda=0,3)$ para a busca aumenta a dissimilaridade entre os elementos, preservando-se contudo a similaridade ao elemento de central de busca, recuperando os dois elementos mais próximos. Por fim, a Figura 2.3 (c) ilustra que ao dar mais importância à diversidade $(\lambda=0,6)$ do que à similaridade, os elementos recuperados possuem maior dissimilaridade ao elemento $s_{q}$, inclusive podendo, como nesse exemplo, não retornar o elemento mais próximo.

Apesar da aparente intuitividade em balancear os conceitos de similaridade e de diversidade por um parâmetro de compromisso $(\lambda)$ entre os mesmos, é possível perceber no exemplo da Figura 2.3 (c) que existem elementos, mesmo após a consideração de diversidade (i.e, os 


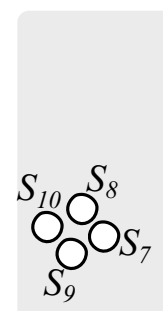

(a)

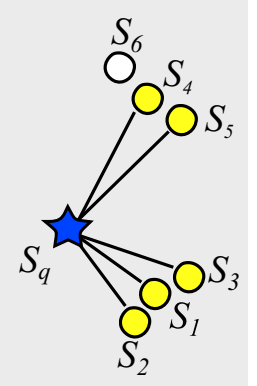

(b)

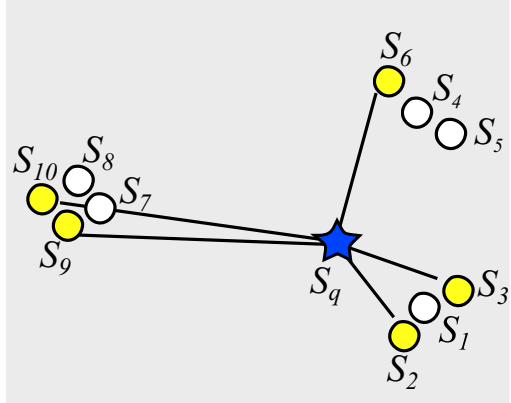

(c)

Figura 2.3: Conjunto resultado para a busca aos 5-vizinhos mais próximos diversos exemplificando o compromisso entre similaridade e diversidade por meio do parâmetro $\lambda$. (a) Busca com preferência de diversidade $\lambda=0,0$, indicando uma busca aos vizinhos mais próximos tradicional. (b) Busca com diversidade priorizando similaridade, $\lambda=0,3$. (c) Busca priorizando diversidade, $\lambda=0,6$.

elementos $s_{3}$ e $s_{9}$ ), que continuam muito próximos de outro elemento já inserido na resposta. Além disso, o ajuste do parâmetro $\lambda$ tem se mostrado difícil e pouco intuitivo em situações reais, sendo necessário um ajuste frequente nas buscas (ANGEL; KOUDAS, 2011).

\subsubsection{Busca aos $k$-Vizinhos Distintos Mais Próximos}

A busca aos $k$-vizinhos distintos mais próximos ( $k$-distinct nearest neighbors query), representada como $k-D N N q$, é uma extensão das buscas $k-N N q$ para evitar a recuperação de informação redundante em conjuntos de dados de imagens com alta cardinalidade. O objetivo da busca $k-D N N q$ (Definição 6) é recuperar os $k$ elementos mais próximos de um elemento $s_{q}$ que sejam distintos por no mínimo uma "distância de separação" $(\phi)$ que precisa ser definida pelo usuário. A distância de separação é um limiar em que o usuário informa e que corresponde a quanto os elementos devem estar separados entre si no mínimo, evitando a seleção de elementos "auto-similares" no conjunto de resultado.

Definição 6. Busca aos $k$-vizinhos distintos mais próximos - $k$ - $D N N q$ : Seja $\mathbb{S}$ um domínio de dados, $S \in \mathbb{S}$ um conjunto de elementos, $\delta$ uma função de distância e um inteiro $k \geq 1$ e uma distância de separação $\phi$. O resultado de uma busca aos $k$-vizinhos distintos mais próximos com elemento central de busca $s_{q} \in \mathbb{S}$ é dado por:

$$
\begin{array}{r}
k-D N N q\left(s_{q}, k, S, \delta, \phi\right)=A=\left\{\forall s_{i}, s_{j} \in A, \forall s_{t} \in S-A: \delta\left(s_{i}, s_{j}\right) \geq \phi \wedge\right. \\
\left(\delta\left(s_{q}, s_{i}\right) \leq \delta\left(s_{q}, s_{j} \vee \exists w \in A: \delta\left(s_{t}, s_{w}\right)<\phi\right),|A|=k\right\} .
\end{array}
$$

Um exemplo de busca aos $k$-vizinhos distintos mais próximos em uma base de imagens é "Selecione as 10 imagens mais similares à imagem $s_{q}$, considerando uma distância de separação mínima de 3 unidades entre os elementos da resposta.". De maneira similar a busca aos $k$-vizinhos diversos, o usuário necessita dizer explicitamente qual é o limiar de separação entre os elementos. Porém, para a correta definição deste parâmetro é necessário que o usuário tenha conhecimento prévio sobre a distribuição dos dados e da densidade da região de busca do elemento $s_{q}$, o que dificulta o uso desta busca. 


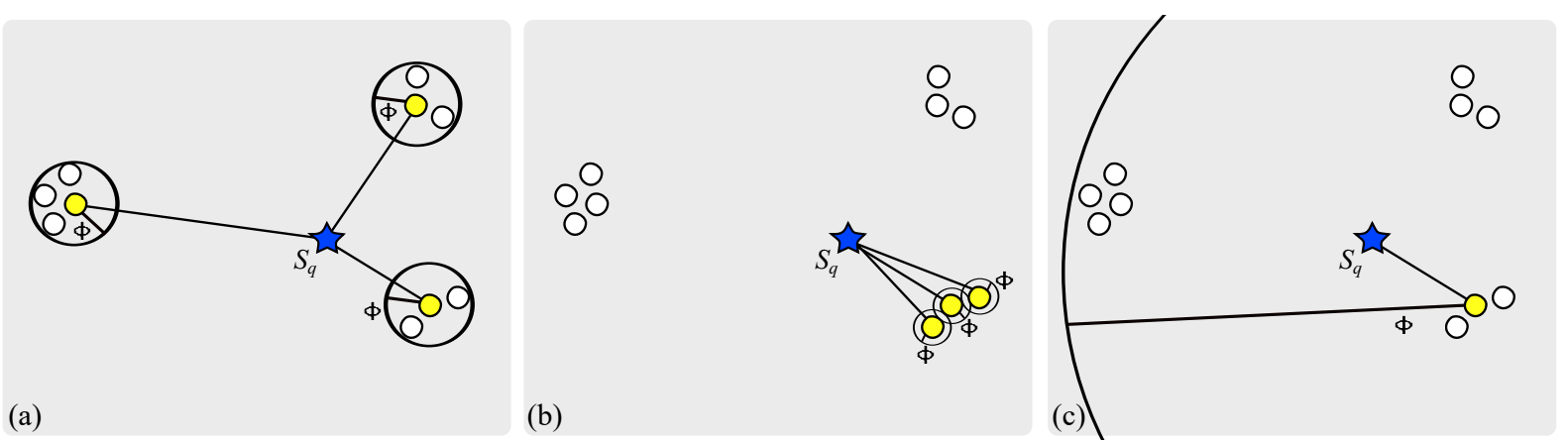

Figura 2.4: Conjunto resultado para a busca aos 3-vizinhos distintos mais próximos do elemento $s_{q}$ com exclusão por distância de separação $\phi$. (a) Definição ideal para a distância de separação, (b) $\phi$ subestimada, resumindo a busca aos vizinhos mais próximos e (c) distância de separação superestimada, o primeiro elemento restringe todo o conjunto de dados.

A Figura 2.4 ilustra a busca $k-D N N q$ em um espaço Euclidiano bi-dimensional com elemento de busca $s_{q}$ e distância de separação $\phi$. É importante notar que caso a distância de separação seja definida com um valor muito pequeno, a busca $k$-DNNq reduz-se à busca aos $k$-vizinhos mais próximos (Figura2.4 (b)). Por outro lado, se o valor for muito grande pode ocorrer de apenas um elemento excluir todos os outros do conjunto de dados, retornando menos que os $k$ elementos requisitados na busca (Figura 2.4 (c)).

\subsubsection{Junções por Similaridade}

Nas subseções anteriores foram apresentados os tipos de busca por similaridade que atuam em um único conjunto de dados complexos, sendo portanto todos eles operadores unários. As junções, por sua vez, são operadores binários, aplicando um operador de comparação sobre dois conjuntos de dados. Existem três tipos de junção por similaridade discutidas com mais frequência na literatura: junção por abrangência (Range join - $\left.{ }^{R q} \wedge\right)$, junção pelos $k$-vizinhos mais próximos ( $k$-Nearest Neighbors join $-\stackrel{k-N N q}{\bowtie}$ ) e junção pelos $k$-pares de vizinhos mais próximos (k-Closest Neighbors join $-\stackrel{k-C N q}{\bowtie}$ ) definidos em Bohm e Krebs (2002).

As Definições 7 e 8 apresentam as junções por abragência e aos $k$-vizinhos mais próximos, respectivamente. Esses dois tipos de junção são variações da aplicação direta dos comparadores por similaridade e dos respectivos operadores de seleção apresentados nas Subseções 2.2.1 e 2.2.2 para junções sobre dois conjuntos de dados complexos. A junção pelos $k$-pares de vizinhos mais próximos (Definição 9), recupera os $k$ pares de elementos dos conjuntos $R$ e $S$ que são mais próximos entre si no geral; recupera apenas os pares de tuplas em que os elementos de ambos conjuntos estão às menores distâncias.

Definição 7. Junção por abrangência - $\stackrel{R q}{\bowtie}$ : Seja $\mathbb{S}$ um domínio de dados, $R \in \mathbb{S}$ e $S \in \mathbb{S}$ dois conjuntos de elementos complexos, $\delta$ uma função de distância e $\epsilon_{q}$ um limiar de dissimilaridade. Uma junção por abrangência recupera os pares de elementos $r_{i} \in R$ e $s_{j} \in S$ distante no máximo $\epsilon_{q}$ entre si. A resposta da busca é dada por:

$$
R \stackrel{R q\left(\epsilon_{q}, \delta\right)}{\bowtie} S=\left\{\left\langle r_{i}, s_{j}\right\rangle \in(R \times S), \delta\left(r_{i}, s_{j}\right) \leq \epsilon_{q}\right\}
$$



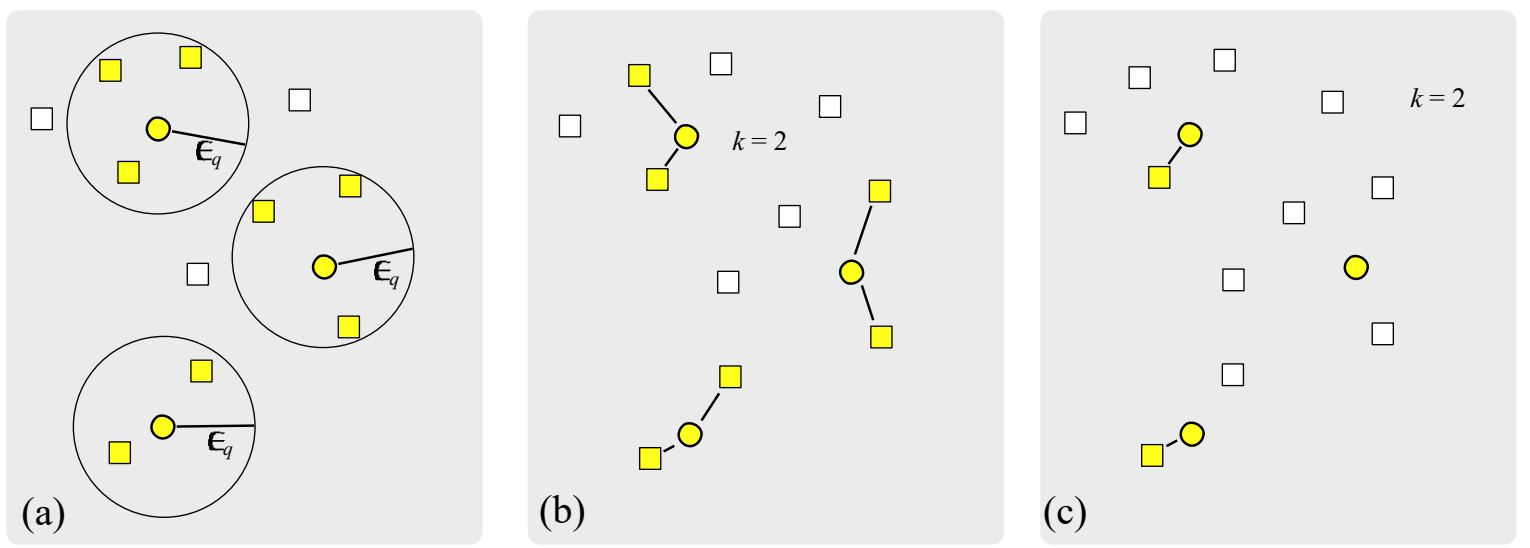

Figura 2.5: Operações de junção por similaridade em um espaço bi-dimensional Euclidiano. (a) Junção por abrangência. (b) Junção pelos $k$-vizinhos mais próximos, com $k=2$. (c) Junção pelos $k$-pares de vizinhos mais próximos, com $k=2$.

Definição 8. Junção pelos $k$-vizinhos mais próximos $-\stackrel{k-N N q}{\bowtie}$ : Seja $\mathbb{S}$ um domínio de dados, $R \in \mathbb{S}$ e $S \in \mathbb{S}$ dois conjuntos de elementos complexos, $\delta$ uma função de distância e um inteiro $k \geq 1$. Uma junção pelos $k$-vizinhos mais próximos retorna os pares de elementos $r_{i} \in R$ e $s_{j} \in S$ de maneira que cada elemento em $R$ é concatenado ao resultado com os $k$-vizinhos mais próximos em $S$. O resultado é dado por:

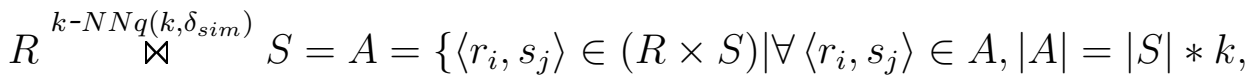

$$
\begin{aligned}
& \left.\forall\left\langle r_{i}, s_{m}\right\rangle \in((R \times S)-A), \delta\left(r_{i}, s_{j}\right) \leq \delta\left(r_{i}, s_{m}\right)\right\} .
\end{aligned}
$$

Definição 9. Junção pelos $k$-pares de vizinhos mais próximos $-\stackrel{k-C N q}{\bowtie}$ : Seja $\mathbb{S}$ um domínio de dados, $R \in \mathbb{S}$ e $S \in \mathbb{S}$ dois conjuntos de elementos complexos, $\delta$ uma função de distância e um inteiro $k \geq 1$. Uma junção pelos $k$-pares de vizinhos mais próximos é dada por:

$$
\begin{array}{r}
R \stackrel{k-C N q\left(k, \delta_{s i m}\right)}{k^{2}} S=A=\left\{\left\langle r_{i}, s_{j}\right\rangle \in(R \times S)\left|\forall\left\langle r_{i}, s_{j}\right\rangle \in A,\right| A \mid=k\right. \\
\left.\forall\left\langle r_{m}, s_{n}\right\rangle \in((R \times S)-A), \delta\left(r_{i}, s_{j}\right) \leq \delta\left(r_{m}, s_{n}\right)\right\} .
\end{array}
$$

A principal diferença da junção $\stackrel{k-N N q}{\bowtie}$ para a junção $\stackrel{k-C N q}{\bowtie}$, é que a junção pelos vizinhos mais próximos recupera os $k$ pares de elementos de $R$ mais próximos a cada elemento de $S$, enquanto a junção pelos $k$-pares recupera os $k$ pares de elementos mais próximos em geral. A Figura 2.5 ilustra os três tipos de junção por similaridade. Nessa figura, os pontos representam elementos do conjunto $R$ e os quadrados representam elementos do conjunto $S$.

\subsection{Métodos de Acesso Métrico}

Se nenhuma estrutura de indexação for utilizada para uma busca por similaridade, a resposta requer executar uma leitura sequencial sobre todos os elementos do conjunto de dados de 


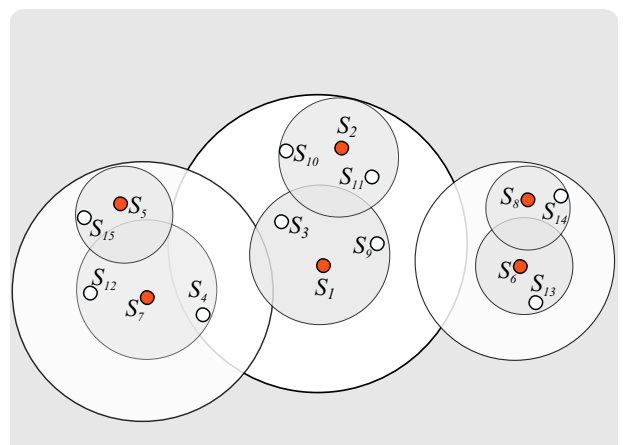

(a)

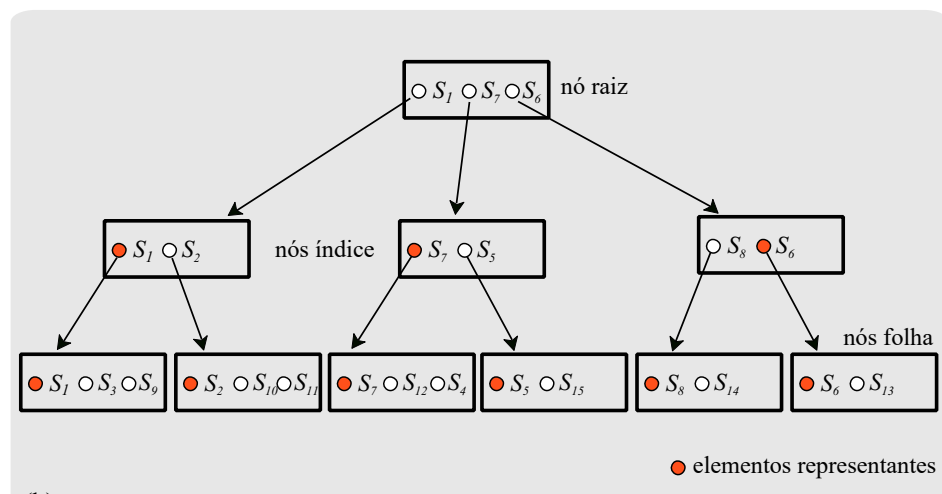

(b)

Figura 2.6: Representação de uma Slim-tree com 15 elementos organizados em 3 níveis hierárquicos e com número máximo de elementos por nó igual a 3. (a) Distribuição espacial. (b) Estrutura lógica. Imagem adaptada de (RAZENTE, 2009).

entrada, calculando a função de distância entre todos os elementos e o elemento central de busca. Essa estratégia não é adequada para grandes bases de dados, uma vez que o custo computacional é muito alto. Assim, um aspecto importante na busca por similaridade está relacionado à utilização de métodos de acesso indexados.

Dado que buscas por similaridade não seguem as propriedades de RO e que a igualdade entre elementos complexos é rara, dados complexos são comumente representados em espaços métricos, o que permite utilizar as propriedades deste espaço para agilizar as buscas. Os métodos de acesso métricos (MAMs) são as estruturas de dados especializadas para indexar os dados representados em espaços métricos para executar buscas por similaridade. O objetivo dos MAMs é a redução do número de cálculos de distância e do número de acessos a disco para executar as buscas por similaridade, onde são exploradas propriedades métricas como a simetria e a desigualdade triangular para tornar o acesso aos dados mais eficiente. Na literatura são encontradas diversas estruturas de indexação. Entre elas estão métodos estáticos como a VP-tree (Vantage Point tree) (YIANILOS, 1993) e a MVP-tree (Multi-Vantage Point tree) (BOZKAYA; OZSOYOGLU, 1997), que são MAMs que constroem a estrutura de indexação utilizando todo o conjunto de dados que precisa ser indexado numa única operação, e não permitem operações posteriores de inserção e remoção de elementos, sendo por isso denominados métodos estáticos. Tais métodos não são adequados em situações em que os dados são atualizados, requisitando sempre uma operação de reconstrução. Outros métodos, como a M-tree (CIACCIA; PATELLA; ZEZULA, 1997) e a Slim-tree (TRAINA JR. et al., 2002), são exemplos de MAMs dinâmicos balanceados que permitem a operação de inserção individual em uma estrutura já construída.

Como exemplo de um MAM dinâmico, descreve-se a seguir a Slim-tree. Uma estrutura Slimtree é construída com a estratégia bottom-up, isto é, ela cresce a partir das folhas em direção à raiz. Ela agrupa os elementos em páginas de tamanho fixo, sendo que cada página corresponde a um nó da árvore. Os elementos são armazenados nas folhas e as entradas dos nós internos definem a hierarquia de organização dos dados. Os nós folhas contém todos os elementos indexados, enquanto os nós internos replicam os elementos escolhidos como representantes. Cada entrada num nó folha contém o identificador do elemento, as informações do elemento para o cálculo de distância e a distância ao elemento representante do nó, o qual está armazenado também no nó pai. 
A Figura 2.6 (a) representa uma Slim-tree em um espaço bi-dimensional Euclidiano, onde os círculos cinza indicam os nós folha e os círculos brancos os nós índice. Os pontos vermelhos indicam os elementos representantes $\left(s_{\text {rep }}\right)$ e cada nó da árvore possui um representante e um raio de cobertura. A Figura 2.6 (b) apresenta a estrutura lógica da árvore. A Slim-tree é o primeiro MAM dinâmico que possui recursos para a avaliação do grau de sobreposição entre seus nós (Fat-Factor) e um algoritmo para minimizar o problema de sobreposição, denominado Slim-down. Uma revisão dos principais métodos de acesso pode ser encontrada nos livros de Zezula et al. (2006) e Samet (2005).

\subsection{Considerações Finais}

Neste capítulo foram apresentados conceitos relacionados a buscas por similaridade e suas variações. Além disso, foi brevemente comentado sobre os métodos de acesso métricos utilizados para tornar as operações de busca por similaridade eficientes. Neste ponto, chamamos a atenção para as buscas por similaridade com diversidade que são uma variação das buscas aos $k$-vizinhos mais próximos aplicadas em conjuntos de dados de alta cardinalidade. A inclusão da propriedade de diversidade é bastante interessante para este projeto de doutorado, pois evitar que um conjunto resultado tenha elementos muitos similares entre si embora similares ao elemento de busca pode aumentar a qualidade da resposta fornecida em conjuntos de dados volumosos. No próximo capítulo serão apresentados os conceitos relacionados a big data. Nele são descritos também, os algoritmos que implementam a propriedade de diversidade nas buscas aos $k$-vizinhos mais próximos. 


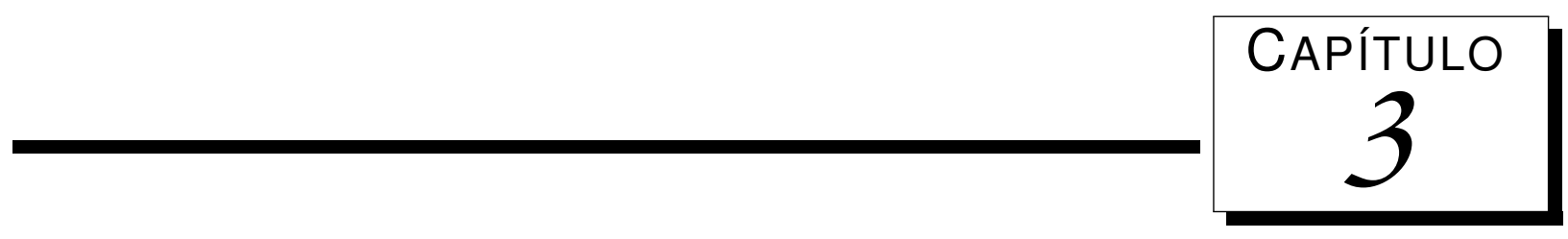

\section{Big Data e Diversificação de Resultados}

A grande capacidade de produzir novos dados em aplicações de apoio ao diagnóstico médico por imagens, coleta de dados de sensores remotos de estações meteorológicas, sistemas governamentais para análise de transações a partir de notas fiscais, ambientes de redes sociais e sistemas de análises científicas desafiam a capacidade de organização e armazenamento dos grandes repositórios de dados e por consequência, influenciam também os operadores de busca. A quantidade de dados imensa tanto em escala, quanto em complexidade, escopo, distribuição e/ou heterogeneidade produzidos por tais sistemas vem sendo referenciada como big data (CUZZOCREA; SONG; DAVIS, 2011). Com o aumento na produção e armazenamento de dados, se torna importante lidar também com outros tipos de dados mais complexos, por exemplo, imagens, filmes, dados geoespaciais, sequências de DNA e séries temporais. Como foi apresentado no Capítulo 2, tais dados a que chamamos complexos não seguem as propriedades das relações de ordem ou de identidade entre seus elementos, sendo preferível compará-los por similaridade.

A atual preocupação das organizações e dos pesquisadores, é resolver o problema de eficiência de acesso em big data por meio de arquiteturas paralelas, não sendo considerado que conforme o espaço vai sendo continuamente preenchido com novos dados, ele tende a ficar tão "denso" que muitos elementos acabam sendo muito similares à muitos outros da base de dados, ou simplesmente quase duplicatas do elemento central de busca, reduzindo a eficácia. O problema de respostas com muitos elementos similares entre si é que torna-se necessária a análise de vários elementos por parte do usuário, o qual tende a perder o interesse se elementos são retornados repetidamente (ZIEGLER et al., 2005). Além disso, a quantidade de resultados pode ser enorme a ponto de impossibilitar a análise de todos os elementos pelo usuário, resultando no seu desinteresse de encontrar a resposta desejada.

Este capítulo apresenta aspectos relacionados à big data e também algoritmos da literatura para melhorar a qualidade das respostas fornecidas pelos operadores de busca por similaridades sobre grandes volumes de dados, utilizando a propriedade de diversidade. A Seção 3.1 discute as definições de big data, enquanto a Seção 3.2 apresenta informações sobre arquiteturas e soluções de big data. Na Seção 3.3 são apresentadas as estratégias para diversificação de resultados. Na Seção 3.4 são apresentados os métodos para avaliação de qualidade de respostas diversificadas. A Seção 3.5 apresenta os protótipos disponíveis na literatura para 
otimização e avaliação de algoritmos de diversificação de resultados. Na Seção 3.6 são apresentados os conceitos e abordagens para a mineração visual de dados com foco em técnicas de projeção de dados. Por fim, são apresentadas considerações finais do capítulo na Seção 3.7.

\subsection{A definição de big data}

O termo big data é amplo e ainda não existe um consenso em sua definição. Assim, um primeiro questionamento é perguntar: "como definir big data?". Tal questionamento é válido, pois a definição é, intuitivamente, relativa e evolui com o tempo, com os avanços tecnológicos e com os requisitos das aplicações. Por exemplo, há quarenta anos um terabyte seria considerado enorme e fora da realidade, enquanto nos dias atuais estamos acostumados a lidar com tal quantidade de dados. Em Madden (2012), o conceito é definido em relação à existência e aplicabilidade dos três V's :

- Velocidade: Consiste em processar o mais rápido quanto possível o conjunto, independente de seu volume de dados, ou seja, os algoritmos de processamento, idealmente, precisam ter complexidade sublinear.

- Variedade: Corresponde ao formato dos dados provenientes de diversas fontes que precisam ser integrados, possuindo esquemas diferentes em cada repositório e domínios diferentes, tal como imagens, vídeos, áudio, séries temporais, documentos, dentre outros.

- Volume: Compreende o conceito que os conjuntos de dados vêm acumulando grande quantidade de itens (cardinalidade) e medidas (dimensionalidade).

De acordo com os três Vs, o volume dos dados, certamente, é sempre crescente, porém a complexidade também é crescente pelo fato de existirem diversos formatos sendo armazenados de diferentes fontes de dados, tornando difícil a integração devido a continuidade do armazenamento de novos dados a cada instante. Por fim, é necessário processar um grande volume de dados complexos em tempo hábil.

Outra definição para big data é realizada por Loukides (2010) e está relacionada ao fato de que quando o tamanho do conjunto de dados faz parte do problema ou as técnicas existentes deixam de ser eficientes, trata-se de big data. Seguindo a mesma ideia, Jacobs (2009) define que pode-se chamar de big qualquer volume de dados que requisite a utilização ou criação de novas metodologias de processamento. Tais definições estão relacionadas ao volume e a velocidade, e este projeto de doutorado segue essas definições, procurando por um modelo de busca por similaridade mais adequado aos conjuntos com grandes volumes de dados, aumentado a eficácia, porém sem comprometer a eficiência dos algoritmos de busca.

\subsection{Arquitetura e Soluções para big data}

Com o aumento da capacidade de produzir e armazenar dados, é comum ter conjuntos de dados ultrapassando as centenas de terabytes e até mesmo petabytes. Dessa maneira, os algoritmos que realizam busca de dados de maneira serial se tornam ineficientes. Por 
exemplo, a tarefa de realizar uma leitura completa de um conjunto de dados de 10 terabytes, considerando uma taxa média de transferência sustentada de 100 megabytes por segundo (uma velocidade alta para os padrões de dispositivos externos - atuais discos e flash drives), necessita de mais de um dia para ser finalizada. Além disso, os discos atuais armazenam no máximo 6 terabytes de dados, e para armazenar um grande conjunto de dados são necessários múltiplos discos. Portanto, para lidar com grandes volumes de dados é interessante considerar o inerente paralelismo existente no armazenamento dos dados para a execução dos algoritmos.

Diferentes soluções foram propostas para suprir a necessidade de alto desempenho para gerenciar e analisar estes dados, como a utilização de sistemas distribuídos que possibilitam o uso de tabelas hash (Distributed Hash Table) (DECANDIA et al., 2007) ou estruturas de arrays multidimensionais (CHANG et al., 2008). Destaca-se ainda o paradigma MapReduce (DEAN; GHEMAWAT, 2004; DEAN; GHEMAWAT, 2008), um modelo computacional distribuído desenvolvido para apoiar o processamento de conjuntos de dados em clusters de servidores. Um dos fatores fundamentais para o sucesso do MapReduce é a sua escalabilidade, simplicidade e baixo custo para implementar uma grande infraestrutura de computadores. Assim, várias aplicações que desejam aproveitar o paralelismo de maneira intuitiva e tornar eficiente a busca em grandes volumes de dados vêm utilizando tal modelo (PAPADIMITRIOU; SUN, 2008; MOISE et al., 2013; FEGARAS; LI; GUPTA, 2012; BORKAR; CAREY; LI, 2012; SILVA; REED, 2012; SCHADT et al., 2010; VERNICA; CAREY; LI, 2010; CHAUDHURI, 2012; HALL et al., 2013; LIU; DUBE; GRAY, 2014; WANG et al., 2016).

Contudo, com a facilidade na utilização do paralelismo, não tem sido abordada a raiz do problema, que é o aumento da densidade do espaço de busca. De fato, apesar do rápido crescimento do volume de dados, o modelo de busca utilizado tem permanecido o mesmo, isto é, utilizam-se os mesmos operadores fundamentais de busca que consideram os dados em espaços "esparsos" (SKOPAL et al., 2009). Dessa maneira, busca-se resolver a eficiência das tarefas de big data, porém, no melhor do nosso conhecimento, poucos trabalhos na área de banco de dados têm procurado melhorar a eficácia (qualidade) das respostas e, principalmente, melhorar os critérios de comparação e dos operadores de busca para tarefas que envolvem grandes volumes de dados.

Existem duas áreas de pesquisa pioneiras em melhorar a qualidade das respostas fornecidas aos usuários, sendo essas a de sistemas de recomendação (ZIEGLER et al., 2005; AGRAWAL et al., 2009; SANTOS; MACDONALD; OUNIS, 2010; SANTOS; MACDONALD; OUNIS, 2011; GIL-COSTA et al., 2011; MAO; SHEN; SUN, 2012; SANTOS; MACDONALD; OUNIS, 2015) e das máquinas de busca de páginas da web (CAPANNINI et al., 2011; YU; LAKSHMANAN; AMER-YAHIA, 2009; VEE et al., 2008; AGRAWAL et al., 2009; LEUKEN et al., 2009; ZHOU et al., 2010; DOU et al., 2011; OZSOY; ONAL; ALTINGOVDE, 2014; ABID et al., 2016; NEGI; JAJU; CHAUDHURY, 2016). Essas pesquisas vêm desenvolvendo técnicas chamadas de diversificação de resultados (result diversification) cujo objetivo é tornar mais relevantes as respostas fornecidas aos usuários levando em consideração o relacionamento entre os elementos no espaço de busca. Tipicamente, a diversificação de resultados é aplicada na busca aos $k$ vizinhos mais próximos gerando a variante chamada de busca aos $k$ vizinhos diversos mais próximos (apresentada na Subseção 2.2.3.1). Existe um aparente contrassenso em aplicar diversidade em buscas por similaridade sobre grandes volumes de dados, uma vez que seu processamento requer uma análise adicional sobre o resultado a ser entregue. No entanto, o objetivo aqui é melhorar a qualidade das respostas, o que pode evitar a necessidade de re-submissão das buscas e levar a uma redução do tempo total dispendido 
na obtenção dos resultados desejados. Deste modo, a próxima seção apresenta as principais estratégias utilizadas para aumentar a qualidade dos resultados usando a propriedade de diversidade, e mostra como pode ser feita a avaliação da qualidade das respostas à buscas com diversidade.

\subsection{Estratégias para Diversificação de Resultados}

Na literatura existem dois grupos de estratégias para a diversificação de resultados: a baseada em atributos e a baseada em conteúdo. A estratégia mais conhecida e utilizada é a baseada em atributos (Attribute-based)(MCNEE; RIEDL; KONSTAN, 2006), e consiste em comparar o quanto cada valor do atributo que compõe a descrição dos dados difere de outros no conjunto de resultado. A estratégia baseada em conteúdo por sua vez, consiste em utilizar apenas os elementos do domínio de dados e a relação de distância entre eles.

A seguir, apresenta-se os principais modelos de diversidade baseados nessas estratégias.

\subsubsection{Diversidade Baseada em Atributo}

A abordagem proposta por Ziegler et al. (2005) adiciona diversificação entre os elementos nas listas de recomendação por meio de uma métrica de similaridade. A ideia é reorganizar as listas utilizando um fator de diversificação $\left(\Theta_{F}\right)$ para definir qual é o grau de dissimilaridade que deve ser empregado na resposta final. Utilizando a métrica proposta por Ziegler, Lausen e Schmidt-Thieme (2004), é possível aumentar ou diminuir a diversidade dos elementos de acordo com a taxonomia de classificação dos atributos. Contudo, apesar dessa proposta perder a precisão média dos resultados, foi demonstrado experimentalmente que os usuários preferem listas de recomendação mais diversificadas do que listas muito precisas, o que evidencia que ao se tratar da satisfação do usuário nem sempre as respostas mais precisas são as melhores.

De maneira similar, Agrawal et al. (2009) buscaram resolver o conflito de buscas com palavras-chave ambíguas (por exemplo, Jaguar, Windows) que fazem parte de mais de uma categoria, comparando os documentos de acordo com sua taxonomia. Diferentemente de Ziegler et al. (2005), o trabalho de Agrawal et al. (2009) considera tanto a relevância dos documentos retornados quanto a diversificação da resposta, buscando maximizar a probabilidade do usuário encontrar pelo menos um resultado interessante em uma resposta final com $k$ elementos. Para tornar a busca mais eficiente, é utilizada uma função que evita colocar novos elementos em categorias que já estão no conjunto de resposta, o que possibilita procurar documentos em outras categorias que ainda não foram analisadas.

Vee et al. (2008) propõem que a diversificação seja realizada usando dados estruturados. A ideia foi utilizar uma lista de índices invertidos contendo os identificadores dos itens de pesquisa para criar uma hierarquia de diversidade para os elementos. A ideia é diversificar a resposta em relação à frequência com que os elementos aparecem na base de dados. Contudo, essa abordagem fica restrita à ordem dos elementos estruturados que possuem relacionamentos bem definidos.

Chen e Li (2007) utilizam uma estratégia de agrupamentos de dados para visualizar os resultados de buscas em $S Q L$ e capturar a percepção das diversas preferências do usuário. 
A premissa dessa estratégia é que o usuário, geralmente, não consegue formular adequadamente buscas para responder exatamente os seus interesses. Ao invés disso, ele utiliza uma busca com uma condição generalizada, e realiza posteriormente várias outras buscas para refinar seus interesses até encontrar a resposta desejada. Desse modo, para incluir as preferências do usuário, foi proposto um método de pós-processamento para inferir as preferências baseando-se no histórico de buscas dos usuários, gerando agrupamentos de preferências. É importante destacar que a proposta de Chen e Li (2007) não é selecionar os agrupamentos mais importantes para o usuário, mas sim apresentar ao usuário as diferenças entre os agrupamentos.

Dou et al. (2011) apresentam uma visão multidimensional para análise da cobertura de subtópicos para buscas na web. É discutido que uma busca pode possuir termos ambíguos (como, por exemplo, eclipse, Defender, tênis) em diversos níveis e que apenas a utilização de uma única dimensão (fonte de dados) não consegue fornecer toda informação necessária para cobertura dos subtópicos de interesse do usuário. Além disso, Dou et al. (2011) segue a mesma premissa propostas por Chen e Li (2007), admitindo que o usuário precisa realizar várias buscas para explicitar o tópico que mais se aproxima das suas necessidades de informação. No entanto, Dou et al. (2011) adotam a abordagem de realizar mineração de dados em diferentes fontes de dados, com o intuito de que cada base forneça um aspecto diferente em relação a ambiguidade do termo de busca.

Apesar da abordagem de diversidade baseada em atributo apresentar bons resultados para área de recomendação e sistemas de recuperação na web, ela depende que o atributo possua um valor significativo ou que os dados estejam organizados hierarquicamente de acordo com uma taxonomia. Além disso, ao se trabalhar com dados complexos (por exemplo, imagens) em espaços métricos, torna-se difícil utilizar a estratégia baseada em atributo, devido ao fato da descrição dos atributos possuírem baixo nível de significado individual (HE; CAI; HAN, 2008; DESERNO; ANTANI; LONG, 2009). Desse modo, é mais interessante considerar a propriedade de diversidade nas buscas que podem ser definidas utilizando apenas a similaridade entre o conteúdo dos elementos a serem recuperados.

\subsubsection{Diversidade Baseada em Conteúdo}

Para a diversificação de resultados com dados complexos em espaços métricos, é preciso definir a propriedade de diversidade de maneira que não seja necessário utilizar valores individuais dos atributos pois, como dito anteriormente, não se pode contar com valores de atributos com significados compreensíveis nesse espaço.

Dessa maneira, são considerados apenas os próprios elementos e a distância entre eles por meio de uma função de distância. Baseado nas definições apresentada na Subseção 2.2.3.1, o problema de diversificação se resume em definir um conjunto de resposta $R \subseteq S$ com tamanho $|R|=k$ em que cada elemento de $R$ é tanto similar a $s_{q}$ com relação a $\delta_{\text {sim }}$ (medida de similaridade), quanto diversos em relação aos outros elementos em $R$ com relação a $\delta_{\text {div }}$ (medida de diversidade), maximizando uma função objetivo de diversificação. Considerese como exemplo de função objetivo a Equação (3.1), definida por Vieira et al. (2011a). O parâmetro de preferência de diversidade $(\lambda)$ representa o limiar de compromisso entre a similaridade e a diversidade no intervalo $[0,1]$. Essa formulação do problema de diversificação para valores de $\lambda>0$, resulta num problema de otimização combinatória cuja complexidade computacional é NP-Difícil (AGRAWAL et al., 2009). 


$$
\mathcal{F}\left(s_{q}, S^{\prime}\right)=(k-1)(1-\lambda) \cdot \operatorname{Sim}\left(s_{q}, S^{\prime}\right)+2 \lambda \cdot \operatorname{Div}\left(S^{\prime}\right) .
$$

O Algoritmo 1 apresenta uma solução exaustiva para o problema de diversificação. Esse algoritmo testa todos os subconjuntos possíveis com tamanho $k$ para encontrar a solução ótima com o maior valor de $\mathcal{F}$. Considerando que $S^{\prime} \subseteq S$ possui cardinalidade $\left|S^{\prime}\right|=m$, a quantidade total de subconjuntos formados por $k$ elementos é dada pela combinação $C(m, k)=m ! /(k ! \cdot(m-k) !)$, resultando na complexidade de tempo $O\left(m^{k}\right)$. Além disso, cada subconjunto requer $O\left(k^{2}\right)$ cálculos de distância da função objetivo, resultando numa complexidade de $O\left(m^{k} k^{2}\right)$, sendo pouco provável responder em tempo hábil em situações reais, com $m>10.000$ e $k>5$. Dias, Bueno e Ribeiro (2013) apresenta uma versão do algoritmo exaustivo com computação paralela dos subconjuntos candidatos em múltiplos processadores. Apesar de reduzir o tempo de processamento quando comparado com o algoritmo tradicional, a complexidade do problema permanece a mesma. Dessa maneira, se torna mais interessante encontrar algoritmos com respostas aproximadas cujo valor da função objetivo seja o maior possível.

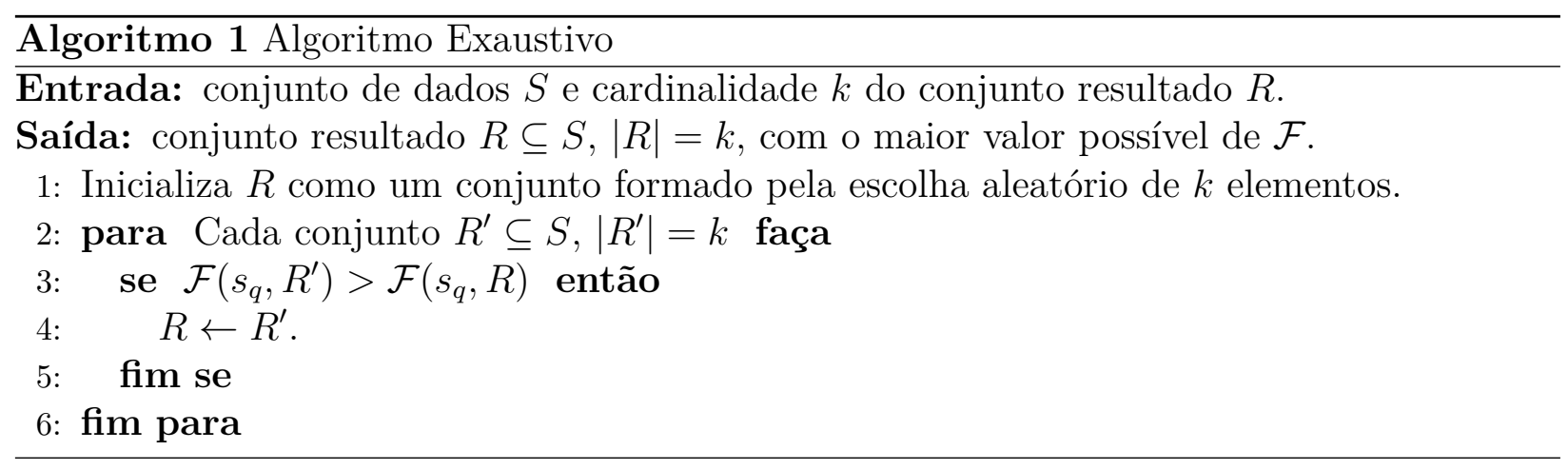

A primeira estratégia utilizada para reduzir a complexidade da solução exaustiva, é reduzir o espaço de busca, de modo que elementos com menor relevância para a busca possam ser excluídos, porém sem afetar a qualidade da resposta. Um modo de reduzir o espaço de busca consiste em atribuir uma distância máxima em relação a similaridade $\left(\delta_{\text {sim }}\right)$ ao elemento central de busca $s_{q}$, assumindo que elementos com distância maior que esse valor não são relevantes para a busca centrada em $s_{q}$. Intuitivamente, essa restrição por um limiar máximo possibilita considerar apenas os $p$ elementos mais próximos de $s_{q}$. Contudo, esse limiar pode ser difícil de ser definido, pois ele depende da distribuição do conjunto e da densidade do espaço no local da busca. Assim, é mais comum solicitar ao usuário que defina diretamente um valor para $p$, que pode ser um valor absoluto ou uma proporção $q>1$ em relação ao valor de $k$, por exemplo $p=q * k$.

Tipicamente, o processo de diversificação utiliza a resposta inicial retornada por um algoritmo que utiliza apenas similaridade como critério de busca onde os elementos são os mais similares em relação ao elemento central de busca $s_{q}$, retornando $p>k$ elementos mais próximos, gerando um conjunto candidato. Posteriormente é realizada a permuta dos $k$ elementos mais próximos por outros não tão próximos de $s_{q}$ no conjunto candidato, mas que, maximizam a função objetivo para um determinado valor de $\lambda$. Contudo, a redução do espaço de busca apenas ameniza o problema, pois o número de combinação ainda continua sendo $C(p, k)$. Uma estratégia amplamente utilizada em conjunto com a redução do espaço de busca consiste em utilizar algoritmos gulosos (greedy) para melhorar a eficiência e encontrar respostas determinísticas (VIEIRA et al., 2011a). 
Os algoritmos gulosos podem ser classificados de acordo com a estratégia utilizada para construir o resultado final, podendo ser incremental, baseada em troca ou baseada em meta-heurísticas (VIEIRA et al., 2011a; DROSOU; PITOURA, 2010). A estratégia de construção incremental inicia a busca com o conjunto vazio e iterativamente escolhe no conjunto candidato o elemento que maximiza a função objetivo. A estratégia baseada em troca inicia a busca com um conjunto inicial considerando apenas a similaridade ao elemento de busca. Depois, cada elemento no conjunto candidato é avaliado para a troca por um outro elemento já inserido na resposta inicial. Caso a troca maximize a função objetivo, o elemento é inserido permanentemente na resposta. A estratégia baseada em meta-heurística utiliza duas fases, sendo a primeira responsável por definir um conjunto inicial e por escolher os elementos que trazem melhor contribuição para a resposta final segundo uma função objetivo. Já a segunda fase faz uma busca local, e troca os elementos para verificar se é possível otimizar o resultado já encontrado.

Uma proposta precursora da literatura na junção dos conceitos de similaridade e diversidade foi realizada por Carbonell e Goldstein (1998). Essa associação foi chamada de importância marginal (marginal relevance). Um elemento recuperado possui maior importância marginal, se for tão similar ao elemento de busca quanto dissimilar aos elementos anteriormente selecionados. O algoritmo Maximal Marginal Relevance (MMR) (Algoritmo 2) utiliza a estratégia de construção incremental do seguinte modo: inicialmente é construído o conjunto de diversidade escolhendo o elemento com maior similaridade para ser inserido no conjunto de resultado $R$ independente do valor de $\lambda$; posteriormente, de forma incremental, são selecionados elementos que maximizem a função objetivo (Equação (3.2)) de acordo com os elementos já inseridos na resposta.

$$
M M R\left(s_{i}\right)=(1-\lambda) \delta_{s i m}\left(s_{i}, s_{q}\right)+2 \lambda \sum_{r_{j} \in R} \delta_{d i v}\left(s_{i}, r_{j}\right)
$$

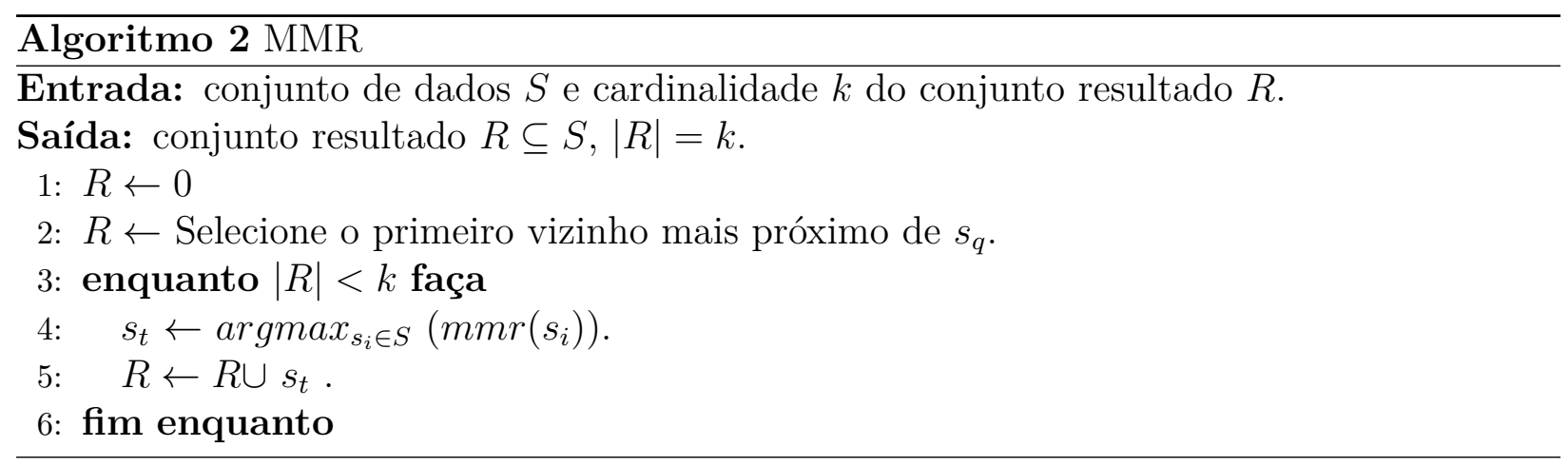

A qualidade dos resultados do MMR é restringida pela escolha do primeiro elemento, pois como esse algoritmo sempre escolhe o elemento mais similar ao elemento de busca $s_{q}$, todas as próximas escolhas são definidas a partir dele. Assim, em situações em que o usuário possui maior preferência por diversidade $(\lambda>0,6)$ a qualidade do MMR é bem inferior quando comparado a outros métodos da literatura (VIEIRA et al., 2011a).

Gollapudi e Sharma (2009) apresenta uma plataforma axiomática com 8 axiomas (invariância escalar, consistência, riqueza, estabilidade, independência de atributos irrelevantes, monotonicidade, força da relevância e força da similaridade) que os sistemas de diversificação de resultados deveriam satisfazer e um teorema que estabelece que nenhuma função objetivo é capaz de satisfazer a todos os axiomas simultaneamente. Além disso, é apresentado um algoritmo guloso com construção incremental chamado MSD (Max-Sum Dispersion). 


$$
M S D\left(s_{i}, s_{j}\right)=(1-\lambda)\left(\delta_{\text {sim }}\left(s_{q}, s_{i}\right)+\delta_{\text {sim }}\left(s_{q}, s_{j}\right)\right)+2 \lambda \delta_{\text {div }}\left(s_{i}, s_{j}\right) .
$$

O algoritmo MSD (Algoritmo 3) funciona do seguinte modo: um conjunto de resultado $R$ é construído incrementalmente pela escolha de pares de elementos que sejam tanto similares ao elemento central de busca $s_{q}$ quanto diversos entre si. Em cada iteração são escolhidos dois elementos do conjunto de dados $s_{i}, s_{j} \in S$ que maximizem a função objetivo (Equação (3.3)). De acordo com essa equação, é necessário analisar os elementos par a par; nas situações em que um valor escolhido de $k$ é ímpar, o método escolhe aleatoriamente qualquer elemento em $S$ como parte da resposta, na última iteração. Um problema inerente do MSD é que o algoritmo considera a diversidade entre os pares de elementos no momento de sua escolha, porém não verifica se a inserção do novo par de elementos não resulta na proximidade dos pares de elementos anteriormente escolhidos.

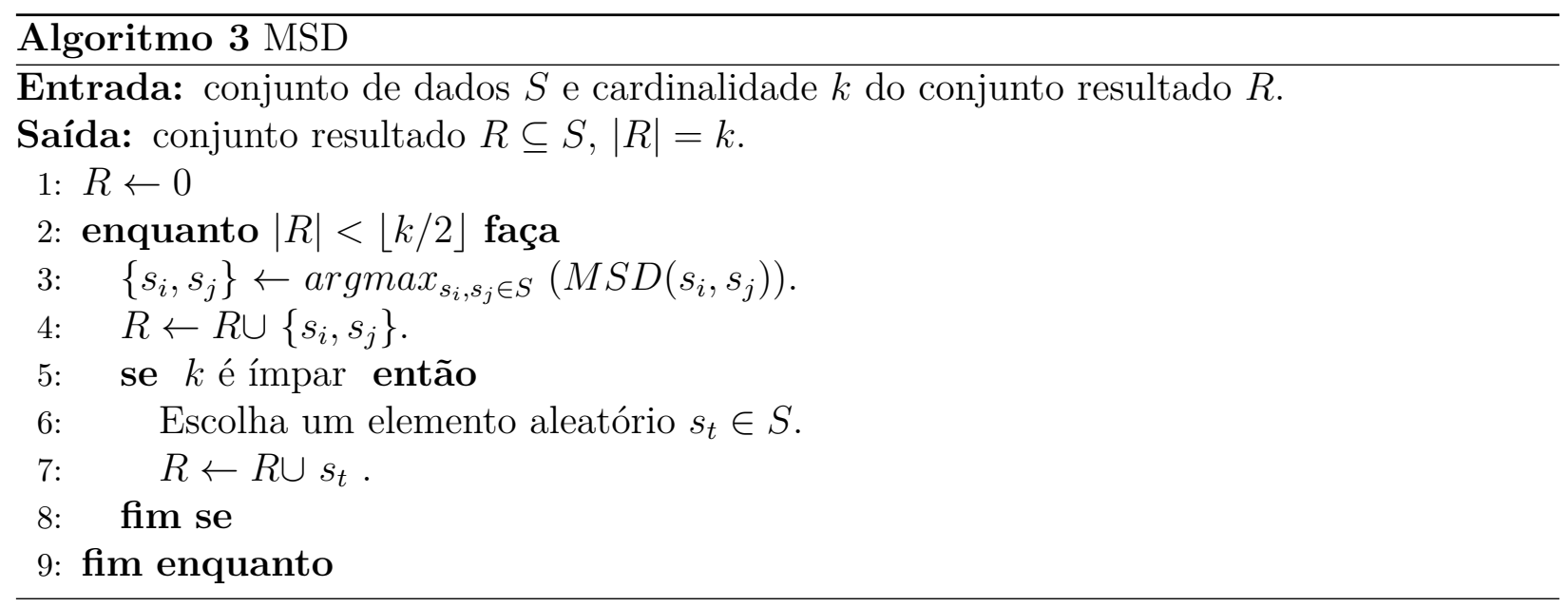

Vieira et al. (2011a) apresenta uma plataforma de avaliação e otimização dos principais algoritmos de diversidade da literatura. Além disso, também define os algoritmos GMC (Greedy Marginal Contribution) e GNE (Greedy Randomized with Neighborhood Expansion) cuja função objetivo (Equação (3.1)) é muito similar à definida por Gollapudi e Sharma (2009), apenas evitando a comparação por pares de elementos.

O algoritmo GMC (Algoritmo 4) também é baseado na estratégia de construção incremental e segue os mesmos passos que o algoritmo MMR, sempre escolhendo o elemento com maior contribuição para resposta. Porém, o GMC utiliza uma função de avaliação de contribuição para o conjunto de resultado diferente do MMR, chamada de maximum marginal contribution - mmc (Equação 3.4).

$$
m m c\left(s_{i}\right)=(1-\lambda) \cdot \delta_{s i m}\left(s_{i}, s_{q}\right)+2 \lambda \sum_{s_{j} \in R_{p-1}} \delta_{d i v}\left(s_{i}, s_{j}\right)+2 \lambda \sum_{l=1}^{l \leq k-p} \delta_{d i v}^{l}\left(s_{i}, s_{j}\right) .
$$

A função $m m c$ considera a contribuição do elemento $s_{i} \in S$ para a função objetivo $\mathcal{F}$, utilizando a similaridade do elemento $s_{i}$ em relação ao elemento $s_{q}\left(\delta_{s i m}\right)$, para os elementos já inseridos na resposta $R_{p-1}\left(\delta_{\text {div }}\right)$ e também para os elementos não inseridos no conjunto de resultado $s_{j} \in S-s_{i}\left(\delta_{d i v}^{l}\right)$. Desse modo, a principal diferença entre os algoritmos que constroem o resultado de forma incremental é a utilização de diferentes funções de contribuição.

A principal diferença entre os algoritmos GNE e GMC é a estratégia de construção do resultado, pois o GNE utiliza uma adaptação da meta-heurística GRASP - Greedy Ran- 


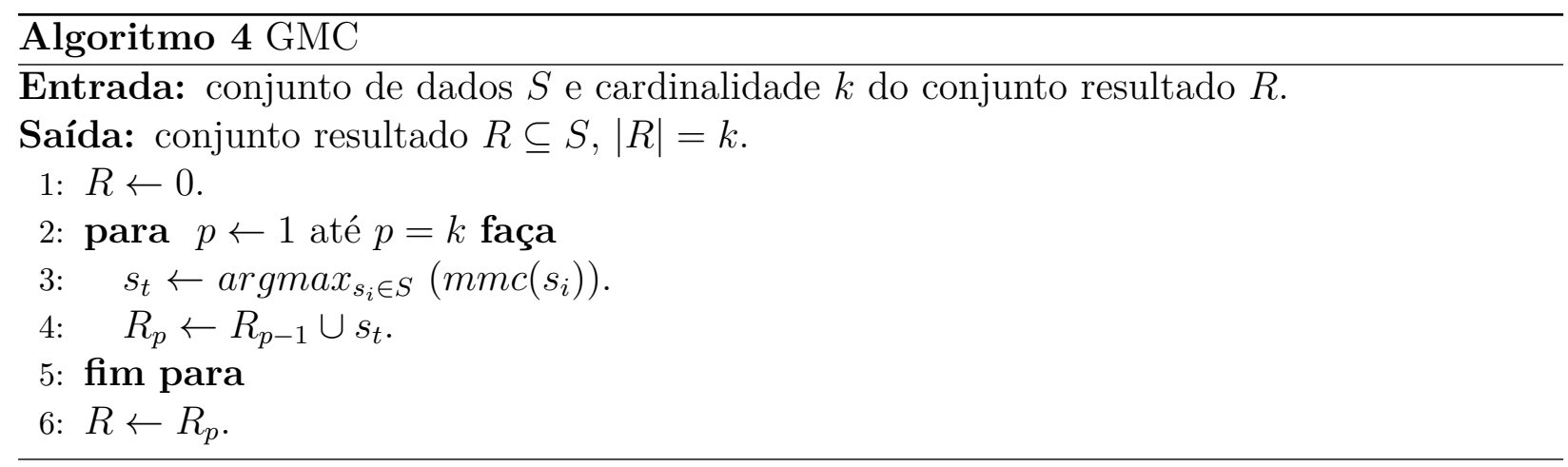

domized Adaptive Search Procedure (FEO, 1995; RESENDE, 2009), enquanto o GMC utiliza a estratégia incremental.

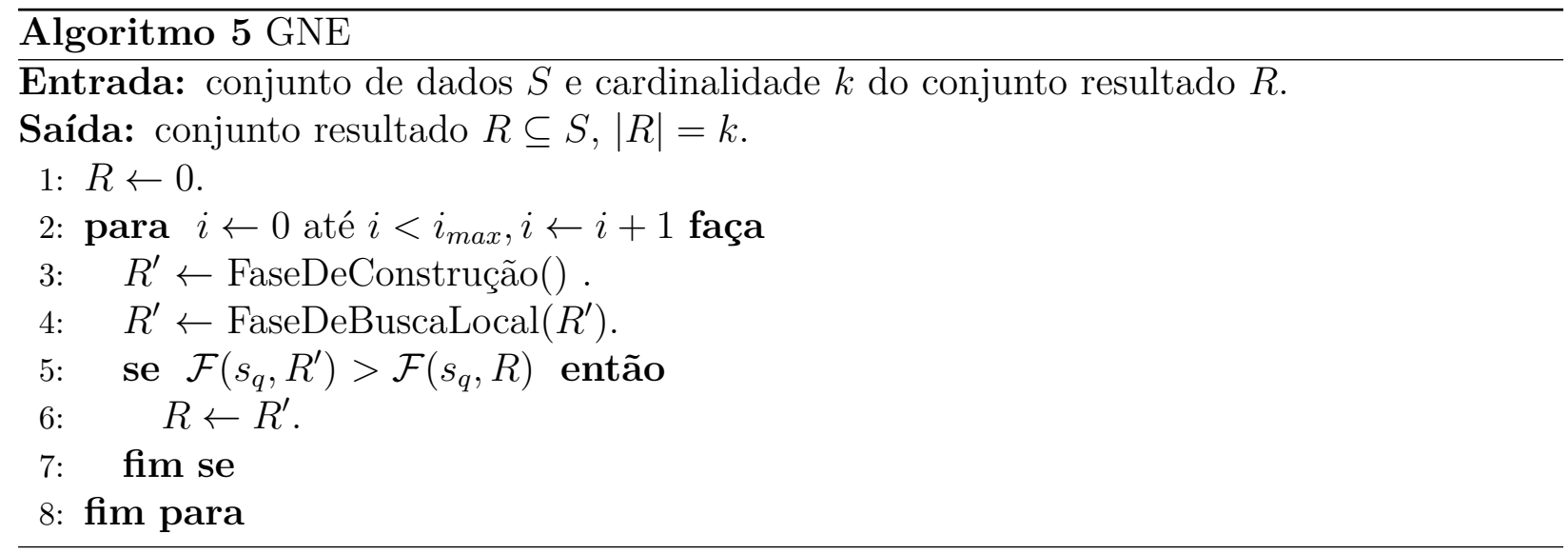

O GNE (Algoritmo 5) é dividido em duas etapas, a construção (FaseDeConstrução()) e a busca local (FaseDeBuscaLocal $\left(R^{\prime}\right)$ ). A etapa de construção consiste em selecionar um conjunto parcial de forma iterativa. Como podem existir muitos candidatos, é utilizada uma lista de tamanho fixo $p$, denominada de lista restrita de candidatos (Restricted Candidate List - $R C L$ ). Desse modo, são escolhidos aleatoriamente os $p$ elementos do conjunto parcial de acordo com a contribuição associada a sua inclusão na solução parcial por meio de uma função de avaliação gulosa (greedy) (Equação (3.4)). A partir da $R C L$, são escolhidos elementos de forma aleatória para compor uma solução inicial que será explorada pela fase de busca local. Portanto, a etapa de busca local, é uma tentativa de melhorar a solução obtida na fase de construção. Nesta etapa, percorre-se a vizinhança da solução corrente buscando uma solução de melhor qualidade. Se não existir uma melhor solução na vizinhança, a solução corrente é considerada um ótimo local e a busca é encerrada.

Yu, Lakshmanan e Amer-Yahia (2009) apresenta o algoritmo Swap (Algoritmo 6) que é composto de duas fases utilizando a estratégia baseada em troca. Na primeira fase, é construído um conjunto de resultado $R$ com os $k$ elementos mais similares ao elemento central de busca $s_{q}$. Na segunda fase, os elementos que não fazem parte do conjunto de resultado $s_{i} \in S-R$ são ordenados de maneira decrescente em relação a similaridade ao elemento $s_{q}$, e cada elemento $s_{i}$ é comparado com os elementos em $R$ para verificar se a troca desses elementos aumenta o valor da função objetivo (por exemplo, Equação (3.2)). É possível perceber pelo Algoritmo 6 que a escolha é sempre baseada na medida de similaridade $\left(\delta_{\text {sim }}\right)$, portanto não é possível garantir a maximização da função objetivo para qualquer valor de $\lambda>0$. 


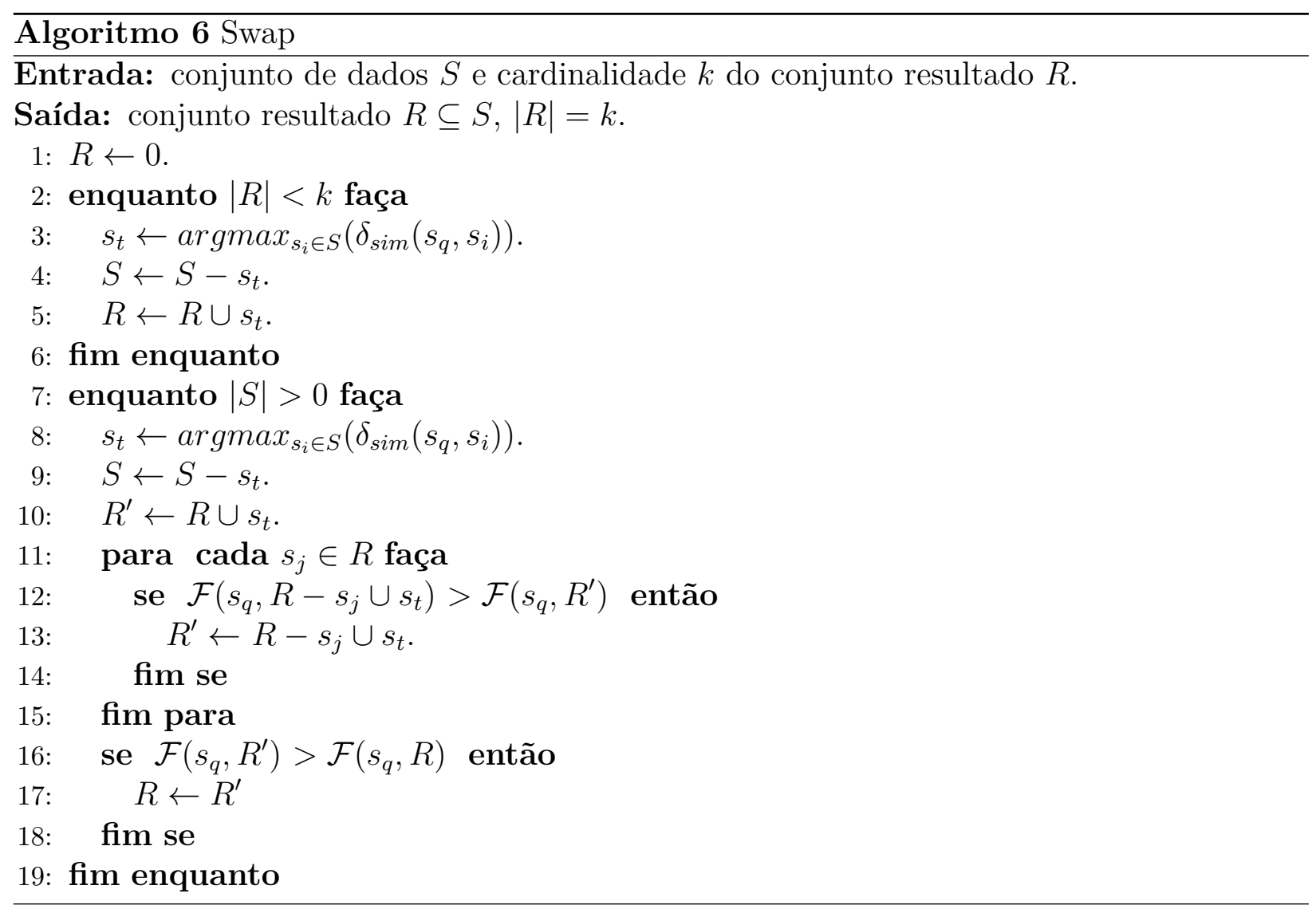

Embora a diversidade tenha sido modelada como uma propriedade dinâmica definida pelo usuário $(\lambda)$, extrínseca aos dados, formando um problema de otimização, ela possui problemas de usabilidade para casos reais. O primeiro problema é a necessidade do usuário definir um parâmetro que vêm se mostrando uma tarefa difícil de ser realizada, pois não existe uma relação entre os resultados retornados para um valor $\lambda=X$ e $\lambda=X \pm \epsilon$. Além disso, os algoritmos gulosos com restrição do espaço de busca também requisitam a definição de outro parâmetro, o número de elementos candidatos, que também requer conhecimento prévio do conjunto de dados por parte do usuário. Por fim, os algoritmos de diversidade modelados como um problema de otimização são utilizados apenas para buscas aos $k$-vizinhos mais próximos, não sendo aplicáveis à buscas por abrangência.

\subsubsection{Diversidade baseada em distância de separação}

Considerando os problemas apresentados em relação à definição de diversidade como um problema de otimização, outra estratégia para inserir diversificação nos resultados, que ao invés de solicitar qual é a preferência de diversidade $(\lambda)$ e o espaço de busca que deve ser considerado, requisita do usuário apenas a distância de separação desejável entre os elementos no conjunto de resultado. Assim, a diversidade passa a ser definida como uma propriedade inerente aos dados que serão apresentados, sendo preciso evitar à redundância no conjunto de resultado.

Uma das primeiras propostas nesse sentido foi definida por Jain, Sarda e Haritsa (2004) que implementa a propriedade de diversidade nas buscas aos $k$-vizinhos mais próximos em espaços multidimensionais. O algoritmo Motley (Algoritmo 7) considera uma variável MinDiv para definir um limiar de separação esperado entre os elementos do resultado e uma função 
booleana para filtrar os elementos da resposta. Se um elemento possui diversidade maior que o limiar definido, então ele é adicionado ao conjunto de resposta.

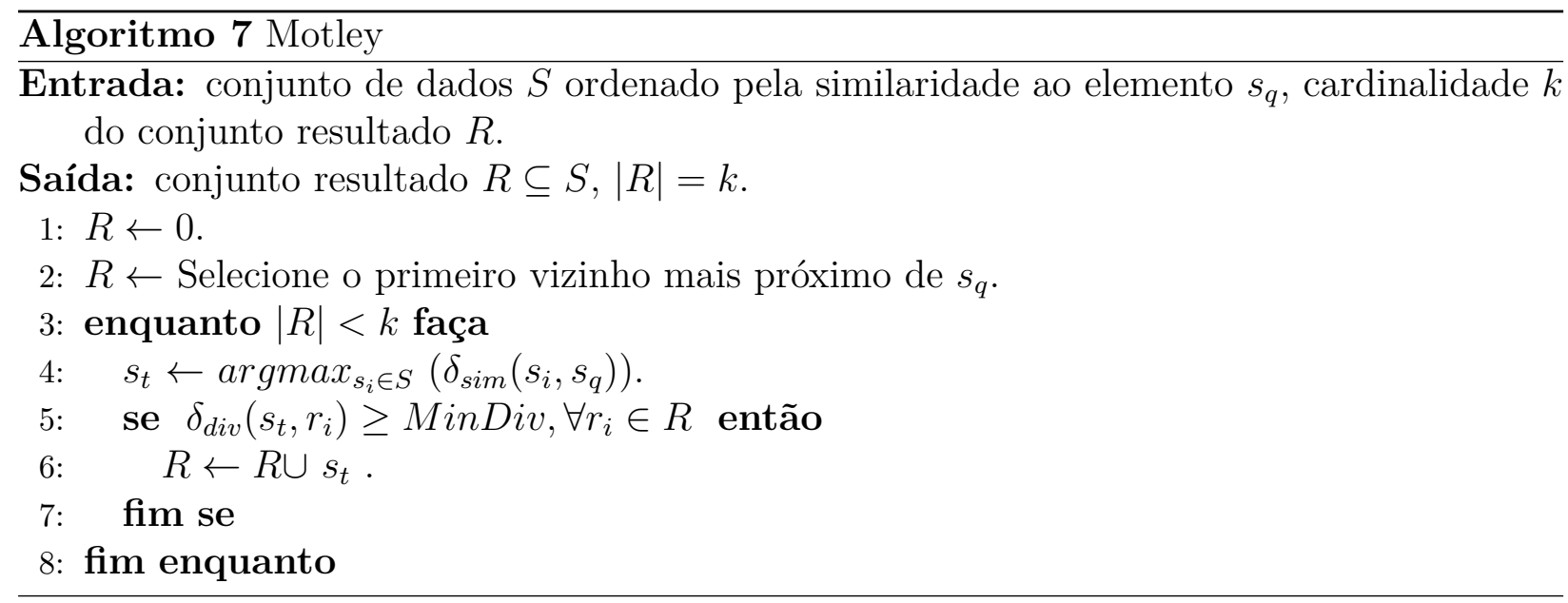

De maneira similar, Skopal et al. (2009) define dois algoritmos, o First-Match (FM) e o Centroid-Match (CM). O algoritmo FM constrói o resultado incrementalmente selecionando os elementos similares ao elemento central de busca, e a cada iteração, verifica se a distância entre os elementos é maior que a distância de separação definida pelo usuário. O algoritmo $C M$ processa o conjunto do mesmo modo, porém o elemento inserido no conjunto de resultado final é o centroide dos elementos considerados similares entre si. O custo do cálculo do centroide torna o $C M$ bem menos eficiente que o $F M$. A desvantagem em utilizar os algoritmos Motley, FM e $C M$ é que a distância de separação dos elementos possui um valor fixo para qualquer elemento, inclusive em relação ao elemento de busca $s_{q}$, sendo um parâmetro difícil de ser ajustado.

Outra técnica baseada na distância de separação entre elementos é a diversificação de seleção em espaços esparsos (Sparse Spatial Selection Diversification - SSSD)(GIL-COSTA et al., 2011). O SSSD utiliza o conceito de pivôs para evitar os cálculos de distância entre elementos que estão dentro de um raio de cobertura para uma estrutura de indexação chamada, Spatial Selection Diversification (SSS) (BRISABOA et al., 2006). O raio de cobertura é especificado pelo usuário e ele também define a abrangência de busca de cada pivô. A principal desvantagem dessa técnica é ser dependente de uma estrutura de índice específica e requisitar conhecimento prévio sobre conjunto de dados por parte do usuário para submissão de buscas. Além disso, a cada nova definição de raio de cobertura é necessário destruir e reconstruir a estrutura de indexação para otimizar a execução da busca, o que pode se tornar um problema caso o usuário reformule a busca múltiplas vezes.

Por fim, a técnica de diversidade DisC (Dissimilar and Covering) (DROSOU; PITOURA, 2012; DROSOU; PITOURA, 2015), considera que o usuário deve apenas informar qual é a distância de separação $(r)$ para encontrar um subconjunto da base de dados em que todos os elementos sejam tanto dissimilares entre si quanto englobem (cubram) todos os elementos da base. Assim, o parâmetro $r$ define o grau de diversidade e a quantidade de elementos que devem fazer parte da resposta. É importante ressaltar que o objetivo da técnica DisC não é responder buscas baseadas em um elemento de busca $s_{q}$, porém é escolher os elementos que são diversos entre si por um limiar de separação e apresentem uma visão completa da base de dados. Desse modo, o usuário apenas pode navegar entre os elementos diversos retornados ou verificar a vizinhança até uma distância máxima $r$ aos elementos retornados. Além disso, o usuário pode alterar a visão sobre a resposta fornecida: ao incrementar o valor de $r$ menos 
elementos retornam e a resposta apresenta uma visão sumarizada da base de dados. Por outro lado, ao decrementar o valor de $r$ mais elementos retornam e a resposta apresenta uma visão mais detalhada. Contudo, apesar de reduzir a quantidade de parâmetros para a diversificação utilizando DisC, a definição continua dependente de conhecimento prévio sobre o conjunto de dados e não é possível realizar a busca baseada em um elemento central de busca, tornando essa técnica diferente das buscas por similaridade baseadas num elemento de referência.

A Figura 3.1 apresenta a linha do tempo para as abordagens de diversificação de resultados existentes na literatura, onde os trabalhos foram classificados em: diversidade baseada em conteúdo, diversidade baseada em atributos e uma categoria para os trabalhos que visam listar e classificar a literatura (surveys).

Inicialmente pode parecer intuitivo permitir ao usuário definir um valor para a distância de separação. Porém, solicitar ao usuário valores que são dependentes da cardinalidade e da distribuição dos dados pode dificultar encontrar as respostas desejadas, forçando o usuário a ressubmeter a busca várias vezes. Apesar da técnica de diversificação por distância de separação ser muito mais eficiente do que as baseadas em otimização, ela possui os mesmos problemas de aplicação, pois é necessário conhecimento prévio para a definição da distância de separação, requisitando usuários mais especializados.

\subsection{Métodos de Avaliação de Resultados com Diversi- dade}

Com o objetivo de avaliar a qualidade da diversidade nas respostas às buscas, vários métodos de avaliação foram propostos na literatura (DROSOU; PITOURA, 2010; DROSOU; PITOURA, 2013; AGRAWAL et al., 2009). A área de recuperação de informação ( Information Retrieval - IR) tem realizado esforços para adaptar os métodos tradicionais de avaliação de precisão na recuperação de elementos relevantes (similares) em relação ao centro de busca, para levar em consideração também o nível de diversidade nos resultados. Os métodos, ganho acumulado descontado normalizado ((Normalized Discounted Cumulative Gain - NDCG), posição média recíproca (Mean Reciprocal Rank - MRR) e precisão razoável média (Mean Average Precision - MAP) são exemplos desses métodos. O objetivo é avaliar os conjuntos de resultados com base na posição em que os elementos aparecem em uma lista ordenada pela relevância (similaridade) dos elementos para a busca.

Um exemplo de adaptação dos métodos tradicionais de avaliação é dado por Clarke et al. (2008) com o método $\alpha-N D C G$. Tal método consiste em uma extensão do NDCG para medir a qualidade (ganho) de um elemento que está numa posição específica da lista de resultados, considerando os elementos que o precedem. O $\alpha$-NDCG é baseado no conceito de information nuggets, como é comumente utilizado na comunidade de sumarização, que representa um pequeno pedaço de informação similar. As desvantagens em utilizar o $\alpha-N D C G$ são a necessidade de um conhecimento a priori dos nuggets e a intensidade considerável de esforço humano necessário para julgar a relevância (similaridade) dos elementos na lista de resultados (DROSOU; PITOURA, 2010).

O método "ganho acumulado descontado normalizado ciente de intenção" ((Intent-Aware Normalized Discounted Cumulative Gain - NDCG-IA) é uma extensão do NDCG proposto por Agrawal et al. (2009) para considerar a importância dos elementos retornados em catego- 


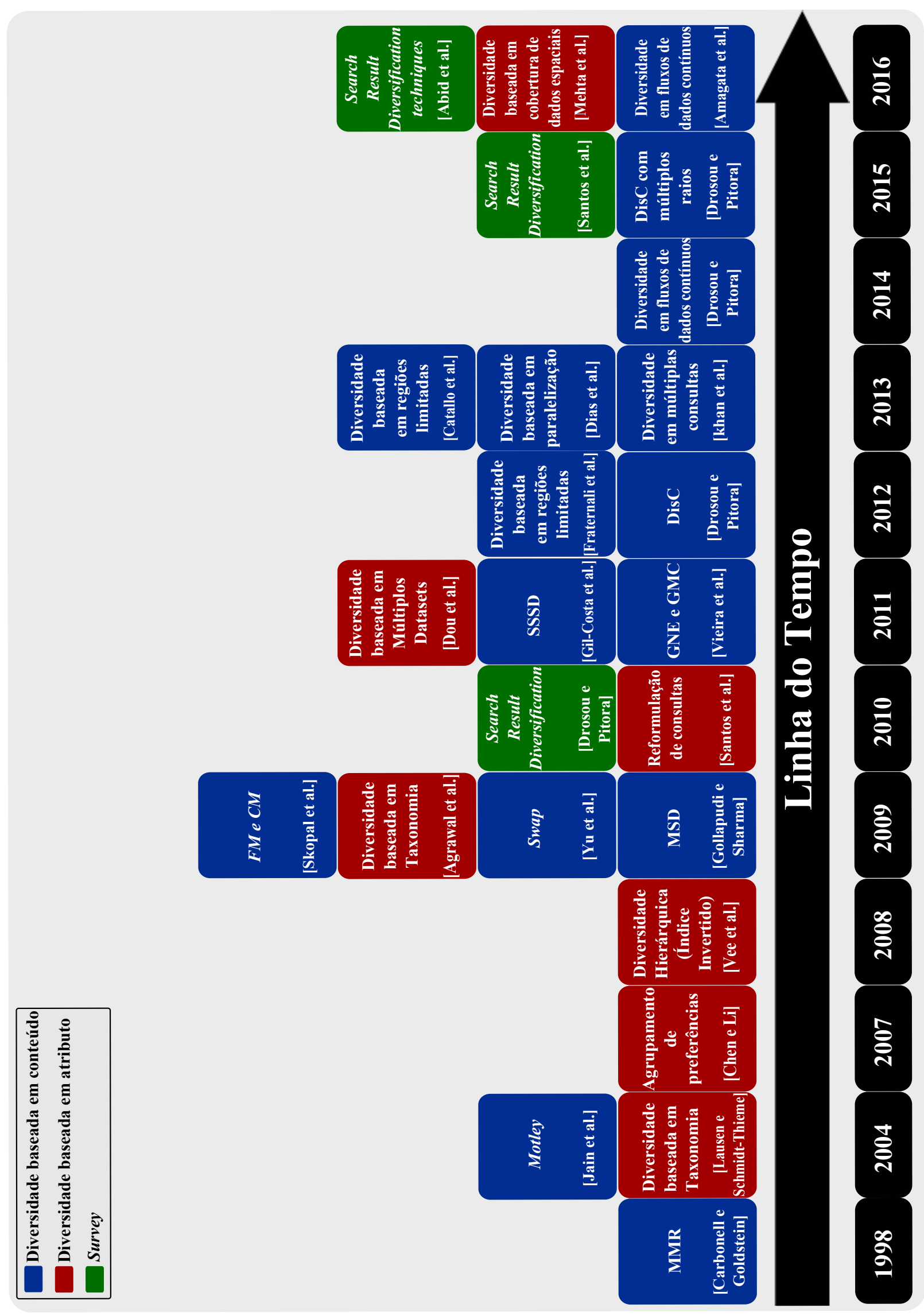

Figura 3.1: Linha do tempo para as abordagens existentes de diversificação de resultados. 
rias diferentes para uma mesma busca. A intuição do $N D C G$-IA é forçar um balanceamento entre, escolher elementos que são mais relevantes (similares) à busca e escolher elementos que cobrem categorias adicionais no conjunto de resultado. De maneira similar, os métodos MAP e MRR também foram adaptados por Agrawal et al. (2009). A principal desvantagem desses métodos de avaliação é a dependência de informações extras, como a taxonomia de atributos categóricos. Assim, as versões adaptadas provenientes da área de recuperação de informação não são interessantes para serem aplicadas em abordagens de diversidade baseadas apenas em conteúdo, pois a única informação disponível são os próprios elementos e a distância entre eles.

Para avaliar a qualidade da diversidade nas abordagens baseadas em conteúdo, dois métodos são comumente utilizados: o método Gap e o método baseado em função objetivo (VIEIRA et al., 2011a; YU; LAKSHMANAN; AMER-YAHIA, 2009; DROSOU; PITOURA, 2010). A principal diferença destes métodos para aqueles adaptados da área de recuperação de informação é que os resultados são vistos como um conjunto ao invés de uma lista ordenada. O método de avaliação baseado em função objetivo avalia o quanto os elementos de um conjunto de resultados para uma busca maximizam uma função de diversidade definida. Por exemplo, considere-se que dois algoritmos $A$ e $B$ foram definidos usando a mesma função objetivo $(\mathcal{F})$, porém utilizando estratégias de construção de resultado distintas. O algoritmo $A$ é considerado melhor do que $B$, se o valor de $\mathcal{F}_{A}$ é maior que o de $\mathcal{F}_{B}$. Assim, o método de avaliação de função objetivo não compara diretamente os conjuntos $A$ e $B$, sendo um método de comparação que avalia qual das estratégias de construção utilizadas nos algoritmos é mais eficaz na tarefa de maximar a função objetivo $\mathcal{F}$. Por sua vez, o método Gap busca normalizar os resultados encontrados pelas funções objetivos $\mathcal{F}_{A}$ e $\mathcal{F}_{B}$ usando o valor ideal fornecido por um algoritmo exaustivo (Algoritmo 1)(VIEIRA et al., 2011a). Por exemplo, considere que $\mathcal{F}_{A}$ e $\mathcal{F}_{O}$ são os valores alcançados pelos algoritmos $A$ e o exaustivo $O$, respectivamente. Assim, o método Gap é definido como a diferença entre $\mathcal{F}_{O}$ e $\mathcal{F}_{A}$, dividido por $\mathcal{F}_{O}$. De maneira similar, é possível usar o método Gap para comparar os elementos diretamente de cada conjunto de resultado fornecido pelos algoritmos $A$ e $O$.

Há ainda um método de avaliação definido por Smyth e McClave (2001) que também pode ser utilizado para comparar resultados de diversidade baseada em conteúdo, chamado de benefício relativo (Relative Benefit) ou índice RB. Intuitivamente, RB mede quanta similaridade é comprometida ao se considerar a propriedade de diversidade no resultado. $\mathrm{O}$ índice é gerado para cada algoritmo que deve ser comparado em relação à resposta fornecida pelo algoritmo $k-N N q$ (sem diversidade) como um padrão de referência $Z$. O índice RB para o algoritmo $A$ é obtido como a razão entre a diferença do conjunto dos $k$-diversos (Definição 5) , $\operatorname{Div}(A)-\operatorname{Div}(Z)$, dividida pela diferença do conjunto dos $k$-similares (Definição 4 ) , $\operatorname{Sim}(A)-\operatorname{Sim}(Z)$. Uma unidade do índice RB significa que cada aumento de diversidade no conjunto dos $k$-diversos é seguido pela redução de uma unidade de similaridade no conjunto dos $k$-similares. Assim, um algoritmo tem boa qualidade quando seu valor de RB é maior que um, indicando que cada unidade subtraída de similaridade ao elemento central de busca é compensada por uma unidade de diversidade (maior separação) entre os elementos selecionados da resposta final. 
File Edit View History Bookmarks Tools Help

(-) DivDB System

DivDB: Diversifying Query Results

\begin{tabular}{|l|l|l||l|}
\cline { 2 - 4 } \multicolumn{1}{l|}{} & method & metric & size \\
\hline Relevance & top-k $\nabla$ & Manhattan (L1) & S: 2000 \\
\hline Diversity & GNE (GRASP with Neighbor Expansion) & Manhattan (L1) & R: 5 \\
\hline Tradeoff $\mathbf{( \lambda )}$ & 0.3 & hint (optional) & none $\quad \nabla$ \\
\hline
\end{tabular}

Query: /home/images/images115.png

Browse

Submit

Disclaimer Help Contact Us

Figura 3.2: Interface gráfica do protótipo DivDB ilustrando que o usuário deve fornecer o caminho de uma imagem de busca e escolher os parâmetros de similaridade e diversidade (VIEIRA et al., 2011b).

\subsection{Protótipos para Otimização e Avaliação de Resul- tados com Diversidade}

Realizar buscas baseadas no conteúdo de imagens ao invés de utilizar atributos textuais (tags) associados às imagens pelos usuários tem atraído considerável atenção nos últimos anos, aumentando o número de ferramentas para recuperação de imagens por conteúdo (CBIR) relatadas na literatura (DATTA et al., 2008). Contudo, os operadores de busca implementados e disponíveis para a recuperação por conteúdo têm evidenciado que com o aumento da cardinalidade as imagens recuperadas podem ser muito similares tanto à imagem do centro de busca quanto entre as outras pertencentes à resposta.

Em conformidade com o que foi apresentado neste capítulo, vários trabalhos consideraram a aplicação da propriedade de diversidade nos operadores de busca como uma maneira de melhorar a qualidade dos resultados recuperados, apresentando uma visão mais abrangente em relação a imagem de busca. Contudo, ainda há questões em aberto no que tange à maneira como o fator de diversidade é utilizado nas buscas, e como é a relação dos elementos na resposta final. Desse modo, foram também criados protótipos para complementar os estudos de como a propriedade de diversidade é aplicada nas abordagens baseadas em distância, sendo que a motivação é comparar as respostas fornecidas pelas abordagens da literatura. Exemplos de protótipos são, o DivDB (VIEIRA et al., 2011b) e o POIKILO (DROSOU; PITOURA, 2013).

O protótipo DivDB (VIEIRA et al., 2011b) visa comparar o desempenho de diferentes algoritmos de diversidade em relação ao parâmetro de compromisso entre a similaridade e a diversidade $(\lambda)$ para conjuntos de imagens. A Figura 3.2 ilustra a interface gráfica do sistema. DivDB foi o primeiro protótipo a reunir e implementar os principais algoritmos de diversidade de diferentes autores num ambiente comum de execução.

O protótipo implementa uma heurística para reduzir o tempo de execução ao possibilitar o usuário escolher qual porção de elementos (qual o tamanho da vizinhança) devem ser considerados no processo de diversificação. Após o usuário definir os parâmetros da busca e informar a imagem de busca, o sistema apresenta o resultado para uma busca aos vizinhos 


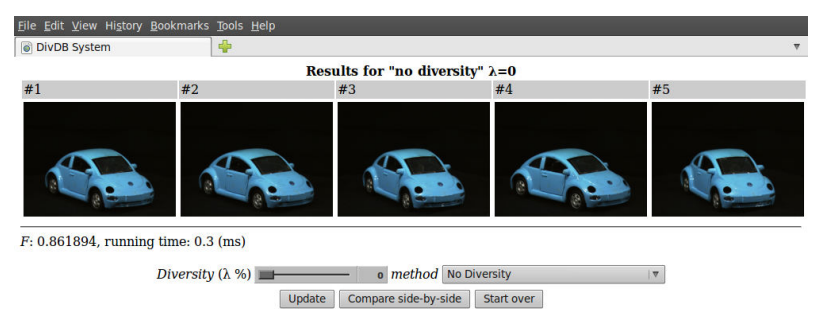

(a)

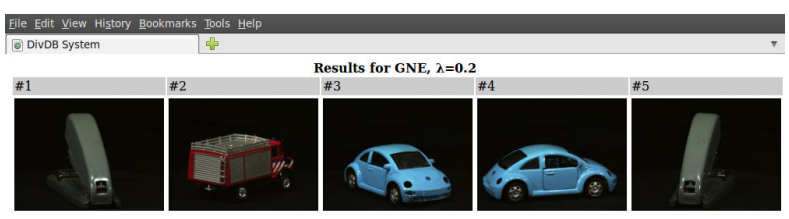

F: 0.862301 , running time: 12.5 (ms) Diversity ( $\mathrm{A} \%)$

(b)

Figura 3.3: Sequência de resultados do protótipo DivDB. (a) Somente similaridade $(\lambda=0)$ (b) Diversidade moderada $(\lambda=0.2)$ (VIEIRA et al., 2011b).

mais próximos (Figura 3.3 (a)) ou para uma busca aos vizinhos diversos mais próximos utilizando o algoritmo GNE (apresentado na subseção 3.3.2), como é ilustrado na Figura 3.3 (b).

Outro diferencial em relação ao DivDB é a possibilidade de definição das buscas utilizando uma extensão da linguagem $S Q L$ para que usuários mais avançados definam buscas mais complexas. Para definir a busca no DivDB é necessário realizar uma busca aninhada em que o comando de seleção interno recupera os vizinhos mais próximos. Posteriormente, é definido um comando de agrupamento aos vizinhos diversos mais próximos e, por fim, é definida uma ordenação com a função objetivo de otimização $\mathcal{F}$. Além disso, é possível informar ao protótipo qual o interesse na busca, eficácia ou eficiência, influenciando qual algoritmo será utilizado para responder a busca. O seguinte comando ilustra uma busca às 5 imagens diversas mais próximas, considerando uma vizinhança de 2000 imagens e com preferência de diversidade em $30 \%(\lambda=0.3)$ com interesse em qualidade, possuindo a seguinte forma:

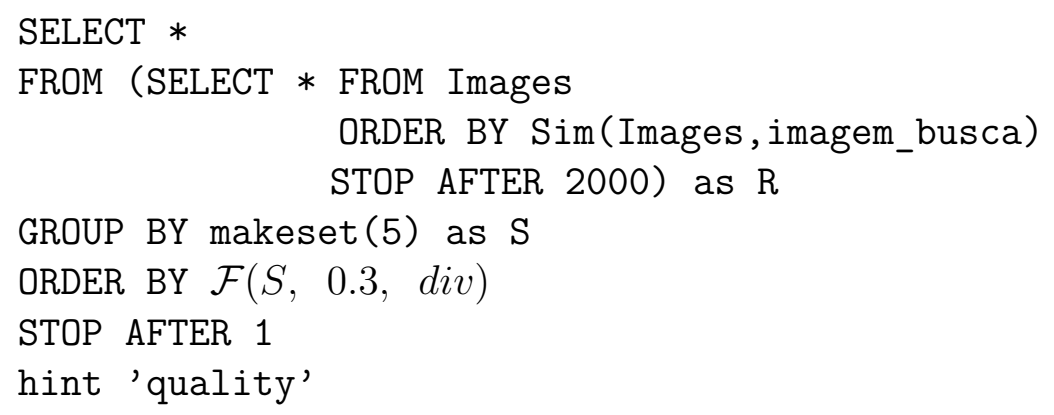

Apesar do usuário ser participativo (definição de parâmetros) no processo de busca no DivDB e possibilitar a definição de comandos $S Q L$, o protótipo não deixa claro como a propriedade de diversidade foi aplicada nas imagens candidatas à resposta final ou qual a relação das imagens no espaço de busca.

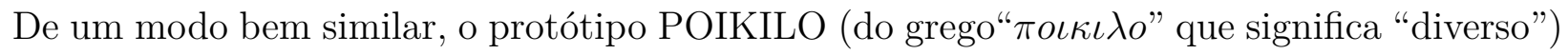
visa auxiliar usuários na tarefa de buscar, visualizar e comparar resultados diversificados com base em diferentes abordagens de diversificação de resultados, incluindo o modelo DisC (comentado na subseção 3.3.3). O POIKILO, assim como o DivDB, também possibilita o ajuste de parâmetros e algoritmos de diversidade, mas o grande diferencial é a disponibilidade de conjuntos de dados geográficos para produzir informações visuais sobre o processo de diversificação do resultado, como pode ser visto na Figura3.4. Além disso, o POIKILO possui variações dos algoritmos de diversidade para lidar com fluxo de dados contínuos (Data Streams) por meio do conceito de janelas deslizantes e da estrutura de dados Cover tree (DROSOU; PITOURA, 2014). Conjuntos de dados de imagens também podem ser buscados 


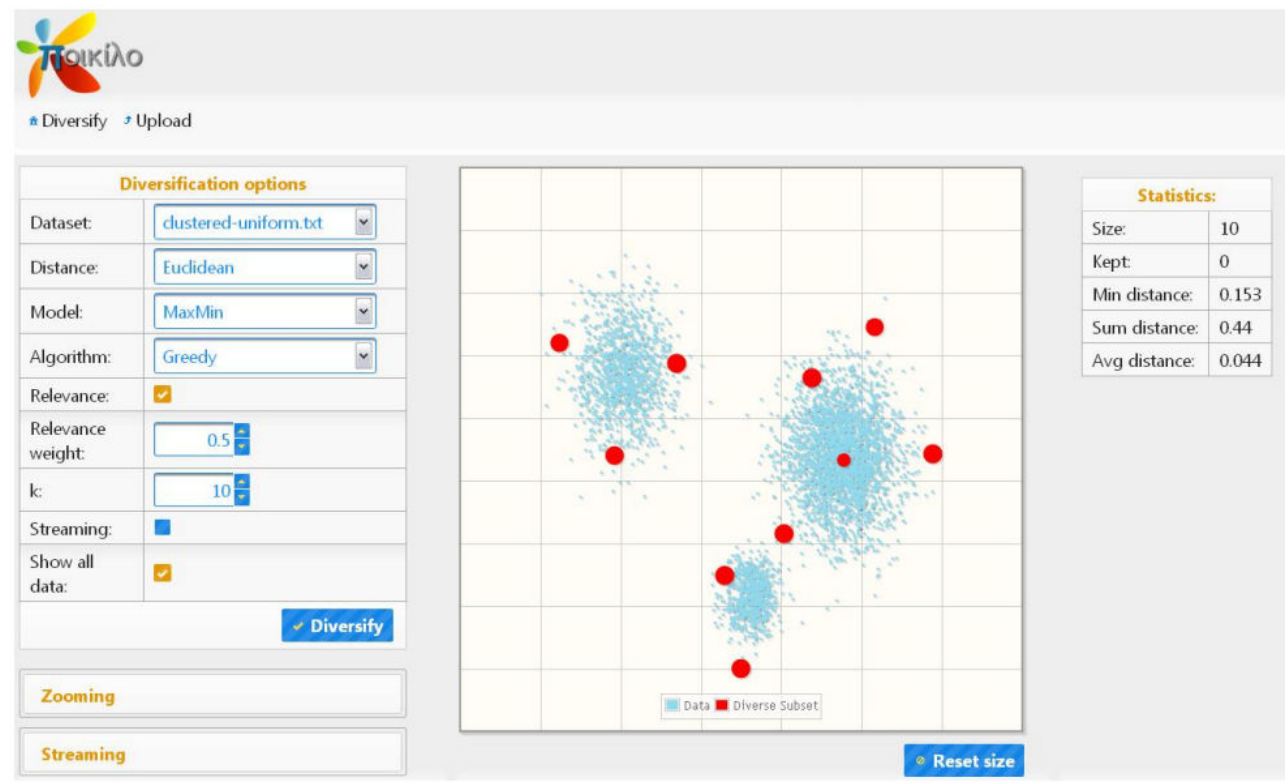

Figura 3.4: Interface gráfica do protótipo POIKILO ilustrando os parâmetros disponíveis para o ajuste do usuário. Além disso, conjuntos de dados geográficos tornam intuitiva a distribuição dos elementos na resposta diversificada (DROSOU; PITOURA, 2013).

no POIKILO, porém não há qualquer tipo de informação visual para indicar quais elementos foram escolhidos no processo de diversificação.

Apesar dos protótipos apresentados nesta subseção possibilitarem que tanto usuários iniciantes quanto avançados experimentem a propriedade de diversidade, nenhum desses protótipos fornecem informações para auxiliar o usuário no entendimento de uma resposta diversificada. $\mathrm{Na}$ próxima seção, serão apresentados conceitos que podem ser incorporados num protótipo de diversificação com o intuito de aumentar a quantidade de informação visual disponível sobre a propriedade de diversidade.

\subsection{Mineração Visual de Dados}

A Mineração Visual de Dados (MVD) tem por objetivo proporcionar uma maneira intuitiva e inovadora para tratar o volume crescente de informações produzidas pela novas aplicações. O objetivo desta atividade é promover uma ponte entre os algoritmos de mineração de dados e a as técnicas de visualização de dados, facilitando a exploração de informações.

Uma dificuldade encontrada comum entre os sistemas de recuperação de conteúdo é que o processo de representação numérica a partir do próprio elemento complexo (por exemplo, das imagens) é realizado de maneira "transparente" por algoritmos de processamento não supervisionados, definidos por um especialista da aplicação. Assim, em certas situações, ocorre um certo distanciamento da concepção de similaridade que o usuário está aguardando, gerando resultados insatisfatórios na recuperação das imagens. A utilização de técnicas voltadas à visualização e interação provenientes da MVD permitem que informações oriundas dos elementos complexos sejam melhor compreendidas e manipuladas pelo usuário.

Diferentes tipos de estratégias de interação e visualização estão sendo estudadas para facilitar a análises e exploração de base de dados de imagens e de suas informações pelos 
usuários (JOIA et al., 2011; GAGAUDAKIS; ROSIN, 2000; HU, 2009). As técnicas de MVD são classificadas de acordo com: a informação a ser exibida, a técnica de visualização e as técnicas de interação e distorção empregadas (KEIM et al., 2002). No contexto de sistemas CBIR, as técnicas de visualização mais amplamente utilizadas são as baseadas em projeções hierárquicas e multidimensionais(JOIA et al., 2011), enquanto as técnicas de interação e distorção dependem das necessidades do usuário. Um fator importante para a viabilidade desses sistemas é facilitar a exploração dos dados complexos para fazer um melhor uso da capacidade visual humana.

Tipicamente, técnicas de projeção multidimensionais fornecem uma maneira de mapear os dados a partir de um espaço com $n$-dimensões para um espaço $d$-dimensional, onde $d \in \mathbb{N}$, porém preservando ao máximo a relação de distância entre elementos no espaço original de $n$-dimensões. Uma projeção multidimensional movimenta os elementos em um espaço $d$ dimensional e verifica como as distâncias entre os elementos podem ser reproduzidas neste espaço, minimizando a função $\varphi$ seguinte:

$$
\varphi=\sum\left(\left(d_{i j}-f\left(\delta_{i j}\right)\right)^{2}\right.
$$

onde $d_{i j}$ representa as distâncias espaciais projetadas e $\delta_{i j}$ representa as distâncias no espaço original com $n$-dimensões. A expressão $f\left(\delta_{i j}\right)$ indica uma transformação não métrica, monótona das distâncias no espaço original de $n$-dimensões, que reproduzem as distâncias originais entre os elementos no espaço de projeção.

Duas projeções multidimensionais são destacadas nesta seção por apresentarem características que as tornam passíveis de serem integradas em um protótipo de CBIR: a técnica FASTMAP (FALOUTSOS; LIN, 1995) e a técnica LAMP (JOIA et al., 2011). A técnica FASTMAP encontra $N$ pontos para mapear $N$ elementos em um espaço $Z-d$, em que $d$ representa a dimensão da base de dados cujas distâncias Euclidianas correspondem às distâncias de um dada matriz de distância $M(N \times N)$. Os elementos são tratados como pontos em um espaço de $n$-dimensões e são projetados em $Z$ direções mutuamente ortogonais. FASTMAP utiliza de uma heurística para reduzir a quantidade de cálculos de distância $O\left(N^{2}\right)$ para apenas $O(N k)$ usando pivôs, sendo bem eficiente no processo de projeção.

A técnica LAMP (Local Affine Multidimensional Projection) propõe mapeamentos locais que partindo de um subconjunto inicial amostral realiza uma projeção inicial para orientar o posicionamento dos demais objetos. Assim, LAMP realiza o mapeamento de cada ponto $x$ utilizando uma transformação afim $f_{x}(p)=p M+t$ que minimiza:

$$
\sum_{i=1} \alpha_{i}\left(f_{x}\left(x_{i}\right)-y_{i}\right)^{2}
$$

onde $M$ é uma matriz em que, $M^{T} M=I$, e $I$ é a matriz identidade. Além disso, $M$ e o vetor $t$ são desconhecidos previamente e $\alpha_{i}$ são escalares de ponderação definidos como:

$$
\alpha_{i}=\frac{1}{\left(x_{i}-x\right)^{2}}
$$

onde $x_{i}$ representa um ponto de controle (amostra), $y_{i}$ é seu mapeamento no espaço projetado e $x$ representa uma instância do elemento que deve ser mapeado. O objetivo da técnica LAMP é possibilitar que o usuário defina posições de pontos de controle que guiem a projeção final. 
Além disso, LAMP realiza projeções locais guiadas pelos pontos de controle, ou seja, a mudança de uma parte do espaço não requisita a alteração de toda a projeção. A abordagem apresentada pelo LAMP visa aproveitar a capacidade visual humana na identificação de padrões e relações entre elementos de uma determinada base de dados.

Em relação à aplicação de técnicas de visualização a sistemas CBIR, há poucos relatos na literatura. Gagaudakis e Rosin (2000) empregam uma técnica de visualização de rede, chamada Pathfind, para visualizar a relação entre imagens oriundas da televisão. $\mathrm{Hu}$ (2009) propôs um sistema de visualização de imagens para analisar a qualidade da representação numérica das imagens de um sistema CBIR. Contudo, a visualização foi utilizada de maneira limitada com intuito apenas de apresentar uma visualização estática da base de imagens. O sistema PEx-Image (Projection Explorer system for Images) (ELER et al., 2009) possibilita visualizar a representação numérica das imagens do mesmo modo que o trabalho proposto por $\mathrm{Hu}$ (2009), porém seu diferencial ocorre ao combinar diferentes tipos de projeções e técnicas de interação para possibilitar ao usuário explorar a distribuição e a classificação de uma base de imagem. Contudo, nenhum dos trabalhos listados nesta monografia realiza buscas considerando diversidade.

\subsection{Considerações Finais}

Neste capítulo foram apresentadas as definições e soluções adotadas para trabalhar com big data, mostrando que o principal foco da literatura é em resolver o problema da eficiência ao se tratar conjuntos de dados volumosos. Foi apresentado também como a diversidade permite evitar que itens muito similares entre si sejam retornados nos resultados, melhorando a qualidade dos conjuntos de resultados.

A diversidade foi inicialmente explorada nas áreas de recuperação de informação e sistemas de recomendação sobre conjuntos de dados em que os atributos possuem valor semântico significativo, como exemplo, palavras-chave. Para tratar dados mais complexos, como imagens, é considerada à diversidade baseada em conteúdo, a qual utiliza apenas os elementos e as distâncias entre eles. A solução mais utilizada e conhecida na literatura para diversificação é dada pela combinação linear das medidas de similaridade ao elemento de busca e da medida de diversidade entre os próprios elementos na resposta, sendo necessário resolver um problema de otimização combinatória para respostas exatas. Assim, algoritmos gulosos são utilizados para encontrar respostas determinísticas em tempo hábil. Outras soluções definem a diversidade por meio de uma distância de separação que os elementos devem manter no conjunto de resultado. Porém, tais soluções apresentam problemas que tornam a propriedade de diversidade difícil de ser incluída em outros operadores de busca e em conjuntos de dados realmente volumosos, devido à alta complexidade de alguns algoritmos e à quantidade de parâmetros que precisam ser definidos pelo usuário.

A Tabela 3.1 apresenta uma comparação dos algoritmos de diversidade baseados em conteúdo revisados nesta monografia em relação aos aspectos que consideramos desejáveis para incluir diversidade no contexto de buscas por similaridade. Para que um algoritmo seja considerado ideal como base para resolver o problema de eficácia em big data, ele não deve ser limitado a usar parâmetros específicos de diversidade, pois o usuário pode não saber como ajustá-lo ou simplesmente não querer realizar tal tarefa. Além disso, o algoritmo não pode depender da utilização de uma estrutura de índices específica, pois tal imposição limita a implementação genérica do conceito. O algoritmo deve ser aplicável a qualquer tipo de operador de 
Tabela 3.1: Aspectos dos algoritmos de diversidade baseada em conteúdo que devem ser considerados para a definição de um modelo e de algoritmos de diversidade apropriados para tratar big data.

\begin{tabular}{|c|c|c|c|c|c|}
\hline Categoria & Otimização & \multicolumn{4}{|c|}{ Distância de Separação } \\
\hline Aspectos & GNE/MSD/MMR & $F M / C M$ & $S S S D$ & Motley & DisC \\
\hline $\begin{array}{l}\text { Requer configuração de } \\
\text { parâmetros específicos? }\end{array}$ & Sim & Sim & Sim & Sim & Sim \\
\hline $\begin{array}{l}\text { Depende de estrutura de } \\
\text { índices específica? }\end{array}$ & Não & Não & Sim & Não & Não \\
\hline $\begin{array}{l}\text { É específico a algum tipo } \\
\text { de busca por similaridade. }\end{array}$ & $k$-NN & $\begin{array}{c}\text { Qualquer } \\
\text { tipo }\end{array}$ & $k-\mathrm{NN}$ & $k$-NN & NN \\
\hline $\begin{array}{l}\text { É escalável com a } \\
\text { cardinalidade do conjunto } \\
\text { de dados? }\end{array}$ & Não & Sim & Sim & Sim & Sim \\
\hline $\begin{array}{l}\text { Depende de conhecimento } \\
\text { a priori do conjunto de } \\
\text { dados para } \\
\text { eficiência/eficácia? }\end{array}$ & Sim & Sim & Sim & Sim & Sim \\
\hline
\end{tabular}

busca por similaridade, e deve poder usar a propriedade de diversidade em qualquer busca, independente do volume dos dados. Outro aspecto é a necessidade dos algoritmos serem escaláveis para a cardinalidade do conjunto, pois nosso objetivo é melhorar a eficácia sem prejudicar severamente a eficiência. Por fim, o algoritmo não deve solicitar que o usuário tenha qualquer tipo de conhecimento em relação ao conjuntos de dados, tornando o uso de diversidade transparente ao operador físico de execução. Como pode ser observado na tabela, nenhum dos algoritmos apresentados atende a todos estes requisitos.

Além disso, as métricas de avaliação de diversidade apresentadas, em sua maioria, são derivadas das tradicionais métricas usadas nas áreas de recuperação de informação e de sistemas de recomendação, em que o conteúdo dos dados possui mais semântica ou o usuário está disposto a avaliar e fornecer informações (feedback) sobre os resultados. Assim, é possível perceber que há bastante espaço para o desenvolvimento de pesquisa e para a definição de métricas de diversidade para algoritmos baseados em conteúdo e em distância de separação. Por fim, os protótipos para avaliação e otimização de diversidade se destinam apenas à disponibilidade dos algoritmos em ambientes de execução em comum (frameworks), não fornecendo meios para aumentar o entendimento de como a diversidade é aplicada em base de imagens.

Os capítulos seguintes apresentam os trabalhos desenvolvidos nesta tese de doutorado. O próximo capítulo apresenta nossa contribuição em um modelo de diversificação de resultados que pode ser aplicado a qualquer operador de busca por similaridade. Ele não requer a definição de parâmetros de ajuste, é independente de estrutura de índices e é escalável com o aumento da cardinalidade do conjunto de dados. 
CAPÍTULO

4

\section{Diversificação de Resultados baseada em Influência}

A abundância de informações disponíveis nas aplicações online cria a necessidade métodos que realizem a recuperação baseada em conteúdo dos dados multimídia armazenados em um Sistema de Gerenciamento de Banco de Dados (SGBDs). Um grande esforço tem sido realizado no desenvolvimento de operadores para buscas por similaridade e, em particular, que recuperem dados representados em espaços métricos. Conforme foi apresentado no Capítulo 2, os dois critérios de comparação por similaridade considerados fundamentais são aqueles que expressam as buscas aos $k$-vizinhos mais próximos $(k-N N q)$ e as buscas por abrangência $(R q)$.

Contudo, como foi discuto no Capítulo 3, os operadores fundamentais tendem a perder sua expressividade quando utilizados sobre grandes volumes de dados, em que o espaço de busca torna-se muito "denso", retornando elementos muitos similares ao elemento central de busca e entre os outros elementos do conjunto de resultado. Por exemplo, considere que alguém deseja comprar um carro e para isso ele considere carros similares ao seu modelo de carro favorito. Nesse caso, a similaridade desejada considera as informações do ano do carro, a potência do motor, a capacidade em volume do porta-malas e a autonomia energética (quantidade de quilômetros percorridos com um litro de combustível). Em seguida, considerando um SGBD com suporte a buscas por similaridade, a pessoa submete a seguinte busca Q1 sobre o conjunto de dados $\operatorname{Carros}^{1}$ :

Q1: "Recupere os 5 (cinco) carros mais similares ao meu modelo favorito, o 'Volkswagen Golf 2.0', cujo ano é 2004."

Dois possíveis resultados para a busca Q1 são apresentados na Figura 4.1. O resultado para a busca utilizando um operador de busca aos $k$ vizinhos mais próximos $k$ - $N N q$ é mostrado na Figura 4.1(a). Como pode ser visto, o operador $k-N N q$ retorna apenas o mesmo modelo de carro, porém em anos distintos, o que é obviamente um resultado insatisfatório, pois somente elementos muito similares uns aos outros são retornados. Nesta situação, elementos muito similares uns aos outros praticamente não adicionam valor ao resultado, obrigando

\footnotetext{
${ }^{1}$ Quatro Rodas magazine. Disponível em: <http://quatrorodas.abril.com.br/carros/resumo/>. Acessado em: 25 de Janeiro de 2013.
} 


\begin{tabular}{|c|c|c|c|c|c|}
\hline \multicolumn{7}{|c|}{$s_{q}=$ Volkswagen Golf 2.0, 2004} \\
\hline Modelo & Ano & Potência & Porta-malas Autonomia & Preço \\
\hline Volkswagen Golf 2.0 & 2004 & 116 & 235 & 8,6 & $\mathrm{R} \$ 23.000$ \\
\hline Volkswagen Golf 2.0 & 2003 & 116 & 235 & 8,6 & $\mathrm{R} \$ 21.500$ \\
\hline Volkswagen Golf 2.0 2002 & 116 & 235 & 8,6 & $\mathrm{R} \$ 21.000$ \\
\hline Volkswagen Golf 2.0 2001 & 116 & 235 & 8,6 & $\mathrm{R} \$ 19.500$ \\
\hline Volkswagen Golf 2.0 2000 & 116 & 235 & 8,6 & $\mathrm{R} \$ 19.000$
\end{tabular}

(a) $k$-NNq: Sem diversificação

\begin{tabular}{|c|c|c|c|c|c|}
\hline \multicolumn{7}{|c|}{$s_{q}=$ Volkswagen Golf 2.0, 2004 } \\
\hline Modelo & \multicolumn{7}{|c|}{ Ano } & Potência Porta-malas Autonomia & Preço \\
\hline Volkswagen Golf 2.0 & 2004 & 116 & 235 & 8,6 & $\mathrm{R} \$ 23.000$ \\
\hline Volkswagen Golf 2.0 & 2002 & 116 & 235 & 8,6 & $\mathrm{R} \$ 21.000$ \\
\hline $\begin{array}{c}\text { Peugeot 206 1.6 16V } \\
\text { Flex Féline }\end{array}$ & 2004 & 110 & 245 & 7,5 & $\mathrm{R} \$ 20.000$ \\
\hline $\begin{array}{c}\text { Volkswagen Golf 1.6 } \\
2002\end{array}$ & 101 & 235 & 8,3 & $\mathrm{R} \$ 22.000$ \\
\hline $\begin{array}{c}\text { GM Corsa Hatch Maxx } \\
\text { 1.8 Flex }\end{array}$ & 2005 & 105 & 260 & 7,3 & $\mathrm{R} \$ 21.000$ \\
\hline
\end{tabular}

(b) Similaridade com Diversidade (sem parâmetros)

Figura 4.1: Resultado para a busca Q1. (a) Resultado da busca utilizando um operador de busca dos $k$-vizinhos mais próximos. (b) Resultado da busca utilizando a nossa proposta de $k$-vizinhos mais próximos com diversidade.

que o analista de dados reformule interativamente a busca até que o resultado desejado seja retornado o que, muitas vezes, pode ser um processo demasiadamente cansativo.

A alternativa considerada nesta tese para recuperar e apresentar aos usuários conjuntos de resultados representativos é a utilização do conceito de diversificação de resultados nos operadores de busca. O objetivo é retornar um conjunto de resposta com elementos similares ao centro de busca, porém heterogêneos entre si. Retomando ao exemplo da busca Q1, o resultado diversificado não deveria incluir apenas o mesmo modelo de carro nos diferentes anos de fabricação, mas deveria também adicionar outros modelos de carros similares ao elemento central de busca, como é mostrado na Figura 4.1(b).

As soluções descritas no Capítulo 3 para a diversificação de resultados apresentam limitações, pois em sua maioria, adicionam a propriedade de diversidade como um problema de otimização combinatória, resultando em algoritmos com custo elevado de execução. Além disso, as técnicas alternativas com custo computacional mais adequado requisitam informações do usuário que nem sempre estão disponíveis ou são de difícil definição, tal como definir a distância de separação entre os elementos na resposta.

Neste sentido, uma questão fundamental deve ser respondida:"Como encontrar o melhor valor para a distância de separação para um elemento central de busca sem conhecimento prévio da distribuição dos elementos?" Existem duas respostas simples para essa questão.

A primeira é submeter a mesma busca várias vezes com valores diferentes para a distância de separação enquanto o conjunto de resposta continua atendendo ao critério de comparação, seja encontrar os $k$ elementos diversos ou qualquer outra medida de diversificação, como exemplo, o somatório das distâncias entre os elementos do resultado final. A segunda resposta é definir uma quantidade $t$ de vizinhos mais próximos de cada elemento na resposta que devem ser ignorados no resultado final. Contudo, ambas alternativas possuem desvantagens. No caso da primeira alternativa, o custo de executar a mesma busca várias vezes (e, possivelmente, precisar do envolvimento do usuário para analisar as respostas) torna tal sugestão inviável, sendo apenas utilizada em ambientes de otimização de sistema offline. A segunda alternativa troca o problema de definir um valor para a distância de separação por definir a quantidade $t$ de elementos mais próximos para cada elemento da resposta, da mesma maneira não sendo óbvio como definir tal valor sem o conhecimento a priori da densidade dos elementos ao redor do elemento central de busca.

Com o objetivo de superar as desvantagens das técnicas existentes, apresentamos neste capítulo um modelo de diversificação de resultados que estima automaticamente qual deve ser o tamanho mínimo da distância de separação entre os elementos, sem requisitar nenhum 
ajuste de parâmetro ou qualquer tipo de conhecimento prévio sobre o conjunto de dados. Além disso, a nova proposta estima a distância mínima de separação adaptativamente, de maneira que, à medida que os elementos incluídos na resposta ficam cada vez mais distantes do elemento central de busca, a distância mínima exigida entre os elementos também aumenta, imitando a percepção intuitiva de que dois elementos distintos parecem mais similares um do outro à medida que se afastam do observador.

Em resumo, este capítulo apresenta as seguintes contribuições:

- Um novo modelo de diversidade, chamado de Diversificação de Resultados baseado em Influência (Result Diversification based on Influence - RDI) em que elementos são considerados diversos um dos outros com base na "influência" dos seus vizinhos ponderados por suas distâncias ao elemento central de busca (resultado ilustrado na Figura 4.1(b)). Além disso, o modelo RDI possui as seguintes características: independência de parâmetros, do domínio de dados e do operador de busca;

- Uma técnica para implementar o modelo RDI nos operadores de buscas aos $k$-vizinhos mais próximos e por abrangência, chamada de Melhores Resultados com Diversificação baseada em Influência (Better Results with Influence Diversification BRID) ;

- Um método de avaliação de diversidade com base no conceito RDI. O método estima a qualidade da resposta baseando-se no grau de sobreposição de influência dos elementos, sendo aplicado tanto a resultados oriundos de algoritmos de diversificação ou até mesmo de algoritmos que consideram apenas similaridade;

- Comparação da técnica BRID com os algoritmos da literatura. Os resultados experimentais atestam que a técnica é mais eficiente e eficaz que os competidores.

O restante deste capítulo é estruturado da seguinte maneira. A Seção 4.1 apresenta o modelo de diversificação baseado em influência. Na Seção 4.2 é apresentada a técnica BRID para implementar as buscas aos $k$-vizinhos diversos mais próximos e por abrangência diversificada. A Seção 4.3 introduz o método de avaliação de sobreposição de influência que pode ser aplicado aos resultados de qualquer operador de busca por similaridade. A Seção 4.4 apresenta os resultados dos experimentos realizados para avaliar o novo modelo de diversificação. Por fim, a Seção 4.5 apresenta as considerações finais deste capítulo.

\subsection{O Modelo de Diversificação de Resultados baseado em Influência}

Uma busca por similaridade recebe como parâmetros o elemento central de busca $s_{q}$ e, dependendo do critério de comparação, uma quantidade $k$ de elementos a serem retornados ou um limiar de dissimilaridade $\left(\epsilon_{q}\right)$ que os elementos retornados não podem exceder. Independente do critério de comparação, todos os elementos retornados são avaliados considerando apenas a similaridade individual de cada elemento em relação ao elemento central de busca. Contudo, as buscas por similaridade não consideram o relacionamento dos elementos do conjunto de resposta, o que possibilita a presença de elementos bastante similares no resultado 
final. Nesta Seção é proposta a utilização do posicionamento relativo dos elementos para determinar uma distância mínima de separação com base no elemento central de busca.

Considere-se que $S=\left\{s_{1}, s_{2}, \cdots, s_{n}\right\}$ seja um conjunto de dados com $n$ elementos amostrados em um domínio de dados $\mathbb{S}$, e que o elemento central de busca também pertence ao domínio $\left(s_{q} \in \mathbb{S}\right)$. Considere que a similaridade entre os pares de elementos $s_{i}, s_{j} \in \mathbb{S}$ é mensurada pela função de distância $\delta: S \times S \rightarrow \mathbb{R}^{+}$que expressa a dissimilaridade entre os elementos, isto é, quanto menor a distância entre os elementos, maior a similaridade entre eles. O problema de diversificação de resultados nas buscas por similaridade pode ser enunciado do seguinte modo: "Como encontrar um conjunto de resultados diversificados $R \subset S$ para uma busca definida pelo elemento $s_{q}$, selecionando em $S$ elementos que sejam similares ao $s_{q}$, porém de uma forma que os elementos em $R$ não sejam muito similares entre uns aos outros". Dois elementos $s_{i}, s_{j} \in S, s_{i} \neq s_{j}$, são considerados diversos uns dos outros sempre que $\delta\left(s_{i}, s_{j}\right)>\xi_{d i v}$, sendo que $\xi_{\text {div }} \geq 0$ é uma distância mínima de separação definida empiricamente. Se essa condição for válida, apenas um dos elementos deve fazer parte de um resultado de busca com diversidade. Neste contexto, as abordagens existentes (consulte a Subseção 3.3.3) dependem da experiência de um usuário para definir adequadamente o valor para $\xi_{d i v}$.

Nossa proposta assume que a distância mínima de separação $\left(\xi_{\text {div }}\right)$ entre os elementos do conjunto de resposta diversificado $R$ deve ser definida automaticamente e ajustada incrementalmente em relação à distribuição de distância dos elementos ao redor do elemento de central de busca $s_{q}$. Assim, a distância de separação entre $r_{i}, r_{j} \in R$ é estimada com base no posicionamento relativo desses elementos a $s_{q}$. Dessa forma, considera-se que existem "forças atrativas" entre os elementos no espaço de busca $S$, chamadas de influência, em que os elementos mais próximos uns dos outros exercem maior influência, isto é, possuem maior probabilidade de apresentar as mesmas características ou as mesmas informações, enquanto os elementos que são mais separados sofrem menor intensidade de influência uns sobre outros, ou seja, tendem a ser mais distintos. Assim, considera-se que a intensidade de influência entre dois elementos $s_{i}, s_{j} \in S$ é mensurada pelo inverso da distância entre os mesmos, como é dado pela Definição 10 .

Definição 10. Influência - $I\left(s_{i}, s_{j}\right)$ : Dados $s_{i}, s_{j} \in S, s_{i} \neq s_{j}$, e uma distância $\delta\left(s_{i}, s_{j}\right)$ entre os elementos, a influência mútua entre os elementos $s_{i}$ e $s_{j}$ é definida como:

$$
I\left(s_{i}, s_{j}\right)=\frac{1}{\delta\left(s_{i}, s_{j}\right)} .
$$

A intensidade da influência é mensurada entre os elementos do espaço de busca $S$ em relação ao elemento central de busca $s_{q}$ e para aqueles elementos que já são considerados diversos. Assume-se que um elemento $s_{i}$ já faz parte do conjunto de resultados diversificados $R$ e que um elemento $s_{j}$ precisa ser avaliado como diverso em relação ao elemento $s_{i}$ e para o elemento $s_{q}$. A intensidade de influência entre $s_{i}$ e $s_{j}$ é comparada com a influência de $s_{q}$ sobre $s_{j}$, e sempre que a condição $I\left(s_{i}, s_{j}\right) \geq I\left(s_{j}, s_{q}\right)$ for satisfeita, $s_{j}$ não pode fazer parte do resultado diversificado devido ao fato de ser "mais influenciado" por $s_{i}$ do que pelo elemento $s_{q}$.

Visando ser intuitivo, porém sem perder a generalidade do conceito, a Figura 4.2 representa os elementos do conjunto de dados $S$ em um espaço euclideano bidimensional. O elemento central de busca $s_{q}$ está representado por uma estrela, e os elementos $s_{i}$ e $s_{j}$ estão representados como pentágonos. A Figura 4.2 (a) ilustra uma situação em que o elemento $s_{j}$ é considerado muito similar ao elemento $s_{i}$ baseando-se na intensidade de influência do ele- 

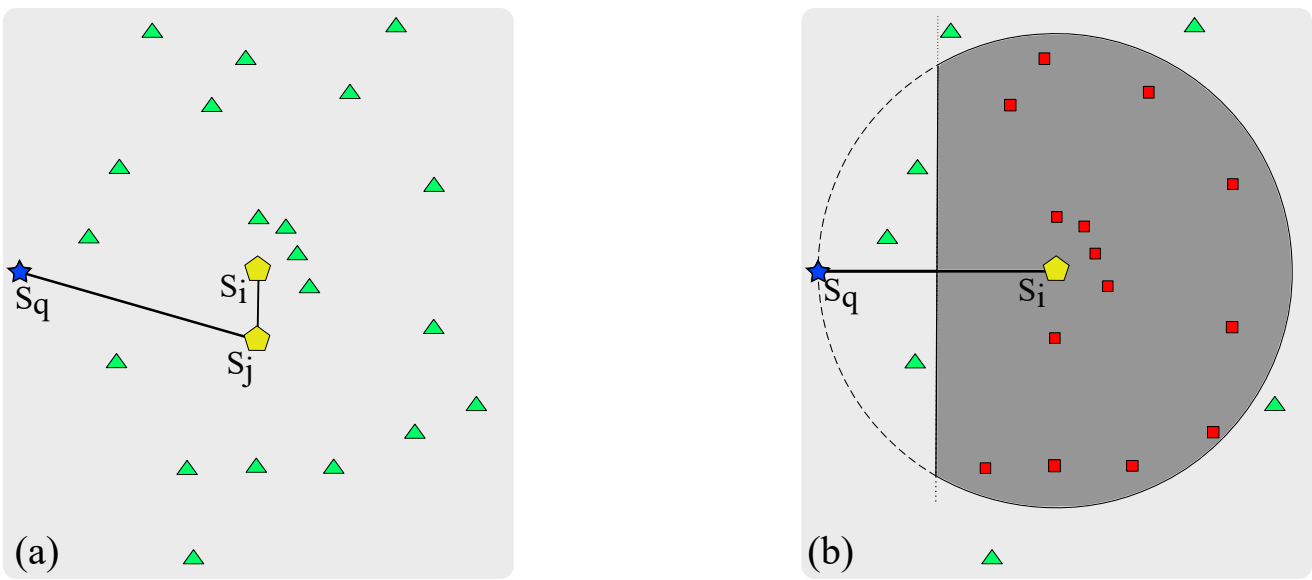

Figura 4.2: Intensidade da influência em conjunto de dados representado em um espaço Euclideano bidimensional. O conjunto de resultado é indicado por pentágonos, enquanto os triângulos representam elementos não influenciados. (a) Cenário em que um elemento $s_{j}$ é considerado mais influenciado por $s_{i}$ do que pelo elemento $s_{q}$. (b) O conjunto diversificado gerado pela intensidade de influência de $s_{i}$ para o elemento central de busca $s_{q}$, elementos considerados muito similares são representados por quadrados e o pentágono ilustra o elemento considerado representativo $s_{i}$.

mento $s_{q}$, indicando que $s_{j}$ pode fornecer mais informação em relação ao elemento $s_{i}$ (um elemento que já faz parte do conjunto de resultados diversificados) do que para o elemento central de busca.

Além disso, é possível usar a intensidade de influência do elemento $s_{i}$ sobre $s_{q}$ para desconsiderar elementos que estejam no "limiar de influência" de $s_{i}$, como pode ser visto na Figura 4.2 (b). Os quadrados representam os elementos mais influenciados por $s_{i}$ do que pelo elemento $s_{q}$ até a intensidade de influência $\left(I\left(s_{i}, s_{q}\right)\right)$, e dado que o elemento $s_{i}$ já faz parte do resultado diversificado $\left(s_{i} \in R\right)$, então os quadrados podem ser, seguramente, excluídos como candidatos para o resultado final. Assim, só é necessário avaliar os elementos definidos como triângulos para continuar a busca. A intuição nesse procedimento é, dado que o elemento $s_{i}$ foi selecionado como distinto dos outros elementos no espaço de busca, então, é possível também utilizar o limiar de influência dele para o elemento central de busca $\left(I\left(s_{i}, s_{q}\right)\right)$ para excluir elementos muito similares de $s_{i}$. Além disso, assumindo que a função de distância $(\delta)$ utilizada para definir a intensidade de influência $(I)$ pode garantir a propriedade de simetria (Subseção 2.1), então pode-se dizer que $s_{i}$ também é capaz de selecionar $s_{q}$ distintamente dos outros elementos no espaço até o limiar de influência. Em outra palavras, $s_{q}$ "influencia" a importância de $s_{i}$ para a busca com a mesma intensidade que o elemento $s_{i}$ influencia o elemento $s_{q}$. Desse modo, o conjunto com todos os elementos $s_{j}$ que podem ser, seguramente, influenciados por $s_{i}$ em um limiar de influência $I\left(s_{i}, s_{q}\right)$ pode ser obtido de acordo com a Definição 11.

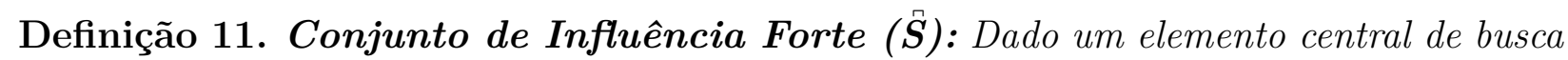
$s_{q}$ e um elemento $s_{i}$, o conjunto de influência forte $(\bar{S})$ de $s_{i}$ para a busca em relação ao elemento $s_{q}$ é dada por:

$$
\bar{S}\left(s_{i}, s_{q}\right)=\left\{s_{j} \in S \mid\left(I\left(s_{i}, s_{j}\right) \geq I\left(s_{i}, s_{q}\right)\right) \wedge\left(I\left(s_{j}, s_{i}\right) \geq I\left(s_{j}, s_{q}\right)\right)\right\} .
$$

É importante notar que o limiar de influência $I\left(s_{i}, s_{q}\right)$ definido para cada conjunto de influência forte possibilita uma distância de separação $\left(\xi_{\text {div }}\right)$ que varia de acordo com a posição 
Tabela 4.1: Buscas por similaridade fundamentais e com diversidade e seus respectivos critérios de comparação.

\begin{tabular}{l|c}
\hline Nome da Busca & Critérios de Comparação \\
\hline Busca por Abrangência & $R q\left(s_{q}, \epsilon_{q}\right)$ \\
Busca por Abrangência Diversificada & $R D q\left(s_{q}, \epsilon_{q}\right)$ \\
Busca aos $k$-Vizinhos mais Próximos & $k-N N q\left(s_{q}, k\right)$ \\
Busca aos $k$-Vizinhos Diversos mais Próximos & $k-N D N q\left(s_{q}, k\right)$ \\
\hline
\end{tabular}

relativa dos elementos em relação ao $s_{q}$, isto é, a distância de separação possui um valor menor para elementos próximos de $s_{q}$ e valor maior quando os elementos estão afastados de $s_{q}$, tornando a distância de separação adaptativa à distância do elemento central de busca. Além disso, o conjunto de influência forte permite definir buscas por similaridade com diversidade usando qualquer critério de comparação ( $k$-vizinhos mais próximos ou por abrangência) em qualquer espaço que uma função de distância $\delta$ mantenha as propriedades de simetria e não-negatividade. Outra característica importante do conjunto de influência forte é que não é necessário solicitar o ajuste da distância de separação, definindo a propriedade de diversidade em buscas por similaridade de uma maneira transparente para o usuário. A Definição 12 apresenta formalmente a busca por similaridade com diversidade utilizando o conceito de influência.

Definição 12. Diversificação de Resultados baseada em Influência - RDI: A busca com similaridade com diversidade com elemento central de busca $s_{q}$ deve garantir que o conjunto de resultado $R$ atenda aos seguintes requisitos:

$$
R=\left\{r_{i} \in S \mid \forall r_{j} \in R, r_{i} \neq r_{j} \Rightarrow r_{i} \notin \bar{S}\left(r_{j}, s_{q}\right)\right\}
$$

A Definição 12 pode ser aplicada às buscas aos $k$ vizinhos mais próximos e por abrangência, permitindo que elas também apresentem a propriedade de diversidade. A tabela 4.1 sumariza as buscas por similaridade fundamentais e as propostas de buscas por similaridade com diversidade desta tese, juntamente com os seus respectivos critérios de comparação. Além disso, a tabela destaca que ambos os critérios de comparação, o de similaridade e o de similaridade com diversidade, disponíveis compartilham os mesmos parâmetros, enfatizando que a nova abordagem é homogênea em relação aos critérios de comparação fundamentais de similaridade. Assim, a propriedade de diversidade foi definida de forma transparente para qualquer busca por similaridade, possibilitando que os operadores de similaridade se adequem às necessidades de conjuntos de dados volumosos.

Definição 13. Busca por Abrangência Diversificada (RDq): Dado um elemento central de busca $s_{q}$ e um limiar de dissimilaridade $\epsilon$, a busca por Abrangência Diversificada seleciona os elementos em $S$ tal que:

$$
\begin{aligned}
& R D q\left(s_{q}, \epsilon\right)=R=\left\{r_{i} \in S \mid \delta\left(r_{i}, s_{q}\right) \leq \epsilon_{q} \wedge\right. \\
& \forall s_{i} \in S-R:\left(\delta\left(r_{i}, s_{q}\right) \leq \delta\left(s_{i}, s_{q}\right) \vee\right. \\
& \left.\left.\exists r_{m} \in R: s_{i} \in \bar{S}\left(r_{m}, s_{q}\right)\right) \wedge \forall r_{j} \in R: r_{i} \notin \bar{S}\left(r_{j}, s_{q}\right)\right\} .
\end{aligned}
$$

Definição 14. Busca aos k-Vizinhos Diversos mais Próximos ( $k-N D N q)$ : Dado um elemento central de busca $s_{q}$ e um número $k$ de elementos, a busca aos $k$-Vizinhos 
Diversos mais Próximos seleciona os $k$ elementos em $S$ tal que:

$$
\begin{array}{r}
k-N D N q\left(s_{q}, k\right)=R=\left\{r_{i} \in S|| R \mid \leq k \wedge\right. \\
\forall s_{i} \in S-R:\left(\delta\left(r_{i}, s_{q}\right) \leq \delta\left(s_{i}, s_{q}\right) \vee\right. \\
\left.\left.\exists r_{m} \in R: s_{i} \in \bar{S}\left(r_{m}, s_{q}\right)\right) \wedge \forall r_{j} \in R: r_{i} \notin \hat{S}\left(r_{j}, s_{q}\right)\right\}
\end{array}
$$

A chamada 'Busca por Abrangência Diversificada' $(R D q)$ recupera todos os elementos do conjunto de dados que diferem do elemento central de busca por, no máximo, um limiar de dissimilaridade indicado e os elementos do conjunto de resultado não influenciam uns aos outros, conforme a Definição13. Da mesma maneira, a 'Busca aos $k$-Vizinhos Diversos Mais Próximos' $(k-N D N q)$ retorna os $k$ elementos mais próximos do elemento central de busca e os elementos no conjunto de resultado não influenciam uns aos outros, conforme a Definição 14.

Embora tenha sido afirmado que a proposta pode ser empregada em espaços métricos ou multidimensionais em que uma função de distância seja definida para comparar dois elementos por similaridade, de fato ela é mais ampla do que isso, pois requer apenas que a função de distância satisfaça as propriedades de simetria e não-negatividade (não sendo necessária a propriedade de desigualdade triangular imposta para definição de um espaço métrico). Portanto, a nova proposta é independente de domínio de dados em relação a espaços multidimensionais, métricos e semi-métricos.

\subsection{A técnica BRID}

A técnica Resultados Melhores com Diversificação baseada em Influência (Better Results with Influence Diversification - BRID) é baseada na abordagem incremental para a construção do conjunto de resultado diversificado $R$ de uma busca com elemento $s_{q}$. Assim, a cada incremento novos elementos são escolhidos para compor a resposta, sempre assegurando os requisitos do conjunto de influência forte até que o critério de parada (o limiar de dissimilaridade $\epsilon_{q}$ nas buscas $R D q$ e o número $k$ de elementos nas buscas $k-N D N q$ ) da busca seja satisfeito. Nesta seção são inicialmente apresentados os fundamentos da técnica BRID e depois mostrado como ela é utilizada para responder aos critérios de comparação. Primeiro mostra-se o critério de $k$-NDNq (Subseção 4.2.1) devido à busca aos $k$-vizinhos diversos mais próximos ser a mais frequente na literatura de diversificação de resultados (veja a Seção3) e, a seguir é apresentado o critério de $R D q$ (Subseção 4.2.2).

A técnica BRID é baseada no conceito de "elementos dominantes em relação ao elemento de busca" (Definição 15), o qual seleciona o elemento mais similar ao elemento central de busca $s_{q}$ preservando os requisitos do RDI (Definição 12) para os elementos já inseridos no resultado. Intuitivamente, BRID assume que o contexto da busca deve ser preservado e para isso a intensidade de influência de um elemento dominante para o elemento de busca $s_{q}$ deve ser máxima em cada escolha de elementos para o conjunto diversificado $R$. Em outras palavras, BRID garante a similaridade do elemento dominante ao elemento central de busca, evitando a situação em que todos os elementos de $R$ são distintos uns aos outros e ao elemento $s_{q}$. Por exemplo, considere-se dois elementos distintos $s_{i}, s_{j} \in S$ em conformidade com os requisitos do RDI, isto é, $s_{i} \notin \widehat{\mathrm{S}}\left(s_{j}, s_{q}\right)$ e $s_{j} \notin \widehat{\mathrm{S}}\left(s_{i}, s_{q}\right)$. Assim, se $I\left(s_{i}, s_{q}\right)>I\left(s_{j}, s_{q}\right)$, é dito que o elemento $s_{i}$ é o elemento não-influenciado mais próximo de $s_{q}$ e sua intensidade de influência 
$\left(I\left(s_{i}, s_{q}\right)\right)$ é utilizada para excluir elementos do espaço de busca que são diretamente mais influenciados por $s_{i}$ do que $s_{q}$. Se mais de um elemento possui a mesma intensidade de influência para o elemento central de busca, o empate é resolvido pela escolha aleatória de um dos elementos. A seguinte definição expressa o conceito de elementos dominantes de maneira que o conjunto de influência forte possa ser utilizado em um algoritmo de busca:

Definição 15. Elemento dominante em relação ao elemento de busca: Seja $s_{q} O$ elemento central de busca, $R$ um subconjunto do conjunto de resposta, tal que $R$ pode ser um conjunto de respostas parciais sendo avaliado durante o processamento da busca. Seja $H_{R, s_{q}}$ o conjunto de elementos $s_{j} \in S$ que não são influenciados por nenhum elemento em $R$, isto é, $H_{R, s_{q}}=\left\{s_{j} \in S-R \mid s_{j} \notin \bar{S}\left(r_{i}, s_{q}\right), \forall r_{i} \in R\right\}$. Então o elemento $s_{j} \in H_{R, s_{q}}$ mais próximos do elemento $s_{q}$ é dito ser o elemento dominante em relação a $s_{q}$.

\subsubsection{Busca aos $k$-Vizinhos Diversos mais Próximos}

O algoritmo Better Results with Influence Diversification para a busca $k-N D N q\left(\mathrm{BRID}_{k}\right)$ foi desenvolvido considerando a Definição $15 . \mathrm{BRID}_{k}$ constrói incrementalmente o conjunto de resultado diversificado $R$ de um critério de comparação $k$ - $N D N q\left(s_{q}, k\right)$ executado sobre um conjunto de dados $S$ até que $k$ elementos diversos sejam obtidos ou o conjunto $S$ fique sem elementos, como é apresentado no Algoritmo 8. O conjunto de resultado inicia sem elementos, a distância mínima de separação $\left(\xi_{\text {div }}\right)$ é inicialmente definida sendo zero e $\mathrm{BRID}_{k}$ seleciona o elemento mais próximo de $s_{q}$ (linhas 1-2). A cada iteração, o elemento $s_{c} \in S$ mais próximo seguinte do elemento central de busca é escolhido como candidato a próximo elemento dominante de $R$ (linhas 3-4). Depois disso, $\mathrm{BRID}_{k}$ avalia se $s_{c}$ pertence ao conjunto de influência forte definido para cada elemento $r_{i}$ já inserido no conjunto de resultado diversificado $R$. Em caso positivo, $s_{c}$ é influenciado por $r_{i}$ e é marcado como "influenciado" (linhas 5-9). Portanto, o próximo elemento mais próximo é avaliado como candidato a dominante, iniciando um novo ciclo de iteração. Se o candidato a dominante $s_{c}$ não é influenciado por nenhum elemento em $R$, então $s_{c}$ é inserido no conjunto de resultado (linhas 11-12) e o limiar de influência $I\left(s_{c}, s_{q}\right)$ é utilizado para excluir os elementos influenciados por esse elemento no conjunto de dados. Este processo se repete até que $R$ possua $k$ elementos dominantes ou o conjunto de dados $S$ fique sem elementos para serem avaliados (linha 3 ).

Como exemplo, considere que o conjunto de dados $S=\left\{s_{1}, s_{2}, s_{3}, s_{4}, s_{5}, s_{6}, s_{7}\right\}$ está definido em um espaço euclideano de duas dimensões e os elementos estão ordenados pela similaridade ao elemento central de busca $s_{q}$ - por exemplo, $s_{1}$ é o elemento mais próximo de $s_{q}$, seguido pelos elementos $s_{2}, s_{3}$, e, assim por diante, como é mostrado na Figura 4.3. O objetivo é recuperar os três elementos mais próximos do $s_{q}$, mas que também são diversos uns dos outros (3- $\left.N D N_{q}\left(s_{q}, 3\right)\right)$ no conjunto de resultado $R$, utilizando a intensidade de influência entre os elementos para excluir os elementos muito similares no conjunto de dados. Na Figura 4.3, $s_{q}$ é representado por uma a estrela, os pentágonos representam os elementos dominantes que já foram inseridos no conjunto de resultado a cada passo. Os quadrados representam os elementos no conjunto de influência forte dos elementos no conjunto $R$ e os triângulos representam os elementos ainda candidatos a dominantes.

O primeiro elemento analisado pelo $\mathrm{BRID}_{k}$ é o elemento mais próximo do $s_{q}$ em $S$, pois o conjunto de resultado $R$ está vazio. Assim, o elemento $s_{1}$ na Figura 4.3 é o primeiro elemento dominante e sua intensidade de influência ao $s_{q}$ é definido como a primeira distância mínima de separação $\left(I\left(s_{1}, s_{q}\right)=\xi_{d i v_{1}}\right.$. Em seguida, os elementos pertencentes ao conjunto forte de influência definido por $s_{1}$, por exemplo, os elementos $s_{2}$ e $s_{3}$ são excluídos do conjunto de 


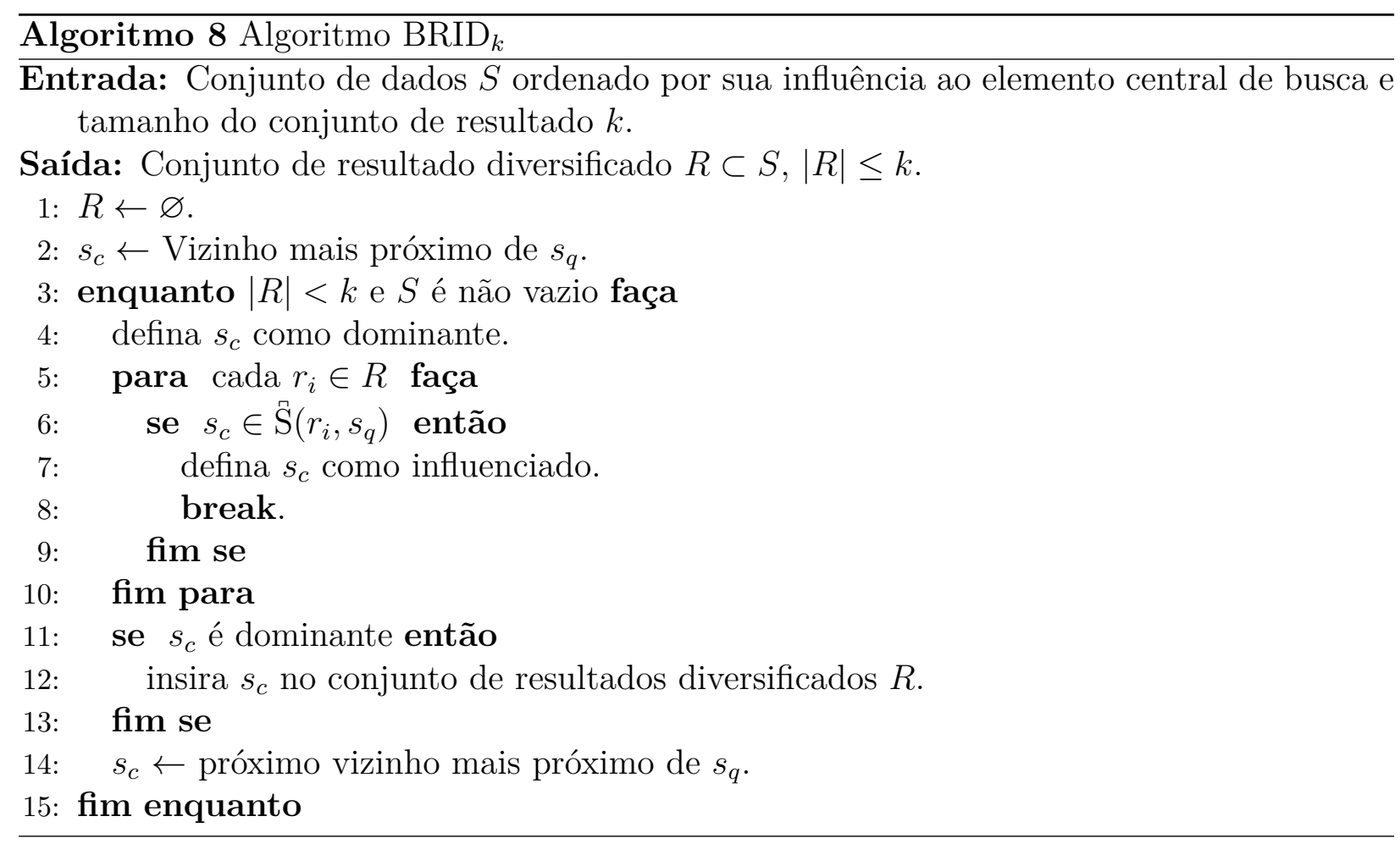

futuros candidatos a dominante (Figure 4.3(a)). O próximo elemento mais próximo em $S$ que não é influenciado por $s_{1}$ é o elemento $s_{4}$ (Figure 4.3(b)) e após avaliação, o mesmo é inserido no conjunto $R$ como segundo elemento dominante e o limiar de influência $I\left(s_{4}, s_{q}\right)$ é definido como a segunda distância mínima de separação $\left(\xi_{d i v_{4}}\right)$.Em seguida, $\mathrm{BRID}_{k}$ exclui os elementos no conjunto de influência forte de $s_{1}$ e $s_{4}$, sendo o elemento $s_{5}$ o próximo elemento que não é influenciado por ambos elementos, sendo inserido em $R$, como é ilustrado na Figura 4.3(c). Nesta etapa, o conjunto $R=\left\{s_{1}, s_{4}, s_{5}\right\}$ já possui a quantidade de elementos requisitada $(k=3)$ e o processamento da busca é finalizado. É importante notar que a distância mínima de separação foi definida utilizando apenas o posicionamento relativo dos elementos no espaço de busca e teve o seu valor ajustado dinamicamente a cada novo elemento inserido em $R$.

\subsubsection{Busca por Abrangência Diversificada}

O algoritmo Better Results with Influence Diversification para buscas $R D q\left(\mathrm{BRID}_{r}\right)$ constrói o conjunto de resultados de maneira análoga ao algoritmo $\mathrm{BRID}_{k}$, mas ajustado para controlar que os elementos retornados estejam no limiar de dissimilaridade máximo definido pelo usuário. Neste caso, é necessário acompanhar a distância dos elementos a $s_{q}$ e caso a distância se torne maior que o limiar de dissimilaridade máximo $\epsilon_{q}$, o processamento é encerrado, como é apresentado na linha 3 do Algoritmo 9.

É importante destacar que existe uma diferença entre a utilização do conceito de diversidade em buscas por similaridade por abrangência em relação à diversidade encontrada a busca aos $k$-vizinhos mais próximos. O conceito de diversidade aplicada nas buscas $k$-NN resulta num caso especial de buscas exploratórias que exclui elementos muito similares no conjunto de dados pela a adição de outros elementos que aumentem a diversidade na resposta mantendo o requisito da quantidade de elementos $(|R|=k)$, porém a escolha dos elementos diversos pode ocorrer em qualquer parte do espaço de busca. Já no caso das buscas por abrangência 

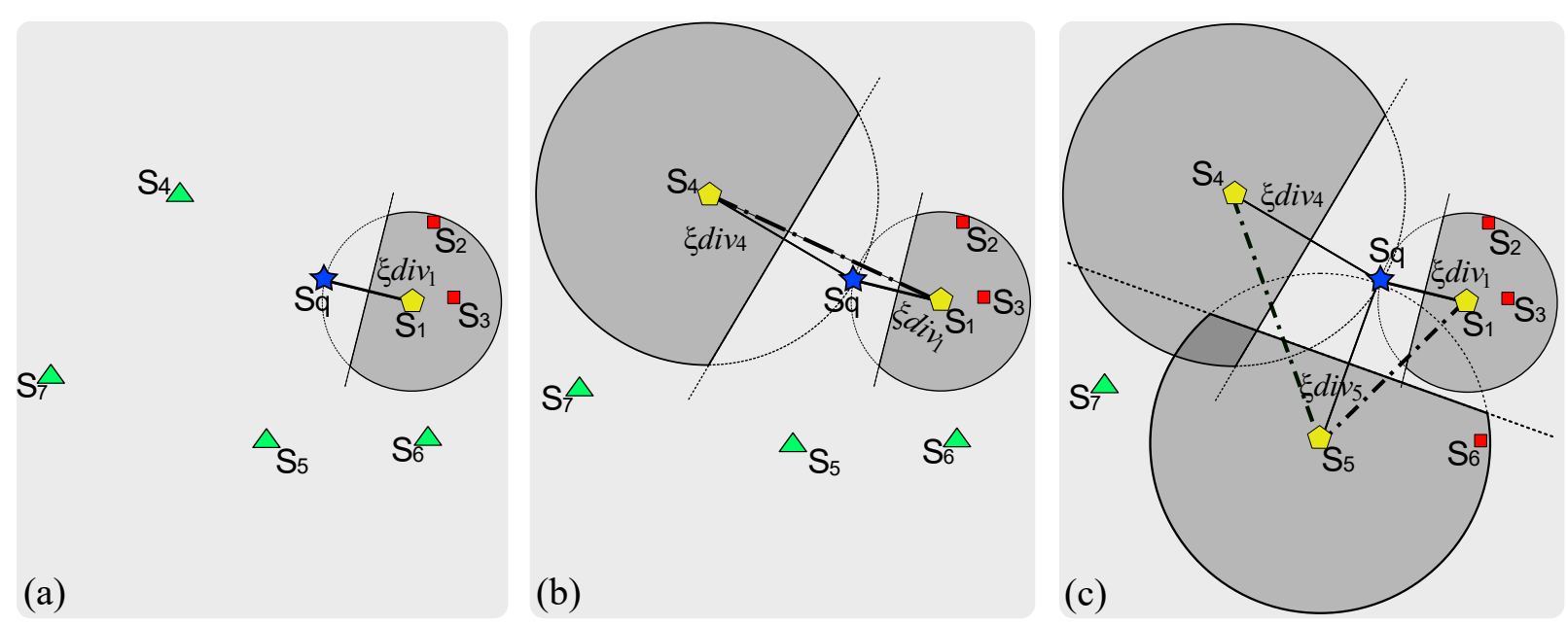

Figura 4.3: Construção em três passos do conjunto de resultado para a busca aos $k$-vizinhos diversos mais próximos em um espaço euclideano bidimensional pelo algoritmo $\mathrm{BRID}_{k}$. Pentágonos representam os elementos dominantes em cada etapa do algoritmo. Quadrados representam os elementos no conjunto de influência forte de ao menos um elemento $r_{i}$ do conjunto de resultados $R$. Triângulos representam os elementos candidatos a dominante que ainda não fazem parte da resposta final.

diversificada, a propriedade também é utilizada para excluir elementos muito similares, porém é mantido o limiar de dissimilaridade máximo, resultando em uma busca cujo resultado diversificado é um subconjunto do conjunto de resultados da busca por abrangência sem a propriedade de diversidade. A Figura 4.4 (a) ilustra o resultado de uma busca $R q$ em que os círculos representam os elementos recuperados no limiar de dissimilaridade máximo $\epsilon_{q} \mathrm{e}$ os quadrados representam elementos que estão mais distante do elemento central de busca que o limiar $\epsilon_{q}$. Como pode ser visto na Figura 4.4 (b), a busca $R D q$ considerou apenas os elementos até o limiar $\epsilon_{q}$ no processo de diversificação, retornando apenas os elementos dominantes (pentágonos) em relação ao $s_{q}$.

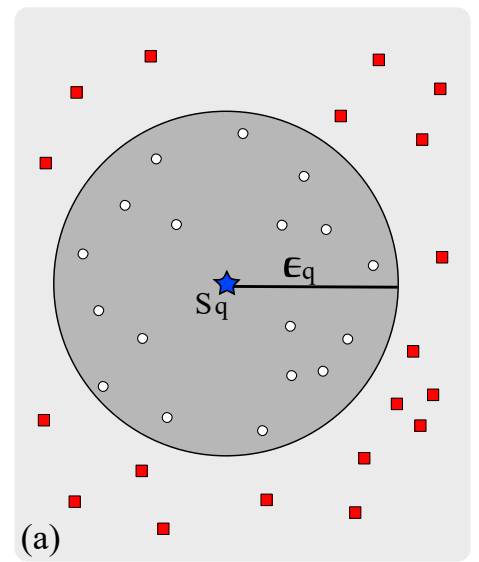

(a)

Figura 4.4: Diferença de interpretação dos resultados para uma busca por abrangência com elemento central de busca $s_{q}$ e limiar de dissimilaridade máximo $\epsilon_{q}$; (a) sem considerar a propriedade de diversidade, círculos representam os elementos selecionados até o limiar $\epsilon_{q}$; (b) considerando a propriedade de diversidade, pentágonos representam os elementos dominantes definidos no processo de diversificação e, é importante notar que ocorreu um redução na quantidade total de elementos retornados quando comparado com a resposta para a busca por abrangência sem diversificação. 


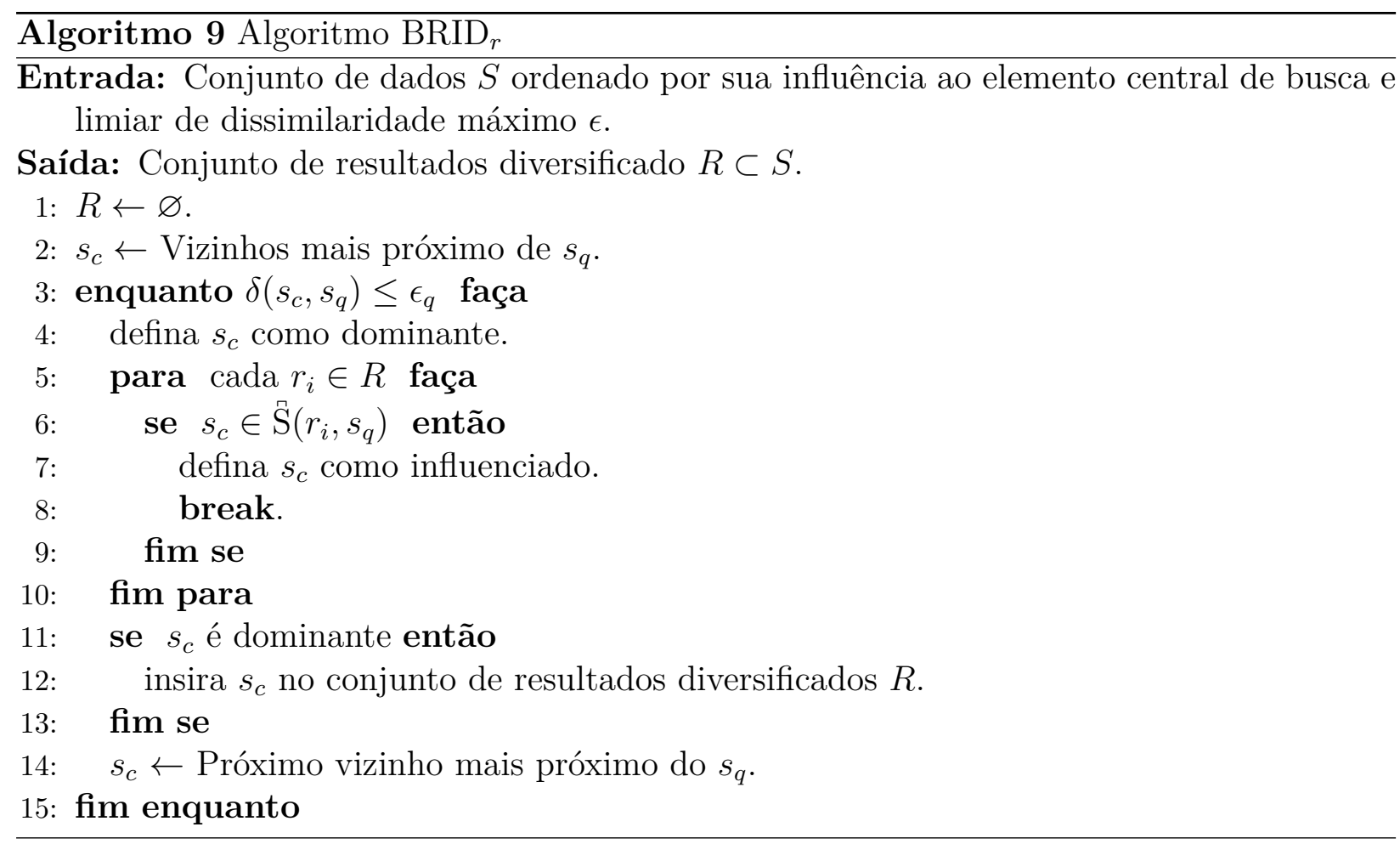

Desse modo, a busca $R D q$ atua como um filtro que reduz, consideravelmente, a cardinalidade do conjunto de resultado enquanto aumenta a diversidade entre os elementos do resultado. Uma busca com propriedades de filtro pode ser útil em situações em que pode-se inferir uma dissimilaridade máxima permitida a partir de um elemento central de busca, porém com o interesse de reduzir a cardinalidade dos resultados e evitar elementos de baixo valor agregado (muito similares entre si). No Capítulo 6 é apresentado como as buscas por abrangência diversificada podem ser utilizadas para melhorar o desempenho dos algoritmos de diversidade que visam resolver um problema de otimização combinatória.
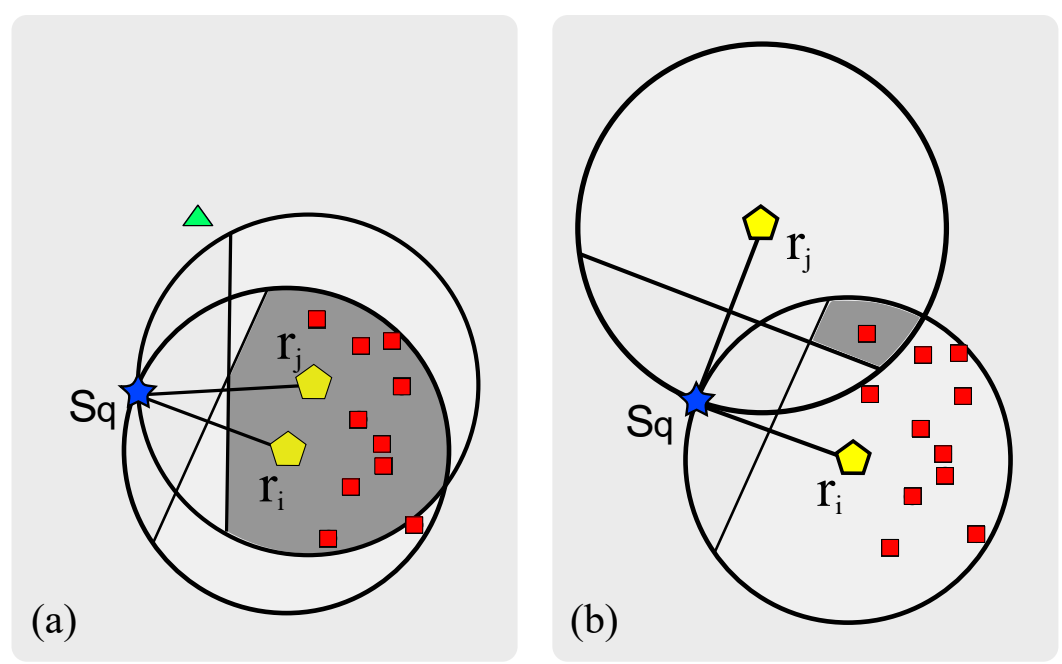

Figura 4.5: Exemplo de como a avaliação por sobreposição de conjunto de influência forte detecta a diversidade entre dois elementos no conjunto de resultados. (a) Conjunto de influência forte com alta sobreposição. (b) Conjunto de influência forte com baixa sobreposição. 


\subsection{Método de Avaliação por Sobreposição de Influên- cia}

Conforme foi discutido na Seção 3.4, as métricas disponíveis para a avaliação de resultados com diversidade são adaptações oriundas da área de sistemas de recomendação ou são definidas para os algoritmos de otimização combinatória. Visando avaliar a propriedade de diversidade para buscas por similaridade sobre dados representados em espaços métricos, foi definido um método de avaliação chamado de Método de Avaliação por sobreposição (Overlap Evaluation Method - OEM), o qual utiliza apenas as distâncias entre os elementos no conjunto de resultado e a distância deles ao elemento central de busca $s_{q}$. Uma das vantagens do OEM é que ele pode ser aplicado nos conjuntos de resultados de qualquer algoritmo da literatura (Seção 3.3) e sobre qualquer conjunto de dados em espaços para o qual uma métrica tenha sido definida.

O método OEM reconstrói o conjunto de influência forte (Definição 11) de cada elemento $r_{i}$ no conjunto de resultados $R$ para verificar se está ocorrendo sobreposição com o conjunto de influência forte definido para outro elemento $r_{j} \in R$, realizando assim a avaliação da sobreposição de diversidade que os elementos em $R$ possuem em relação ao elemento central de busca $s_{q}$. Por utilizar apenas as relações de distância existentes no conjunto de resultado, definimos uma medida chamada de "diversidade inerente " $\omega\left(R, s_{q}\right)$ de $R$ para o elemento $s_{q}$, da seguinte maneira.

Definição 16. Diversidade Inerente de uma Busca: Dado um conjunto de resultado $R$ de uma busca por similaridade com elemento central de busca $s_{q}$, a Diversidade Inerente $\omega\left(R, s_{q}\right)$ é avaliada como:

$$
\omega\left(R, s_{q}\right)=\sum_{i=1}^{|k-1|} \sum_{j=i+1}^{|k|} 1-\left[\frac{\left|\tilde{S}\left(r_{i}, s_{q}\right) \cap \bar{S}\left(r_{j}, s_{q}\right)\right|}{\left|\bar{S}\left(r_{i}, s_{q}\right) \cup \bar{S}\left(r_{j}, s_{q}\right)\right|}\right] .
$$

Como pode ser inferido da Equação 4.1, dois elementos $r_{i}, r_{j} \in R\left(r_{i} \neq r_{j}\right)$ são consideradores muito similares se os seus respectivos conjuntos de influência forte possuem muitos elementos em comum. A Figura 4.5 ilustra como a sobreposição captura a diversidade. A Figure 4.5(a) mostra uma situação cujo resultado possui um par de elementos que influenciam muitos elementos em comum, enquanto a Figure 4.5(b) mostra uma situação em que um par de elementos do resultado compartilham poucos elementos nos conjuntos de influência forte.

Quanto maior o valor de $\omega$, melhor é a diversidade inerente encontrada no conjunto de resultado $R$ para um elemento central de busca $s_{q}$. O valor $\omega=0$ corresponde ao pior cenário de diversidade para um conjunto de resultado, pois todos os elementos em $R$ influenciam todos os mesmos elementos no conjunto de dados $S$. Contudo, não há um limite superior para $\omega$, pois tal valor é dependente da cardinalidade do conjunto de resultado $R$. Assim, para fazer uma comparação utilizando a Equação 4.1 somente é válida se os dois conjuntos de resultados possuírem a mesma quantidade de elementos. Visando possibilitar a comparação da sobreposição dos conjuntos de resultados com diferente cardinalidades, definimos também uma versão normalizada da diversidade inerente, chamada de diversidade absoluta para uma busca, como é definida a seguir:

Definição 17. Diversidade Absoluta para uma Busca: Dado um conjunto de resultado $R$ de uma busca por similaridade com elemento central de busca $s_{q}$ e um número $k$ de 
elementos em $R(k=|R|)$, a Diversidade Absoluta $\bar{\omega}\left(R, s_{q}\right)$ é avaliada da seguinte maneira:

$$
\bar{\omega}\left(R, s_{q}\right)=\frac{2 \cdot \omega\left(R, s_{q}\right)}{k(k-1)} .
$$

O intervalo de $\bar{\omega}\left(R, s_{q}\right)$ é $[0,1]$, assim, de maneira distinta da diversidade inerente $\omega$, o valor de diversidade absoluta $\bar{\omega}=1$ significa um resultado com diversidade ideal, pois nenhum par de elemento influencia os mesmos elementos no conjunto de dados e $\bar{\omega}=0$ continua indicando o pior resultado possível. É importante destacar que a diversidade absoluta possibilita comparar os resultados das buscas aos $k$-vizinhos mais próximos com distintos valores para $k$ e também para os resultados das buscas por abrangência com diferentes limiares de dissimilaridade máxima.

\subsection{Experimentos}

Esta seção apresenta os resultados experimentais avaliando o desempenho e a qualidade da diversificação alcançada pelo nosso algoritmo $\mathrm{BRID}_{k}$ para responder as buscas aos $k$-vizinhos diversos mais próximos utilizando o conceito de influência. BRID $_{k}$ foi comparado com três dos melhores algoritmos de diversificação de resultados existentes na literatura: Greedy Marginal Contribution (GMC), Greedy Randomized With Neighborhood Expansion (GNE) e FirstMatch (FM) que respondem à busca aos $k$-vizinhos distintos mais próximos. Além disso, são apresentados os resultados para o algoritmo $\mathrm{BRID}_{r}$ desenvolvido para responder as buscas por abrangência diversificada. Este último é comparado apenas com a versão do algoritmo sem diversidade, pois não existem algoritmos para diversificação de resultados de consultas por abrangência na literatura. Assim, somente ilustramos os benefícios da diversificação de resultados nesse tipo de busca. As subseções a seguir descrevem os conjuntos de dados utilizados, a metodologia de teste e os resultados obtidos.

\subsubsection{Conjunto de Dados e Descrição dos Experimentos}

Aqui são apresentados resultados de experimentos que avaliam os algoritmos propostos e executados sobre seis conjuntos de dados reais e sintéticos, sumarizados na Tabela 4.2. Para cada conjunto de dados, a tabela mostra o seu nome, o seu número total de elementos (Nro. de elementos), a sua dimensionalidade (Dimensões) e a função de distância utilizada $(\delta)$, juntamente com uma breve descrição (Descrição) e a referência do local em que os dados foram obtidos.

Todos os algoritmos foram implementados utilizando a linguagem $\mathrm{C}++$ e e executados na mesma plataforma de testes para garantir comparações justas entre os competidores. Os experimentos foram executados em um computador com a seguinte configuração: 2 processadores Intel ${ }^{\circledR}$ Xeon ${ }^{\mathrm{TM}} 5600$ com 96 GB de memória RAM e disco rígido de 16 TB. O sistema operacional utilizado foi o CentOS Linux 6.2.

\footnotetext{
${ }^{2}$ U.S. Census Bureau Homepage - American Census 2000. Último acesso em: 11 de Setembro de 2014. Disponível em: <http://www.census.gov/>

${ }^{3}$ Amsterdam Library of Object Images Homepage. Último acesso em: 25 de Maio de 2016. Disponível em: $<$ http://staff.science.uva.nl/ aloi/>
} 
Tabela 4.2: Estatísticas dos conjuntos de dados

\begin{tabular}{|c|c|c|c|c|}
\hline Conjunto de dados & Nro. de elementos & Dimensões & $\delta$ & Descrição \\
\hline U.S Cities & 25.375 & 2 & $L_{2}$ & $\begin{array}{l}\text { Conjunto de dados de co- } \\
\text { ordenadas geográficas e } \\
\text { características econômicas } \\
\text { das cidades americanas, } \\
\text { obtido do sítio U.S. Cen- } \\
\text { sus Bureau }{ }^{2} \text {. }\end{array}$ \\
\hline Carros & 1.046 & 4 & $\overline{L_{1}}$ & $\begin{array}{l}\text { Modelo de carros de di- } \\
\text { ferentes montadoras testa- } \\
\text { dos pela revista Quatro } \\
\text { Rodas, entre Maio de } 2001 \\
\text { e Junho de } 2005 \text {, obtido do } \\
\text { sítio da revista Quatro Ro- } \\
\text { das }{ }^{1} \text {. }\end{array}$ \\
\hline Aloi & 72.000 & 144 & $L_{2}$ & $\begin{array}{l}\text { Conjunto de imagens co- } \\
\text { loridas rotacionadas no } \\
\text { plano a cada } 5 \text { graus, com- } \\
\text { posto por } 1.000 \text { objetos, } \\
\text { obtido do sítio Amsterdam } \\
\text { Library of Object Images }{ }^{3} \text {. }\end{array}$ \\
\hline EnglishWords & 24.893 & adimensional & $\bar{L} L_{\text {edit }}$ & 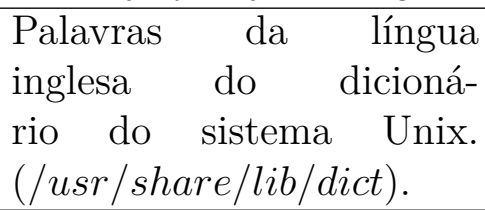 \\
\hline Synthetic3D & 100.000 & 3 & $L_{2}$ & $\begin{array}{l}\text { Conjunto de dados Sinté- } \\
\text { tico com três atributos e } \\
\text { cardinalidade variando de } \\
10.000 \text { até } 100.000 \text { com } \\
\text { distribuição gaussiana e } \\
\text { com } 5 \text { clusters. }\end{array}$ \\
\hline SynthMultiD & 30.000 & 105 & $L_{2}$ & $\begin{array}{l}\text { Conjuntos de dados com } \\
\text { dimensionalidade variando } \\
\text { de } 5 \text { até } 105 \text { dimensões } \\
\text { com distribuição gaussi- } \\
\text { ana. }\end{array}$ \\
\hline
\end{tabular}

Foram definidas três propriedades para avaliação dos algoritmos: a qualidade de diversificação da resposta, o desempenho e a escalabilidade. Os experimentos de desempenho e qualidade mostram que o algoritmo proposto supera os algoritmos testados em ambos os quesitos, qualidade de diversificação e em tempo de execução, sendo, pelo menos, duas ordens de magnitude mais rápido. Por fim, os experimentos de escalabilidade mostram que os algoritmos baseados na técnica BRID são escaláveis tanto em relação ao crescimento das dimensões quanto da cardinalidade do conjunto de dados. 


\subsubsection{Avaliação de Desempenho e Qualidade de Diversificação}

O conjunto de experimentos realizados envolveu tanto a análise de desempenho em relação ao tempo total de execução quanto a análise da qualidade das respostas utilizando a medida de Diversidade Absoluta $(\bar{\omega})$ para uma busca . Para cada conjunto de dados avaliado, foram realizadas escolhas aleatórias de elementos distintos para a criar um conjunto de teste com o total de 100 elementos de busca. Além disso, todos os elementos do conjunto de dados foram utilizados para compor a solução diversificada nos algoritmos avaliados, isto é, não foi utilizada nenhum heurística de amostragem para reduzir a complexidade dos algoritmos.

Cada medida no gráfico de tempo de execução, em escala logarítmica, representa a média em milissegundos necessária para processar 100 buscas aos $k$-vizinhos diversos mais próximos com um valor constante de $k$, porém para elementos centrais de busca distintos. Assim, quanto menor os valores de um algoritmo no gráfico de tempo de execução, melhor é o desempenho do algoritmo. De maneira similar, cada medida no gráfico de diversidade absoluta mostra a diversificação média para as mesmas 100 buscas utilizadas no experimento de desempenho. Os resultados apresentados no gráfico de diversidade absoluta indicam o oposto, valores maiores indicam melhores respostas diversificadas.

Por fim, a configuração dos parâmetros os algoritmos foi feita da seguinte maneira: os algoritmos GMC e GNE foram ajustados de acordo com as especificações indicadas por Vieira et al. (2011a) para obter o melhor desempenho relatado nos experimentos do artigo original. Além disso, o parâmetro de balanceamento entre a similaridade e a diversidade $(\lambda)$ foi definido em $\lambda=0.5$, que também foi relatado como sendo a configuração que, na média, apresenta a melhor diversificação. Como o algoritmo FM é baseado em outro modelo de diversificação, apenas o parâmetro de distância de separação foi ajustado para dois valores: 1.0 e 1.3. Tais valores, propostos por Skopal et al. (2009) representam, respectivamente, o ajuste para encontrar a melhor diversificação no resultado e o ajuste para a execução da busca com desempenho mais rápido.

\section{Experimentos com o conjunto de dados U.S Cities}
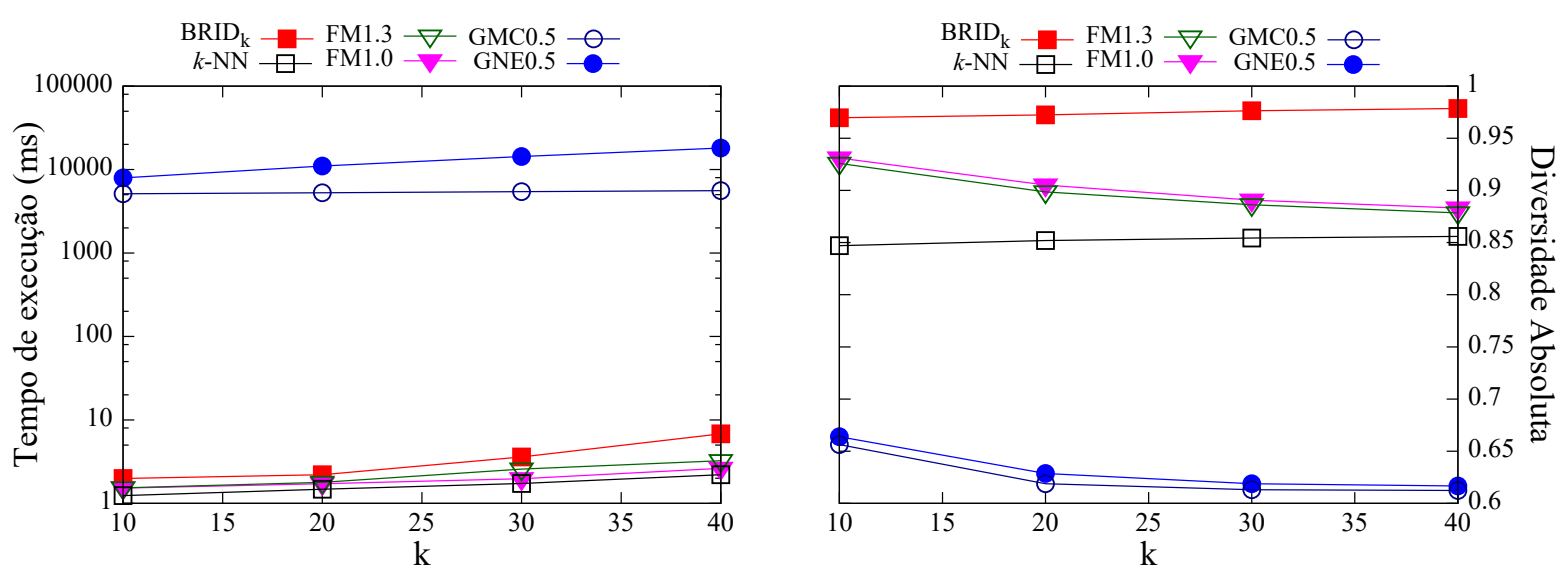

(a) Média do tempo de execução vs. quantidade $k$ de (b) Média de diversidade absoluta vs. quantidade de vizinhos.

$k$ vizinhos.

Figura 4.6: (a) Tempo de execução e (b) resultados qualitativos para o conjunto de dados U.S Cities com $k$ variando de 10 até 40 . 
No primeiro conjunto de experimentos, o objetivo foi avaliar como o algoritmo proposto se comporta em conjunto de dados de baixa dimensionalidade. Assim, neste experimento é avaliado o tempo necessário e a diversificação resultante para buscas aos $k$-vizinhos diversos mais próximos com o valor de $k$ variando de 10 até 40 vizinhos. Além disso, incluíram-se os resultados do algoritmo tradicional (sem diversidade) de $k$-NN para melhorar o entendimento do desempenho e da medida de diversidade absoluta. Apenas as coordenadas geográficas (latitude e longitude) foram utilizadas para a comparação dos elementos. Os resultados alcançados são apresentados na Figura 4.6.

A Figura 4.6(a) mostra que os algoritmos GNE e GMC possuem o maior tempo de execução entre os algoritmos avaliados, o que já era previsto, pois esses algoritmos possuem um custo quadrático de comparações em relação ao número de elementos no conjunto de dados. Tal comportamento pode ser confirmado neste conjunto de dados (com baixa cardinalidade), pois tanto o GMC quanto o GNE foram, respectivamente, três e quatro ordens de magnitude mais lentos que os algoritmos $\mathrm{FM}$ e $\mathrm{BRID}_{k}$. Apesar disso, o alto custo de execução dos algoritmos GNE e GMC não foi o bastante para melhorar a qualidade da diversificação, pois ambos obtiveram os piores resultados para diversidade absoluta, como pode ser visto na Figura 4.6(b). Na verdade, a escolha dos elementos diversificados dos algoritmos GNE e GMC resultaram em maior sobreposição de influência entre os elementos quando comparado com o resultado do algoritmo $k$-NN (sem diversidade). Uma possível causa para esse resultado é que tanto o GNE quanto o GMC escolhem elementos mais afastados do elemento central de busca para aumentar a contribuição da função objetivo, porém tal escolha não evita a escolha de elementos pertences a mesma região do espaço. Dado que os próximos experimentos serão realizados com conjuntos de dados com cardinalidade e dimensionalidade maiores do que o conjunto U.S Cities, os algoritmos GMC e GNE não serão apresentados nos gráficos porque eles não são executados em tempo de execução aceitável.

Em relação ao algoritmo BRID $_{k}$, o tempo de execução foi ligeiramente menor que do algoritmo FM, como pode ser visto na Figura 4.6(a). Tal comportamento também era previsto, uma vez que a cada novo elemento inserido na resposta $\left(r_{i} \in R\right)$ no algoritmo $\mathrm{BRID}_{k}$ é necessária a definição de uma nova distância mínima de separação $\xi_{\text {div }}$ que deve avaliada para identificar os elementos correspondentes do conjunto de influência forte $(\widetilde{\mathrm{S}})$. Esta avaliação de influência requer mais processamento do que o algoritmo FM, que utiliza uma distância de separação fixa em torno dos elementos no conjunto de resultados. Entretanto, o ligeiro ganho de desempenho é alcançado à custa de impor ao usuário a necessidade de definir uma distância de separação que nem sempre é conhecida. Por outro lado, a técnica BRID é livre de parâmetros, avaliando a distância de separação de maneira adaptável, o que aumenta a qualidade final do resultado. De fato, a Figura 4.6(b) mostra que a diversificação alcançada pelo algoritmo $\mathrm{BRID}_{k}$ é sempre significativamente melhor do que aquela obtida pelo algoritmo FM. Além disso, $\mathrm{BRID}_{k}$ é o único algoritmo que segue a mesma tendência do algoritmo $k$-NN, reduzindo a sobreposição de influência quando a cardinalidade da resposta final aumenta. Portanto, a Figura 4.6 confirma que utilizar uma distância fixa ao redor de cada elemento de resposta pode não resultar na melhor solução.

\section{Experimentos com o conjunto de dados Aloi}

O segundo conjunto de experimentos tem por objetivo avaliar nossa proposta em relação a conjuntos de dados de alta dimensionalidade. O conjunto de imagens Aloi foi representado por 144 características extraídas pelo extrator momentos de cores proposto por Stricker 
(1995). Novamente, os algoritmos foram avaliados em relação ao tempo de execução e pela diversidade absoluta.

A Figura 4.7(a) mostra os resultados para o tempo de execução no conjunto de dados Aloi. Ela mostra que $\mathrm{BRID}_{k}$ foi uma ordem de magnitude mais rápido que ambas as configurações do algoritmo FM. Além disso, a Figura 4.7(b) mostra que $\mathrm{BRID}_{k}$ manteve sua superioridade em relação à diversidade absoluta para os algoritmos avaliados, incluindo o algoritmo $k$-NN. É importante destacar que o comportamento do $k$-NN está de acordo com o fato bem conhecido de que em alta dimensionalidade todos os pares de elementos tendem a estar em distâncias similares (BEYER et al., 1999). Esse fato também influencia o algoritmo $\mathrm{BRID}_{k}$, embora com menor intensidade do que os outros algoritmos. Além disso, neste conjunto de dados, o tempo adicional necessário para avaliar cada nova distância mínima de separação é compensado pelo aumento do número de elementos que podem ser rapidamente excluídos como candidatos usando a distância de separação adaptável. De fato, a similaridade da distância entre os pares de elementos leva a um aumento na dificuldade na discriminação de quais são os vizinhos mais próximos de cada elemento no espaço de busca. Neste cenário, a distância mínima de separação variável do algoritmo $\mathrm{BRID}_{k}$ auxilia na tarefa de discriminação de vizinhos mais próximos, possibilitando um desempenho, no geral, mais eficiente em conjuntos de dados de alta dimensionalidade.

\section{Experimentos com o conjunto de dados English Words}

O terceiro conjunto de experimentos objetivou avaliar o algoritmo $\mathrm{BRID}_{k}$ em conjuntos de dados puramente métricos (conjunto adimensional). Desse modo, a comparação dos elementos foi realizada utilizando a função de distância $L_{E d i t}$. Os resultados são apresentados na Figura 4.8.

$\mathrm{O}$ algoritmo $\mathrm{BRID}_{k}$ continuou sendo mais eficiente do que ambas as configurações do algoritmo FM no quesito tempo de execução, como pode ser visto na Figura 4.8(a). De maneira previsível, o tempo de execução de todos os algoritmos avaliados nestes experimentos foi maior que nos outros experimentos devido à função de distância utilizada na comparação dos elementos apresentar maior custo que as funções da família $L_{p}$ de distâncias utilizadas
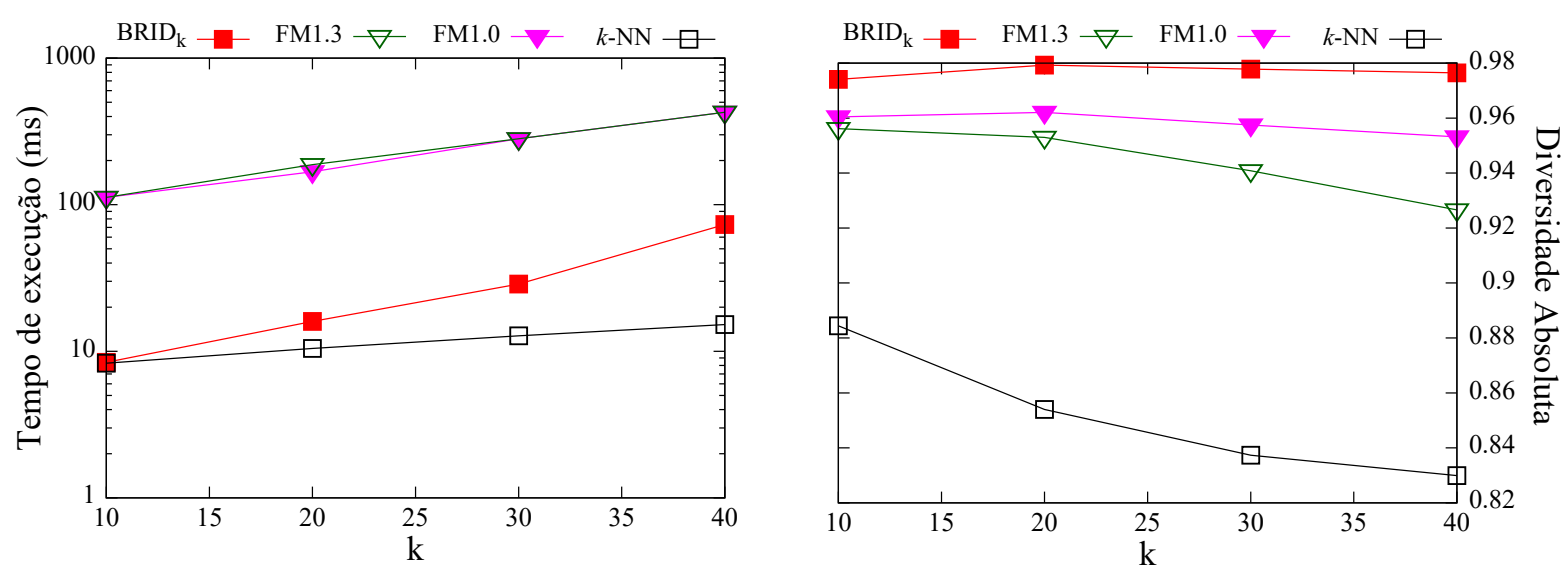

(a) Média do tempo de execução vs. quantidade $k$ de (b) Média de diversidade absoluta vs. quantidade de vizinhos.

$k$ vizinhos.

Figura 4.7: (a) Tempo de execução e (b) resultados qualitativos para o conjunto de dados Aloi com $k$ variando de 10 até 40 . 
anteriormente. Em relação à diversidade absoluta, $\mathrm{BRID}_{k}$ manteve sua qualidade superior aos outros algoritmos, porém a diferença da qualidade entre os algoritmos se tornou menor, como é apresentado na Figura 4.8(b). A justificativa para uma diferença menor entre os algoritmos é o fato que a função $L_{E \text { dit }}$ causa muitos empates de distância entre os elementos, tornando o espaço bem mais condensado.

\section{Experimentos com o conjunto de dados Carros}

O quarto conjunto de experimentos visou comparar empiricamente a qualidade de diversificação entre os algoritmos $\mathrm{BRID}_{k}$ e FM com o intuito de aumentar o entendimento sobre a diferença entre a diversidade retornada com uma distância de separação variável e fixa. Como o conjunto de dados Carros possui cardinalidade reduzida e ambos os algoritmos apresentaram, praticamente, o mesmo tempo de execução, os gráficos de tempo de execução e de diversidade absoluta foram omitidos. Porém, utilizamos os resultados para ilustrar a diferença das respostas obtidas pelos algoritmos.

Neste experimento, o algoritmo FM foi, inicialmente, executado várias vezes com distâncias de separação distintas variando entre 0.0 e 2.0 para uma mesma busca Q1:

Q1: "Recupere os 5 (cinco) carros mais similares ao meu modelo favorito, o 'Volkswagen Golf 2.0', cujo ano é 2004."

A Figura 4.9(b), mostra o resultado para distância de separação menor que 2.0, sendo que de 0.0 até 1.8 todos os resultados foram os mesmos, não havendo troca de elementos quando comparado com o resultado da busca aos $k$-vizinhos mais próximos tradicional (Figura $\left.4.9(\mathrm{a})^{4}\right)$. Isso evidencia que sem o conhecimento prévio da distribuição de distância pode ser difícil escolher valores padrões em conjuntos de dados diferentes. O conjunto de resultados começa a diversificar apenas com distância de separação igual ou maior que 2.0, como é mostrado na Figura 4.9(d). Este experimento confirma que a qualidade da diversificação está diretamente relacionada com a capacidade do usuário em ajustar o parâmetro de diversificação, podendo

\footnotetext{
${ }^{4}$ As Figuras 4.1(a) e 4.1(b) foram replicadas nas Figuras 4.9(a) e 4.9(c), respectivamente, para auxiliar na comparação entre os elementos resultados.
}
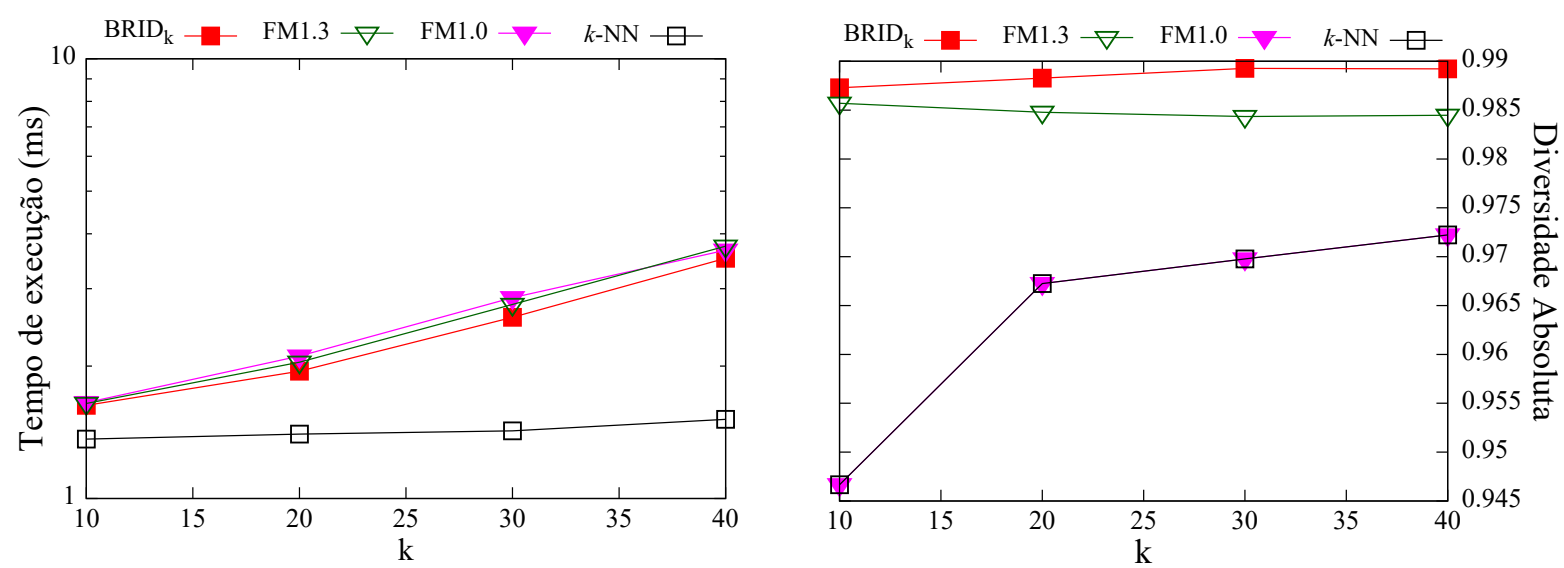

(a) Média do tempo de execução vs. quantidade $k$ de (b) Média de diversidade absoluta vs. quantidade de vizinhos. $k$ vizinhos.

Figura 4.8: (a) Tempo de execução e (b) resultados qualitativos para o conjunto de dados EnglishWords com $k$ variando de 10 até 40. 
se tornar um processo exaustivo executar o algoritmo FM várias vezes com valores diferentes de distância de separação até encontrar uma resposta adequada. Posteriormente, o próximo passo no experimento foi executar o algoritmo $\mathrm{BRID}_{k}$. Como ele não requer ajuste de parâmetro, só foi necessário executá-lo uma vez e os resultados são apresentados na Figura 4.9(c) 4

Concluindo, os experimentos de avaliação de qualidade indicaram que o algoritmo $\mathrm{BRID}_{k}$ apresentou melhor diversidade absoluta em todos os conjuntos de dados analisados. Em relação ao desempenho, $\mathrm{BRID}_{k}$ mostrou-se competitivo ao algoritmo FM (abordagem de distância de separação fixa) em conjuntos de dados de baixas dimensões e adimensionais (puramente métricos), porém com o aumento da dimensionalidade $\mathrm{BRID}_{k}$ foi até uma ordem de magnitude mais rápido que o $\mathrm{FM}$ em conjuntos de alta dimensionalidade. Além disso, $\mathrm{BRID}_{k}$ foi até quatro ordens de magnitude mais rápido que os algoritmos GMC e GNE, ambos representantes da abordagem de diversidade como um problema de otimização combinatória. Portanto, os resultados apresentados nesta seção indicam que o conceito de diversidade pode ser automaticamente definido, sem parâmetros específicos, sem aumentar o custo computacional e sem reduzir a qualidade da resposta fornecida.

\subsubsection{Experimento com as buscas por abrangência diversificada}

Neste conjunto de experimentos foi utilizado o conjunto de dados Carros para ilustrar o efeito da propriedade de diversidade em uma busca por abrangência. No Capítulo 6 este tipo de busca será retomado para apresentar uma aplicação das buscas por abrangência diversificada e outros experimentos. Nas buscas $k$-NN, a diversidade é utilizada para excluir elementos muito similares e incluir outros no resultado, porém a única restrição é manter o requisito de ter no máximo $k$ elementos, porém os elementos podem ser escolhidos em qualquer parte do espaço. Já nas buscas $R q$, a diversidade também é utilizada para excluir elementos muitos similares, porém o requisito de manter o limiar máximo de dissimilaridade é respeitado. Assim, os elementos que podem ser escolhidos como diversos não podem exceder a esse limiar, tornando os resultados das buscas $R D q$ um subconjunto do resultado das buscas $R q$ em que apenas os elementos mais diversos de uma região delimitada do espaço de busca são selecionados. Portanto, a busca atua como um filtro sobre a cardinalidade dos resultados e definem uma visão sumarizada do resultado. A Figura 4.9(f) mostra os resultados do algoritmo $\mathrm{BRID}_{r}$ para a busca com elemento central de busca sendo o modelo de carro "Volkswagen Golf 2.0" até um limiar máximo de dissimilaridade de 20.0 unidades. O algoritmo $R q$ sem diversidade retornou 100 elementos, porém apenas os 15 elementos mais próximos do elemento de busca estão apresentados na Figura 4.9(e). Como pode ser visto, há muito elementos muito similares na resposta, aumentando o esforço de análise dos elementos, e diminuindo o valor agregado da resposta. De maneira oposta, a busca por abrangência diversificada $(R D q)$ retornou apenas 10 elementos (Figura 4.9(f)), porém esses elementos acrescentam muito mais informação ao resultado do que a centena de elementos retornados pela busca por abrangência, pois apenas os elementos mais distintos foram retornados. Além disso, não foi necessário definir qualquer valor para controlar a quantidade de elementos na resposta ou como considerar quais elementos são diversos ou não. 


\begin{tabular}{|c|c|c|c|c|c|}
\hline \multicolumn{6}{|c|}{$s_{q}=$ Volkswagen Golf 2.0, 2004} \\
\hline Modelo & Ano & Potência & Porta-malas & Autonomia & Preço \\
\hline Volkswagen Golf 2. & 2004 & 116 & 235 & 8,6 & $\mathrm{R} \$ 23.000$ \\
\hline Volkswagen Golf 2. & 2003 & 116 & 235 & 8,6 & $\mathrm{R} \$ 21.500$ \\
\hline Volkswagen Golf 2. & 2002 & 116 & 235 & 8,6 & $\mathrm{R} \$ 21.000$ \\
\hline Volkswagen Golf 2. & 2001 & 116 & 235 & 8,6 & $\mathrm{R} \$ 19.500$ \\
\hline Volkswagen Golf 2. & 2000 & 116 & 235 & 8,6 & $\mathrm{R} \$ 19.000$ \\
\hline
\end{tabular}

(a) $k$-NNq: Sem diversificação

\begin{tabular}{|c|c|c|c|c|c|}
\hline \multicolumn{6}{|c|}{$s_{q}=$ Volkswagen Golf 2.0, 2004} \\
\hline Modelo & Ano & Potênci & rta-m & Autonomia & Preço \\
\hline Volkswagen Golf 2.0 & 2004 & 116 & 235 & 8,6 & $\mathrm{R} \$ 23.000$ \\
\hline Volkswagen Golf 2.0 & 2002 & 116 & 235 & 8,6 & $\mathrm{R} \$ 21.000$ \\
\hline $\begin{array}{l}\text { Peugeot } 2061.616 \mathrm{~V} \\
\text { Flex Féline }\end{array}$ & 2004 & 110 & 245 & 7,5 & $\mathrm{R} \$ 20.000$ \\
\hline Volkswagen Golf 1.6 & 2002 & 101 & 235 & 8,3 & $\mathrm{R} \$ 22.000$ \\
\hline $\begin{array}{l}\text { GM Corsa Hatch Maxx } \\
1.8 \text { Flex }\end{array}$ & 2005 & 105 & 260 & 7,3 & $\mathrm{R} \$ 21.000$ \\
\hline
\end{tabular}

(c) $\mathrm{BRID}_{k}$ : Similaridade com Diversidade (sem parâmetros)

\begin{tabular}{|c|c|c|c|c|c|}
\hline Modelo & Ano & PotênciaPorta-malas Autonomia & Preço \\
\hline Volkswagen Golf 2.0 & 2004 & 116 & 235 & 8,6 & $\mathrm{R} \$ 23.000$ \\
\hline Volkswagen Golf 2.0 & 2003 & 116 & 235 & 8,6 & $\mathrm{R} \$ 21.500$ \\
\hline Volkswagen Golf 2.0 & 2002 & 116 & 235 & 8,6 & $\mathrm{R} \$ 21.000$ \\
\hline Volkswagen Golf 2.0 & 2001 & 116 & 235 & 8,6 & $\mathrm{R} \$ 19.500$ \\
\hline Volkswagen Golf 2.0 & 2000 & 116 & 235 & 8,6 & $\mathrm{R} \$ 19.000$
\end{tabular}

(b) FM: Distância de sepação $=1.8$

\begin{tabular}{|l|l|l|l|l|c|}
\hline \multicolumn{7}{|c|}{$s_{q}=$ Volkswagen Golf 2.0, 2004} & \\
\hline Modelo & Ano & \multicolumn{1}{c|}{ Potência Porta-malas Autonomia } & Preço \\
\hline Volkswagen Golf 2.0 & 2004 & 116 & 235 & 8,6 & $\mathrm{R} \$ 23.000$ \\
\hline Volkswagen Golf 2.0 & 2002 & 116 & 235 & 8,6 & $\mathrm{R} \$ 21.000$ \\
\hline Volkswagen Golf 2.0 & 2000 & 116 & 235 & 8,6 & $\mathrm{R} \$ 19.000$ \\
\hline $\begin{array}{c}\text { Peugeot 206 1.6 16V } \\
\text { Flex Féline }\end{array}$ & 2004 & 110 & 245 & 7,5 & $\mathrm{R} \$ 20.000$ \\
\hline Volkswagen Polo 1.6 & 2004 & 101 & 240 & 8,0 & $\mathrm{R} \$ 20.300$ \\
\hline
\end{tabular}

(d) FM: Distância de sepação $=2.0$

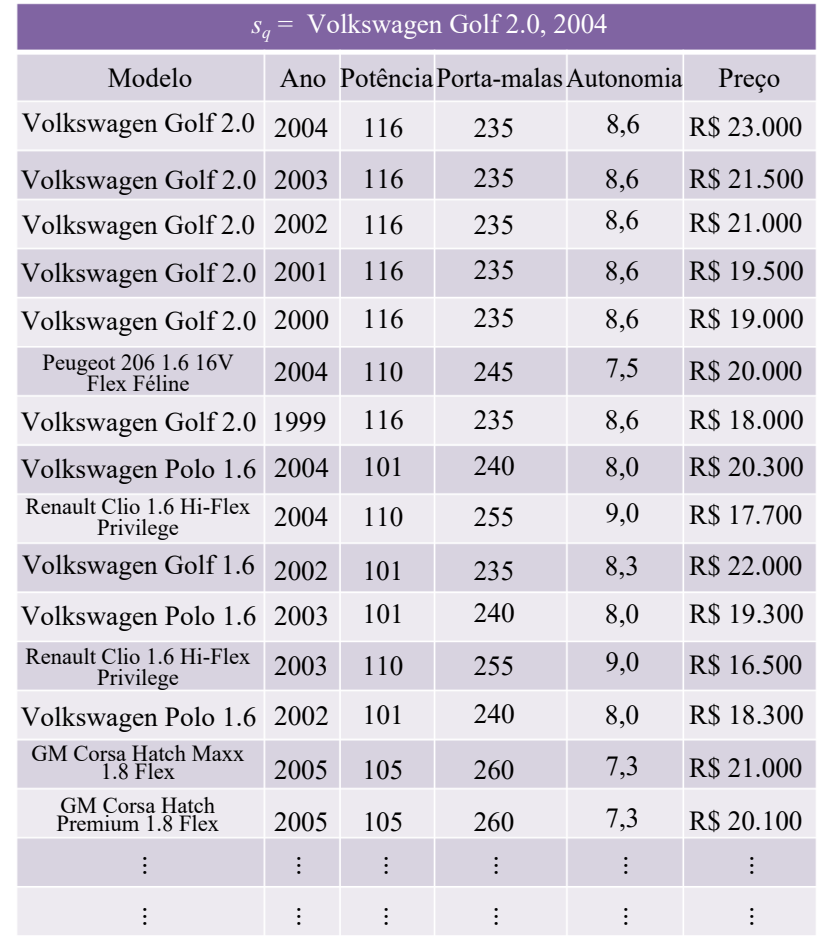

(e) $\mathrm{R}_{\mathrm{q}}$ : Sem diversificação

\begin{tabular}{|c|c|c|c|c|c|}
\hline \multicolumn{6}{|c|}{$s_{q}=$ Volkswagen Golf 2.0, 2004} \\
\hline Modelo & Ano & Potênci & rta-mala & utonomia & Preço \\
\hline Volkswagen Golf 2.0 & 2004 & 116 & 235 & 8,6 & $\mathrm{R} \$ 23.000$ \\
\hline Volkswagen Golf 2.0 & 2002 & 116 & 235 & 8,6 & $\mathrm{R} \$ 21.000$ \\
\hline $\begin{array}{l}\text { Peugeot } 2061.616 \mathrm{~V} \\
\text { Flex Féline }\end{array}$ & 2004 & 110 & 245 & 7,5 & $\mathrm{R} \$ 20.000$ \\
\hline Volkswagen Golf 1.6 & 2002 & 101 & 235 & 8,3 & $\mathrm{R} \$ 22.000$ \\
\hline $\begin{array}{l}\text { GM Corsa Hatch Maxx } \\
1.8 \text { Flex }\end{array}$ & 2005 & 105 & 260 & 7,3 & $\mathrm{R} \$ 21.000$ \\
\hline Volkswagen Golf 2.0 & 2000 & 116 & 235 & 8,6 & $\mathrm{R} \$ 19.000$ \\
\hline Citroen $\mathrm{C} 8$ & 2004 & 138 & 225 & 6,6 & $\mathrm{R} \$ 29.500$ \\
\hline Fiat Stilo $1.816 \mathrm{~V}$ & 2003 & 122 & 273 & 7,1 & $\mathrm{R} \$ 19.200$ \\
\hline Volkswagen Polo $1.016 \mathrm{~V}$ & 2003 & 79 & 240 & 8,1 & $\mathrm{R} \$ 17.300$ \\
\hline $\begin{array}{c}\text { Volkswagen Golf GTI } \\
1.8 \text { Turbo }\end{array}$ & 1999 & 150 & 235 & 6,8 & $\mathrm{R} \$ 16.000$ \\
\hline Ford Ecosport XLT 1.6 & 2004 & 98 & 292 & 8,1 & $\mathrm{R} \$ 24.200$ \\
\hline $\begin{array}{l}\text { GM Zafira Elegance } \\
\text { 2.0 Automática }\end{array}$ & 2005 & 121 & 150 & 7,4 & $\mathrm{R} \$ 28.900$ \\
\hline
\end{tabular}

(f) $\mathrm{BRID}_{r}$ : Similaridade com Diversidade (sem parâmetros)

Figura 4.9: Resultado para a busca Q1 para os algoritmos $k$-NN, BRID $_{k}$ e FM, $R q$ e $\mathrm{BRID}_{r}$.

\subsubsection{Experimentos de Escalabilidade}

Com o objetivo de avaliar a escalabilidade do algoritmo $\mathrm{BRID}_{k}$, foram definidos dois conjuntos de experimentos utilizando dados sintéticos. O primeiro conjunto de experimento é destinado a avaliar o comportamento do $\mathrm{BRID}_{k}$ quando varia-se a cardinalidade do conjunto de dados (Figura 4.10). O conjunto de dados Synthetic3D foi gerado seguindo uma distribuição gaussiana num espaço de três dimensões com os valores de cada dimensão no intervalo $[0,1]$. A cardinalidade do conjunto de dados variou de 10.000 até 100.000 elementos em incrementos de 10.000 elementos. A cada incremento, foram realizadas 100 buscas com elementos centrais de busca distintos com valor fixo de $k=10$. Foram medidos tanto a média do tempo de execução (em milissegundos) quando a média da diversidade absoluta. 


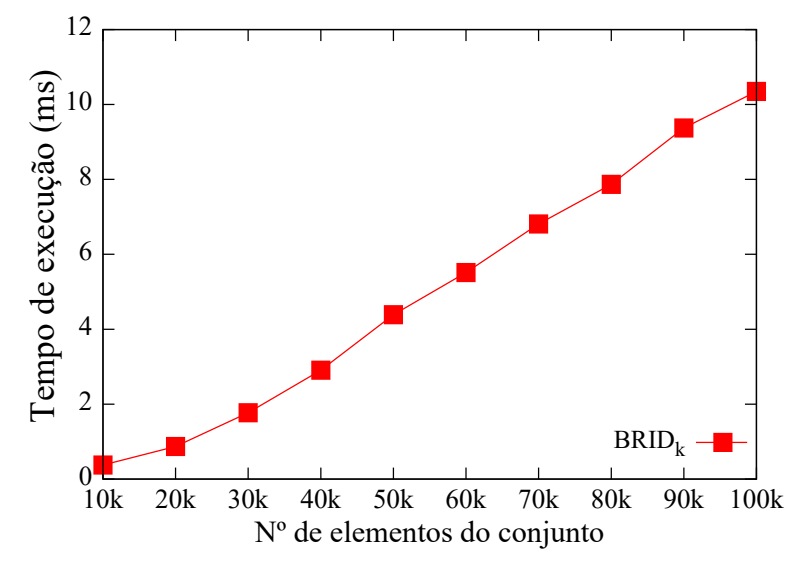

(a) Synthetic3D: $S$

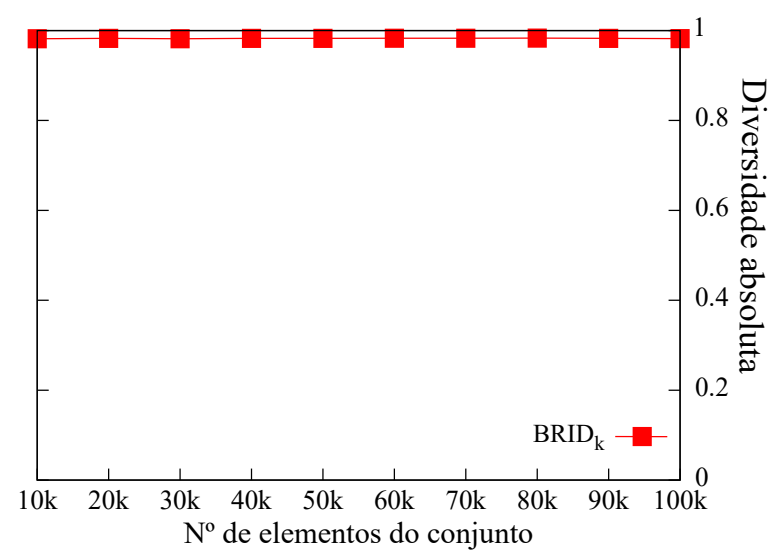

(b) Synthetic3D: $\bar{\omega}(\mathrm{S})$

Figura 4.10: (a) Escalabilidade em relação a cardinalidade do conjunto de dados Synthetic3D e (b) resultados para a avaliação da diversidade absoluta em relação ao aumento da cardinalidade do conjunto de dados.

Os resultados da Figura 4.10(a) indicam que o algoritmo proposto possui um comportamento próximo do linear em relação ao tempo de execução. Portanto, pode-se considerar que o algoritmo $\mathrm{BRID}_{k}$ é escalável para grandes bases de dados. Em relação à qualidade da diversificação, o resultado apresentado na Figura 4.10(b) mostra que o BRID ${ }_{k}$ é estável em relação a diversidade absoluta mesmo com o aumento da cardinalidade do conjunto de dados.

O segundo conjunto de experimentos de escalabilidade avaliou o algoritmo $\mathrm{BRID}_{k}$ em relação ao aumento da dimensionalidade do conjunto de dados (Figura 4.11). O conjunto de dados SynthMultiD foi gerado seguindo uma distribuição gaussiana com uma cardinalidade fixa de 30.000 elementos, variando a dimensionalidade do conjunto de 5 até 105 dimensões em incrementos de 10 dimensões, sendo que os valores em cada dimensão estão no intervalo $[0,1]$. Da mesma maneira que no primeiro experimento de escalabilidade, a cada incremento foram realizadas 100 buscas com elementos centrais de busca distintos e valor fixo de $k=10$. Foram medidas tanto a média do tempo de execução (em milissegundos) quando a média da diversidade absoluta.

A Figura 4.11(a) mostra que o comportamento do $\mathrm{BRID}_{k}$ para o tempo de execução tende a ser sub-linear em relação ao aumento da dimensionalidade do conjunto de dados, confirmando que o algoritmo pode ser utilizado em conjuntos de dados com centenas de dimensões (como já havia sido testado no conjunto Aloi). Os resultados para a diversidade absoluta, mostrados na Figura 4.11(b), comprovam que o BRID $_{k}$ também é estável quanto ao aumento da dimensão do conjunto de dados.

Os experimentos realizados nesta seção mostram que o algoritmo BRID $_{k}$ é tanto escalável em relação ao crescimento da cardinalidade quanto em relação à quantidade de dimensões do conjunto de dados. Além disso, o algoritmo é estável em relação à diversidade absoluta das respostas retornadas. 


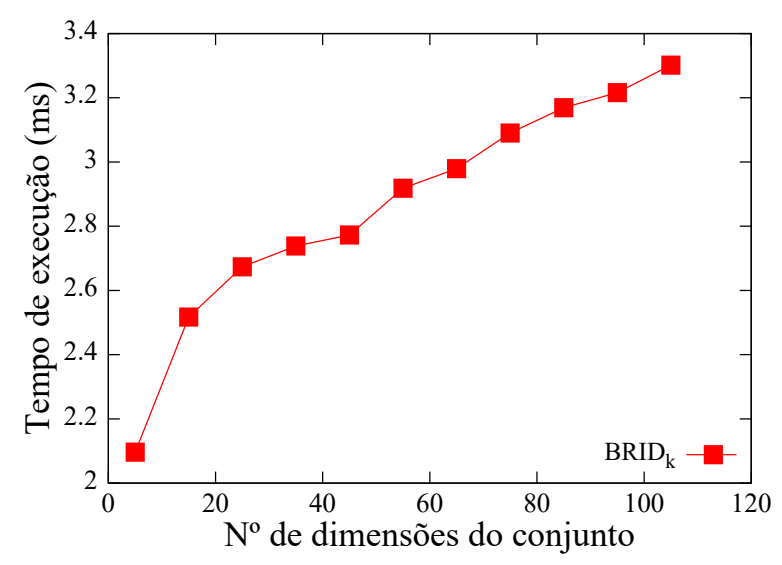

(a) SynthMultiD: $S$

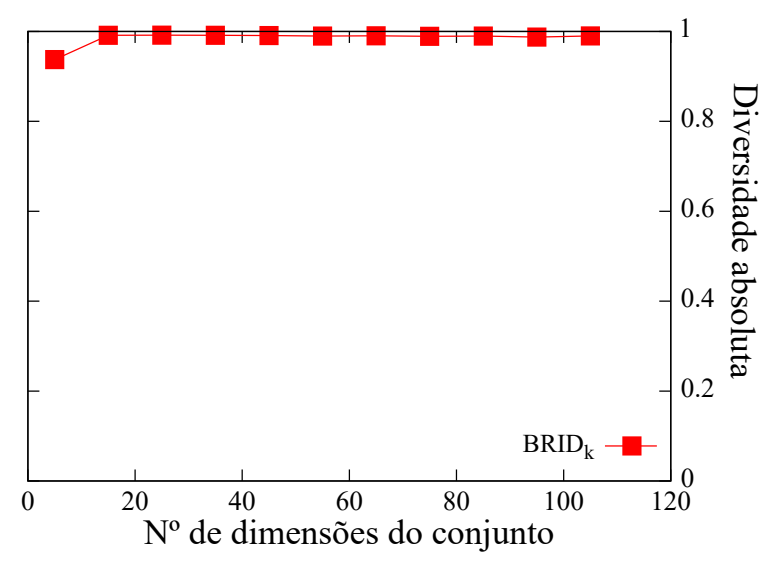

(b) SynthMultiD: $\bar{\omega}(\mathrm{S})$

Figura 4.11: (a) Escalabilidade em relação a dimensionalidade do conjunto de dados SynthMultiD e (b) resultados para a avaliação da diversidade absoluta em relação ao aumento da dimensionalidade do conjunto de dados.

\subsection{Considerações Finais}

Este capítulo apresentou a proposta de um novo modelo de diversidade para consultas por similaridade baseado no conceito de influência, que visa definir a propriedade de diversidades nas busca por similaridade de maneira transparente, utilizando apenas a posição relativa dos elementos no espaço de busca. O modelo proposto possui as seguintes características: é independente de parâmetros, pois não requer o ajuste de parâmetros de compromisso entre a similaridade e a diversidade nem quantificar uma distância de separação entre os elementos; é independente do domínio de aplicação, pois apresenta uma solução genérica para realizar busca por similaridade em qualquer espaço em que uma função de distância com propriedade de simetria possa ser definida. Além disso, diferentemente de todas as outras abordagens propostas na literatura que fornecem diversidade apenas para as buscas aos $k$-vizinhos mais próximos, o modelo proposto pode ser aplicado também a qualquer busca por similaridade, sendo que neste capítulo foi apresentada as buscas por abrangência diversificada. Foi apresentada uma técnica, chamada de BRID, para implementar as buscas por similaridade com diversidade utilizando o conceito de influência. Outra contribuição alcançada foi a definição de um modelo de avaliação da qualidade de diversificação de resultados com base no conceito de influência, que pode ser utilizado para avaliar os conjuntos de resposta dos algoritmos que expressam ou não a propriedade de diversidade. Por fim, foram apresentados experimentos utilizando tanto conjunto de dados reais quanto sintéticos, que confirmaram que a proposta apresentada é tanto eficiente quanto eficaz, sendo escalável para grandes volumes de dados.

O próximo capítulo apresenta a definição das junções diversificadas, o primeiro operador binário de diversificação de resultados com base no conceito de influência da literatura, o qual visa garantir um conjunto de resultado de menor cardinalidade, diversificado e mais útil para junções por similaridade. 


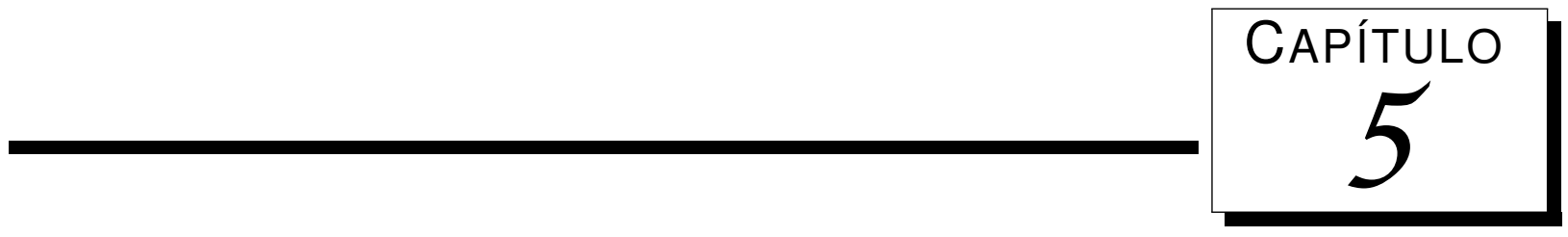

\section{Junção Diversificada}

Com a crescente capacidade das aplicações de produzir e consumir dados mais complexos, como imagens e posições geo-referenciadas, ocorre também um maior interesse para que os modernos Sistemas Gerenciadores de Base de Dados (SGBD) apresentem soluções não só para armazenar, mas também recuperar tais dados usando comparações de seu conteúdo. Conforme foi discutido no capítulo 2 , variações dos operadores relacionais clássicos estão sendo investigadas para incluir as operações de busca por similaridade nos SGBDs, sendo de maneira mais frequente os operadores de seleção por similaridade, mas também as junções por similaridade.

Tipicamente, existem três tipos de junção por similaridade discutidos na literatura, dos quais a junção por abrangência (muitas vezes sendo referenciada apenas como junção por similaridade) é o tipo de junção mais discutido e recorrente na literatura (AUGSTEN; BOHLEN, 2013; LIU; SHEN; WANG, 2016; XIAO et al., 2009; CARVALHO et al., 2016; CHEN et al., 2017; SILVA; REED, 2012; SILVA et al., 2013a; ZHANG et al., 2014). A junção por abrangência é útil em diversos contextos, tais como casamento de cadeia de caracteres (strings), limpeza de dados e detecção de objetos quase duplicados. No entanto, considere-se o seguinte exemplo em que a intuitividade e expressividade dos resultados produzidos pela junção por similaridade podem ser melhorados.

Seja um cenário de emergência em que um ou mais incidentes podem requisitar providências imediatas para reduzir as consequências adversas aos residentes e à propriedade. Suponha que um sistema de controle de emergência baseado em crowdsourcing, como o sistema desenvolvido pelo projeto Rescuer ${ }^{1}$, pode receber vários relatórios de testemunhas contendo fotos com meta-informação, por exemplo, coordenada geo-localizada do incidente. Neste cenário, é razoável considerar que o sistema com vários incidentes identificados pode receber uma grande quantidade de fotos, gerando um questionamento: "Como capturar uma visão abrangente ao redor das regiões dos incidentes usando uma quantidade reduzida de fotos?". Existem dois modos possíveis para utilizar o operador de junção por abrangência para responder a tal questionamento usando a similaridade da localização dos incidentes identificados

\footnotetext{
${ }^{1}$ RESCUER: Reliable and Smart Crowdsourcing Solution for Emergency and Crisis Management. Disponível em: <http://www.rescuer-project.org/>. Acessado em: 04 de Março de 2017.
} 
pela geo-localização das fotos até um perímetro (limiar de similaridade máximo) definido por um especialista.

O primeiro modo utiliza o operador de junção por abrangência como um operador de busca. Entretanto, ao realizar o pareamento das imagens até um limiar máximo, muito dos pares resultantes podem representar a mesma informação, pois muitas fotos podem ser fotografadas a partir do mesmo ponto de vista (criando perspectivas quase duplicadas). O segundo modo utiliza o operador de junção por abrangência como um operador de pré-processamento ou de filtragem, enviando o resultado da junção para um algoritmo de agrupamento de dados (clustering) para sumarizar a resposta final para apresentação aos usuários. Os dois modos possuem desvantagens. O primeiro considera apenas a similaridade em relação aos incidentes e as fotos, não considerando a similaridade entre os pares da resposta. Por exemplo, seja um resultado composto pelos pares na forma $\left\langle s_{1}, t_{a}\right\rangle,\left\langle s_{1}, t_{b}\right\rangle,\left\langle s_{2}, t_{c}\right\rangle$ e $\left\langle s_{2}, t_{d}\right\rangle$ em que $s_{1}$ e $s_{2}$ são localização de incidentes na relação $S$. Os elementos $t_{a}, t_{b}, t_{c}$ e $t_{d}$ são fotos próximas de cada incidente identificado na relação $T$. Porém, considere-se que os pares são muito similares entre si, isto é, $t_{a}$ e $t_{b}$ retornam a mesma quantidade de informação sobre o incidente $s_{1}$ que os pares $t_{c}$ e $t_{d}$ sobre $s_{2}$, gerando uma resposta final com alta cardinalidade, o que requer mais esforço da equipe de controle de emergência para entender a região do incidente. $\mathrm{O}$ segundo modo troca o problema de "análise de muitos pares similares" pelo correto "ajuste de um algoritmo de agrupamento" que será executado na operação subsequente. Note-se que o desempenho dos algoritmos de agrupamento são diretamente afetados pela cardinalidade dos dados de entrada. Além disso, é comum que seja necessário executar os algoritmos mais de uma vez para o correto ajuste dos parâmetros e por fim encontrar os resultados desejados. Sendo assim, o segundo modo é computacionalmente mais caro, podendo inviabilizar sua implementação. Porém, ele facilita a tarefa da equipe de controle ao reduzir a quantidade de informação analisada.

Superando ambas desvantagens, um resultado mais interessante para o cenário de emergência seria a captura de uma perspectiva mais abrangente ao redor de cada região de incidente, utilizando a informação do relacionamento entre as fotos para obter uma visão mais diversificada sobre os incidentes e de preferência utilizando poucas fotos. Conforme foi discutido no capítulo 3, a diversidade tem sido estudada como uma forma de apresentar visões heterogêneas para um elemento de busca. Contudo, no melhor do nosso conhecimento, as definições de diversidade têm sido exploradas, exclusivamente, em operadores correspondentes à seleção por similaridade, sendo aplicada no critério de comparação de $k$-NN para se ter total controle da quantidade de elementos retornados. Isso se deve à natureza das aplicações que orientaram o desenvolvimento de tal conceito as quais quase sempre, são focadas para motores de busca na internet e sistemas de recomendação.

Neste capítulo será apresentado o conceito de junção diversificada: uma operação binária que recebe dois conjuntos de dados como entrada e combina os elementos atendendo ao critério de similaridade, porém garantindo também uma resposta com menor cardinalidade e diversificada. Além disso, esse capítulo mostra que o conceito de influência (definido no capítulo 4) é consistente e genérico o suficiente para ser utilizado em operadores de busca seja unários ou binários.

Em resumo, este capítulo apresenta as seguintes contribuições:

- A definição de uma base teórica para combinar os conceitos de buscas que apresentam diversidade e junções por similaridade; 
- Apresentação de um operador de busca que aumenta a utilidade das junções por abrangência;

- Um algoritmo para computar as junções por similaridade com diversidade;

- Comparação do novo operador binário de diversificação com o algoritmo tradicional de junção por similaridade. Os resultados experimentais mostram que as junções diversificadas têm custos computacionais equivalentes aos das junções por similaridade, porém seus resultados apresentam uma visão mais ampla dos elementos de ambos os conjuntos de entrada.

O restante deste capítulo é estruturado da seguinte maneira. A Seção 5.1 apresenta o conceito de junção por diversidade. A Seção 5.2 apresenta os resultados experimentais realizados para avaliar o novo operador binário de diversidade. Por fim, a Seção 5.3 apresenta as considerações finais deste capítulo.

\subsection{Junções por Similaridade Diversificada}

Inicialmente, vamos apresentar nossa intuição sobre como a combinação de conceitos antagônicos como similaridade e diversidade podem aprimorar a aplicabilidade de junções por similaridade. Tipicamente, as buscas são expressas pela combinação de operadores de busca, por exemplo, a operação de junção é composta pelo operador de produto cartesiano seguido de uma operação de seleção. Assim a resposta de uma junção por abrangência possui propriedades relacionadas às do operador de seleção por abrangência, um operador que seleciona os elementos até um limiar máximo de similaridade do elemento central de busca.

Conforme foi discutido no capítulo 2, um critério de similaridade pura (sem considerar diversidade) gera um conjunto de resultados com elementos muito similares uns aos outros, o que aumenta a cardinalidade do conjunto de resultado sem aumentar o valor agregado do conteúdo da informação. Por exemplo, a Figura 5.1 (a) representa os elementos de dois conjuntos de dados $S$ e $T$ em um espaço Euclideano de duas dimensões, sendo que as estrelas representam os elementos no conjunto de dados $S$, os triângulos representam elementos em $T$ e os círculos delimitam o limiar máximo de elementos de $T$ que pode ser combinados com os elementos de $S$. No entanto, do mesmo modo que o operador de seleção por similaridade diversificado pode aprimorar os resultados com a avaliação da diversidade dos elementos, uma junção por similaridade diversa pode também apresentar uma melhor perspectiva dos elementos, como é ilustrado na Figura 5.1 (b). É importante ressaltar que cada elemento em $S$ pode ser associado com um número diferente de elementos em $T$, dependendo da distribuição dos elementos no espaço de busca. Na Figura 5.1 (b), os quadrados representam os elementos em $T$ que foram ignorados para serem combinados com os elementos do conjunto $S$, pois eles provavelmente apenas representavam a mesma informação já presente por outros pares formados no conjunto de resultado, apresentando o comportamento desejado para o cenário de emergência descrito anteriormente.

O problema de junção por abrangência diversificada (Definição 18) pode ser definido do seguinte modo. Sejam $S$ e $T$ dois conjuntos de dados, cada um amostrados do mesmo domínio de dados complexos $\mathbb{S}$. O operador de junção por abrangência diversificada (ou apenas DS-join) recupera todos os pares de tuplas de ambos os conjuntos onde a distância entre 


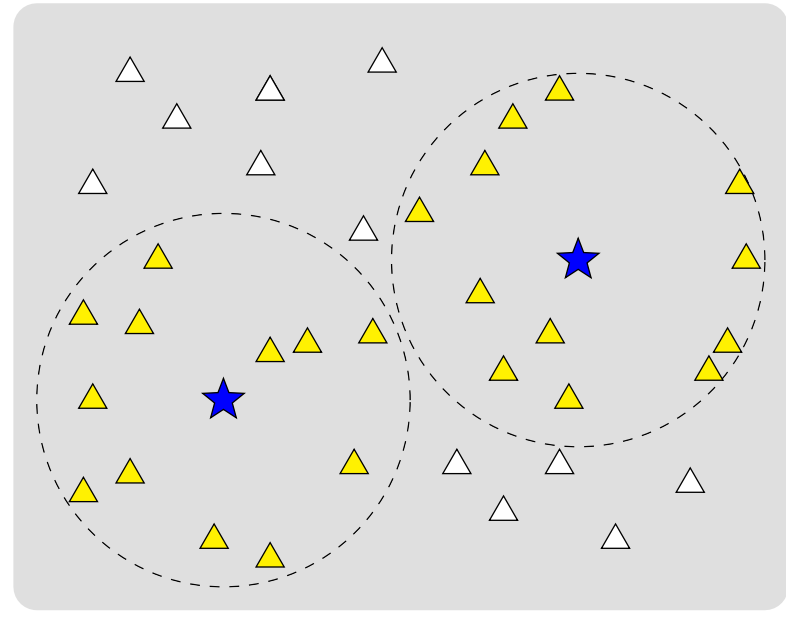

(a) Junção por abrangência

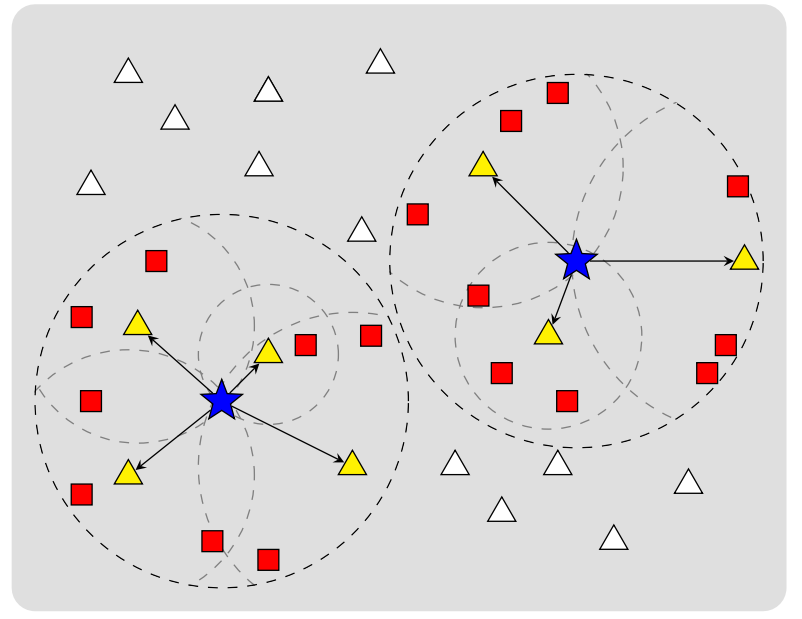

(b) Junção por abrangência diversificada

Figura 5.1: Junção por abrangência num espaço Euclidiano de duas dimensões. Estrelas são as regiões de incidente da primeira relação $S$, triângulos representam as fotos enviadas sobre os incidentes da segunda relação $T$. Círculos pontilhados agrupam os elementos da relação $S$ que foram pareados com a relação $T$. Quadrados são os elementos de $T$ que não foram pareados com os elementos de $S$ na junção por abrangência diversificada.

elementos não exceda um limiar máximo de similaridade e, ao mesmo tempo, garanta que os pares resultantes são diversos entre si. Formalmente:

Definição 18. Junção por Abrangência Diversificada (DS-join): Sejam $S$ e T dois conjuntos de dados, cada um compartilham o mesmo dominio de dados complexos, $S \in \mathbb{S} e$ $T \in \mathbb{S}$. Seja $\delta$ uma métrica definida para o domínio $\mathbb{S}, \epsilon_{q}$ um limiar máximo de similaridade $e$ RngDiv $\left(\delta, \epsilon_{q}\right)$ um operador de comparação por similaridade com diversidade por abrangência.

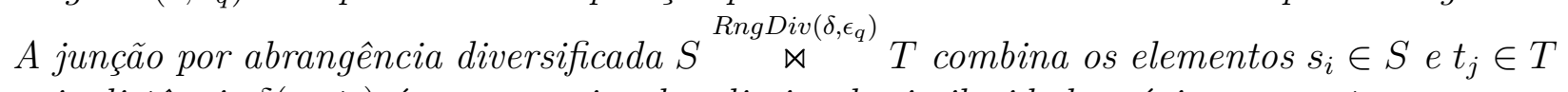
cuja distância $\delta\left(s_{i}, t_{j}\right)$ é menor ou igual ao limiar de similaridade máximo $\epsilon_{q}$ e retorna apenas os pares de elementos no conjunto de resposta resultante $\left\langle s_{i}, t_{j}\right\rangle,\left\langle s_{i}, t_{m}\right\rangle \in(S \times T)$ que estão separados por uma distância mínima (de influência) baseada na posição relativa de $t_{j}$ e $t_{m}$ para $s_{i}$, isto é:

$S \stackrel{\operatorname{RngDiv}\left(\delta, \epsilon_{q}\right)}{\bowtie} T=R=\left\{\left\langle s_{i}, t_{j}\right\rangle \in(S \times T) \mid \delta\left(s_{i}, t_{j}\right) \leq \epsilon_{q} \wedge \forall\left\langle s_{i}, t_{j}\right\rangle \in R:\left\langle s_{i}, t_{j}\right\rangle \notin \stackrel{T}{T}\left(t_{m}, t_{j}\right)\right\}$.

Vamos interpretar a Definição 18 e ver como ela formaliza essa intuição. A primeira parte da definição, $\left\langle s_{i}, t_{j}\right\rangle \in(S \times T) \mid \delta\left(s_{i}, t_{j}\right) \leq \epsilon_{q}$ garante que somente os elementos em $S$ só serão combinados com os elementos mais similares (restritos pelo limiar de similaridade $\left.\epsilon_{q}\right)$ do conjunto de dados T. A segunda parte, $\forall\left\langle s_{i}, t_{j}\right\rangle \in R:\left\langle s_{i}, t_{j}\right\rangle \notin \stackrel{\sim}{\mathrm{T}}\left(t_{m}, t_{j}\right)$ garante que a diversidade esteja presente no conjunto de resultado, selecionando apenas os pares de elementos separados por uma distância mínima de separação. Considere-se que somente os elementos $t_{j}, t_{m} \in T$ mais distantes que a distância mínima de separação para outras tuplas em $T$ serão selecionadas, utilizando o conceito de influência (definido no capítulo4). Os elementos influenciados por $t_{j}$ estão representados por $\tilde{T}\left(t_{j}, t_{m}\right)$. A intuição é que os elementos $t_{m}$ fornecem a mesma informação (ou equivalente) daquela apresentada em $t_{j}$ quando os mesmos são combinados com o elemento $s_{i}$. Assim, o resultado final só precisa combinar as tuplas não influenciadas do conjunto de dados T. Assim, a definição de Conjunto de Influência Forte (Definição 11 do capítulo 4) foi estendida para criar um conjunto de 
influência forte a partir de dois conjuntos de dados (Definição 19), em que os elementos $t_{m} \in T$ podem ser ignorados como possíveis candidatos à combinação das tuplas de $S$, tomando como base apenas os elementos $t_{j} \in T$ e o elemento correspondente $s_{i} \in S$.

Definição 19. Conjunto de Influência Forte - $\tilde{T}$ : Dado um elemento $s_{i}$ de um conjunto de dados $S$ e outro $t_{j}$ no conjunto de dados $T$, o conjunto de influência forte $\stackrel{\sim}{T}$ de $t_{j}$ em relação a cada elemento $s_{i}$ é dado por:

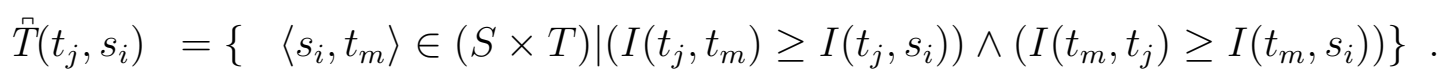

A Definição 18 combinada com a Definição 19 possibilita restringir os elementos do conjunto de dados $T$ utilizando um elemento pertencente ao conjunto $S$, permitindo selecionar apenas os elementos em $T$ dentro de um dado limiar de similaridade $\epsilon_{q}$, que são diversos entre si de uma forma transparente ao usuário. A utilização do conceito de diversidade baseado em influência é muito interessante no processo de junção, pois como os elementos em $T$ podem estar em regiões tanto densas como esparsas em relação aos elementos em $S$, retirar o requisito de definição de parâmetros específicos para o processo de diversificação permite que o processo de junção seja realizado sem a definição de valores padrão que nem sempre se adequam as particularidades de cada busca. Nesse aspecto, o conceito de influência permite que a distância de separação se adapte automaticamente durante o processo de junção, baseando-se apenas na distribuição dos dados em $T$ ao redor dos elementos de $S$.

\section{Algoritmo para Junção por similaridade diversificada:}

A maneira mais tradicional para computar as junções por similaridade é por meio da estratégia de laços aninhados (nested-loop). O algoritmo 10 combina a estratégia de iteração de laços aninhados com as operações de poda de elementos influenciados por outros elementos no conjunto de dados $T$ para possibilitar a execução da operação de junção por abrangência diversificada. As linhas 2-8 executam a junção por similaridade interna. Na linha 6 , os dois

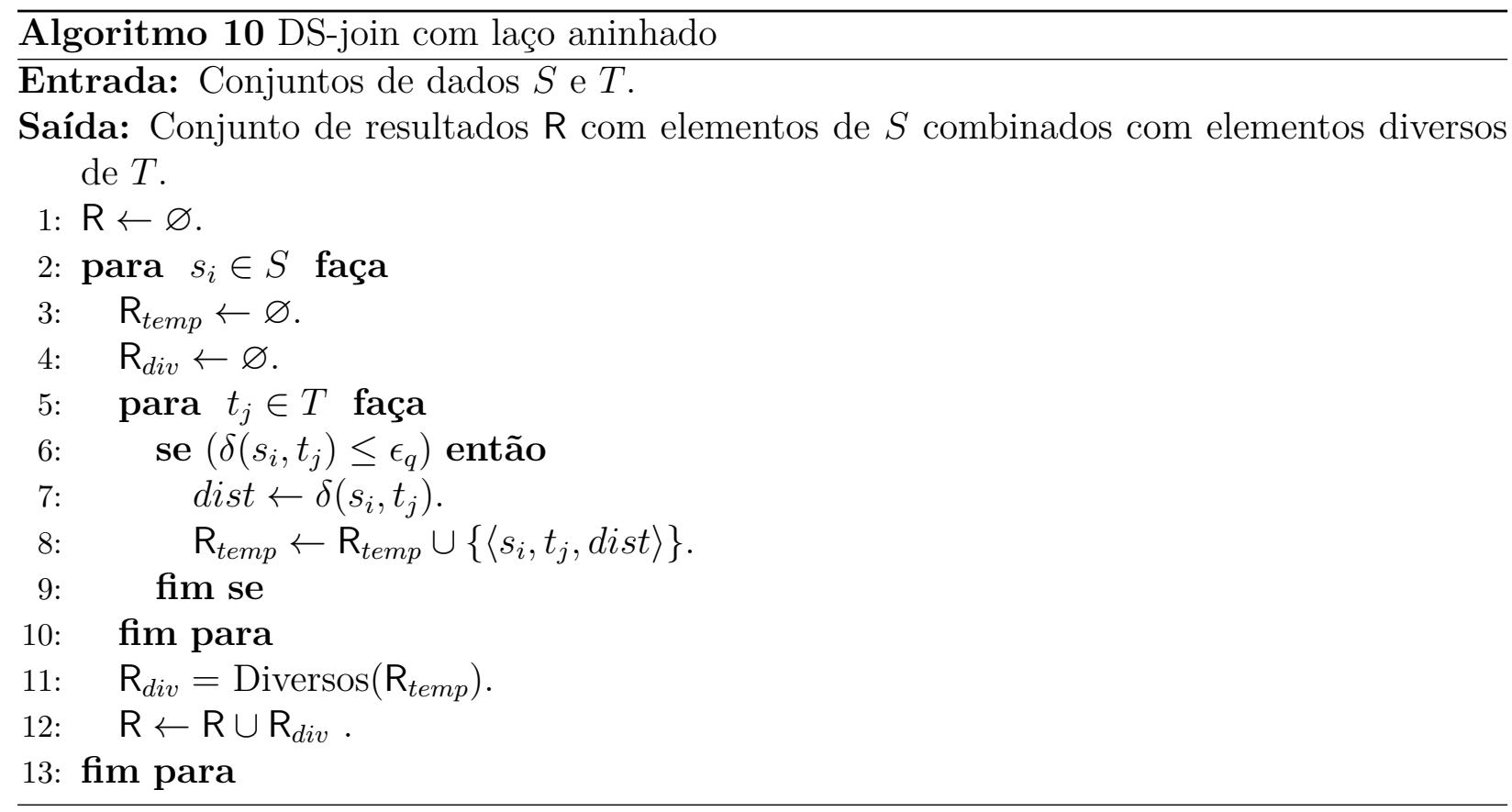




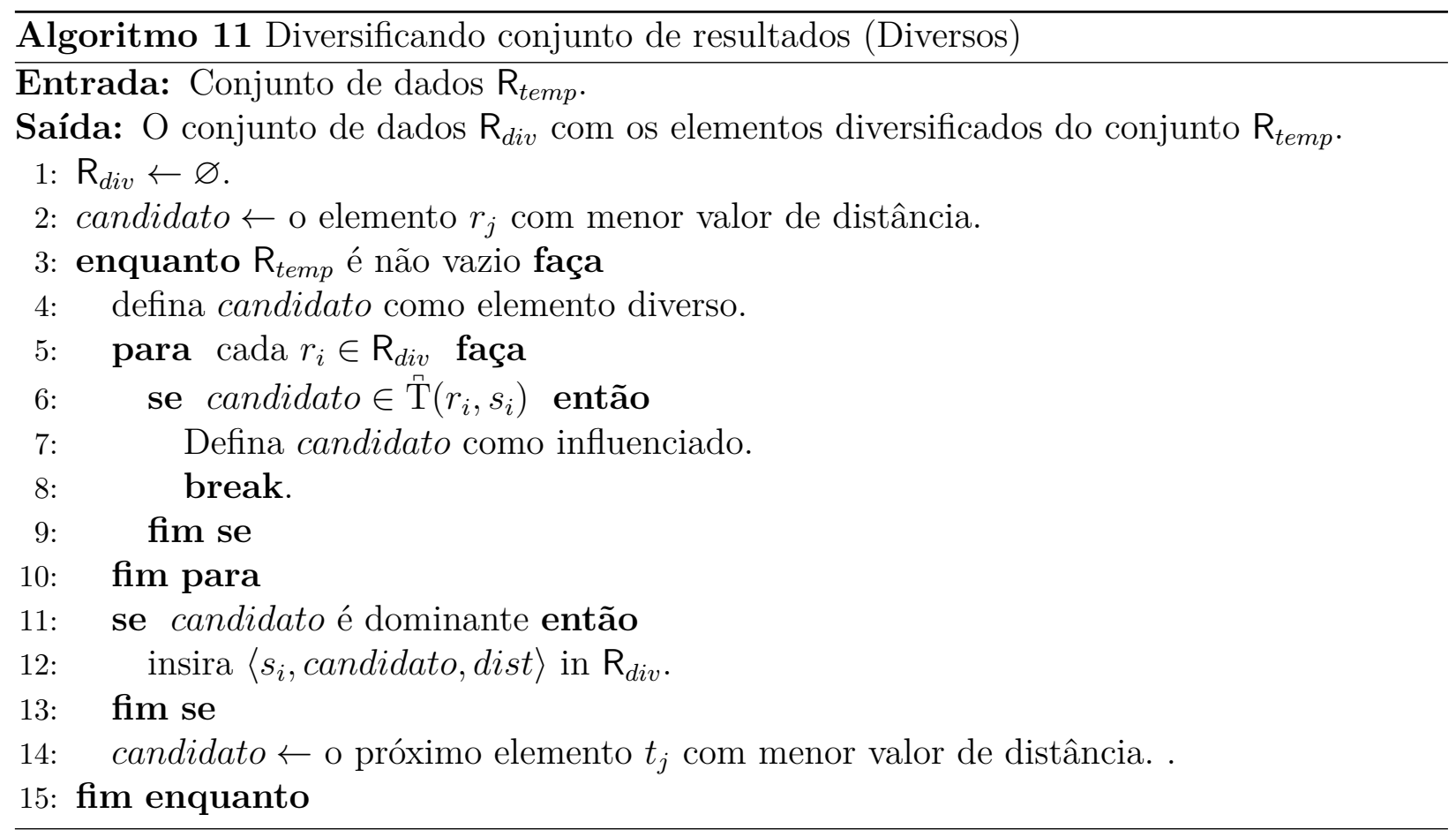

elementos que estão no limiar de similaridade $\epsilon_{q}$ são concatenados e incluídos no resultado, juntamente com a similaridade calculada. Os elementos são mantidos ordenados em relação à similaridade dos elementos de $T$ para o elemento $s_{i}$ no conjunto de resultado $\mathrm{R}_{\text {temp }}$. A utilização de uma fila de prioridade torna o armazenamento mais simples e eficiente dos elementos nesta parte do algoritmo. Como o conceito de diversidade é aplicado para cada elemento do conjunto $S$, a função Diversos (linha 11) é utilizada sobre todos os elementos que foram selecionados até o limiar máximo de similaridade $\epsilon_{q}$.

No Algoritmo 11 (método Diversos), a intuição é realizar a poda dos elementos muito similares dentro do requisito do limiar de distância máxima para o elemento em $S$, de tal forma que a resposta se torna um subconjunto daquela que seria retornada pela junção por abrangência tradicional, reduzindo a cardinalidade da resposta utilizando apenas os elementos do conjunto de dados $T$ que podem apresentar uma visão abrangente para cada elemento em $S$. A distância de elemento candidato a diverso no conjunto $T$ para o elemento $s_{i} \in S$ precisa ser mínima entre todos os elementos em $T$. Por isso, que a primeira distância mínima entre os elementos em $T$ é considerada como sendo zero. A cada iteração, o elemento mais próximo de $s_{i}$ em $T$ é considerado um candidato a elemento diverso (candidato) (linhas 3-4). Depois disso, esse elemento é avaliado se pertence ao conjunto de influência forte de algum outro elemento já selecionado. Caso verdade, o elemento candidato é influenciado por algum elemento em $R$ e é marcado como um elemento influenciado podendo ser podado da resposta final (linhas 5-7). Por outro lado, se candidato não é influenciado por nenhum outro elemento em $\mathrm{R}_{\text {div }}$, então candidato é inserido no conjunto de resultado (linhas 11-12). É importante notar que a quantidade de elementos selecionados depende da distribuição dos dados no espaço de busca ao redor do elemento $s_{i} \in S$. Tal processo se repete até que todo conjunto de entrada $\mathrm{R}_{\text {temp }}$ tenha sido avaliado (linha 3 ). 


\subsection{Experimentos}

Esta seção apresenta os resultados experimentais que validam a proposta do operador de junção por abrangência diversificada em comparação com o algoritmo tradicional de junção por abrangência (Sim-join) e com um algoritmo baseado na busca aos $k$-vizinhos distintos (Distjoin) (apresentada na seção 2.2.3.2), pois o restante das definições de diversidade existentes na literatura são restritas ao operador de comparação aos $k$-vizinhos mais próximos. Para a composição do algoritmo Dist-join foi necessário adaptar alguns conceitos, pois o mesmo foi baseado na busca aos $k$-vizinhos distintos mais próximos, porém como sua definição de diversidade é baseada em distância de separação, é possível mudar o critério de parada para restringir o espaço de busca por um limiar máximo de similaridade. No entanto, Dist-join requisita a definição de uma distância de separação $\phi$ que é fixa para todos os elementos avaliados, por exemplo, a mesma distância de separação para todos os elementos do conjunto de dados $S$. Todos os algoritmos comparados foram implementados utilizando a estratégia de laço aninhado para possibilitar comparações justas.

O objetivo do experimento é comparar o impacto da utilização da propriedade de diversidade com base no conceito de influência e com distância de separação fixa no operador de junção por similaridade.

\subsubsection{Conjuntos de Dados}

Foram executados experimentos sobre os algoritmos avaliados sobre dois conjuntos de dados reais (Aloi e Proteins) e utilizando vários conjuntos sintéticos (Synth) com diferentes dimensionalidades e cardinalidades. O conjunto de dados Aloi (Amsterdam Library of Object Images $)^{2}$ consiste de 72.000 imagens coloridas de objetos rotacionados no plano a cada 5 graus, composto por 1.000 objetos. Cada imagem foi representada por um vetor de característica com 144 dimensões que sumarizam as informações de cores do conteúdo da imagem. A função de distância $L_{1}$ foi utilizada para computar a similaridade entre os elementos do conjunto. O conjunto de dados Proteins ${ }^{3}$ consiste de 12.866 cadeias de aminoácidos representadas por caracteres. Este conjunto de dados é puramente métrico e possibilita avaliar o DS-join em dados que não podem ser representados em um espaço multidimensional. Foram retidas as proteínas cujos tamanhos variam entre 2 e 15 aminoácidos. A métrica $L_{e d i t}$ foi utilizada para comparação dos elementos. Os conjuntos de dados sintéticos Synth possuem cardinalidade variando de 1.000 até 10.000 pontos em 2, 4, 8, 16 e 32 dimensões para cada conjunto, os quais foram gerados com distribuição aleatória (uniforme). Todos os conjuntos de dados sintéticos tiveram seus elementos avaliados em relação a similaridade utilizando a função de distância $L_{2}$. A tabela 5.1 sumariza a variação dos parâmetros e indica os valores padrão entre parênteses para os experimentos quando os mesmos não estão especificados na descrição dos testes.

Foram consideradas duas estratégias para avaliar os algoritmos: A primeira (Seção 5.2.2) avalia o comportamento dos algoritmos com o aumento do limiar de similaridade máxima $\epsilon_{q}$ em relação tempo de execução e a cardinalidade final dos resultados utilizando os conjuntos de dados reais; A segunda estratégia (Seção 5.2.3) realiza uma análise de escalabilidade do

\footnotetext{
${ }^{2}$ Amsterdam Library of Object Images Homepage. Último acesso em: 25 de Maio de 2016. Disponível em: $<$ http://staff.science.uva.nl/ aloi/>

${ }^{3}$ Proteins: Disponível em: http://www.uniprot.org/uniprot Último acesso em: 19 de Abril de 2015
} 
Tabela 5.1: Configuração dos experimentos

\begin{tabular}{|c|c|c|}
\hline \hline Parâmetro & conjunto de dados & Valores \\
\hline \hline \multirow{3}{*}{$|S|$} & Aloi & 100 \\
\cline { 2 - 3 } & Proteins & 861 \\
\cline { 2 - 3 } & Synth & $(1.000) ; 2.500 ; 5.000 ; 7.500 ; 10.000$ \\
\hline \multirow{4}{*}{$|T|$} & Aloi & 72.000 \\
\cline { 2 - 3 } & Proteins & 12.005 \\
\cline { 2 - 3 } & \multirow{2}{*}{ Synth } & $1.000 ; 2.500 ; 5.000 ;$ \\
& & $7.500 ;(10.000)$ \\
\hline \multirow{2}{*}{$\epsilon_{q}$} & Aloi & $(1.0) ; 2.0 ; 3.0 ; 4.0 ; 5.0$ \\
\cline { 2 - 3 } & Proteins & $(5) ; 6 ; 7 ; 8 ; 9$ \\
\hline Dimensão & Synth & $2 ;(4) ; 8 ; 16 ; 32$ \\
\hline \hline
\end{tabular}

operador DS-join variando tanto a cardinalidade dos conjuntos de dados $S$ e $T$ quanto à dimensionalidade dos dados, utilizando os conjuntos de dados sintéticos.

Os experimentos foram executados em um computador com a seguinte configuração: processador Intel ${ }^{\circledR}$ Core $^{\mathrm{TM}}$ i7-4770 com 16 GB de memória RAM. O sistema operacional utilizado foi a distribuição GNU Linux Ubuntu 14.04. Toda os algoritmos foram implementados na mesma plataforma de avaliação, utilizando a linguagem $\mathrm{C}++$ e ambos os conjuntos de dados $S$ e $T$ foram armazenados em disco, isto é, os elementos são carregados para memória apenas quando eles são requisitados pelo processo de junção.

\subsubsection{Avaliação de Desempenho e da Cardinalidade do Conjunto de Resultados}

Com o objetivo de avaliar o desempenho, foi mensurado o tempo total de execução dos algoritmos e para realizar uma análise da redução da cardinalidade dos conjuntos de resposta foi mensurado o número de elementos pertencentes ao conjunto final de resultados retornados pelos algoritmos DS-join, Dist-join e pelo tradicional Sim-join. Os conjuntos de dados Aloi e Proteins foram utilizados para ilustrarem dois casos representativos relativos a operações de junções em dados complexos, dados em altas dimensões e em espaços puramente métricos, respectivamente. O limiar de similaridade máximo $\epsilon_{q}$ foi definido do seguinte modo: o valor mínimo recupera aproximadamente $1 \%$ do montante total de elementos da operação de produto cartesiano e o valor máximo para recuperar aproximadamente $10 \%$ desse total de elementos. Naturalmente, cada conjunto de dados distinto possui um intervalo de valores diferentes para o limiar $\epsilon_{q}$.

A Figura 5.2 apresenta os resultados para o conjuntos de dados Aloi. Para esse conjunto foram definidos dois valores para a distância de separação do algoritmo Dist-join: 1.0 e 1.3. Esses valores representam, respectivamente, a melhor configuração baseado na qualidade da resposta e no desempenho do algoritmo, segundo o artigo original. A Figura 5.2(a) mostra o tempo de execução em segundos dos algoritmos para o conjunto Aloi. Como pode ser visto, todos os algoritmos obtiveram o mesmo tempo de execução quando o limiar de similaridade é pequeno, pois o resultado final possui apenas alguns elementos. No entanto, quando o limiar de similaridade aumenta, ambas as configurações do Dist-join têm seus desempenhos 


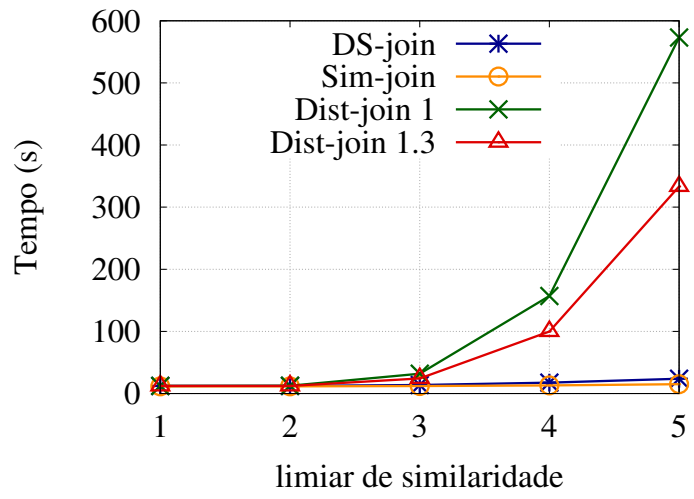

(a) Tempo de execução.

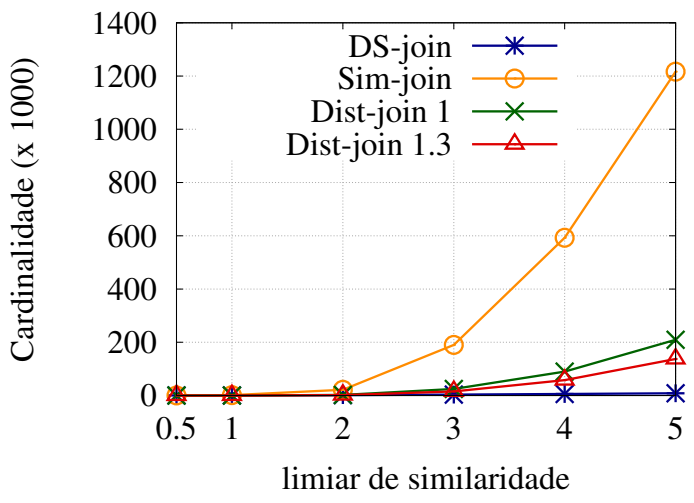

(b) Tamanho do conjunto de resultados.

Figura 5.2: Avaliação do desempenho e análise da redução de cardinalidade para o conjunto de dados Aloi.

degradados, sendo em media 10 vezes mais lentos que o algoritmo tradicional Sim-join. Esse comportamento ocorre devido ao parâmetro de distância de separação ser fixo para os elementos do conjunto $S$, sem considerar a distribuição dos elementos do conjunto $T$ em relação aos de $S$. Por outro lado, os experimentos mostram que o DS-join é muito mais eficiente que o Dist-join, indicando que o ajuste dinâmico da distância mínima do conceito de influência possui melhor desempenho que usar apenas um valor fixo. Em relação ao Sim-join (sem diversidade), o DS-join foi em média 20\% mais lento, apresentando portanto um impacto relativamente pequeno no desempenho para a adição de diversidade. A Figura 5.2(b) mostra os resultados referentes a análise do tamanho do conjunto de resultados para o conjunto Aloi. Neste experimento, a intuição utilizada foi que um bom algoritmo de junção diversificada deve selecionar um número reduzido de elementos para garantir a cobertura da mesma região do espaço dos elementos recuperados pelo algoritmo Sim-join. Nesse aspecto, DS-join teve desempenho melhor que ambas as configurações do Dist-join, realizando a cobertura do mesmo espaço dos dados utilizando apenas 1\% dos elementos recuperados pelo Sim-join

A Figura 5.3 apresenta os resultados para o conjuntos de dados Proteins. Neste experimento, a distância de separação para o Dist-join foi definida como: $\phi=6$. A Figura 5.3(a) mostra o tempo de execução num conjunto de dados puramente métrico. Novamente, o DS-join foi mais rápido que o algoritmo Dist-join, mas dessa vez ele foi pelo menos duas vezes mais rápido para o menor valor do limiar de similaridade $\epsilon_{q}$ e até uma ordem de magnitude mais rápido quando $10 \%$ do total de elementos é recuperado no processo de junção. Além disso, mesmo o Dist-join apresentando tempo de execução mais elevado, não foi o suficiente para garantir um conjunto de resultados com menor quantidade de elementos, pois o DS-join recuperou em média, três vezes menos elementos que o Dist-join, como é apresentado na Figura 5.3(b).

Os resultados apresentados ressaltam que o DS-join acrescenta a diversidade nas junções por similaridade com um tempo equivalente quando comparado com a versão do algoritmo sem diversidade (Sim-join), enquanto que o outro algoritmo de diversificação (Dist-join) foi 10 vezes mais lento que o Sim-join. Além disso, DS-join foi capaz de reduzir a cardinalidade dos resultados para até $1 \%$ da quantidade de elementos retornados, sem requisitar a definição de parâmetros, confirmando que o conceito de influência é capaz de inserir a diversidade de modo transparente e intuitivo no operador de junção por similaridade. 


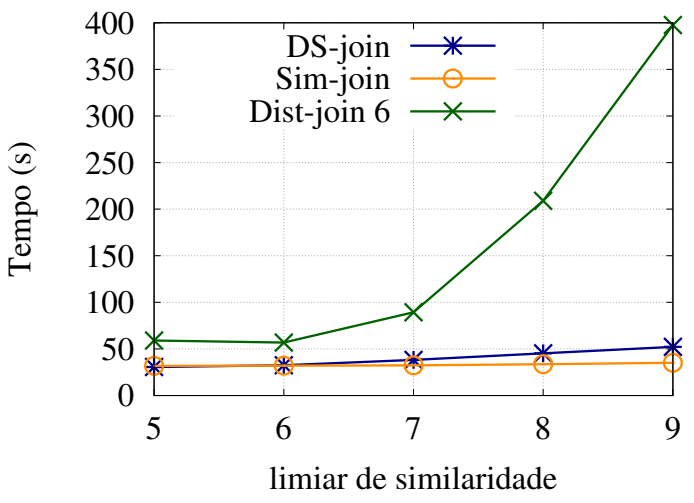

(a) Tempo de execução.

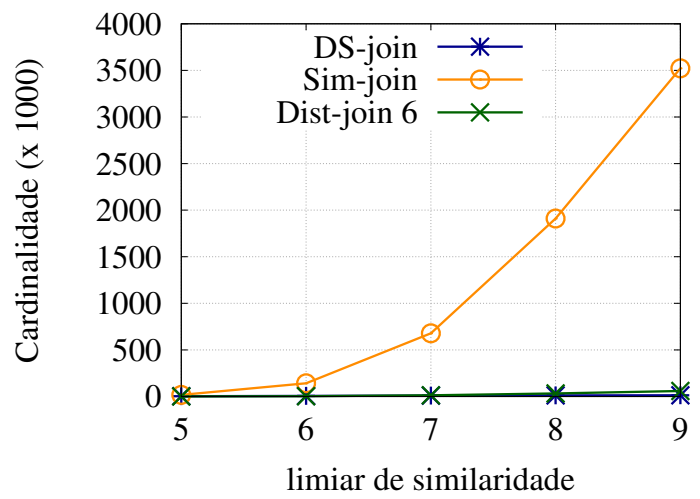

(b) Tamanho do conjunto de resultados.

Figura 5.3: Avaliação do desempenho e análise da redução de cardinalidade para o conjunto de dados Proteins.

\subsubsection{Experimentos de Escalabidade}

Com o objetivo de avaliar a escalabilidade do algoritmo DS-join, foram definidos dois conjuntos de experimentos utilizando dados sintéticos. O primeiro conjunto de experimento é destinado a avaliar o comportamento do DS-join quando a cardinalidade do conjunto de dados é incrementada. A figura 5.4(a) mostra o efeito do crescimento da cardinalidade em ambos os conjuntos de dados $S$ e $T$. Como pode ser visto, DS-join seguiu o mesmo comportamento do algoritmo Sim-join (sem diversidade) com uma pequeno incremento no tempo de execução: na média a diferença foi menor que 7\%. Esses resultados mostram que a inclusão de diversidade num operador de junção por similaridade, mesmo que utilizando uma estratégia de laço aninhado, não degrada o desempenho geral em relação a variação de ambos os conjuntos de dados.

O segundo conjunto de experimentos de escalabilidade avaliou os efeitos do aumento da dimensionalidade do conjunto de dados no desempenho do DS-join. A Figura 5.4(b) mostra que a diferença entre o DS-join e o Sim-join se manteve próxima (aproximadamente 10\%) para o aumento da dimensionalidade de ambos os conjuntos de dados, $S$ e $T$. Como já

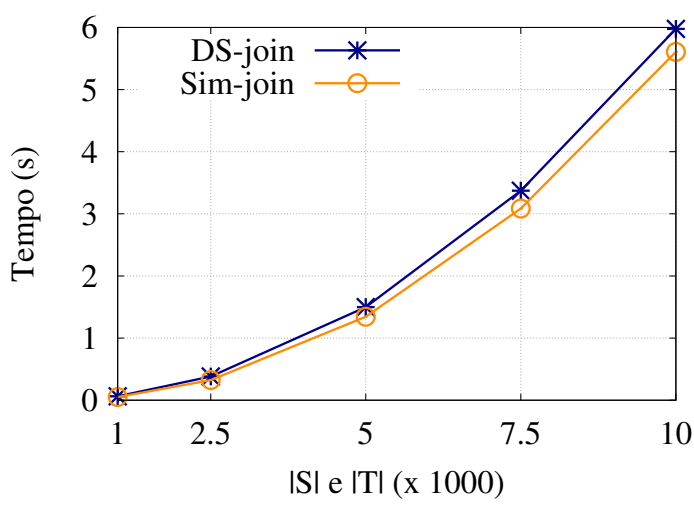

(a) Synth: Cardinalidade.

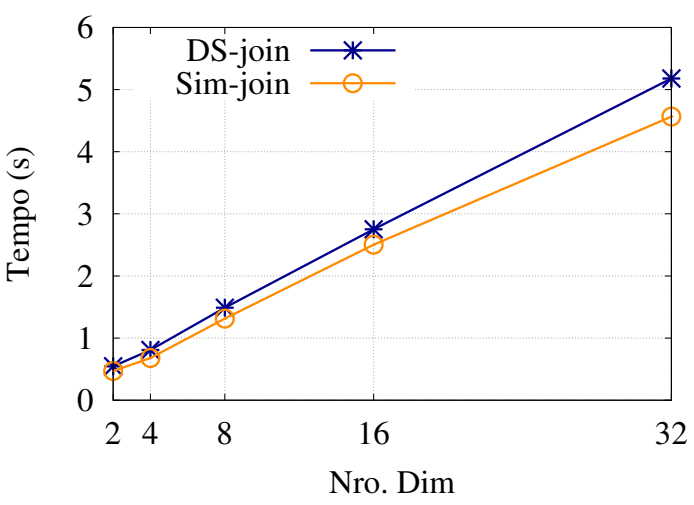

(b) Synth: Dimensionalidade.

Figura 5.4: Avaliação de escalabilidade em relação (a) cardinalidade e (b) dimensionalidade sobre os conjuntos de dados Synth. 
era esperado, o custo do DS-join aumenta com a dimensionalidade, uma vez que o cálculo de distância entre os elementos se torna computacionalmente cada vez mais custoso com o aumento das dimensões, pois o DS-join considera tanto a similaridade quanto a diversidade entre os elementos. No entanto, o aumento do custo não é muito grande e pode ser considerado mínimo quando comparado com o ganho de apresentar uma resposta com menor quantidade de elementos e com uma visão abrangente para os pares de elementos formados.

\subsection{Considerações Finais}

Este capítulo apresentou a proposta de um operador de junção por similaridade diversificada baseada no conceito de influência para estender a aplicação da propriedade de diversidade para operadores binários de buscas por similaridade. O operador proposto possui as seguintes características: é independente de parâmetros, pois não requer o ajuste da distância de separação entre os elementos para cada elemento do conjunto de dados; é capaz de reduzir a cardinalidade dos resultados dos operadores de junção por abrangência, retornando apenas os elementos diversos que representam a mesma região do limiar de similaridade máxima. Além disso, diferentemente de todas as outras abordagens propostas na literatura, o conceito de diversidade baseada em influência é o primeiro capaz de ser aplicado para qualquer critério de comparação por similaridade e em operadores de busca unários (seleções) e binários (junções). Foi apresentado também um algoritmo baseado na estratégia de laços aninhados para implementar as junções por abrangência diversificada utilizando o conceito de influência. Por fim, foram apresentados experimentos utilizando tanto conjunto de dados reais e sintéticos que confirmam que é possível incluir diversidade no operador de junção sem causar impactos significativos no desempenho geral, mas aumentando a utilidade das respostas retornadas com um número reduzido de elementos.

Os próximos capítulos apresentam aplicações para o modelo de diversificação baseado em influência, referentes as atividades da segunda frente de trabalhos desta tese. Especificamente, o próximo capítulo descreve como utilizar a influência para criar uma estratégia de amostragem capaz de melhorar tanto a eficiência quanto a eficácia dos algoritmos de diversidade baseados em problemas de otimização combinatória, possibilitando que novas aplicações se beneficiem das características desses algoritmos sem se preocupar com o custo computacional. 



\section{Otimização da Diversificação por meio de Técnicas de Amostragem}

As abordagens de diversificação de resultados têm por objetivo recuperar elementos similares a um dado elemento central de busca, ao mesmo tempo em que garantem um determinado grau de diversidade entre os elementos, aumentando a relevância dos resultados obtidos. Conforme foi discutido no capítulo 3, a maioria dos algoritmos da literatura são baseados numa estratégia de otimização combinatória de critério duplo, em que a similaridade e a diversidade precisam competir entre si, sendo essas medidas balanceadas por um parâmetro definido pelo usuário. Contudo, soluções ideais para essas estratégias possuem, no pior caso, um custo computacional NP-Difícil.

Tipicamente, os algoritmos de diversificação de resultado realizam uma etapa inicial de filtro para reduzir o custo computacional, restringindo o espaço de busca para um subconjunto dos dados originais. Assim, uma busca aos $k$-vizinhos diversos mais próximos é realizada em duas fases: Uma fase de filtragem de candidatos e uma fase de computação de diversidade. A literatura pressupõe que a primeira fase deve ser realizada utilizando o algoritmo dos $m$-vizinhos mais próximos para recuperar um conjunto de candidatos $S$, tal que, $|S|=m$ e $m>k$. A fase de computação de diversidade recebe como entrada o subconjunto $S$ para selecionar o conjunto dos $k$-diversos $R \subseteq S,|R|=k$, maximizando a função objetivo de diversificação. Tanto o número $m$ de elementos no espaço de busca reduzido e a maneira como eles são selecionados apresentam um papel importante para a fase de filtragem de candidatos, pois a fase de computação de diversidade requer, $m^{2}$ comparações entre esses elementos, sendo interessante a utilização de conjuntos de candidatos de baixa cardinalidade.

A maioria das pesquisas (como também foi apresentado no capítulo 3) possui o foco somente na fase de computação de diversidade, sendo utilizadas heurísticas gulosas com diferentes estratégias de construção do conjunto de resultados. No entanto, no melhor do nosso conhecimento, nenhuma das pesquisas anteriores investigou o impacto da fase de filtragem de candidatos quanto à eficácia e eficiência que poderiam ser obtidas substituindo o algoritmo tradicional de busca aos vizinhos mais próximos.

Este capítulo irá explorar como os principais algoritmos de diversificação de resultado podem se beneficiar com a mudança da estratégia utilizada na fase de filtragem de candidatos. 
Foi definida uma plataforma de avaliação para comparar diferentes formas de geração de um conjunto de candidatos. Especificamente é ilustrado como a utilização do conceito de influência (definido no capítulo 4) pode realizar uma amostragem do conjunto de dados, resultando em um conjunto de candidatos de menor cardinalidade capaz de reduzir os custos de execução dos algoritmos sem comprometer a qualidade final da resposta diversificada.

Em resumo, este capítulo apresenta as seguintes contribuições:

- Uma plataforma de avaliação para a inclusão de novas técnicas para a fase de filtragem;

- Técnicas para implementar amostragem com base no conceito de influência, seleção aleatória e por agrupamento de dados;

- Comparação das novas técnicas da fase de filtragem de candidatos. Os resultados dos experimentos atestam que a utilização de técnicas mais elaboradas nessa fase podem reduzir o tempo total de execução em até duas ordens de magnitude, sem prejudicar a qualidade dos resultados.

O restante deste capítulo é estruturado da seguinte maneira. Seção 6.1 apresenta a plataforma de avaliação da fase de filtragem de candidatos dos algoritmos de diversificação de resultados, enquanto a Seção 6.2 apresenta as novas técnicas de filtragem. A Seção 6.3 apresenta os resultados experimentais realizados para avaliar as técnicas de filtragem. Por fim, a Seção 6.4 apresenta as considerações finais deste capítulo.

\subsection{Plataforma de Avaliação}

A fase de filtragem de candidatos visa reduzir a complexidade dos algoritmos ao definir uma região de interesse com cardinalidade inferior à do conjunto de dados original, excluindo os elementos que apresentarão baixa relevância para a resposta final. A intuição para realizar a restrição do conjunto de dados vem dos motores de busca para a web (search engine) e dos sistemas de recomendação, em que o interesse dos usuários está focado nos resultados mais relevantes. Como já dito, o método utilizado para restringir o espaço de busca é um algoritmo para os $k$-vizinhos mais próximos $(k-\mathrm{NN})$, porém tal abordagem não verifica a contribuição individual de cada elemento do conjunto de candidatos, apresentando apenas redução na quantidade total de elementos comparados.

O objetivo aqui é encontrar técnicas para a escolha de conjunto de candidatos com a similaridade preservada ao elemento de busca, porém evitando a inclusão de elementos que apresentem baixa contribuição para a fase de computação de diversidade, isto é, elementos muito similares aos que já foram inseridos no conjunto de candidatos. A plataforma de avaliação conta com dois módulos: O módulo de filtragem de candidatos e o módulo de computação de diversidade, organizados de acordo com a Figura 6.1. O módulo de filtragem de candidatos possui o algoritmo tradicional do $k$-NN e três novas técnicas para amostragem de um conjunto de dados (que serão descritas na Seção 6.2). A plataforma utiliza os conjuntos de candidatos gerados por cada uma das técnicas de filtragem para avaliar a qualidade e o tempo de execução no módulo de computação de diversidade cujos algoritmos foram implementados para representar diferentes estratégias de construção de resultados, a baseada em meta-heurística (GNE), baseada em construção incremental (GMC, MMR , MSD) e baseada em troca de elementos (SWAP). Detalhes sobre os algoritmos de computação de diversidade podem ser encontrados no Capítulo 3. 


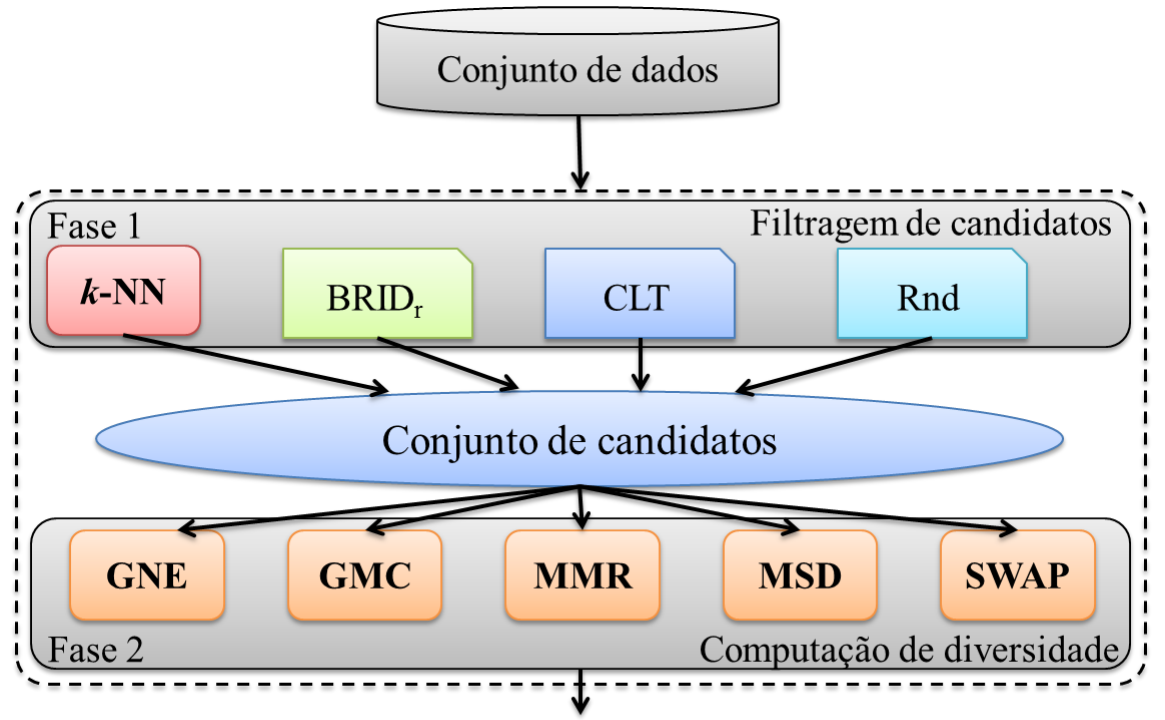

Resultado Diversificado

Figura 6.1: Visão geral da plataforma de avaliação.

\subsection{Técnicas para melhorar a fase de Filtragem de Candidatos}

Foram consideradas técnicas alternativas para gerar o conjunto de candidatos, incluindo a seleção de elementos aleatórios, algoritmos de agrupamento de dados como o algoritmo dos $k$-medóides, e selecionando elementos baseados no conceito de influência. Cada técnica definida possui uma suposição para melhorar a qualidade e/ou o desempenho dos algoritmos na fase de computação de diversidade.

\section{Técnica baseada na seleção aleatória de elementos $(R n d)$}

A técnica mais simples para gerar um conjunto de candidatos se baseia na seleção aleatória de elementos no conjunto de dados original $S$. Contudo, os elementos selecionados precisam ser similares ao elemento central de busca $\left(s_{q}\right)$, garantido que o conjunto de candidatos $C$ representa os elementos mais relevantes para a diversificação. Desse modo, é necessário definir uma distância máxima de similaridade $\left(\xi_{\max }\right)$ até o elemento $s_{q}$ para os elementos do conjuntos de candidatos.

Assim, a técnica $R n d$ escolhe aleatoriamente elementos $s_{i} \in S$ verificando a restrição de distância máxima, $\delta\left(s_{q}, s_{i}\right)<\xi_{\max }$, até que uma quantidade de elementos sejam selecionados, como pode ser visto no algoritmo 12. É necessário definir dois parâmetros: a quantidade $p$ de candidatos a serem selecionados aleatoriamente e a distância máxima de similaridade $\left(\xi_{\max }\right)$ ao elemento central de busca $s_{q}$. Rnd é a técnica mais rápida de todas, pois executa apenas um cálculo de distância para cada elemento selecionado, sem realizar qualquer análise do conjunto final de candidatos. Definir um valor correto para o parâmetro $p$, em geral, requisita várias execuções experimentais variando seu valor até que seja alcançado um equilíbrio adequado entre qualidade e desempenho. A intuição é que Rnd é capaz de reduzir o tempo de execução da fase de filtragem de candidatos e o tempo total de execução, porém não há qualquer garantia que seja gerado um conjunto de dados de boa qualidade. 


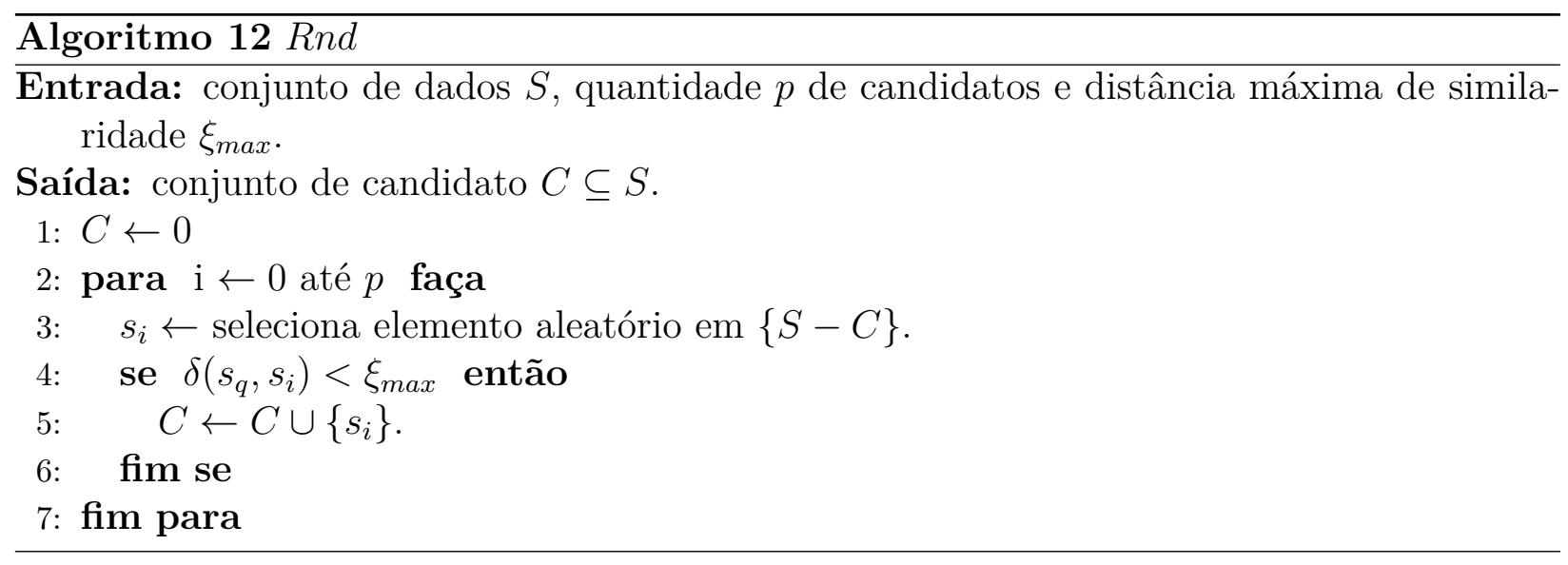

\section{Técnica baseada em agrupamento de dados $(C L T)$}

A utilização de uma técnica baseada em um algoritmo de agrupamento de dados do tipo $k$ medóides, certamente, requer mais processamento e, consequentemente, um tempo maior de execução que as abordagens de seleção aos vizinhos mais próximos e por elementos aleatórios. Contudo, a suposição é que obter o agrupamento dos elementos pode gerar um conjunto de candidatos que tenha melhor sumarização da vizinhança em torno do elemento central de busca.

É possível realizar o agrupamento dos elementos de dois modos: no conjunto original $S$ ou em um conjunto previamente filtrado pelo estratégia dos vizinhos mais próximos. O primeiro modo realiza o agrupamento dos elementos sem qualquer restrição no espaço de busca, porém requisita uma seleção dos elementos representativos mais próximos do elemento central de busca. O segundo modo utiliza um conjunto de candidatos temporário $T$ filtrado por um algoritmo de $k$-NN para encontrar os grupos localizados ao redor do elemento central de busca. Este último modo é mais rápido do que o anterior, uma vez que a cardinalidade do conjunto filtrado $T$ pode ser muito menor do que a cardinalidade de todo o conjunto de dados $S$, sem impor efeitos adversos sobre o conjunto de candidatos. Por essa razão, o algoritmo 13 implementa em duas fases a abordagem de agrupamentos de dados, realizando um filtro aos $m$-vizinhos mais próximos e posteriormente o agrupamento aos p-medóides. Como parâmetro, é requisitada a quantidade $m$ de vizinhos que devem ser filtrados do conjunto original $S$ e a quantidade $p$ de grupos que devem ser encontrados. Como também ocorre na técnica Rnd, a correta definição desses valores podem precisar da execução do algoritmos algumas vezes para encontrar um balanceamento entre o número de grupos e a quantidade de elementos

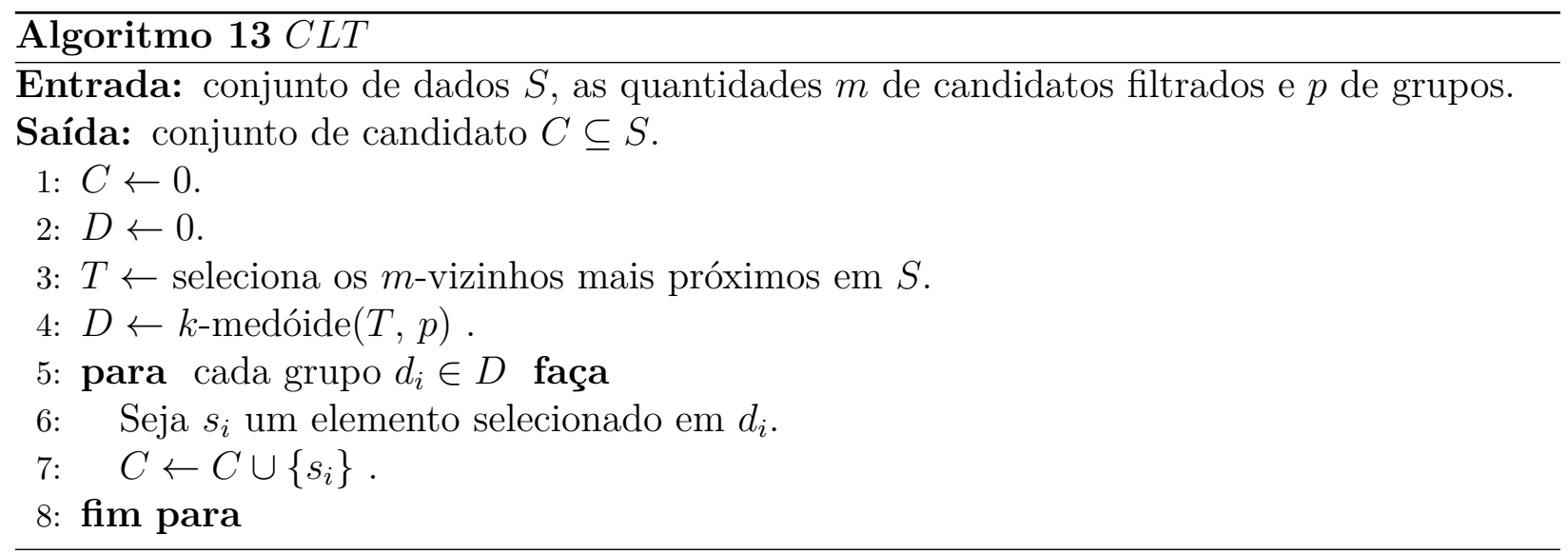




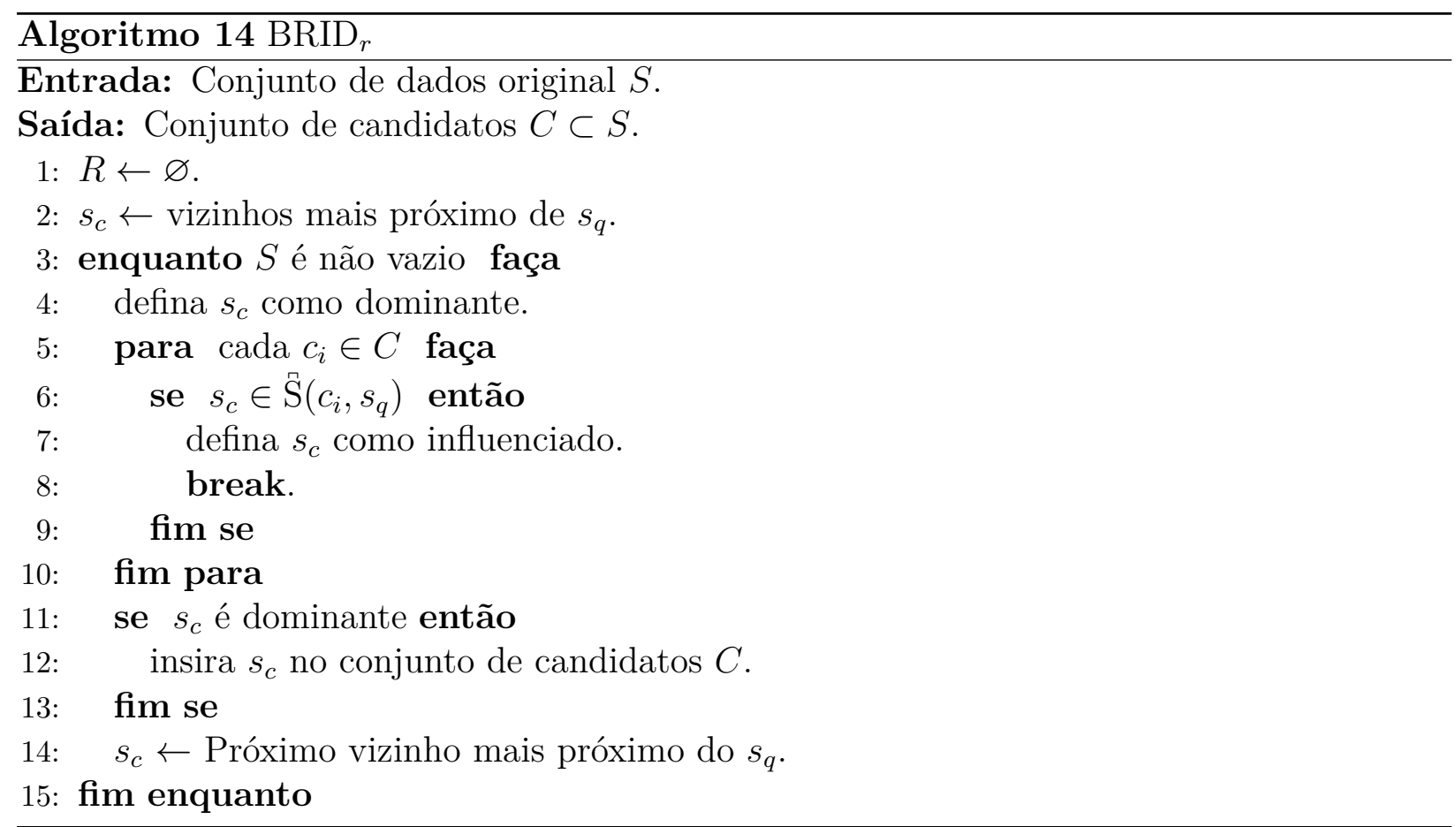

necessários. Um aspecto a ser considerado é que a tarefa de agrupamento é relacionada à distribuição e à densidade dos dados, enquanto a diversificação de resultados é relacionada ao posicionamento dos elementos em relação a um centro de busca. Neste quesito, a utilização de agrupamento de dados possibilita escolher elementos de acordo com a distribuição dos grupos, embora os elementos selecionados possam não resultar num conjunto de candidatos adequado para a diversificação.

\section{Técnica baseada no conceito de influência $\left(B R I D_{r}\right)$}

Conforme foi discutido no capítulo 4, a seleção de elementos baseada no conceito de influência segue a natureza fundamental de elementos similares a um centro de busca, mas os elementos selecionados devem manter uma distância mínima de separação entre os mesmos. Assim, utilizar esse conceito para gerar um conjunto de candidato pode resultar em elementos que são naturalmente diversos do elemento central de busca, evitando a escolha de elementos próximos uns dos outros.

As técnicas anteriores visavam reduzir a cardinalidade do conjunto de candidatos utilizando formas mais eficientes (Rnd) ou que pudessem representar melhor a distribuição dos elementos do conjunto de dados $(C L T)$. Com a técnica $B R I D_{r}$, a suposição é que deve-se considerar a diversidade dos elementos desde a fase de filtragem de candidatos, garantindo que os elementos candidatos estejam pelo menos distantes por uma distância de separação automaticamente adaptável que pode ser aplicado direto ao conjunto de dados original $S$, baseando-se na técnica BRID (Subseção 4.2) e nas buscas por abrangência diversificada $(R D q)$.

O algoritmo 14 é, essencialmente, o mesmo Algoritmo 9 que foi apresentado no capítulo anterior, porém como não é necessário controlar a distância máxima de similaridade até o elemento de busca, a verificação foi ajustada para verificar se o conjunto de dados está vazio ou não (linha 3). Assim, essa técnica não requisita qualquer definição de parâmetros 

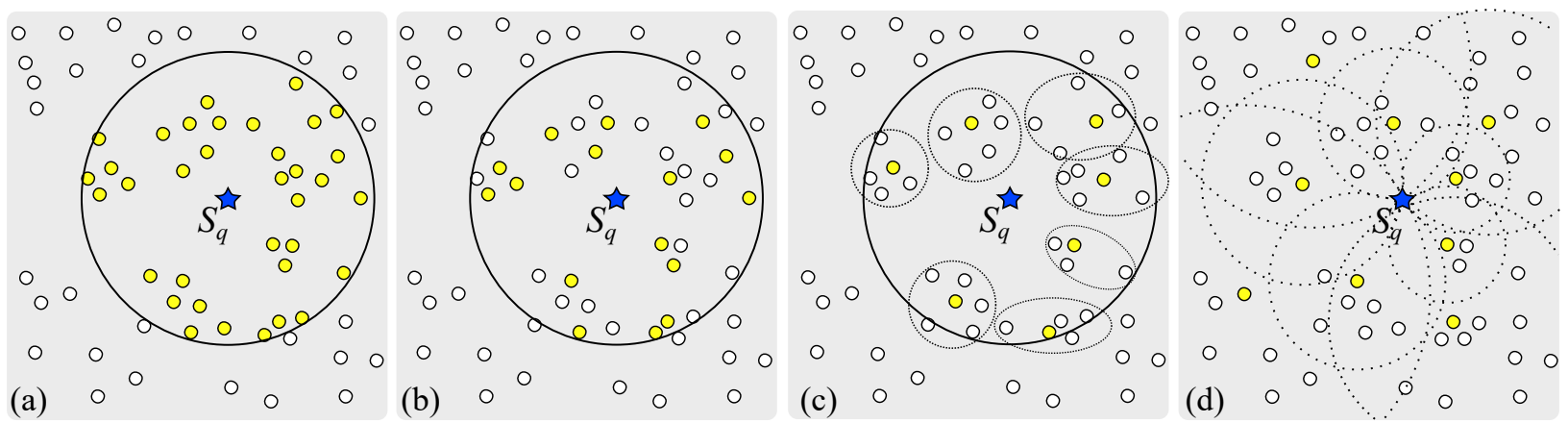

Figura 6.2: Representação dos diferentes conjuntos de candidatos gerados na fase de filtragem de candidatos (a) $k$-NN, (b) Rnd, (c) CLT e (d) BRID .

para a construção do conjunto de candidatos, possibilitando combinar duas definições de diversidade em um único algoritmo de diversificação de resultados. Neste sentido, o custo total da fase de computação de diversidade foi dividida com a fase de filtragem de candidatos, permitindo que a fase de computação atue como uma fase de refinamento de diversidade.

A Figura 6.2 ilustra os diferentes conjuntos de resultados para um mesmo elemento central de busca $s_{q}$ (representado por uma estrela). A técnica tradicional de $k$-NN (Figura 6.2 (a)) reduz a cardinalidade em relação ao conjunto original, recuperando apenas os pontos amarelos com relação ao elemento $s_{q}$. A técnica Rnd (Figura 6.2 (b)) também utiliza a restrição de similaridade máxima, recuperando menos elementos que o $k-\mathrm{NN}$, porém não há garantia que os elementos estão distantes uns dos outros, diferente da técnica CLT (Figura 6.2 (c)) em que apenas um elemento é escolhido de cada grupo. Além disso, tanto Rnd quanto CLT requer a definição do raio de busca, que o $k$-NN obtém a partir da quantidade $k$ que, esta sim, deve ser fornecida. $B R I D_{r}$ é o único que não requer nenhum parâmetro. Como pode ser visto na Figura $6.2(\mathrm{~d})$, a técnica $B R I D_{r}$ foi a única aplicada diretamente no conjunto original e, mesmo sem qualquer restrição de similaridade, manteve os elementos próximos da área que foi delimitada pelas outra técnicas.

\subsection{Experimentos}

Esta seção apresenta os resultados experimentais que avaliam as técnicas para a fase de filtragem de candidatos propostas neste capítulo para fornecer conjuntos de candidatos aos algoritmos de diversificação. A técnica tradicional de $k$-NN foi considerada como base para as comparações das técnicas desenvolvidas, pois é ela que é usada pelas técnicas disponíveis na literatura. Além disso, foram considerados algoritmos com diferentes abordagens de construção de resultados para avaliar o impacto da mudança na técnica de filtragem. Os seguintes algoritmos foram implementados: Greedy Randomized With Neighborhood Expansion (GNE), Greedy Marginal Contribution (GMC), Maximal Marginal Relevance (MMR), Max-Sum Dispersion (MSD) e SWAP.

Os experimentos visam avaliar o balanceamento (trade-off) entre o desempenho e a qualidade dos resultados da fase de filtragem de candidatos quando diferentes técnicas de construção de conjunto de candidatos são utilizadas. 


\subsubsection{Conjuntos de Dados}

Foram executados experimentos sobre as técnicas de filtragem propostas e comparadas sobre dois conjuntos de dados reais: U.S Cities and Aloi. Outros experimentos foram executados, porém como os conjuntos de dados possuíam características similares os resultados serão omitidos por não apresentarem evidências diferentes das que serão discutidas. O conjunto de dados U.S Cities consiste em coordenadas geográficas e características econômicas de 25.375 cidades americanas, obtido do sítio U.S. Census Bureau ${ }^{1}$. Os elementos do conjunto U.S Cities foram comparados utilizando a distância Euclideana $\left(L_{2}\right)$ para ambas as funções de distância, $\delta_{\text {sim }}$ e $\delta_{d i v}$, sobre as coordenadas geográficas de latitude e longitude. O conjunto de dados Aloi (Amsterdam Library of Object Images) consiste em 72.000 imagens coloridas de objetos rotacionados no plano a cada 5 graus, composto por 1.000 objetos, obtido do sítio Amsterdam Library of Object Images ${ }^{2}$. Cada imagem foi representada por um vetor de característica com 144 dimensões que sumarizam as informações de cores do conteúdo da imagem. Os vetores foram comparados utilizando a distância Euclideana $\left(L_{2}\right)$ tanto para $\delta_{\text {sim }}$ quanto $\delta_{\text {div }}$.

Foram consideradas duas estratégias para avaliar o impacto da fase de filtragem de candidatos: (i) medindo o tempo necessário para executar as buscas de similaridade com diversidade sobre os conjuntos de candidatos gerados pelas técnicas $k$-NN, Rnd, CLT e BRID; (ii) medindo a qualidade da diversificação do conjunto de resultado final utilizando cada uma das técnicas por meio da métrica de avaliação de função objetivo (apresentada na Seção 3.4). A avaliação por meio da função objetivo possibilita quantificar a maximização do conjunto de resultado com base na função objetivo de diversidade utilizada por cada método. Assim, para ter um valor de referência padrão, nós utilizamos a mesma função objetivo de diversidade em todos os algoritmos avaliados e utilizamos os resultados da técnica $k$-NN como base de comparação. Por exemplo, considere dois algoritmos $A$ e $B$, o algoritmo $B$ é considerado melhor que o algoritmo $A$ se $\mathcal{F}_{B}$ é maior que $\mathcal{F}_{A}$, independente da técnica utilizada na fase de filtragem de candidatos.

Por fim, os experimentos foram executados em um computador com a seguinte configuração: processador Intel ${ }^{\circledR}$ Core $^{\mathrm{TM}}$ i7-4770 com 8 GB de memória RAM. O sistema operacional utilizado foi a distribuição GNU Linux Ubuntu 11.10. Toda as técnicas e os algoritmos foram implementados na mesma plataforma de avaliação utilizando a linguagem $\mathrm{C}++$, garantindo comparações justas entre os competidores.

\subsubsection{Avaliação de Desempenho}

O conjunto de experimentos realizados envolveu a análise de desempenho em relação ao tempo de execução dos algoritmos utilizando os conjuntos de candidatos gerados pelas técnicas propostas. Para cada conjunto de dados, foram realizadas escolhas aleatórias de elementos distintos para a composição de um conjunto de testes com 100 elementos de busca. Além disso, para cada busca de teste a quantidade de elementos diversos a serem recuperados foi definida em $k=5$.

\footnotetext{
${ }^{1}$ U.S. Census Bureau Homepage - American Census 2000. Último acesso em: 11 de Setembro de 2014. Disponível em: <http://www.census.gov/>

${ }^{2}$ Amsterdam Library of Object Images Homepage. Último acesso em: 25 de Maio de 2016. Disponível em: $<$ http://staff.science.uva.nl/ aloi/>
} 


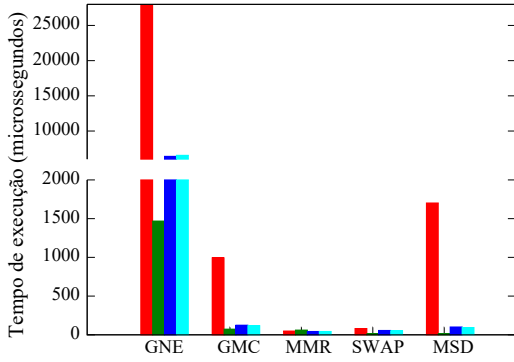

(a) Espaço de busca $=400$

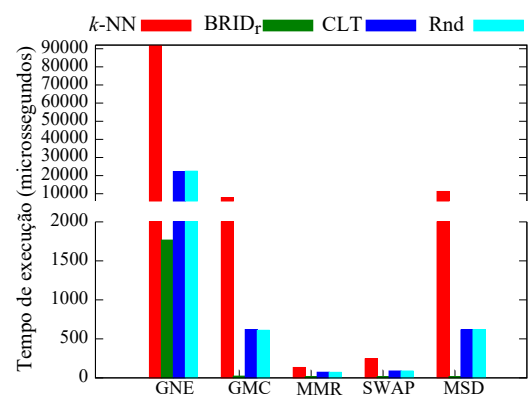

(b) Espaço de busca $=1200$

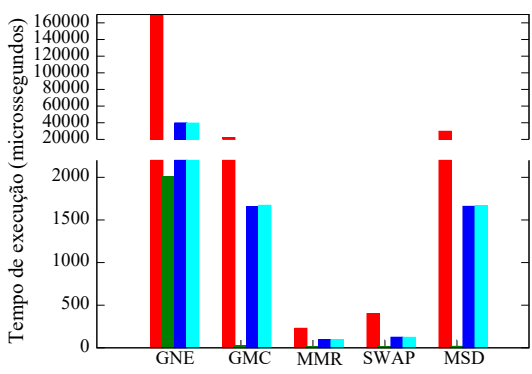

(c) Espaço de busca $=2000$

Figura 6.3: Tempo de execução da fase de computação de diversidade em relação a cada técnica de filtragem no conjunto de dados U.S Cities. Valores próximos da base indicam melhores técnicas de filtragem.

As Figuras 6.3 e 6.4 apresentam os resultados para o tempo médio de execução em microssegundos para a execução da fase de computação de diversidade quando o espaço de busca varia entre 400 e 2.000 elementos com incrementos de 800 elementos para os conjuntos de dados testados. Por exemplo, um espaço de busca com 400 elementos, todas as técnicas de filtragem de candidatos devem obter um conjunto de candidatos com 400 elementos em relação ao elemento central de busca, sendo que a técnica $k$-NN recupera os 400 vizinhos mais próximos. Como as técnica $C L T$ e $R n d$ requisitam a definição de um parâmetro adicional $p$ para, respectivamente, ajustar o número de grupos e elementos selecionados aleatoriamente para cada busca, foram realizadas várias execuções do mesmo conjunto de testes para valores distintos de $p$ que teve os valores no intervalo de $25 \%$ até $75 \%$ do número total de elementos do espaço de busca com incrementos de $10 \%$. Ao final, foram escolhidos os valores de $p$ que apresentaram o melhor balanceamento (trade-off) entre a qualidade do conjunto e o tempo de execução. Em todos os experimentos, utilizou-se o valor de $p$ como $\{100,300,500\}$ para a técnica $C L T$ e para o $R n d\{150,660,900\}$.

As Figuras 6.3 mostram os tempos de execução para o conjunto de dados U.S Cities. A Figura 6.3(a) mostra que, com exceção do MMR, todos os algoritmos foram mais rápidos utilizando qualquer uma das técnicas propostas para a fase de filtragem de candidatos quando comparado com a técnica tradicional dos vizinhos mais próximos $(k-\mathrm{NN})$. Por exemplo, o tempo de execução da fase de computação de diversidade do algoritmo GNE foi reduzido em 16 vezes com a utilização da técnica $\mathrm{BRID}_{r}$ para o espaço de busca com 400 elementos e reduziu em até 70 vezes o tempo para o espaço de busca com 2.000 elementos. É interessante constatar que o algoritmo MSD obteve o segundo pior tempo de execução na fase de computação de diversidade com a utilização da técnica $k$-NN, porém com a substituição da fase de filtragem para $\mathrm{BRID}_{r}$, o MSD se tornou o algoritmo mais rápido.

As Figuras 6.3(b) e 6.3(c) mostram que, à medida que o espaço de busca aumenta, cada algoritmo continua se beneficiando com o uso das estratégias de filtragem de candidatos. A redução proporcionada permite que conjuntos de dados muito maiores possam ser submetidos a buscas por similaridade com diversidade, habilitando que sejam de fato usadas em big data. É importante ressaltar que $\mathrm{BRID}_{r}$ foi a técnica que mais reduziu o tempo de execução da fase de computação de diversidade para cada algoritmo avaliado. Isso ocorre devido ao fato que a busca por abrangência diversificada com ajuste adaptável de distância de separação seleciona apenas elementos que não são influenciados por outros no espaço de busca, realizando podas em regiões que já possuem um candidato selecionado, de maneira distinta 


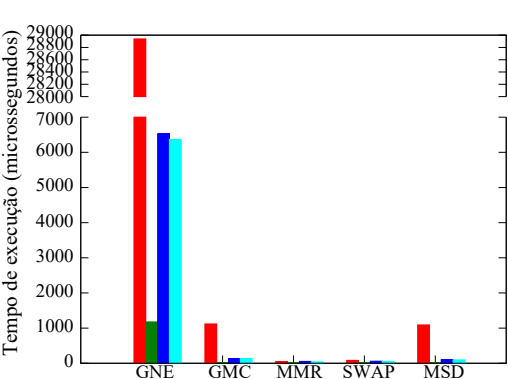

(a) Espaço de busca $=400$

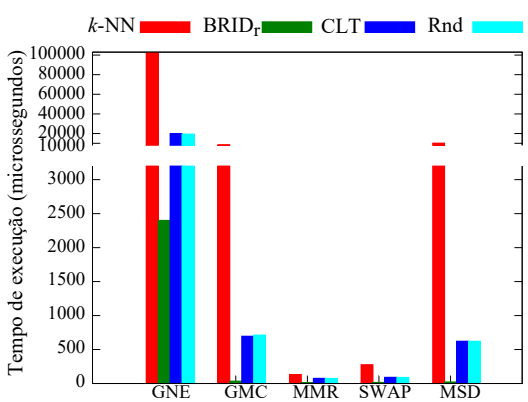

(b) Espaço de busca $=1200$

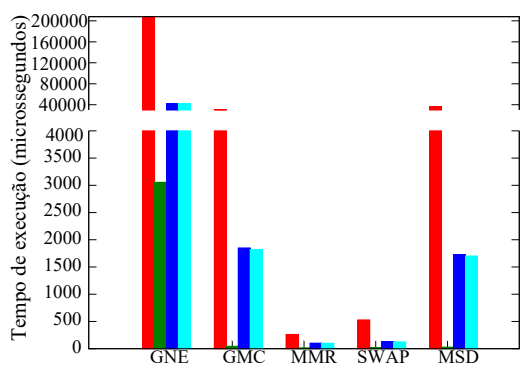

(c) Espaço de busca $=2000$

Figura 6.4: Tempo de execução da fase de computação de diversidade em relação cada técnica de filtragem no conjunto de dados Aloi. Valores próximos da base indicam melhores técnicas de filtragem.

das outras estratégias, as quais selecionam uma quantidade de elementos pré-determinada, sem realizar exclusão de regiões que já possuem elementos.

As Figuras 6.4(a) até 6.4(c) mostram o tempo de execução da fase de computação de diversidade para o conjunto de dados Aloi. O objetivo foi avaliar as técnicas de filtragem de candidatos em relação a dados de alta dimensionalidade. Como já era esperado, o custo da fase de computação de diversidade aumentou consideravelmente, pois houve também aumento no custo no cálculo de distância. No entanto, todos os algoritmos continuaram se beneficiando dos conjuntos de candidatos gerados pelas técnicas propostas, independentemente do tamanho do espaço de busca, como pode ser visto na Figura 6.4.

A Figura 6.5 apresenta os resultados para o tempo médio total de execução (considerando as duas fases de diversificação: filtragem de candidatos e computação de diversidade) para um espaço de busca com 1.200 elementos para os conjuntos de dados avaliados. A Figura 6.5(a) revela que a técnica $C L T$ aumentou o tempo total de execução dos algoritmos em seis vezes quando comparado com o $k$-NN, mostrando que a utilização de uma técnica com custo computacional mais alto na primeira fase pode até reduzir o custo computacional para a segunda fase do processo de diversificação, porém não será o suficiente para reduzir o tempo total de processamento da busca. Além disso, apesar da técnica Rnd ser mais rápida que $\mathrm{BRID}_{r}$ na fase de filtragem de candidatos, Rnd requisita a execução de várias buscas para encontrar o número adequado de elementos no conjunto candidato, o que nos experimentos sempre levou a um número maior do que os obtidos pela técnica $\mathrm{BRID}_{r}$, ocorrendo um

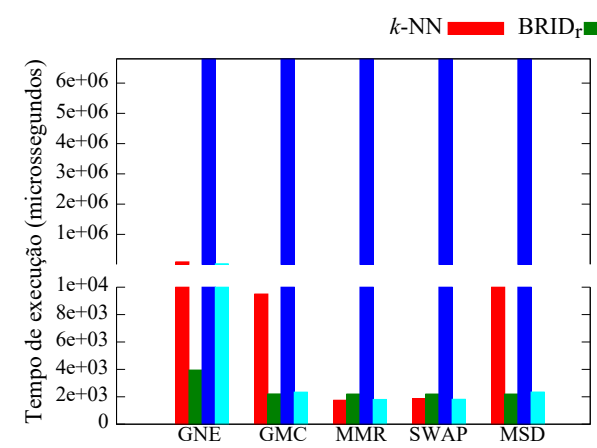

(a) Tempo total de execução: U.S Cities

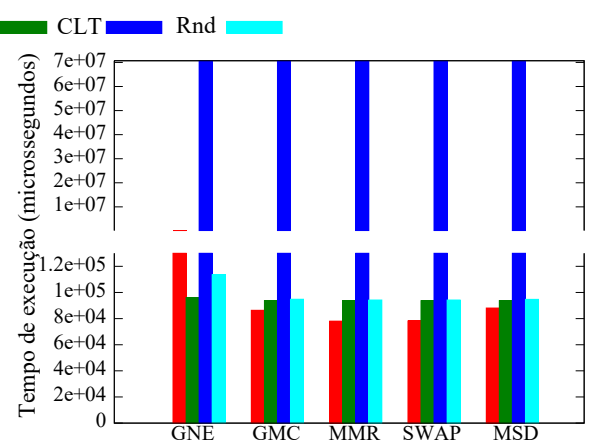

(b) Tempo total de execução: Aloi

Figura 6.5: Tempo total de execução total para diversificação de resultados. Fase de filtragem de candidatos + fase de computação de diversidade, (a) conjunto U.S Cities e (b) conjunto Aloi. 
empate técnico entre as duas técnicas dependendo do algoritmo avaliado. Por exemplo, Rnd tornou o algoritmo MMR até $10 \%$ mais rápido do que a versão original utilizando a técnica $k$-NN. Em outra situação, o algoritmo GNE foi uma ordem de magnitude mais eficiente do que o $k$-NN. Os resultados da Figura 6.5(b) ilustram os resultados para o conjunto de dados Aloi, revelando que o tempo total de execução dos algoritmos utilizando a técnica $C L T$ se torna proibitivo, aumentando em até três ordens de magnitude o tempo médio necessário para apresentar uma resposta diversificada. Ainda na mesma figura, é possível ver que o o algoritmo GNE, conhecido na literatura por apresentar respostas de alta qualidade, porém com alto custo computacional, foi o algoritmo que mais se beneficiou da fase de filtragem com $\mathrm{BRID}_{r}$, apresentando tempo de execução próximos dos algoritmos MMR e MSD.

Os resultados experimentais apresentados nesta seção indicam que uma técnica de filtragem mais elaborada pode melhorar o desempenho dos algoritmos de diversificação em relação a estratégia comumente utilizada de $k$-NN. A utilização da busca por abrangência diversificada como técnica de filtragem $\left(\mathrm{BRID}_{r}\right)$ possibilitou reduzir o tempo de execução do algoritmo mais lento em ordens de magnitude A combinação da amostragem de influência obtida por BRID permite diminuir o tempo de execução do algoritmo mais lento em ordens de magnitude, enquanto a técnica ingênua Rnd diminuiu o tempo de execução do algoritmo mais rápido em quase $10 \%$.

\subsubsection{Avaliação de Qualidade de Diversificação}

Visando avaliar a qualidade da resposta final dos algoritmos de diversificação, foram calculados os valores da função objetivo $\mathcal{F}$ para a técnica de filtragem proposta, bem como para a versão tradicional $k$-NN. Seguindo o mesmo protocolo do experimento anterior, para cada conjunto de dados foram escolhidos 100 elementos de forma aleatória para compor um conjunto de testes e as buscas foram executadas com $k=5$. O parâmetro de preferência de diversidade dos algoritmos $(\lambda)$ foi variado a partir de 0.1 (baixa diversidade) até 0.5 (similaridade e diversidade balanceadas) em incrementos de 0.2 .

A Figura 6.6 apresenta os resultados para o conjunto de dados U.S Cities. Como pode ser percebido, cada algoritmo obteve o mesmo valor para a função objetivo, mesmo utilizando as novas técnicas de filtragem, indicando que a substituição do algoritmo de $k$-NN na fase de filtragem não apresentou redução na qualidade das respostas. É importante destacar

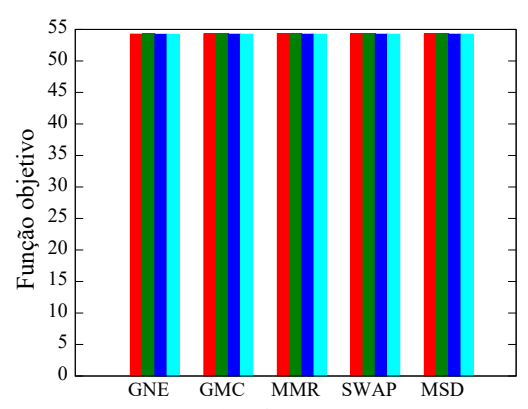

(a) $\lambda=0.1$

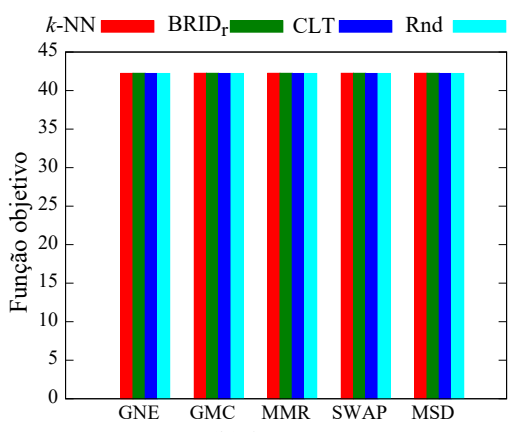

(b) $\lambda=0.3$

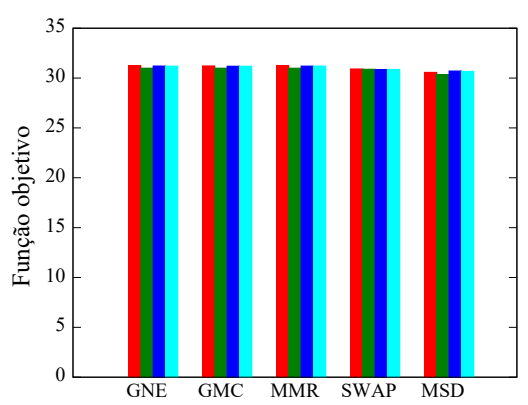

(c) $\lambda=0.5$

Figura 6.6: Qualidade de diversificação dos algoritmos para as estratégias de filtragem de candidatos quando a preferência de diversidade ( $\lambda$ ) é incrementada no conjunto de dados U.S Cities. Valores mais próximos do topo indicam melhores resultados. 


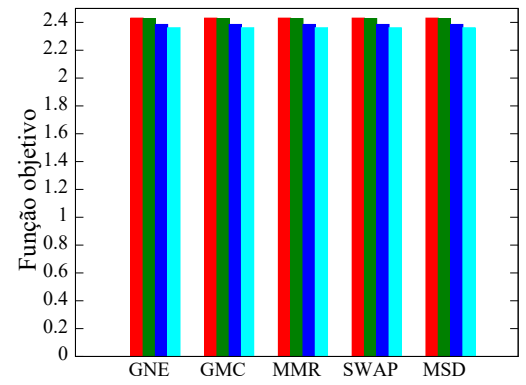

(a) $\lambda=0.1$

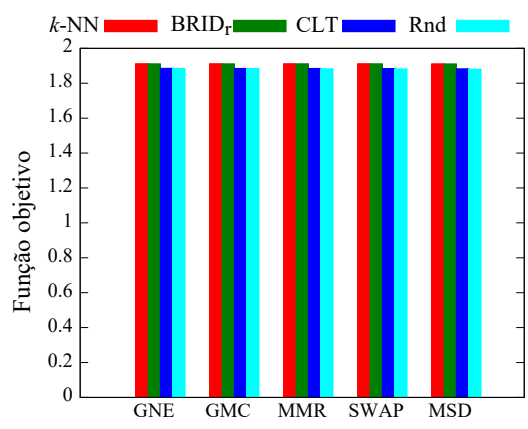

(b) $\lambda=0.3$

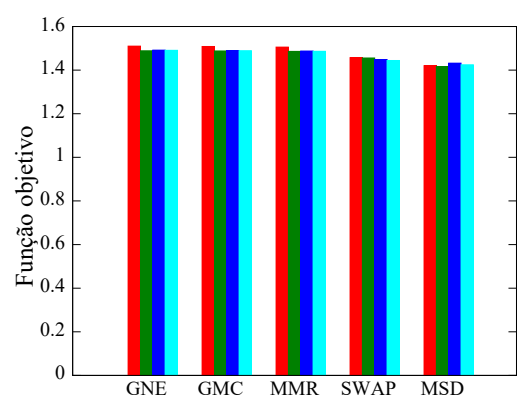

(c) $\lambda=0.5$

Figura 6.7: Qualidade de diversificação dos algoritmos para as estratégias de filtragem de candidatos quando a preferência de diversidade $(\lambda)$ é incrementada no conjunto de dados Aloi.

que, mesmo, a técnica $\mathrm{BRID}_{r}$ tenha selecionado em média apenas 6.8\% (78 elementos) do número total de elementos do espaço de busca, não houve qualquer prejuízo à qualidade final da resposta. A Figura 6.6(c) mostra que mesmo com o aumento da participação da diversidade $(\lambda=0.5)$, a qualidade se manteve inalterada, sendo que a maior diferença de técnica de filtragem ao resultado do $k$-NN foi em até $2 \%\left(\mathrm{BRID}_{r}\right)$, enquanto $C L T$ e Rnd apresentaram praticamente os mesmos valores que o $k$-NN.

A Figura 6.7 mostra os resultados para o conjunto de dados Aloi. Com o aumento da dimensionalidade do conjunto, apenas a técnica $\mathrm{BRID}_{r}$ alcançou os mesmos resultados de qualidade que a técnica $k$-NN. É importante destacar que a técnica Rnd apresentou, novamente, os menores valores de qualidade, porém os resultados foram em média apenas $1 \%$ menores que os da técnica $k$-NN. Além disso, todas as estratégias de filtragem obtiveram os mesmos resultados quando a preferência de diversidade é balanceada (Figura 6.7(c)).

\subsection{Considerações Finais}

Este capítulo mostrou a importância que a fase de filtragem de candidatos possui nos algoritmos que modelam a propriedade de diversidade como um problema de otimização combinatória, tanto na qualidade quanto no tempo de execução. Foram apresentadas técnicas para a criação de um conjunto de candidatos com base nos conceitos de seleção aleatória de elementos, algoritmos de agrupamento de dados e no conceito de influência definido nesta tese. O objetivo das técnicas propostas foi aumentar a qualidade dos elementos escolhidos como candidatos para reduzir a quantidade de elementos necessários para a fase de computação de diversidade. A intuição é que se apenas elementos representativos de cada vizinhança são escolhidos como candidatos, é possível reduzir o número de comparações necessárias para escolher os elementos diversos de um centro de busca. Foi apresentada uma plataforma de avaliação para validar as técnicas propostas. Os resultados experimentais utilizando conjunto de dados reais confirmaram que a mudança de técnica na fase de filtragem é capaz de tornar os algoritmos mais eficientes, sem comprometer a qualidade dos resultados. Em especial, a técnica $\mathrm{BRID}_{r}$ baseada na busca por abrangência diversificada reduziu em até 70 vezes o tempo de execução do algoritmo mais custoso testado (GNE), reduzindo em duas ordens de magnitude o tempo total de execução, tornando a execução do GNE similar a dos algoritmos mais eficientes MMR. Portanto, os resultados mostram como as buscas por abrangência diversificada podem ser utilizadas para realizar amostragem do conjunto de dados, inclusive 
para realizar a composição de conceitos de diversidade em uma única proposta. Os ganhos de tempo de execução, aliados à manutenção da qualidade tornam nossa contribuição apta a ser usada mesmo para conjuntos de dados de elevada cardinalidade.

O próximo capítulo apresenta uma técnica para recuperar os elementos considerados representativos para as buscas por similaridade e, ao mesmo tempo, realizar o agrupamento relativo dos elementos considerados muito similares entre si, visando reduzir o esforço de navegação nos resultados dos sistemas de recuperação de imagem por conteúdo. A técnica é baseada no conceito de influência e possibilitou a realização de agrupamentos locais que aumentam a quantidade de informação disponível para análise, reduzindo a necessidade de refinamento nas buscas sem poluir a tela dos sistemas com resultados que não trazem informações novas. 


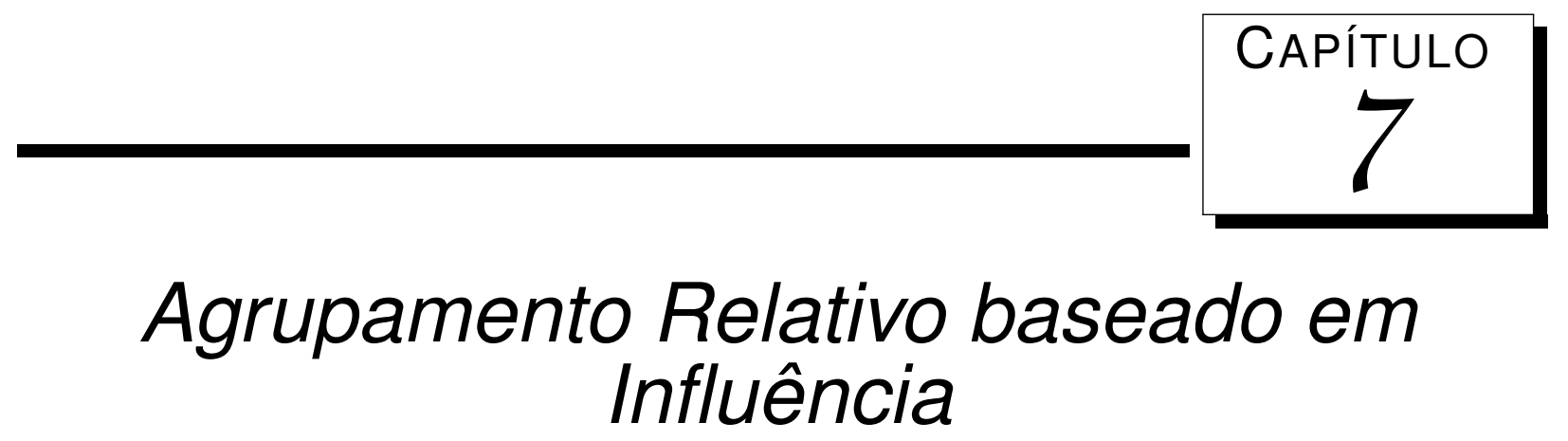

A recuperação automática de imagens similares tem sido estudada extensivamente em vários domínios de aplicação, como exemplo, na detecção de objetos, reconhecimento facial, prevenção de crimes, situações de emergência e em exames médicos baseados em imagens. Tipicamente, os estudos desenvolvidos utilizam o conteúdo extraído das imagens e os operadores de similaridade dos $k$-vizinhos mais próximos e por abrangência como atividades principais para definição das ferramentas de recuperação de imagem baseadas em conteúdo (CBIR).

Dessa maneira, os sistemas CBIR que utilizam os operadores fundamentais de similaridade retornam listas de imagens que, por muitas vezes, apresentam conjuntos de resultados muito similares entre si. Nos capítulos anteriores foi discutido como utilizar a diversidade para melhorar a qualidade dos resultados ao selecionar imagens que apresentam uma visão mais abrangente sobre o conjunto de dados. Contudo, existem casos em que é interessante não descartar as imagens muito similares, como exemplo, imagens de circuitos de segurança, exames médicos, situações de emergência. No caso de uma aplicação médica, radiologistas podem analisar novos casos considerando uma base de dados histórica com casos já resolvidos com anomalias similares ao caso atual, visando obter novas percepções e contribuições para acelerar o processo de diagnóstico. Neste aspecto, a recuperação de imagens muito similares a imagem de busca é importante para garantir ao especialista que o sistema está configurado e recuperando apenas os casos mais relevantes. Contudo, com o aumento dos casos armazenados, torna-se possível que o especialista tenha que lidar com centenas de imagens com anomalias similares ao caso de interesse. Assim, o especialista precisa navegar por longas listas de resultado até encontrar as imagens que realmente o auxiliam no diagnóstico do novo caso, o que pode ser um processo longo, cansativo e que muitas vezes desestimula o uso das ferramentas CBIR. Por exemplo, a Figura 7.1 (a) ilustra a resposta para uma busca em um espaço Euclideano aos cinco casos mais similares ao caso de busca (representado pela estrela) e os quadrados representam os casos retornados. Como pode ser visto, o usuário recebe dois casos similares a outros retornados, porém para navegar por todos os casos mais próximos é necessário re-submeter a busca aumentando a quantidade de casos retornados.

As abordagens de diversificação de resultados podem aumentar a relevância dos resultados obtidos ao selecionar apenas os casos que sejam considerados similares ao caso atual e, ao 


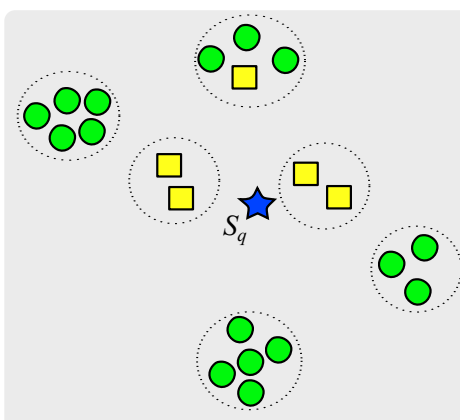

(a)

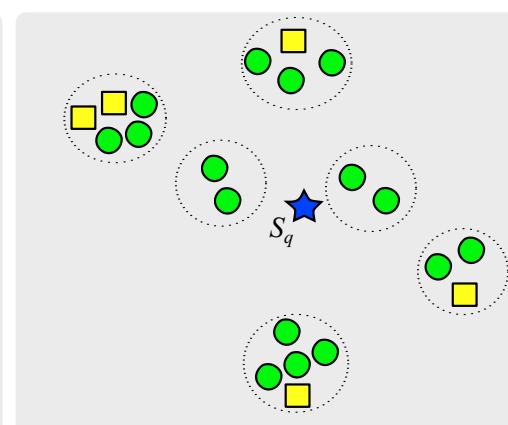

(b)

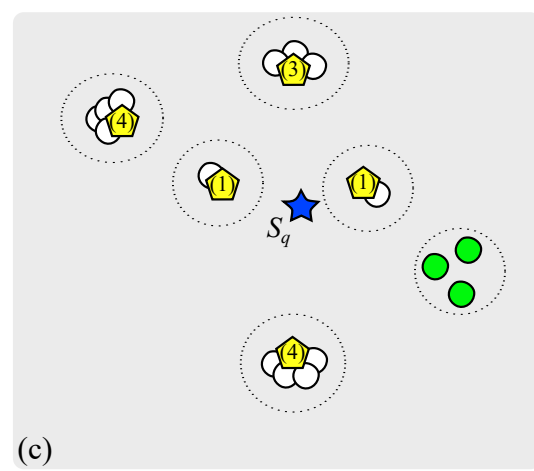

Figura 7.1: Seleção dos elementos para uma busca por similaridade em um espaço Euclideano de duas dimensões. Quadrados são os elementos selecionados. (a) Resultado para uma busca utilizando o algoritmo $k$-NN para o elemento $s_{q}$. (b) Resultado utilizando um algoritmo de diversificação de resultado, elementos são escolhidos para apresentar uma visão heterogênea para o elemento de busca, porém excluindo outros elementos. (c) Resultado para nossa proposta de agrupamento relativo baseado na influência dos elementos: elementos representativos (pentágonos) e os elementos considerados muito similares (círculos).

mesmo tempo, garantido que os mesmos apresentem uma visão heterogênea da vizinhança dos casos similares (Figura 7.1 (b)). No entanto, os algoritmos de diversificação constroem os resultados descartando os elementos muito similares aos já selecionados, o que pode se tornar um problema em um ambiente de análise médica, pois qualquer das imagens pode ser útil para o especialista, sendo importante mantê-las disponíveis de maneira eficiente e eficaz.

Neste capítulo será explorado como a diversidade baseada em influência pode pode ser utilizada para criar agrupamentos relativos de elementos muito similares, recuperando mais informações para o especialista desde a primeira busca submetida ao sistema (como é ilustrado na Figura 7.1(c)). Além disso, o usuário pode visualizar e navegar iterativamente pelos grupos de elementos muitos similares, começando por um elemento representativo, acelerando o processo de navegação e análise de um espaço de busca.

Em resumo, este capítulo apresenta as seguintes contribuições:

- Uma técnica para agrupar elementos muito similares, chamada de Relative Grouping based on Influence - ReGI;

- Uma heurística para ajustar a influência dos elementos para garantir o contexto de similaridade das buscas em domínios médicos;

- Um estudo de caso em imagens de ressonância magnética e a comparação experimental da nova técnica de agrupamento em conjuntos de dados reais. Os resultados experimentais atestam que a técnica é duas ordens de magnitude mais rápida para agrupar elementos e aumenta a qualidade das resposta em até $40 \%$.

O restante deste capítulo é estruturado da seguinte maneira. Seção 7.1 apresenta a técnica ReGI para agrupamento de elementos muito similares e a heurística para ajuste de influência. A Seção 7.2 apresenta os resultados experimentais realizados para avaliar as técnica de agrupamento e um estudo de caso em imagens de domínio médico. Por fim, a Seção 7.3 apresenta as considerações finais deste capítulo. 


\subsection{ReGI: Agrupamento relativo baseado em Influên- cia}

A técnica de agrupamento relativo baseado em influência (Relative Grouping based on Influence - ReGI) tem por objetivo recuperar os elementos similares a um elemento central de busca que estejam separados por uma distância mínima de separação e agrupar os elementos que sejam considerados muito similares a outro já inserido na resposta. A definição dos grupos é realizada de acordo com a influência dos elementos representativos escolhidos e com a posição relativa dos elementos no espaço de busca, criando uma maneira de sumarizar uma região do espaço de busca considerando um elemento central de busca. Os elementos agrupados são ordenados em relação ao elemento representativo para garantir uma visão hierárquica daqueles considerados muito similares. Além disso, o agrupamento desses elementos muito similares no conjunto resultado pode ser interessante por causa de outros dados associados a eles, por exemplo, outros metadados. Desse modo, ReGI define uma maneira inteligente de agrupar e exibir os resultados, evitando que longas listas de resultados sejam retornadas aos especialistas de aplicações. Assim, procura-se apresentar inicialmente uma visão sumarizada dos elementos, sem eliminar o restante dos elementos muito similares, apresentando o comportamento esperado para aplicações que precisam recuperar elementos em grandes volumes de dados.

ReGI é construído a partir do conceito de diversificação de elementos baseado em influência (apresentado no capítulo 4) para selecionar os elementos dominantes (representativos) em relação ao elemento central de busca. O conceito de influência possibilita induzir a diversidade de modo transparente, reduzindo a quantidade de parâmetros que precisam ser ajustados em uma busca ao mesmo tempo que viabiliza tratar e apresentar uma fração dos dados. Antes de apresentar o algoritmo desenvolvido, vamos apresentar a heurística limite de contexto (Context-Boundary - CB) para controlar e restringir o crescimento da influência dos elementos no espaço de busca.

Os algoritmos de diversificação que analisam vários elementos para induzir a diversidade em uma busca possuem dois pontos a serem considerados para o domínio de aplicação médica: 1) A dificuldade de manter o espaço de busca no contexto dos elementos mais similares ao elemento de busca, isto é, evitar a escolha de elementos apenas nas regiões extremas do conjunto de dados (Figura 7.1 (b)), e 2) manter um tempo aceitável de recuperação dos elementos (o custo computacional). O primeiro ponto está relacionado com a semântica dos elementos retornados, pois elementos muito diferentes do centro de busca podem induzir os especialistas a pensarem que o sistema mal interpretou a busca submetida. O segundo ponto está relacionado a aceitabilidade do sistema, pois o tempo de um especialista é muito valioso para esperar por minutos para receber um resultado que talvez precise ser re-submetido ao sistema.

Para lidar com esses pontos, é possível considerar que existe um limite máximo para o contexto (Definição 20) do elemento de busca, evitando que elementos mais afastados que uma distância $\xi_{\max }$ participem da resposta final. Abordagens equivalentes são utilizadas pelos algoritmos apresentados nos capítulos 3 e 6 para reduzir o custo computacional e definir uma região de interesse para os elementos na busca. No entanto, a correta definição para um $\xi_{\max }$ deve feita para cada elemento de busca, tornando difícil que ele seja parametrizado por profissionais para utilização em aplicações com grande volume de dados. 


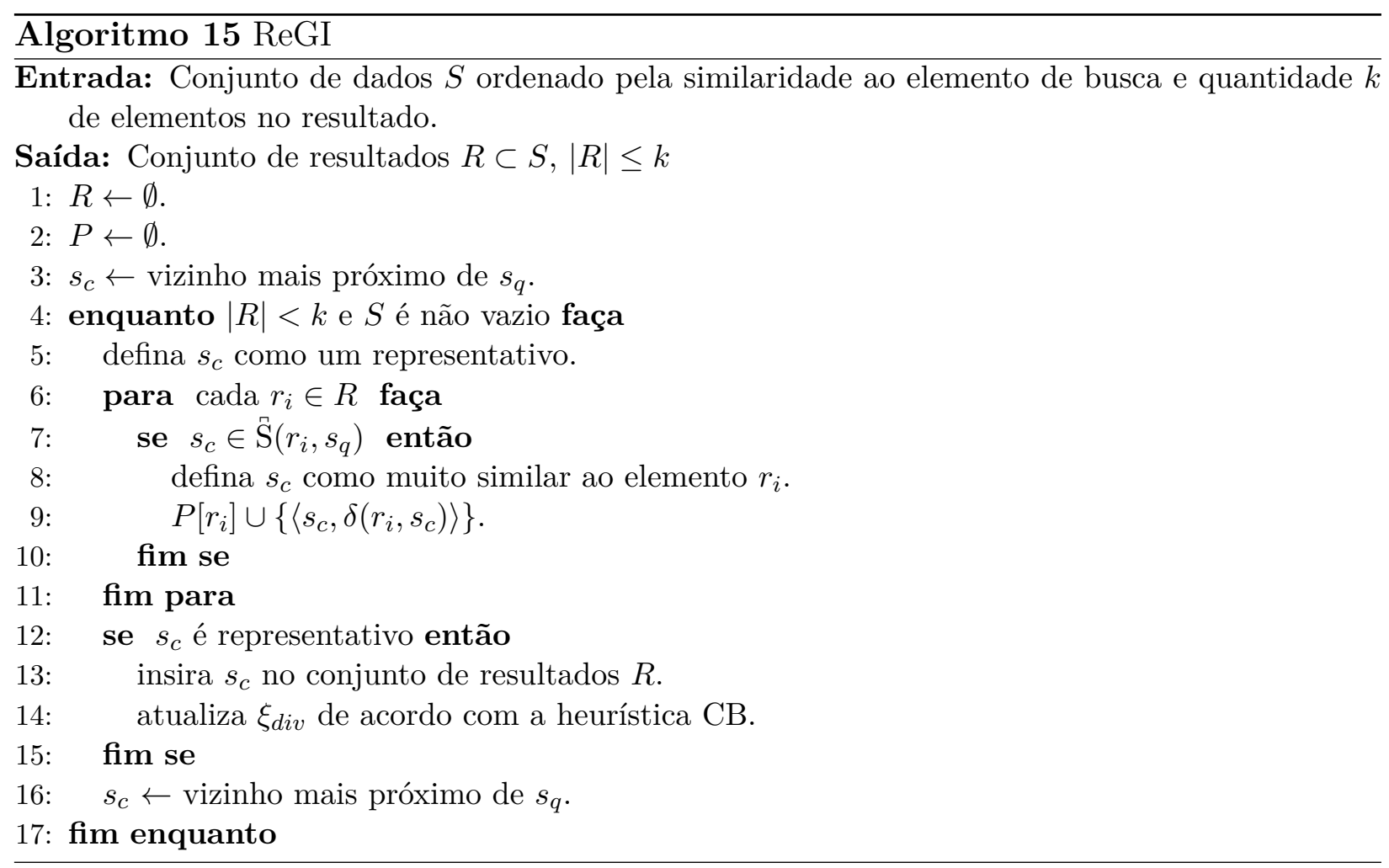

Definição 20. Limite Máximo de Contexto(LMC): Dado um domínio de dados $\mathbb{S}$, um conjunto de dados $S \in \mathbb{S}$, um elemento central de busca $s_{q} \in \mathbb{S}$, uma distância $\xi_{\text {max }}$, $\xi_{\text {max }} \in \mathbb{R}$ e uma função de distância $\delta$, os elementos mais similares ao elemento $s_{q}$ estão no subconjunto $S^{\prime} \subset S \mid \forall s_{j} \in S^{\prime}, \delta\left(s_{j}, s_{q}\right) \leq \xi_{\max }$.

Assim, para reduzir o esforço de definição de um limite máximo de contexto, a heurística Context-Boundary se baseia no conceito de influência, utilizando o posicionamento relativo dos elementos para definir a área de interesse da busca, se adaptando a distribuição de distância dos elementos no espaço de busca sem requisitar qualquer informação ao usuário. Inicialmente, a influência de um elemento é definida como zero, possibilitando a escolha do elemento mais similar ao elemento de busca. A distância do primeiro elemento ao $s_{q}$ é utilizada para definir o tamanho do grupo dos elementos muito similares, gerando a área de influência $\xi_{d i v_{1}}=\delta\left(s_{1}, s_{q}\right)$. Em sua definição original (Seção 4.2), a influência dos elementos aumenta com a distância para o elemento central de busca. Contudo, para evitar a situação que poucos elementos representem o entorno do elemento central de busca, a próxima área de influência definida por um elemento inserido no conjunto de resposta é definida pela Equação 7.1.

$$
\xi_{d i v_{i}}=\frac{1}{i} \sum_{u=1}^{i} \delta\left(s_{u}, s_{q}\right)
$$

É importante ressaltar que o controle da expansão de influência no espaço de busca possibilita a definição de um espaço de busca focado nos elementos ao redor de $s_{q}$ sem requisitar qualquer parâmetro de restrição de espaço. Tal comportamento é possível porque a busca se ajusta de acordo com o posicionamento dos elementos e pela quantidade de elementos no conjunto de resultados, tornando o método adequado para aplicações em áreas onde os profissionais não precisam configurar os parâmetros de busca, tal como a área médica. 
A técnica Relative Grouping based on Influence (ReGI) constrói o conjunto de resultados de maneira incremental, selecionando os elementos representativos (elementos que não são muito similares de outros na resposta) para o agrupamento dos elementos no espaço de busca, como é apresentado pelo Algoritmo 15. O conjunto de resultado inicia-se vazio e a primeira área de influência $\left(\xi_{\text {div }}\right)$ também começa como zero. ReGI seleciona o elemento mais próximo do elemento central de busca (linhas 1-2). A cada iteração, o elemento $s_{c} \in S$ mais próximo do elemento de busca é definido como candidato a representativo do conjunto de resultado $R$ (linhas 3-5).

Em seguida, ReGI avalia se $s_{c}$ é muito similar (influenciado) por algum outro elemento $r_{i}$ que já faz parte do conjunto de resultado $R$. Se $\delta\left(s_{c}, s_{q}\right)>\delta\left(s_{c}, r_{i}\right)$, então $s_{c}$ é considerado muito similar pelo elemento $r_{i}$. Neste cenário, um elemento muito similar é considerado influenciado. Portanto, $s_{c}$ é marcado como muito similar ao $r_{i}$ e é inserido no grupo dos elementos muito similares de $r_{i}$ (linhas 5-10). Cada grupo é ordenado pela distância dos elementos ao seu representativo. Os grupos são representados como listas $P\left[r_{i}\right]$, tal que $P\left[r_{i}\right]:\left\{s_{1}^{i}, s_{2}^{i}, s_{3}^{i}, \ldots s_{n}^{i}\right\} \mid \delta\left(s_{1}^{i}, s_{2}^{i}\right) \leq \delta\left(s_{1}^{i}, s_{3}^{i}\right) \leq \ldots \leq \delta\left(s_{1}^{i}, s_{n}^{i}\right)$. Os elementos representativos sumarizam o grupo dos elementos muito similares em relação a similaridade ao elemento central de busca.

A maioria dos algoritmos excluem os elementos muito similares, considerando que eles fornecem informações com baixo valor agregado. Isso ocorre devido a natureza das aplicações em que esses algoritmos são aplicados. Por outro lado, ReGI foi desenvolvido para atender aplicações em que cada elemento do espaço é necessário para a tarefa de análise, então os elementos agrupados para cada representativo ficam a disponíveis caso requisitados para evitar a submissão de uma nova busca por esses elementos. A operação de apresentar os elementos muito similares do grupo sem realizar uma nova busca é chamada de busca relativa.

Por outro lado, sempre que um candidato $s_{c}$ não faz parte de outro grupo de elementos muito similares em $R$, ele é inserido no conjunto de resultado como um representativo (linhas 12-14) e a influência é novamente ajustada de acordo com o posicionamento relativo e a quantidade de elementos no resultado, utilizando a heurística CB. Como exemplo, o elemento mais próximo de $s_{q}$ é sempre considerado o primeiro elemento representativo do conjunto e a sua distância ao elemento de busca é utilizada para definir o tamanho do grupo e a área de influência $\left(\xi_{d i v 1}=\delta\left(s_{1}, s_{q}\right)\right)$. Cada elemento $s_{j}$ no espaço de busca com similaridade $\delta\left(s_{j}, s_{1}\right) \leq \xi_{d i v 1}$ é atribuído ao grupo representado por $s_{1}$ e removido do espaço de busca. O próximo elemento representativo $r_{2}$ que não é muito similar para $s_{1}$ é inserido em $R$ e o $\xi_{\text {div } 2}$ é definido por $\left(\delta\left(s_{1}, s_{q}\right)+\delta\left(r_{2}, s_{q}\right)\right) / 2$. Tal processo se repete até que $k$ elementos representativos tenham sido recuperados ou o conjunto de dados $S$ fique vazio (linha 3 ).

A visão do especialista da aplicação no front-end de um CBIR é uma lista de resultados com $k$ elementos representativos, porém é possível navegar nos elementos agrupados de cada elemento representativo. Como ReGI já realizou o processamento dos elementos muito similares, esses são apresentados juntamente com qualquer outro metadado associado. É importante ressaltar que, ReGI facilita o processo de refinamento de busca, pois por meio da busca relativa é possível realizar o deslocamento do espaço de busca pela escolha de um novo elemento central de busca. 


\section{$7.2 \quad$ Experimentos}

Esta seção apresenta os resultados experimentais que avaliam a técnica ReGI quando comparada com o algoritmo tradicional de $k$-NN, o algoritmo de diversificação baseado no algoritmo de agrupamento de dados $k$-medoide (CLT), o algoritmo Greedy Randomized With Neighborhood Expansion (GNE) e o algoritmo de diversidade específico para dados em domínios médicos (OPT). O algoritmo CLT utiliza um conceito similar ao do ReGI, pois agrupa os elementos muito similares e retorna um conjunto de elementos representativos. Foram utilizados sete conjuntos de dados reais, sendo dois específicos do domínio médico para um caso de estudo, todos sumarizados na Tabela 7.1. Para cada conjunto de dados, a tabela indica o seu nome, cardinalidade do conjuntos (Nro. de elementos), número de Dimensões e as funções de distância utilizadas $(\delta)$, seguidos de uma breve descrição e a fonte de obtenção dos dados.

Tabela 7.1: Estatísticas dos conjuntos de dados

\begin{tabular}{|c|c|}
\hline Conjunto de dados & Nro. de elementos \\
\hline Aloi & $\begin{array}{l}72.000 \quad 144 \quad L_{2} \\
\text { Conjunto de imagens coloridas rotacionadas no plano a cada } 5 \\
\text { graus, composto por } 1.000 \text { objetos, obtido do sítio Amsterdam } \\
\text { Library of Object Images }{ }^{1} \text {. }\end{array}$ \\
\hline Colors & $\begin{array}{l}112.682 \quad 112 \quad L_{2} \\
\text { Conjunto de vetores de características extraídos de imagens co- } \\
\text { loridas. Fonte:Biblioteca de espaco } \text { Métrico }^{2} \text {. }\end{array}$ \\
\hline Faces & $\begin{array}{l}1.016 \quad L_{1} \\
\text { Conjunto de vetores de características extraídos de imagens de } \\
\text { faces humanas. Fonte:Biblioteca de espaço Métrico }{ }^{2} \text {. }\end{array}$ \\
\hline Fire & $\begin{array}{l}27216 \quad L_{2} \\
\text { Conjunto de fotos de incidentes de incêndio. As imagens foram } \\
\text { obtidas a partir de simulações de situação de emergência, reali- } \\
\text { zadas em um Complexo Industrial pelo projeto Rescuer }{ }^{3} \text {. }\end{array}$ \\
\hline ImageCLEFmed & $\begin{array}{l}5.042 \quad 310 \quad L_{1} \\
\text { Conjunto de imagens biomédicas de } 32 \text { categorias disjuntas de } \\
\text { uma coleção maior de seis conjuntos de dados utilizados para } \\
\text { a tarefa de recuperação de imagem médica no ImageCLEFmed } \\
2007 \text { (MÜLLER et al., 2008). }\end{array}$ \\
\hline MRIBalan & $\begin{array}{l}704 \quad 30 \\
\text { Conjunto de imagens de ressonância magnética obtidas do Hospi- } \\
\text { tal das Clínicas de Ribeirão Preto da Universidade de São Paulo } \\
\text { (USP). }\end{array}$ \\
\hline Nasa & $\begin{array}{l}40.150 \quad 20 \\
\text { Conjunto de vetores de características extraídos de imagens da } \\
\text { NASA. Fonte:Biblioteca de espaço Métrico }{ }^{2} \text {. }\end{array}$ \\
\hline
\end{tabular}

\footnotetext{
${ }^{1}$ Amsterdam Library of Object Images Homepage. Último acesso em: 25 de Maio de 2016. Disponível em: $<$ http://staff.science.uva.nl/ aloi/>

${ }^{2}$ International Workshop on Similarity Search and Applications (SISAP). Último acesso em: 25 de Maio de 2016. Disponível em: <http://www.sisap.org/dbs/>

${ }^{3}$ RESCUER: Reliable and Smart Crowdsourcing Solution for Emergency and Crisis Management. Disponível em: <http://www.rescuer-project.org/>. Acessado em: 04 de Março de 2017.
} 


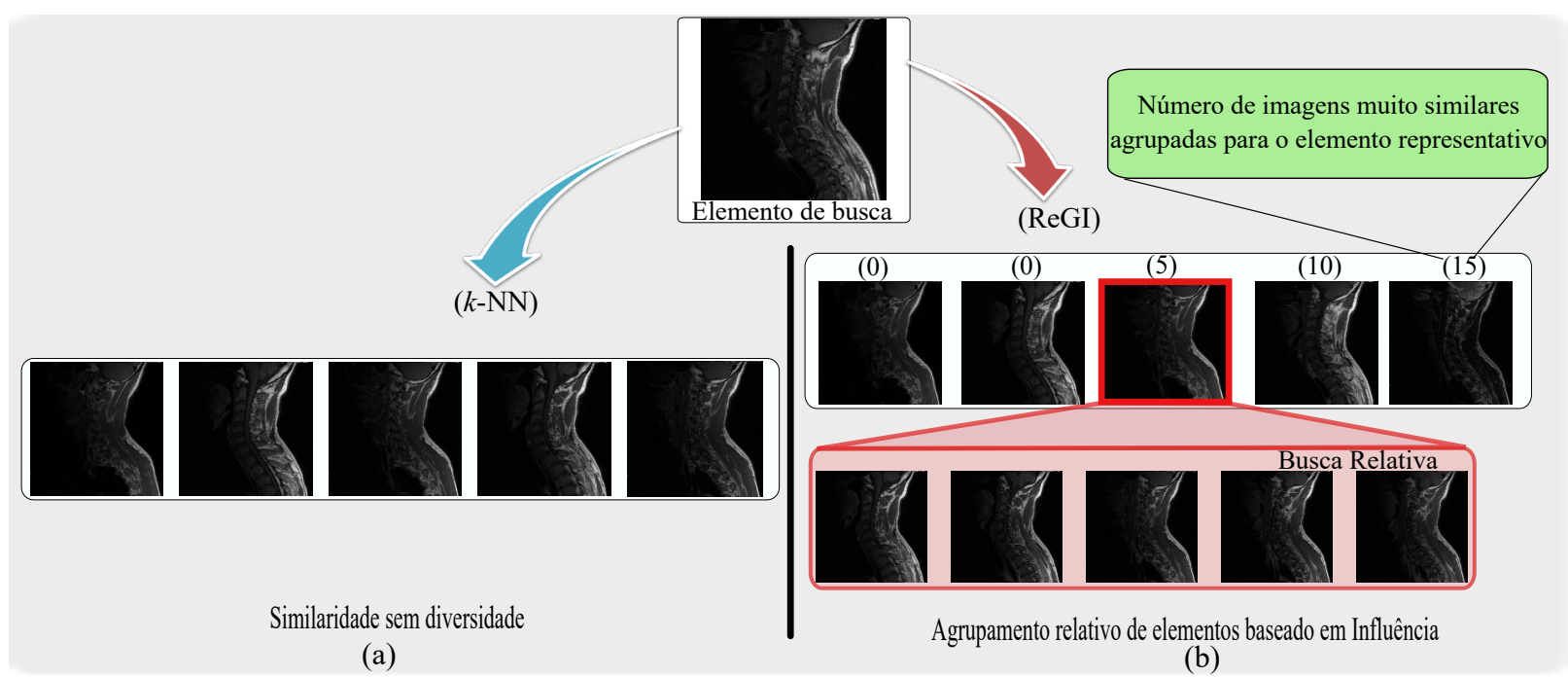

Figura 7.2: Resultados para uma busca sobre o conjunto de dados MRIBalan com o "elemento de busca" ilustrado e considerando $k=5$. (a) Os resultados para a busca utilizando o algoritmo $k$-NN. (b) Os resultados recuperados por ReGI com destaque para o grupo de imagens muito similares, ilustrando a operação de busca relativa. É importante notar que 3 das imagens retornadas pelo algoritmo de $k$-NN foram agrupadas como sendo muito similares ao terceiro elemento representativo da resposta do ReGI.

Os experimentos foram divididos em duas partes: (i) Um estudo de caso sobre a utilização de ReGI em domínios de dados médicos, em que os resultados das buscas foram apresentados a especialistas em sistemas de recuperação por conteúdo. (ii) Testou-se ReGI sobre conjuntos de dados de diferentes domínios para verificar sua aplicabilidade por meio de três fatores: primeiro, foi medido o custo computacional para responder e agrupar os elementos - experimento de desempenho. Segundo, foi medida a quantidade de elementos retornados pelo ReGI em uma única busca quando comparado com o algoritmo tradicional de $k$-NN experimento de recuperação de informação. Por fim, foi verificado a qualidade da escolha dos elementos representativos - experimento de qualidade.

Os experimentos foram executados em um computador com a seguinte configuração: processador Intel ${ }^{\circledR}$ Core $^{\mathrm{TM}}$ i7-4770 com 8 GB de memória RAM. O sistema operacional utilizado foi a distribuição GNU Linux Ubuntu 11.10. Toda as técnicas e os algoritmos foram implementados na mesma plataforma de avaliação utilizando a linguagem $\mathrm{C}++$, garantindo comparações justas entre os competidores.

\subsubsection{Estudo de Caso}

Com o aumento da cardinalidade dos conjuntos de cados, a apresentação de elementos muito similares nos resultados aumenta a quantidade de esforço na análise dos elementos, pois, frequentemente, é necessário realizar mais de uma submissão de busca e navegar por vários elementos até que a informação desejada seja encontrada. No entanto, se os elementos muito similares estiverem disponíveis para visualização de maneira adequada, isto é, com baixo custo de recuperação, é possível reduzir o tempo de análise do especialista.

ReGI foi implementado em um protótipo e apresentado para especialistas em sistemas de recuperação por conteúdo para avaliação das buscas utilizando um estratégia tradicional de $k$-NN e utilizando a técnica de agrupamento relativo. Foi solicitado para os especialistas que 
realizassem buscas pelos cinco casos mais próximos utilizando um conjunto de teste com casos a serem avaliados, considerando a similaridade das imagens de ressonância magnética do conjunto de dados MRIBalan. Um dos resultados desse estudo de caso é apresentado na Figura 7.2. os resultados para a busca utilizando um algoritmo de $k$-NN são apresentados na Figura 7.2 (a). Apesar do especialista ter interesse em analisar todas as imagens muito similares, a forma de apresentação requer a solicitação de um valor de $k$ muito grande para analisar outras imagens. Por exemplo, a Figura 7.2 (b) apresenta as cinco imagens representativas retornadas por ReGI e a indicação numérica quando existem imagens muito similares agrupadas para uma imagem do resultado. Em seguida, se uma das imagens representativas é interessante para o especialista, é possível expandir a busca sem a necessidade de re-submissão da busca ao sistema, como é ressaltado na caixa em vermelho na Figura 7.2 (b). É importante perceber que a cobertura da busca no espaço de busca foi aprimorada para recuperar as imagens mais diversas, porém sem perder o contexto de similaridade da imagem de busca e sem requisitar qualquer ajuste de parâmetros.

Os especialista afirmaram que ReGI é, de fato, capaz de apresentar as imagens do resultado de maneira mais significativas do que a abordagem com o $k$-NN, fornecendo mais informações sobre o relacionamento das imagens, sendo capaz de reduzir a necessidade de refinamentos adicionais de busca. Eles também destacaram que as buscas por similaridade com diversidade sem a definição de parâmetros foi mais simples e adequada para uma possível implementação em sistemas de recuperação de imagens médicas para uso diário na rotina clínica.

\subsubsection{Avaliação de Desempenho}

Com o objetivo de avaliar o desempenho da técnica ReGI em comparação aos competidores foi medido o tempo de execução dos algoritmos para seis dos conjuntos de dados, o conjunto de dados Fire foi excluído nesta seção devido sua baixa cardinalidade. Para cada conjunto de dados avaliado, foram escolhidos aleatoriamente 100 elementos para compor um conjunto de teste. Cada ponto nos gráficos de tempo representam o tempo em escala logarítmica para responder 100 buscas com valor constante de $k$, mas com elementos centrais de busca distintos. O parâmetro de preferência de diversidade dos algoritmos CLT, GNE e OPT foram definidos como $\lambda=0.5$ para garantir o equilíbrio entre respostas similares e diversas. Além disso, o espaço de busca dos algoritmos CLT, GNE e OPT foram restringidos utilizando um limite máximo de contexto para reduzir o custo computacional de processar todos os elementos do conjunto de dados. Para definir o limiar foram executadas várias execuções do algoritmo e mensurado o custo benefício entre respostas dentro do contexto máximo de similaridade com desempenho e qualidade. Em relação ao ReGI, como é uma técnica independente de parâmetros de diversificação, foi necessário apenas definir o valor $k$ de elementos a serem recuperados.

A Figura 7.3 mostra o tempo médio necessário para responder as buscas quando o valor de $k$ é variado de 3 até 11 para os conjuntos de dados médicos MRIBalan (Figura 7.3 (a)) e ImageCLEFmed (Figura 7.3 (b)). Neste experimento, apenas foi considerado o algoritmo OPT para comparação, pois o GNE possui a mesma definição de diversificação, porém não é específico para dados em domínios médicos. Como já era esperado, o algoritmo de $k$-NN (sem diversificação) é o mais rápido dos competidores, pois tal método apenas considera a relação de similares dos elementos, realizando menos operações que os outros algoritmos. Portanto, a utilização do método $k$-NN foi utilizado como base para mensurar o quão próximo os algoritmos se aproximam do mínimo teórico do tempo de execução. Neste quesito, ReGI 


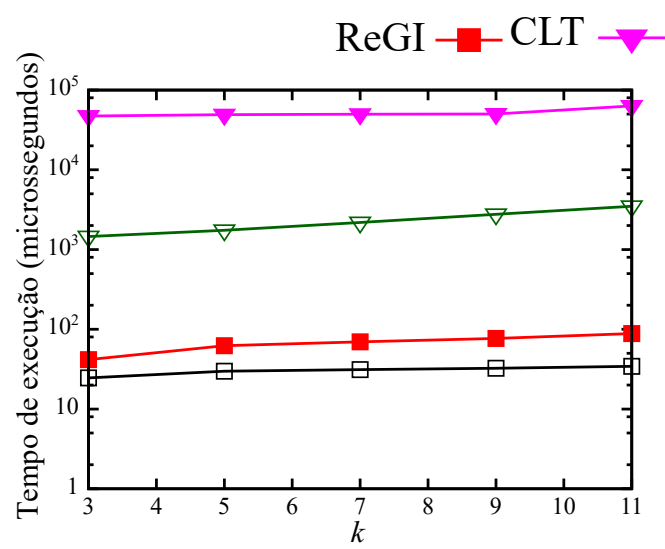

(a) MRIBalan

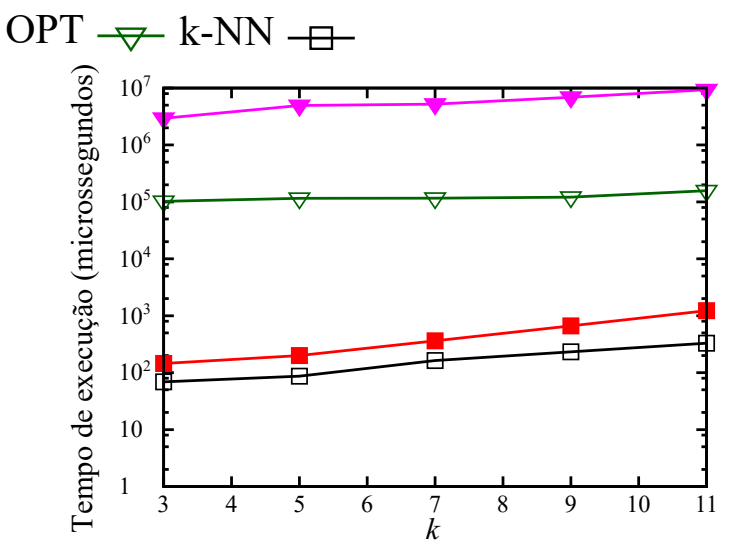

(b) ImageCLEFMed

Figura 7.3: Tempo de execução para os conjuntos de dados (a) MRIBalan e (b) ImageCLEFmed para $k$ variando de 3 até 11 .

obteve tempo de execução similares aos do $k$-NN para valores baixos de $k$, dobrando, em média, o tempo de execução. Em relação aos algoritmos de diversificação e de agrupamento, ReGI foi a técnica mais rápida, por exemplo, sendo uma ordem de magnitude mais rápida que o OPT para o conjunto MRIBalan e três ordens para o conjunto ImageCLEFmed. Em relação ao algoritmo CLT, ReGI foi, respectivamente, quatro e cinco ordens de magnitude mais rápida nos conjuntos MRIBalan e ImageCLEFmed. Como o algoritmo CLT é baseado no algoritmo de agrupamento de dados $k$-medoide, é necessário realiza a atualização dos medoides a cada iteração, justificando o tempo mais elevado de execução.

A Figura 7.4 apresenta os resultados para os conjuntos de dados Aloi, Colors, Faces e Nasa. Como esses domínios de dados não impõe restrição para a quantidade de elementos no conjunto de resultados como o domínio médico, o valor de $k$ foi variado de 5 até 25 para verificar o impacto no desempenho dos algoritmos quando mais elementos devem ser recuperados. Além disso, o algoritmo GNE foi utilizado para os experimentos nesses conjuntos de dados. Como pode ser percebido, a diferença entre o ReGI e o $k$-NN aumentou com o aumento da quantidade de elementos a serem retornados, sendo quase uma ordem de magnitude mais lento. Contudo, os conjuntos de dados da Figura 7.4 ou possuem maior cardinalidade ou dimensão do que os conjuntos em domínio médico, assim, o custo do cálculo da função de distância possui maior efeito do que naqueles conjuntos. Por exemplo, no conjunto de dados Nasa (Figure $7.4(\mathrm{~d})$ ) para $k=5$, ReGI apresentou a menor diferença para o algoritmo $k$-NN e, no outro extremo, ReGI obteve a maior diferença para o $k$-NN no conjunto Faces (Figure 7.4 (c)) que possui 761 dimensões. Entretanto, mesmo com o aumento da cardinalidade e dimensionalidade, ReGI foi pelo menos duas ordens de magnitude mais rápido que o GNE e quatro ordens de magnitude para o CLT.

Os resultados apresentados nesta seção indicam que ReGI supera todos os concorrentes por uma margem significativa e com tempo de execução próximo do algoritmo de $k$-NN, enquanto os outros competidores são facilmente 100 vezes mais lentos. Portanto, ReGI pode ser integrado em sistemas de recuperação por conteúdo de imagens sem impactos significativos no desempenho de recuperação. 


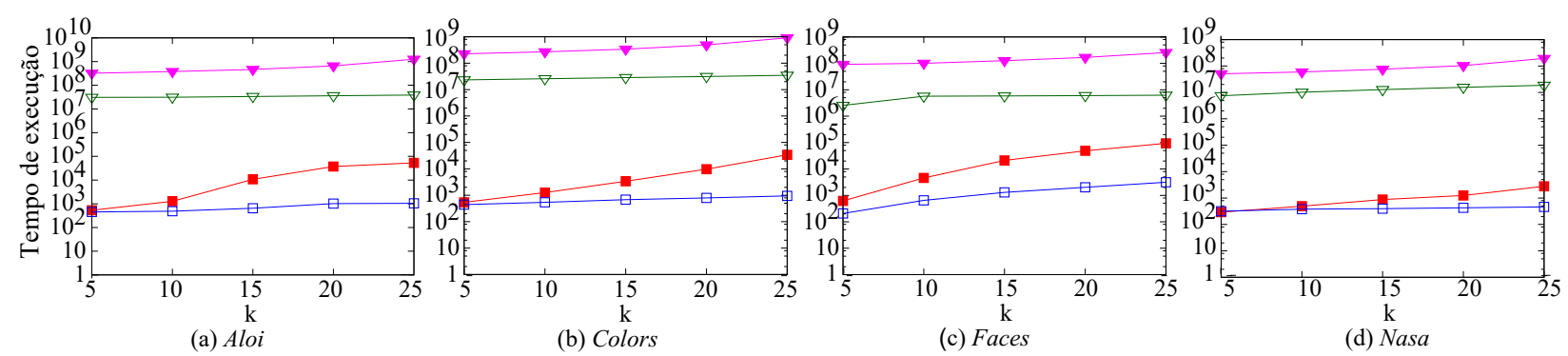

$\mathrm{CLT} \rightarrow \quad \mathrm{ReGI}-\quad \mathrm{GNE} \rightarrow \quad \mathrm{k}-\mathrm{NN} \square$

Figura 7.4: Tempo de execução para $k$ variando de 5 até 25 nos conjuntos: (a) Aloi , (b) Colors , (c) Faces, e (d) Nasa.

\subsubsection{Avaliação de Qualidade}

Com objetivo de comparar a qualidade da escolha dos elementos representativos foi mensurado o benefício relativo (Relative Benefit - índice RB) (Seção 3.4). Como muitas aplicações são desenvolvidas para retornar conjuntos de resultados com poucos elementos, tipicamente $k \leq 10$, é importante comparar a qualidade dos algoritmos para o índice RB quando o valor de $k$ é pequeno. Assim, foram considerados dois valores nos testes, $k=5$ e $k=10$.

Os resultados são apresentados na Figura 7.5, em que valores próximos do topo do gráfico indicam melhores algoritmos. A Figura 7.5 (a) mostra que o algoritmo CLT possui baixa qualidade para $k=5$ em todos os conjuntos avaliados, em média com índice RB de 0.81 . Uma razão para valores tão baixos é que a operação de atualização de medoide não leva em consideração a similaridade para o elemento central de busca, resultando em representativos que representam a distribuição dos dados e não da região ao redor do elemento de busca.

ReGI apresentou boa qualidade em todos os conjuntos de dados, possuindo média de 3.5. No conjunto de dados Fire, ReGI obteve índice RB quase duas vezes maior que o valor alcançado pelo GNE, sendo que no conjunto de dados Colors a qualidade dos resultados foi, exatamente, duas vezes melhor. A superioridade de ReGI está associada ao fato do conjunto de resultados ser construído incrementalmente com a definição da distância de separação ser definida baseada na posição relativa dos elementos, evitando elementos com baixa contribuição de diversidade como representativos e agrupando-os.

A Figura 7.5 (b) mostra que mesmo com o aumento da quantidade $k$ de elementos retornados, ReGI ainda obteve os melhores valores de índice RB na maioria dos conjuntos de dados,

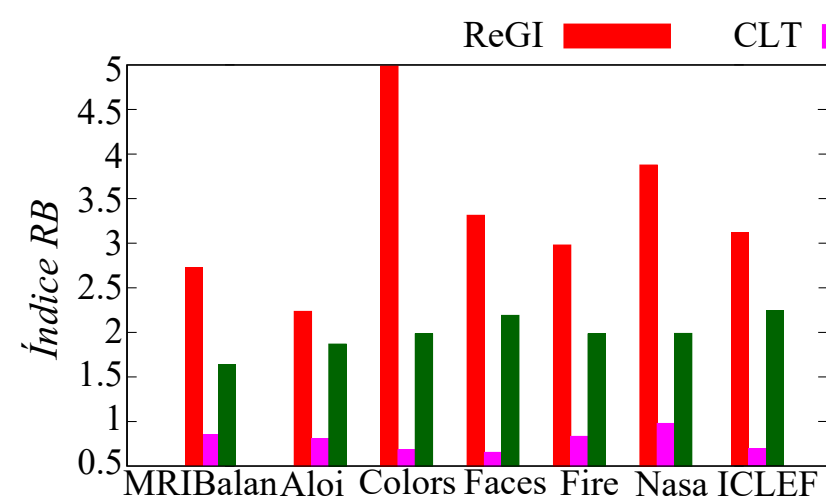

(a) $k=5$

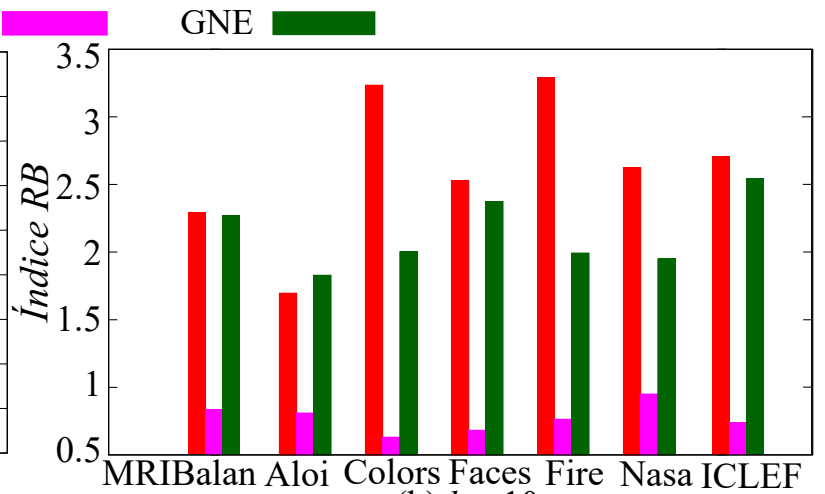

(b) $k=10$

Figura 7.5: Benefício Relativo para (a) $k=5$ e (b) $k=10$. 
enquanto o CLT continua com os piores resultados. O único caso que GNE foi melhor que o ReGI foi para o conjunto de dados Aloi, embora a diferença foi apenas de $10 \%$.

Os resultados apresentados nesta seção indicam que a utilização do conceito de influência e a heurística CB do ReGI asseguram uma escolha de elementos representativos que apresentam diversidade no resultado final. Assim, o usuário inicialmente percebe um conjunto diverso na quantidade $k$ de elementos requisitados e pode navegar pelos elementos muito similares agrupados à seu critério.

\subsubsection{Avaliação de Recuperação de Informação}

No último fator avaliado, foram mensurados o número médio de imagens recuperadas pelo ReGI e $k$-NN para avaliar as capacidades e limitações de cada técnica para recuperação de informação. Por uma questão de concisão, os gráficos dos conjuntos de dados ImageCLEFmed, Fire, Nasa foram omitidos por apresentarem o mesmo comportamento dos outros conjuntos de dados, sendo que os conjuntos MRIBalan, Aloi, Colors e Faces escolhidos como representativos para os experimentos realizados.

A Figura 7.6 (a) apresenta os resultados para a quantidade de imagens retornadas em média no conjunto de dados MRIBalan quando $k$ é variado no intervalo de $[3,11]$ elementos. Apesar da grande quantidade de elementos retornados por ReGI, os elementos estão agrupados e ordenados de acordo com os elementos representativos, que são mantidos no começo das listas dos grupos para serem os primeiros elementos a serem apresentados ao usuário e apresentarem uma visão diversificada ao redor do elemento central de busca. Os resultados da Figura 7.6 (b) Confirmam esse argumento, pois ReGI retorna o número de elementos requisitados ao especialista, enquanto o $k$-NN retorna menos do que $50 \%$ das imagens representativas, ou seja, que não são muito similares a outras do conjunto de resultado.

A Figura 7.7 apresenta os resultados para os demais conjuntos de dados testados. Para o conjunto de Dados Aloi (Figura 7.7(a)), ReGI obteve os melhores resultados do experimento, recuperando 108 vezes mais imagens que o $k$-NN quando $k=25$, reduzindo a necessidade de reformulação de busca e o esforço de navegação em um espaço de busca de 2.700 imagens. Para os conjuntos Colors (Figura 7.7 (b)) e Faces (Figura 7.7 (c)), ReGI recuperou 10 e 12 vezes mais imagens que o $k$-NN, respectivamente. De maneira similar ao que ocorreu

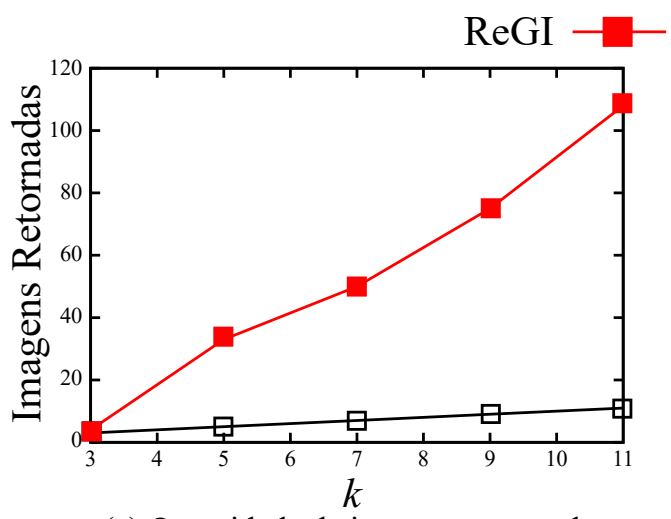

(a) Quantidade de imagens retornadas

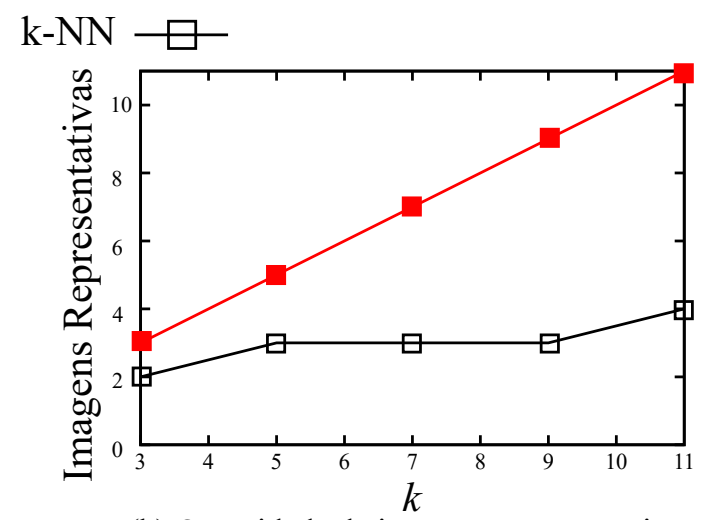

(b) Quantidade de imagens representativas

Figura 7.6: Relação entre a quantidade de elementos retornados e representativos nos resultados do conjunto de dados MRIBalan. 


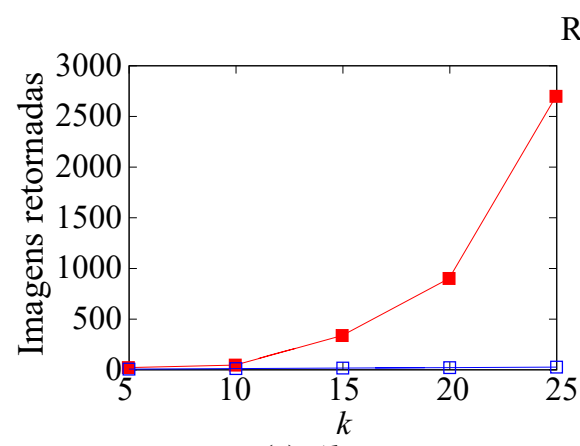

(a) Aloi

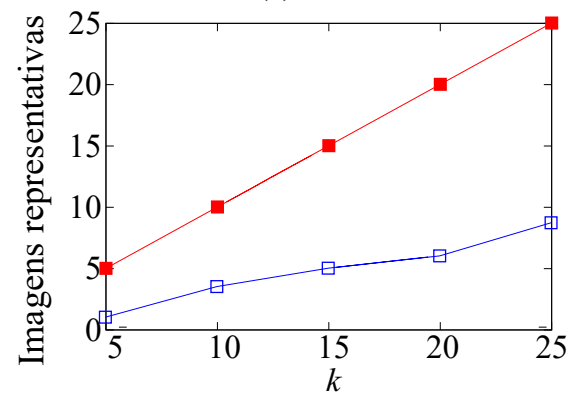

(d) Aloi

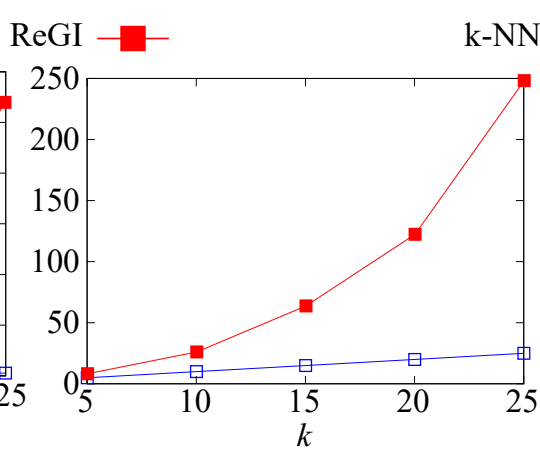

(b) Colors

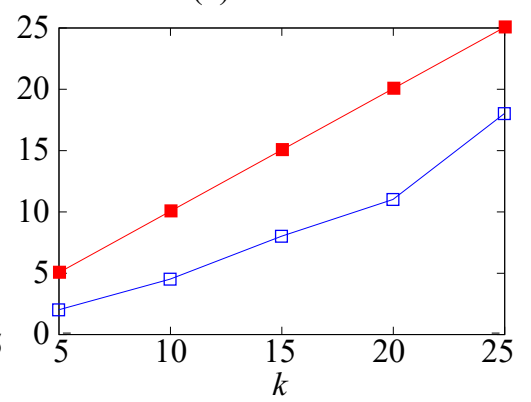

(e) Colors

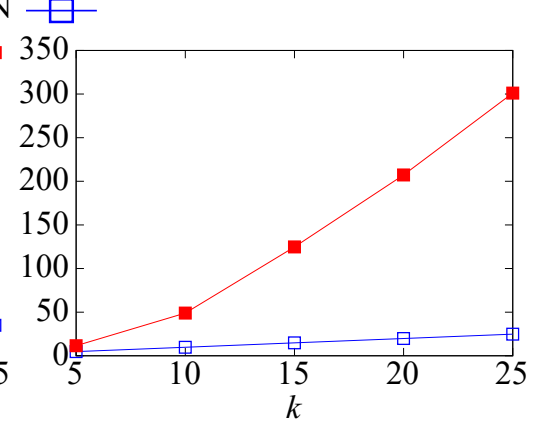

(c) Faces

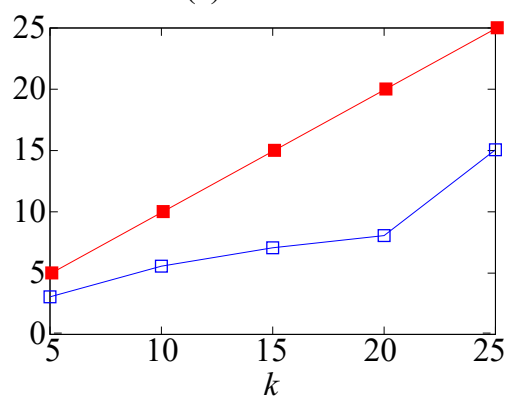

(f) Faces

Figura 7.7: Relação entre a quantidade de elementos retornados e representativos nos resultados dos conjuntos de dados Aloi, Colors e Faces. (a), (b) e (c): quantidade de imagens retornadas; (d), (e) e (f): quantidade imagens representativas retornadas.

com o conjunto MRIBalan, ReGI assegurou a quantidade correta de imagens representativas dos grupos no conjunto de resposta final, enquanto o algoritmo $k$-NN continuou recuperando elementos muito similares, porém houve um aumento de $50 \%$ para $60 \%$ de imagens representativas no conjunto final para o conjunto de dados Colors, como pode ser visto nas Figuras 7.7 (d), (e) e (f).

Os fatores avaliados nos experimentos indicam que ReGI assegura bons níveis de diversidade (fator de qualidade) entre os elementos consideradores representativos com um custo computacional (fator de desempenho) muito menor que os competidores, enquanto que permite, na média, agrupar muitos mais elementos por busca (fator de recuperação de informação. Além disso, ReGI não requer a definição de parâmetros de diversificação e a heurística de limite de contexto possibilitou recuperar imagens diversas apenas entre os elementos ao redor do centro de busca.

\subsection{Considerações Finais}

Este capítulo apresentou a nova técnica para agrupar automaticamente elementos muito similares com base no conceito de influência para apresentar somente os elementos mais representativos à busca. A técnica ReGI proposta inclui uma nova maneira de apresentar os resultados de uma busca, sem poluir a exibição com muita informação, uma vez que apenas os elementos mais representativos são apresentados ao usuário, aumentando a probabilidade de apresentar novas informações a partir do primeiro resultado em uma seção de interação. Além disso, nenhuma informação é omitida ou perdida em comparação com a abordagem de $k$-NN, pois todos os elementos no espaço de busca são agrupados e ordenados de acordo com um elemento representativo, tornando mais fácil a navegação nos resultados. 
A principal motivação para a definição de ReGI é aprimorar a maneira que os resultados são apresentados para sistemas de recuperação de imagem médicas. Contudo, os resultados experimentais realizados em outros domínios de dados indicam que ReGI é um conceito genérico o suficiente para ser aplicado em outros conjuntos de dados para aumentar a expressividade da operação de recuperação agrupando os elementos muito similares.

O próximo capítulo apresenta as atividades referentes a terceira frente de trabalho desta tese, um conjunto de métodos para avaliar a qualidade dos resultados dos algoritmos de diversificação de resultados baseados em conteúdo. Os métodos definidos se baseiam apenas nos elementos e nas relações de distâncias que podem ser calculadas diretamente, reduzindo a necessidade de definição de conjuntos de dados com validação por parte do usuário. Além disso, os métodos complementam as informações de outras medidas utilizadas na validação dos algoritmos, aumentando o entendimento de como as técnicas induzem a propriedade de diversidade nas buscas por similaridade, bem como indicando em quais tipos de conjuntos de dados ainda há espaço para aprimoramentos dos algoritmos ou definições de diversidade. 



\section{Avaliando a Diversificação de Resultados}

Os sistemas gerenciadores de base de dados sempre tiveram o foco no armazenamento e recuperação eficiente de grandes volumes de dados escalares. Com o início do suporte de dados como imagens, vídeos e muitos outros tipos considerados mais complexos, várias pesquisas foram conduzidas para possibilitar novas maneiras de recuperação destes dados e, principalmente, para tornar a execução das buscas por similaridade mais eficientes. De maneira geral, melhores desempenhos são alcançados com a utilização de estruturas de indexação, sendo um requisito para a aplicação em grandes volumes de dados complexos. Outra questão que tem se mostrado de importância primordial, é a melhoria da eficácia das respostas fornecidas, isto é, evitar a recuperação de respostas com elementos muito similares entre si. Para lidar com essa questão, áreas de pesquisa, tais como a de recuperação de informação e sistemas de recomendação introduziram a propriedade de diversidade nos resultados apresentados aos usuários. Neste trabalho de doutorado foi considerado também a inclusão desta propriedade nos operadores de busca dos SGBDs.

Nós últimos capítulos foram apresentadas diversas abordagens para a consideração de diversidade baseando-se apenas no conteúdo dos elementos (capítulo 3), bem como nossas propostas de diversificação de resultado baseado no conceito de influência (capítulos 4, 5, 6 e 7). No entanto, existem poucos métodos de avaliação capazes de medir com precisão a diversidade dos conjuntos de resultados recuperados por algoritmos que se baseiam apenas no conteúdo dos dados, como foi relatado no capítulo 3.

Neste capítulo será explorado a avaliação de conjuntos de resultados diversificados baseados na abordagem de distância entre os elementos. Foi proposto um novo conjunto de métodos para medir a precisão dos algoritmos de diversificação de resultados, com base no uso de várias análises estatísticas obtidas de diferentes estratégias para medir a diversidade de conjuntos de resultados. Além disso, também foi proposta a definição de um "espaço de resposta", no qual cada elemento é uma possível solução de busca. Tal espaço permite a comparação de buscas e a definição de propriedades que permitem desenvolver diretrizes para escolher qual é o algoritmo de busca por similaridade com diversidade mais adequado para um dado conjunto de dados.

Em resumo, este capítulo apresenta as seguintes contribuições: 
- Dois métodos de avaliação para comparar conjuntos de resultados utilizando apenas os elementos e a relação de distância entre os conjuntos avaliados, sendo que um conjunto deve ser definido como de referência para comparação;

- O conceito de "espaço de resposta" cujo objetivo é evidenciar a distribuição de distância dos conjuntos diversos por meio de diferentes critérios estatísticos. Neste capítulo, em específico, serão apresentados seis critérios de avaliação de diversificação implementados no extrator de características de diversidade;

- Comparação dos novos métodos de avaliação de conjuntos diversificados. Os resultados experimentais atestam que a utilização dos métodos propostos fornecem mais detalhes sobre os conjuntos de resultados comparados.

O restante deste capítulo é estruturado da seguinte maneira. A Seção 8.1 apresenta os métodos desenvolvidos para comparação de conjuntos de resultados diversificados e o conceito de "espaço de resposta". A Seção 8.2 apresenta os resultados experimentais realizados para avaliar a proposta dos novos métodos. Por fim, a Seção 8.3 apresenta as considerações finais deste capítulo.

\subsection{Avaliação de Diversidade}

Esta seção apresenta o conceito de espaço de resposta, que se baseia em um conjunto de medidas estatísticas em relação aos conjuntos de resultados fornecidos para uma busca, sendo o principal objetivo comparar os diferentes tipos de respostas fornecidos pelos algoritmos de diversificação.

Considere-se que $S=\left\{s_{1}, \ldots, s_{n}\right\}$ é um conjunto de dados com $n$ elementoss extraídos de um domínio de dados $\mathbb{S}$ e que $s_{q} \in \mathbb{S}$ é um elemento central de busca. Considere-se também que $R_{i} \subset S$ é um conjunto de resultados para uma busca com elemento em $s_{q}$, que seleciona em $S$ elementos similares ao $s_{q}$, e também diversos entre os outros elementos do conjunto, de acordo com uma algoritmo de diversificação $\mathfrak{F}$. O conjunto de conjuntos resultados $R$ é a união de todos os conjuntos resultados $R_{i}$ para o mesmo elemento central de busca $s_{q}\left(R=\bigcup R_{i}\right)$. O objetivo da nossa proposta é avaliar a qualidade dos conjuntos de resultados fornecidos pelos algoritmos de diversificação baseados no conteúdo dos elementos seguindo duas estratégias para mensurar a diversidade: 1) Resultado baseado em estatísticas e 2) comparação de conjunto de resultados. A primeira estratégia extraí características de cada conjunto $R_{i} \in R$ e as compara utilizando o método de características de dissimilaridade (Dissimilarity Feature method - DiF $F_{M}$ ), que está detalhado na próxima Subseção 8.1.2.1. As características são obtidas por meio de um extrator de métricas de diversidade $\mathfrak{L}$, que utiliza apenas a distância entre os elementos no conjunto $R_{i}$, pois é a única informação sempre disponível. A segunda estratégia compara diretamente os elementos dos conjuntos de resultados utilizando os métodos de dissimilaridade (Dissimilarity Method - $D_{M}$ ) e o método de erro de dissimilaridade (Dissimilarity Error - $D E_{M}$ ), apresentados nas próximas Subseções, respectivamente, 8.1.2.2 e 8.1.2.3.

A Figura 8.1 ilustra os principais componentes de nossa proposta de avaliação de diversificação. O conjunto de dados de exemplo $S=\left\{s_{1}, s_{2}, \ldots, s_{10}\right\}$ mostrado na Figura 8.1(a) é o espaço de busca composto por elementos extraídos de um domínio $\mathbb{S}$. O algoritmo de diversificação $\mathfrak{F}$ é executado sobre os elementos de $S$ e com elemento central de busca $s_{q}$ 


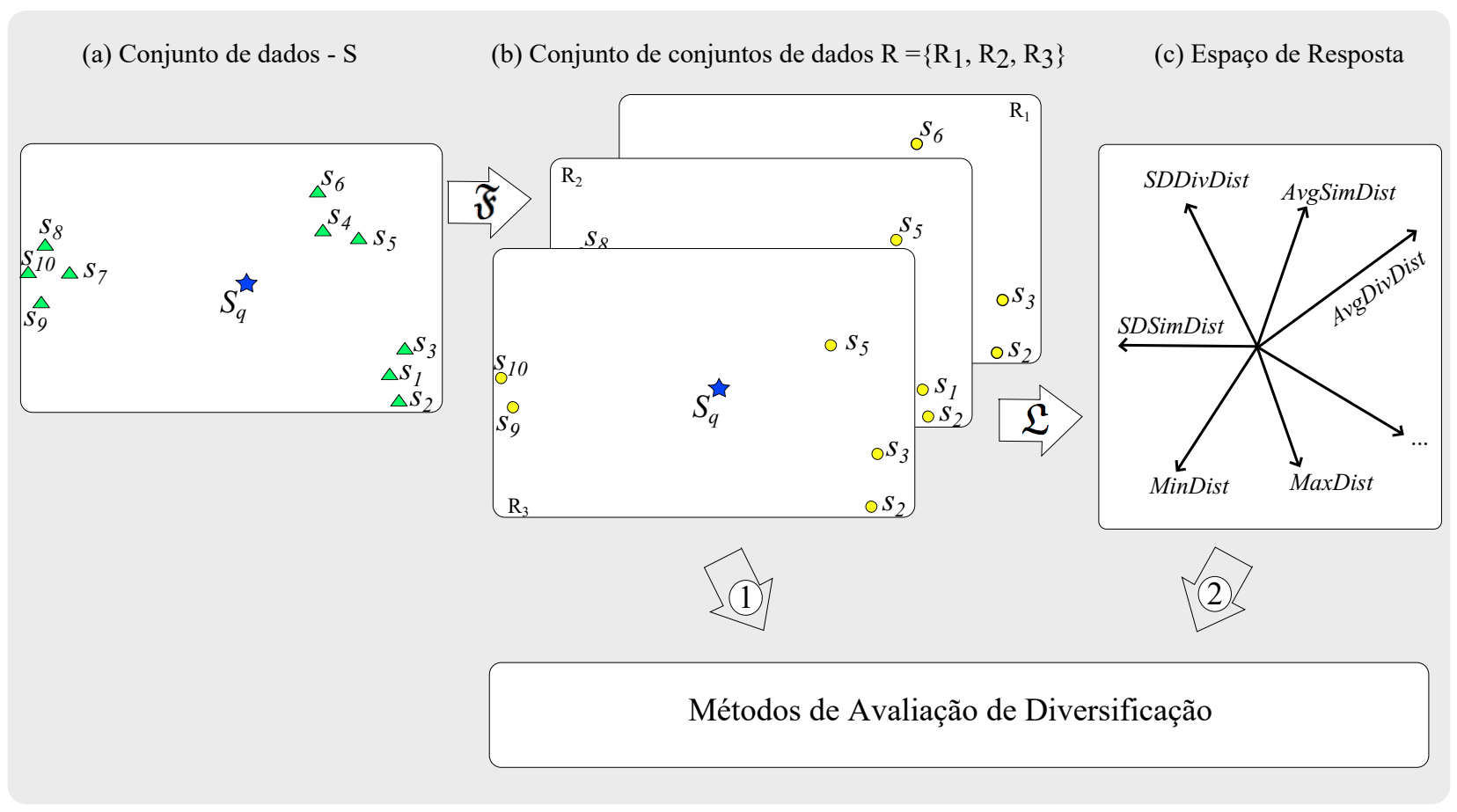

Figura 8.1: Mapeamento do espaço de resposta.

(representado como um estrela). A Figura 8.1(b) apresenta a execução do algoritmo utilizando três configurações distintas, ou seja, modificando os parâmetros de entrada, sendo gerado um conjunto de conjuntos de resultado para o mesmo elemento central de busca $\left(R=\left\{R_{1}, R_{2}, R_{3}\right\}\right)$. Para cada conjunto de resultados $R_{i}$, o extrator de métricas de diversidade $\mathfrak{L}$ extraí características apropriadas para a avaliação de diversideade e as mapeia para o espaço de resposta $\mathbb{L}$ (Definição 21), como mostrado na Figura 8.1(c). Com o intuito de avaliar a qualidade dos resultados, os conjuntos de resultados $R_{1}, R_{2}$ e $R_{3}$ podem ser analisados pelo nossos 'Métodos de Avaliação de Diversificação', utilizando os métodos de dissimilaridade e/ou erro de dissimilaridade (Seta (1) da Figura 8.1), e/ou o espaço de resposta $\mathbb{L}$ pelo método de caractéristicas de dissimilaridade, também implementado no 'Método de Avaliação de Diversificação' (Seta (2) da Figura 8.1). A escolha depende do tipo de informação esperada pelo o usuário durante a análise dos algoritmos.

Definição 21. Espaço de Resposta (L): Dado $R$ um conjunto de conjuntos de resultados e um extrator de métricas de diversidade $\mathfrak{L}$, um espaço de resposta $\mathbb{L}$ é um espaço $m$-dimensional em que $m$ é o número de características extraídas por $\mathfrak{L}$ e cada elemento em $\mathbb{L}$ representa uma distribuição de distância de uma solução de diversidade possível para um elemento central de busca $s_{q}$.

As próximas seções detalham as características extraídas pela nossa proposta de extrator de métricas de diversidade $\mathfrak{L}$ de cada conjunto de resultados e apresentam os métodos de avaliação que compõe o módulo de 'Métodos de Avaliação de Diversificação'.

\subsubsection{O Vetor de Características de Diversidade}

O vetor de características de diversidade $d v_{i}$ representa as características extraídas de cada conjunto de resultado $R_{i} \in R$ por um extrator de métricas de diversidade $\mathfrak{L}$ em um espaço de 
resposta $\mathbb{L}$ que serão utilizados para comparação entre os resultados dos algoritmos. Foram propostas características que podem ser calculadas diretamente pelo extrator $\mathfrak{L}$ por meio das relações de distância entre os elementos no conjunto de resultado, a única informação disponível nos algoritmos de diversidade baseado em conteúdo. As características capturam diferentes estatísticas que são utilizadas pelo método de avaliação baseado em resultados para mensurar a qualidade de um conjunto de resultado em um espaço de resposta $\mathbb{L}$.

De maneira mais formal, seja $D V=\left\{d v_{1}, \ldots, d v_{n}\right\}$ o conjunto de vetores de características de diversidade extraídos por $\mathfrak{L}$ do conjunto de conjuntos de resultados $R=\left\{R_{1}, \ldots, R_{n}\right\}$, isto é, $\mathfrak{L}\left(R_{i}\right)=d v_{i}$. Portanto, cada $d v_{i}$ possui características $\left(f_{1}, \ldots, f_{m}\right)$, em que $m$ é o número de características extraídas por $\mathfrak{L}$, por exemplo, o número de dimensões do espaço de resposta $\mathbb{L}$. Neste trabalho $\mathbb{L}$ foi definido como um espaço 6-dimensional e $d v_{i}$ é composto por seis características descritas a seguir:

i. Distância Média de Diversidade (AvgDivDist), representa o quão diversos são os elementos de um conjunto de resultados entre uns dos outros. Essa característica é estimada pela distância de diversidade média entre os elementos do conjunto de resultados, como é mostrado na Equação 8.1.

$$
\operatorname{AvgDivDist}\left(R_{i}\right)=\frac{\sum_{u=1}^{|k-1|} \sum_{v=u+1}^{|k|} \delta_{d i v}\left(r_{u}, r_{v}\right)}{k \cdot(k-1)}
$$

ii. Distância Média de Similaridade (AvgSimDist), representa o quão similares são os elementos de um conjunto de resultados em relação ao elemento central de busca. Essa características se refere a distância de similaridade média entre o elemento $s_{q}$ para cada elemento do conjunto de resultados, como mostrado na Equação 8.2.

$$
\operatorname{AvgSimDist}\left(R_{i}, s_{q}\right)=\frac{\sum_{u=1}^{|k|} \delta_{s i m}\left(r_{u}, s_{q}\right)}{k}
$$

iii. Desvio Padrão da Distância de Diversidade (SDDivDist), responsável por mensurar a dispersão das distâncias de diversidade individuais em $R_{i}$ em comparação com a característica AvgDivDist. Por exemplo,SDDivDist verifica se as distâncias entre os elementos no conjunto de resultados estão ou não distribuídas igualmente. Caso SDDivDist possua um valor próximo de zero, os elementos estão igualmente espaçados, enquanto valores mais altos indicam a presença de grupos de elementos (cluster) em $R_{i}$. SDDivDist é calculada pela Equação 8.3.

$$
\operatorname{SDivDist}\left(R_{i}, s_{q}\right)=\sqrt{\frac{\sum_{u=1}^{|k-1|} \sum_{v=u+1}^{|k|}\left(\delta_{d i v}\left(r_{u}, r_{v}\right)-\operatorname{Avg} \operatorname{DivDist}\left(R_{i}\right)\right)^{2}}{k \cdot(k-1)}} .
$$

iv. Desvio Padrão da Distância de Similaridade (SDSimDist), mensura a dispersão das distâncias de similaridade individuais em comparação a característica AvgSimDist. Por exemplo, SDSimDist verifica se as distâncias entre cada elemento do conjunto de resultado ao elemento $s_{q}$ estão igualmente distribuídas, sendo calculada pela Equação 8.4.

$$
\operatorname{SDSimDist}\left(R_{i}, s_{q}\right)=\sqrt{\frac{\sum_{u=1}^{|k|}\left(\delta_{\operatorname{sim}}\left(r_{u}, s_{q}\right)-\operatorname{AvgSimDist}\left(R_{i}\right)\right)^{2}}{k}} .
$$


v. Distância Mínima (MinDist), representa a menor distância de diversidade entre qualquer par de elementos no conjunto de resultados. É definida na Equação 8.5.

$$
\operatorname{MinDist}\left(R_{i}\right)=\min _{r_{u}, r_{v} \in R_{i}}\left(\delta_{d i v}\left(r_{u}, r_{v}\right)\right) \text {. }
$$

vi. Distância Máxima (MaxDist), representa a maior distância de similaridade entre o elemento de central de busca e qualquer elemento do conjunto de resultados, sendo calcula pela Equação 8.6.

$$
\operatorname{Max} \operatorname{Dist}\left(R_{i}, s_{q}\right)=\max _{r_{u} \in R_{i}}\left(\delta_{\text {sim }}\left(r_{u}, s_{q}\right)\right) .
$$

Com as características extraídas do conjunto de resultado $R_{i}$, o vetor de características de diversidade $d v_{i}$ resultante é mapeado para o espaço de resposta $\mathbb{L}$. Portanto, a qualidade e a precisão de cada conjunto de resultado $R_{i}$ é avaliada pela a análise do espaço $\mathbb{L}$, como será descrito nas próximas seções.

\subsubsection{Método de Avaliação de Diversificação}

O método de avaliação da diversificação é composto por duas estratégias: Estatísticas baseadas em resultados e por comparações de conjuntos de resultados. A primeira estratégia compara os pares de vetores de características de diversidade $d v_{1}$ e $d v_{2}$, mapeados em um espaço de resposta $\mathbb{L}\left(d v_{1}, d v_{2} \in \mathbb{L}\right)$, enquanto a segunda estratégia mensura o quão dissimilar são dois conjuntos de resultados $R_{r}$ e $R_{t}\left(R_{r}, R_{t} \in R\right)$. O conjunto de resultados de referência $R_{r}$ se refere à melhor solução possível para o problema, no geral requer a execução de um algoritmo exaustivo para encontrar a resposta ideal. O conjunto de resultados objetivo $R_{t}$ é fornecido por um dos algoritmos que devem ser avaliados. Em termos gerais, todos os métodos propostos para comparação de conjuntos de resultados recebem como entrada um conjunto de resultados, gerado pelo algoritmo de diversidade a ser avaliado e retornam um valor que expressa a diversificação alcançada entre os elementos do conjunto de resultados em relação aos critérios inerentes de diversificação de cada método.

\subsubsection{Método de Dissimilaridade de Características $\left(D i F_{M}\right)$}

Esta seção apresenta o Método de Dissimilaridade de Características (Dissimilarity Feature Method - $D i F_{M}$ ) para representar a dissimilaridade entre um conjunto de resultado objetivo $R_{t}$ e o conjunto de resultado de referência $R_{r}$, realizando a avaliação em seus respectivos vetores de características $d v_{t}$ e $d v_{r}$. O principal benefício do $D i F_{M}$ é possibilitar a avaliação de conjuntos de resultados sem realizar qualquer comparação de elementos. Além disso, DiF $F_{M}$ permite a utilização e definição de características personalizadas para uma dada avaliação de diversidade além daquelas que foram propostas na Seção 8.1.1. Valores baixos para $D i F_{M}$ implicam que o $d v_{t}$ é muito similar ao $d v_{r}$, enquanto valores altos implicam em maiores dissimilaridades entre os conjuntos de resultados, como é ilustrado na Figura 8.2. Intuitivamente, o extrator de características de diversidade $\mathfrak{L}$ assume que é possível interpretar a distribuição de distâncias entre os elementos do conjunto de resultado como uma distribuição de probabilidade, visando descrever as distâncias de similaridade e de diversidade como um 


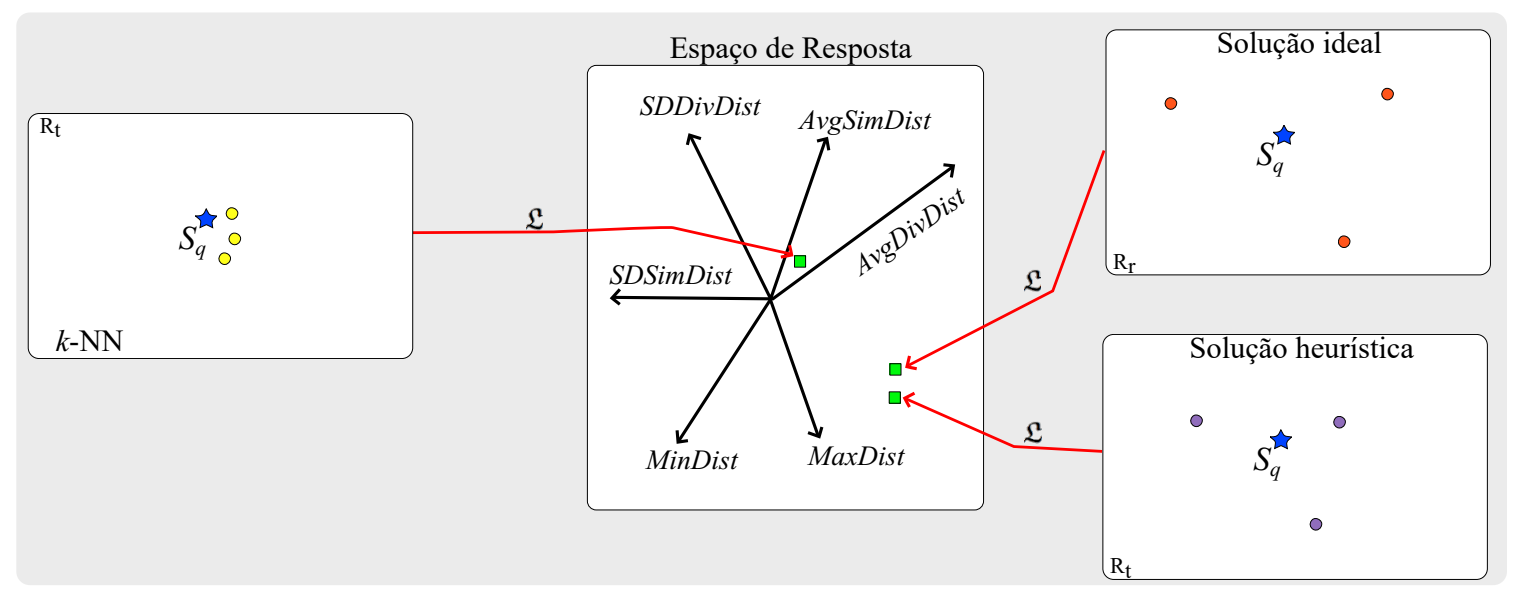

Figura 8.2: Avaliação de qualidade do $D i F_{M}$ no espaço de resposta.

distribuição Gaussiana. Para estabelecer a dissimilaridade entre $d v_{t}$ e $d v_{r}$, foi proposto o uso da função de distância apresentada na Equação 8.7, corresponde ao somatório ponderado das diferenças entre as características dos vetores de diversidade. Por uma questão de simplicidade, não foi realizada qualquer ponderação $\left(W_{i}=1\right)$ na seção de experimentos, porém diferentes pesos $W_{i}$ podem ser utilizados para cada característica quando se sabe a priori que alguma características é mais relevante do que outra para a definição de diversidade de um algoritmo.

$$
D i F_{M}\left(d v_{r}, d v_{t}\right)=\sum_{i=1}^{n}\left|d v_{r}[i]-d v_{t}[i]\right| * W_{i}
$$

\subsubsection{Método de Avaliação de Dissimilaridade $\left(D_{M}\right)$}

O Método de Avaliação de Dissimilaridade (Dissimilarity Evaluation Method - $D_{M}$ ) representa a discrepância entre o conjunto de resultado objetivo $R_{t}$ e o conjunto de resultado de referência $R_{r}$. É definida uma relação como sendo a similaridade relativa entre os dois conjuntos de resultados. Visando estabelecer a dissimilaridade entre $R_{t}$ e $R_{r}$, foi proposto aplicar a distância de Jaccard para comparar os conjuntos de resultados, como é definido na Equação 8.8. Valores baixos de $D_{M}$ implicam que $R_{t}$ é similar ao $R_{r}$, enquanto valores altos indicam um maior dissimilaridade entre os conjuntos. Assim, o método $D_{M}$ visa avaliar os conjuntos de resultados tão similares quanto possíveis.

$$
D_{M}\left(R_{r}, R_{t}\right)=1-\frac{\left|R_{r} \cap R_{t}\right|}{\left|R_{r} \cup R_{t}\right|}
$$

A Figura 8.3 ilustra o método $D_{M}$ em dois casos distintos, (a) com alta dissimilaridade e (b) com alta similaridade. Os círculos brancos representam os elementos de dados de cada conjunto de resultados, enquanto os losangos verdes representam os elementos na intersecção dos conjuntos $R_{r}$ e $R_{t}$ (áreas em branco). Na Figura 8.3(a), o conjuntos de resultados compartilham apenas um elemento em comum, portanto, $D_{M}=0.8$. Por outro lado, na 


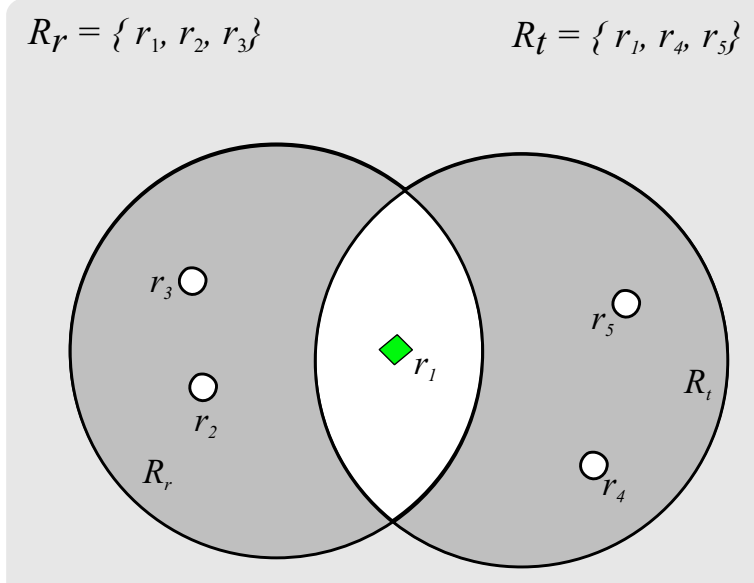

(a)

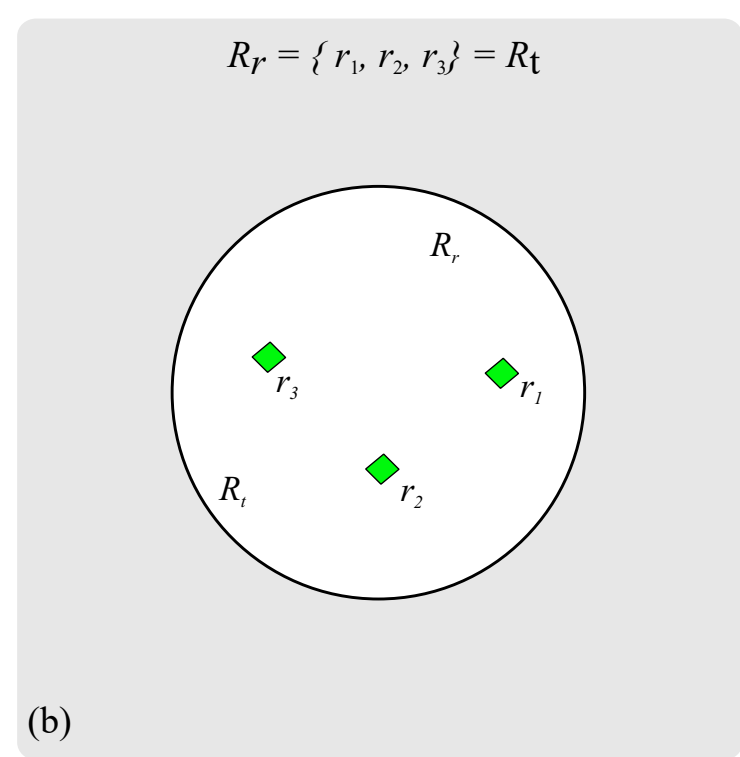

Figura 8.3: Método $D_{M}$. (a) Conjuntos de resultados dissimilares $\left(D_{M}=0.8\right)$. (b) Conjuntos de resultados similares (iguais) $\left(D_{M}=0.0\right)$.

Figura 8.3(b), $R_{t}$ compartilha todos os elementos com $R_{r}$, resultando em $D_{M}=0.0$. Assim, a proposta $D_{M}$ mensurou corretamente que os conjuntos de resultados na Figura 8.3(a) são mais dissimilares do que aqueles da Figura 8.3(b).

\subsubsection{Método de Avaliação do Erro de Dissimilaridade $\left(D E_{M}\right)$}

O método $D_{M}$ apresentado na subseção anterior compara os conjuntos de resultados de maneira binária, isto é, $D_{M}$ verifica se os elementos em $R_{t}$ são ou não os mesmos que os de $R_{r}$. Portanto, $D_{M}$ é insensível a cada elemento do conjunto de resultados objetivo ser um vizinho mais próximo de uma contraparte no conjunto de resultados de referência ou se eles estão muito afastados uns dos outros, restringindo a análise do $D_{M}$ a avaliar os elementos de dados por casamento exato (igualdade). Para lidar com essa questão, o método $D_{M}$ foi estendido para lidar com a dissimilaridade avaliando o posicionamento dos elementos, dando origem ao método Dissimilarity Error Evaluation Method - $D E_{M}$. Por exemplo, caso os elementos de $R_{t}$ sejam os mesmos elementos em $R_{r}$, a dissimilaridade entre os conjuntos continua em zero, como ocorre no método $D_{M}$. No entanto, se os elementos em $R_{t}$ são similares, mas não exatamente os mesmos elementos do conjunto $R_{r}$, é considerado entre os elementos um grau de similaridade. Para alcançar esse objetivo, os elementos do conjunto de resultados de referência $R_{r}$ são definidos como centroides de clusters a que os elementos em $R_{t}$ precisam ser atribuídos. Assim, cada elemento em $R_{t}$ é associado a um único elemento em $R_{r}$, isto é, a seu vizinho mais próximo. Desse modo, $D E_{M}$ representa o erro estimado de dissimilaridade para cada elemento $R_{t i} \in R_{t}$ para seu "representante de grupo (cluster)" $R_{r i} \in R_{r}$, como é mostrado na Equação 8.9. Valores baixos indicam que os elementos em $R_{t}$ são similares aos elementos de $R_{r}$, enquanto valores mais altos implicam em elementos mais dissimilares uns dos outros. 


$$
D E_{M}\left(R_{r}, R_{t}\right)=\sum_{i=1}^{|k|} \delta_{s i m}\left(R_{t i}, R_{r i}\right)
$$

Na Equação 8.9, $\delta_{s i m}\left(R_{t i}, R_{r i}\right)$ é a distância entre o i-éssimo elemento de $R_{t}$ e sua contraparte no conjunto $R_{r}$. A Figura 8.4 ilustra a intuição utilizada pelo método $D E_{M}$ para dois casos distintos com conjuntos de resultados compostos por três elementos, (a) conjunto de resultados compartilhando um elemento e (b) nenhum dos conjuntos compartilham elementos. Círculos brancos indicam elementos do conjunto de resultado objetivo $R_{t}$, círculos amarelos indicam elementos do conjunto de resultado de referência $R_{r}$, enquanto diamantes verdes representam os elementos que aparecem em ambos os conjuntos de resultados, isto é, a distância do elemento $r_{t i} \in R_{t}$ para o seu representante em $r_{r i} \in R_{r}$ é zero. O tamanho da seta indica a distância (erro) de cada elemento $R_{t i}$ para sua contraparte $R_{r i}$. Na Figura 8.4(a), dois conjuntos de resultados $R_{r}$ e $R_{t}$ possuem um elemento em comum $\left(r_{r 1}=r_{t 1}\right)$, assim a distância entre esses elementos é igual a zero $(d=0)$. Para os elementos $r_{t 2}$ e $r_{t 3}$, as distâncias para seus representantes de grupo $r_{r 2}$ e $r_{r 3}$ são, respectivamente, dois $(d=2)$ e três $(d=3)$, portanto, o erro total é por $D E_{M}=5$. Por outro lado, na Figura 8.4(b), dois conjuntos de resultados que não possuem nenhum elemento em comum, mas os elementos em $R_{t}$ são similares aqueles em $R_{r}$. As distâncias de $r_{t 1}$ para $r_{r 1}$, de $r_{t 2}$ para $r_{r 2}$ e de $r_{t 3}$ para $r_{r 3}$ são todas igual a um $(d=1)$, assim o erro total é dado por $D E_{M}=3$. Portanto, o erro de dissimilaridade do resultado da Figura 8.4(b) é menor que o da Figura 8.4(a) mesmo não compartilhando elementos.

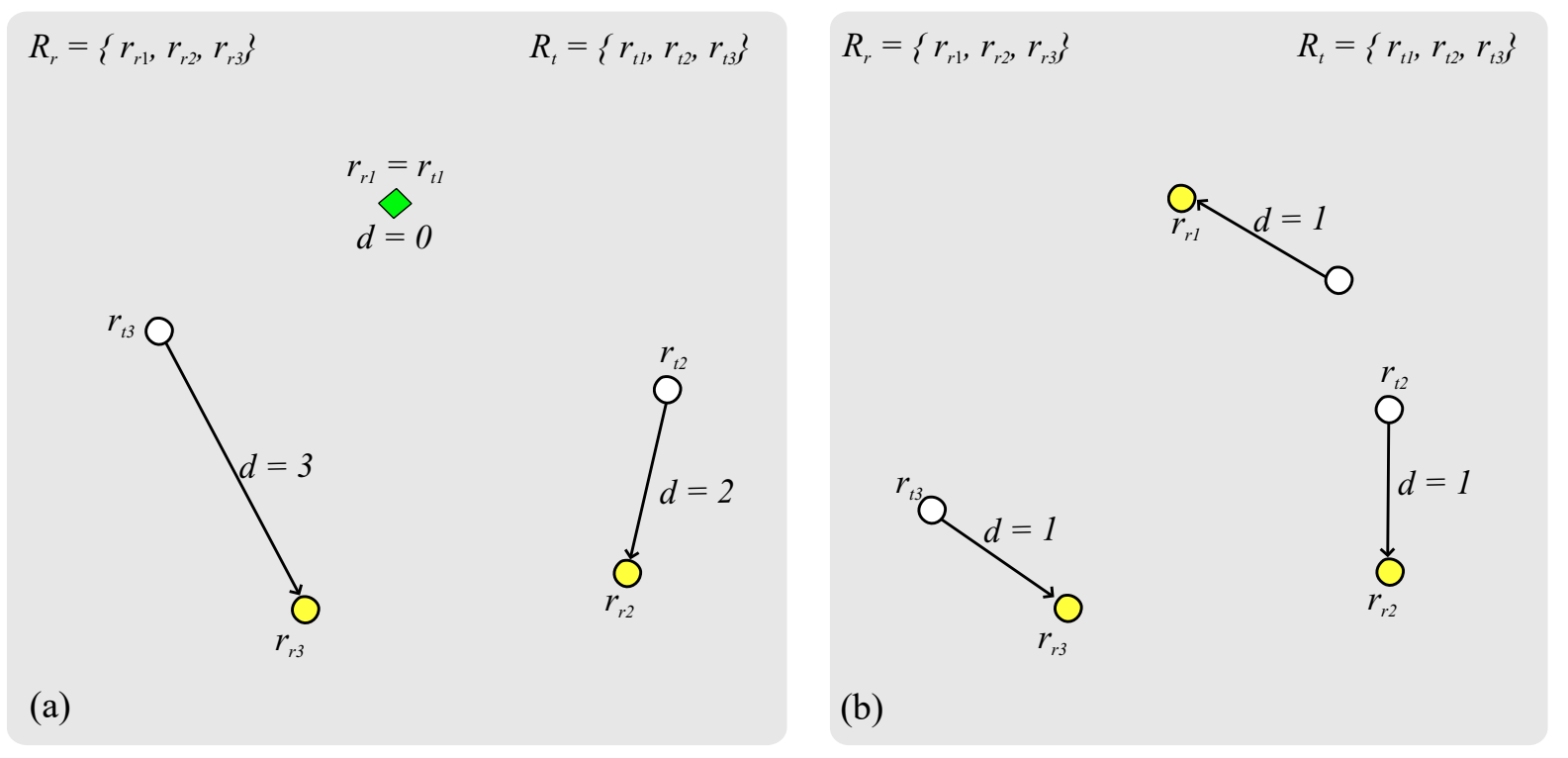

Figura 8.4: Método $D E_{M}$. (a) Conjuntos de resultados com $D E_{M}=5$. (b) Conjuntos de resultados com $D E_{M}=3$.

\subsection{Experimentos}

Esta seção apresenta os resultados experimentais para as proposta de métodos de avaliação de diversificação para algoritmos baseados em conteúdo sobre quatro conjuntos de dados reais sumarizados na Tabela 8.1. Para cada conjunto de dados, a tabela indica o seu nome, cardinalidade do conjuntos (Nro. de elementos), número de Dimensões e as funções de dis- 
Tabela 8.1: Estatísticas dos conjuntos de dados avaliados

\begin{tabular}{|c|c|c|c|c|}
\hline Conjunto de dados & Nro. de elementos & Dimensões & $\delta_{\text {sim }}, \delta_{d i v}$ & Descrição \\
\hline Aloi & 72.000 & 144 & $L_{2}$ & $\begin{array}{l}\text { Conjunto de imagens co- } \\
\text { loridas rotacionadas no } \\
\text { plano a cada } 5 \text { graus, com- } \\
\text { posto por } 1.000 \text { objetos, } \\
\text { obtido do sítio Amsterdam } \\
\text { Library of Object } \text { Images }^{1} \text {. }\end{array}$ \\
\hline U.S Cities & 25.375 & 2 & $\overline{L_{2}}$ & $\begin{array}{l}\text { Conjunto de dados de co- } \\
\text { ordenadas geográficas e } \\
\text { características econômicas } \\
\text { das cidades americanas, } \\
\text { obtido do sítio U.S. Cen- } \\
\text { sus Bureau }{ }^{2} \text {. }\end{array}$ \\
\hline Nasa & 40.150 & 20 & $L_{2}$ & $\begin{array}{l}\text { Conjunto de vetores de } \\
\text { características extraídos } \\
\text { de imagens da NASA. } \\
\text { Fonte:Biblioteca de espaço } \\
\text { Métrico }^{3} \text {. }\end{array}$ \\
\hline Faces & 1.016 & 761 & $L_{1}$ & $\begin{array}{l}\text { Conjunto de vetores de ca- } \\
\text { racterísticas extraídos de } \\
\text { imagens de faces humanas. } \\
\text { Fonte:Biblioteca de espaço } \\
\text { Métrico }^{3} \text {. }\end{array}$ \\
\hline
\end{tabular}

tâncias utilizadas $\left(\delta_{\text {sim }}\right.$ e $\left.\delta_{\text {div }}\right)$, seguidos de uma breve descrição e a fonte de obtenção dos dados. É importante destacar que os métodos de avaliação operam sobre a cardinalidade do conjuntos de resultados, sendo assim insensíveis a cardinalidade do conjunto de dados, porém a densidade do conjunto de dados pode afetar a qualidade dos métodos, contudo tal fator é apenas indiretamente relacionado com a cardinalidade do conjunto de dados.

Foram avaliados os seguintes algoritmos de diversificação de resultados: Greedy Randomized With Neighborhood Expansion (GNE), o algoritmo First-Match (FM), Maximal Marginal Relevance (MMR) e o algoritmo SWAP. Foi considerada uma mesma plataforma de avaliação para garantir a comparação justa entre os algoritmos que foram codificados utilizando a linguagem de programação $\mathrm{C}++$.

Foram consideradas duas estratégias para avaliar a diversidade alcançada: a extração de estatísticas dos conjuntos de resultados para comparar os algoritmos e uma comparação direta dos elementos de cada conjunto de resultados. Os estudos experimentais foram conduzidos em duas partes: (1) Na Seção 8.2.1, foram realizadas análises de validação nos métodos propostos de avaliação, apresentados na Seção 8.1.2, comparando-os com duas medidas comumente utilizada para avaliar algoritmos baseados em conteúdo, por exemplo, a medida

\footnotetext{
${ }^{1}$ Amsterdam Library of Object Images Homepage. Último acesso em: 25 de Maio de 2016. Disponível em: $<$ http://staff.science.uva.nl/ aloi/>

${ }^{2}$ U.S. Census Bureau Homepage - American Census 2000. Último acesso em: 11 de Setembro de 2014. Disponível em: <http://www.census.gov/>

${ }^{3}$ International Workshop on Similarity Search and Applications (SISAP). Último acesso em: 25 de Maio de 2016. Disponível em: <http://www.sisap.org/dbs/>
} 
Gap e a função objetivo (Seção 3.4); e (2) na Seção 8.2.2, foram exploradas as características de diversidade extraídas de cada conjunto de resultado fornecido pelos algoritmos testados, comparando-as com as características do conjunto de resultado do algoritmo $k$-NN para identificar a mudança de cada característica no processo de diversificação.

Os experimentos foram realizados em um computador com a seguinte configuração: processador Intel ${ }^{\circledR}$ Core $^{\text {TM }}$ i7-4770 com 8 GB de memória RAM. O sistema operacional utilizado foi a distribuição GNU Linux Ubuntu 11.10.

\subsubsection{Comparação de Métodos de Avaliação de Diversificação}

Os métodos de avaliação de diversificação propostos na Seção 8.1.2 foram comparados com os métodos comumente utilizados para avaliar algoritmos de diversificação, Gap e função objetivo $(\mathcal{F})$, utilizando as respostas de um algoritmo exaustivo como conjunto de resultado de referência $\left(R_{r}\right)$ como resultado ideal (ground truth). Devido ao alto custo computacional (NP-Difícil) necessário para obter um conjunto de resultados com o algoritmo exaustivo, o espaço de busca dos elementos foi restringido para os 200 elementos mais similares ao elemento central de busca e o número de vizinhos diversos mais próximos foi definido como $k=5$ para todos os conjuntos de dados avaliados. Visando garantir uma comparação justa entre os algoritmos de otimização, foi utilizada a seguinte função para todos os algoritmos implementados, $\mathcal{F}\left(s_{q}, S\right)=(k-1)(1-\lambda) \cdot \delta_{\text {sim }}\left(s_{q}, S\right)+2 \lambda \cdot \delta_{\text {div }}(S)$. Para cada conjunto de dados, o parâmetro $\lambda$ foi variado entre 0.1 até 0.9 . Para criar um conjunto de teste de busca, foram escolhidos aleatoriamente 100 elementos distintos para serem utilizados como centros de busca. Cada ponto nos gráficos de qualidade representam a média da métrica avaliada para 100 buscas com valores de $k$ e $\lambda$ constantes, porém com elementos centrais de busca distintos. Nos gráficos (a) das Figuras 8.5, 8.6, 8.7 e 8.8, valores mais próximos do topo indicam melhores algoritmos. Nos demais gráficos, valores mais próximos da base indicam melhores algoritmos. Contudo, a interpretação pode ser diferente para cada método de avaliação. Por exemplo, valores baixos para o método $D_{M}$ representam que o conjunto de resultado possui muitos elementos em comum com o conjunto de referência, enquanto que valores baixos para o método $D E_{M}$ indicam que o conjunto de resultado possui o menor erro de dissimilaridade entre os elementos selecionados nos conjuntos $R_{r}$ e $R_{t}$, o que não significa que os elementos sejam os mesmos, exceto quanto os valores de $D_{M}$ e $D E_{M}$ são ambos igual a zero.

O parâmetro do algoritmo FM (distância de separação) foi definido empiricamente para cada conjunto de dados, variando a distância de separação em incrementos de 0.1 até o conjunto de resultado retornar a quantidade exata de elementos diversos requisitados em um espaço de busca de 200 elementos mais similares ao elemento central de busca. Assim, foram escolhidos dois valores possíveis para distância de separação (um valor médio e o mais alto) com o intuito de preservar as mesmas condições que os algoritmos GNE, MMR e SWAP serão executados, possibilitando a comparação dos elementos no mesmo espaço de busca e com condições semelhantes.

\section{Experimentos com o conjunto de dados U.S Cities}

O primeiro conjunto de experimentos, visou avaliar os métodos em dados de baixa dimensionalidade. Assim, os resultados de cada algoritmo foram comparados com o conjunto de resultado de referência definido pelo algoritmo exaustivo no conjunto de dados U.S Cities, variando $\lambda$ entre 0.1 até 0.9 . Para esse conjunto de dados, a distância de separação do algoritmo FM foi definida como: $\mathrm{FM}_{\text {conf } 1}=0.5$ e $\mathrm{FM}_{\text {conf } 2}=1.0$. Apenas as coordenadas 

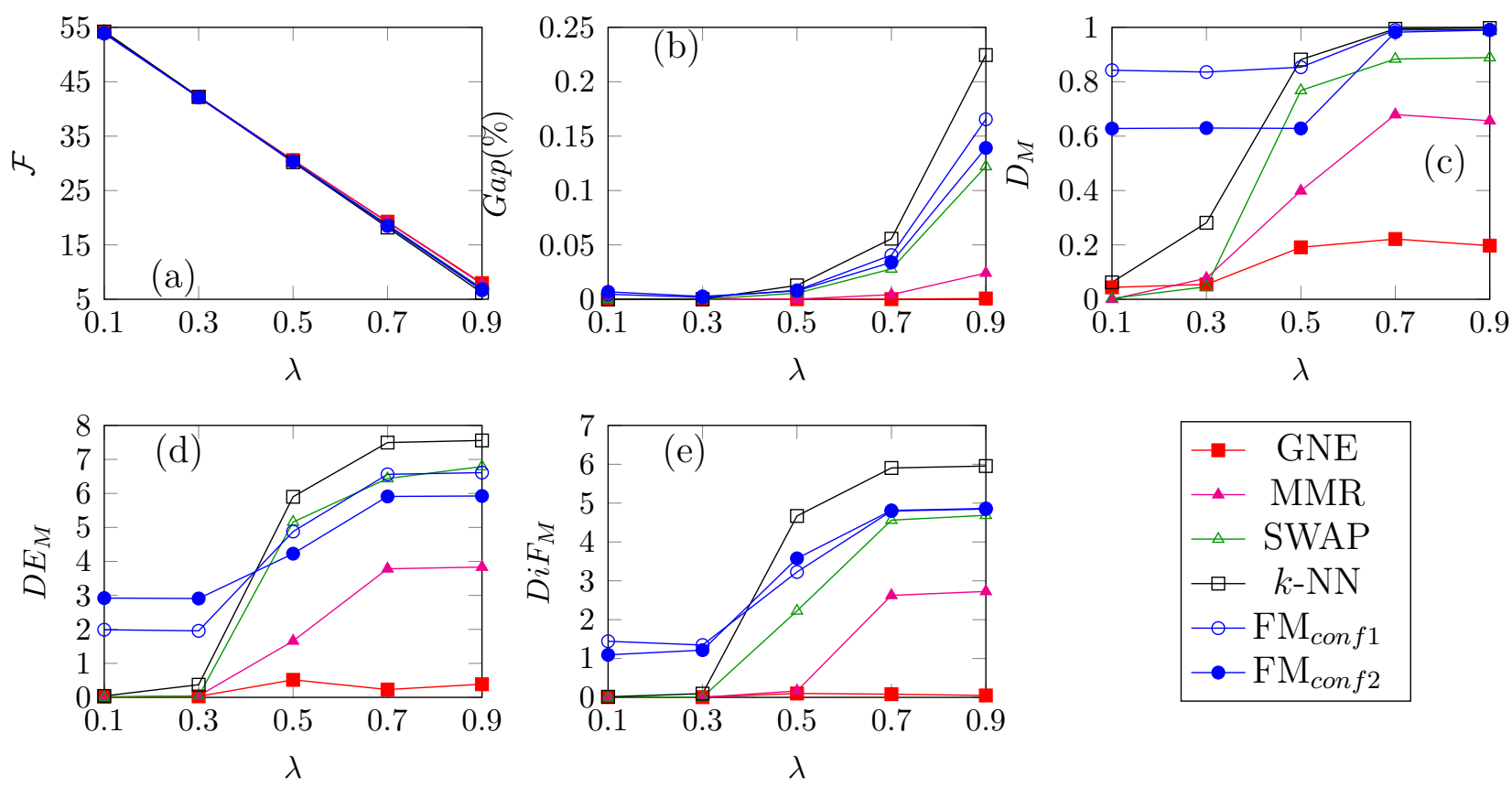

Figura 8.5: Comparação dos cinco métodos de avaliação de diversificação sobre o conjunto de dados U.S Cities variando a preferência de diversidade. Valores mais próximos do topo indicam melhores algoritmos no Gráfico (a), para o restante dos gráficos valores mais próximos da base indicam melhores algoritmos.

geográficas (latitude e longitude) foram utilizadas na comparação dos elementos durante o experimento.

A Figura 8.5 mostra os resultados para o conjunto de dados U.S Cities. As Figuras 8.5 (a) e (b) apresentam os valores para os métodos de função objetivo $(\mathcal{F})$ e o método gap, respectivamente. Como pode ser visto na Figura 8.5 (a), todos algoritmos, incluindo o algoritmo $k$-NN (sem diversificação), possuem valores similares de função objetivo e, de acordo com a Figura 8.5 (b), a maior diferença entre o algoritmo exaustivo foi de $20 \%$. Tais resultados sugerem que os métodos de avaliação utilizados retornam valores muito próximos em qualidade para os algoritmos avaliados, mesmo para o $k$-NN, um algoritmo que não considera diversidade.

Por outro lado, utilizando os métodos de avaliação propostos neste trabalho de doutorado, é possível verificar claramente a diferença entre os conjuntos de resultados retornados pelos algoritmos testados. Por exemplo, a Figura 8.5 (c) mostra os resultados para o método $D_{M}$ e, como pode ser visto, existem discrepância entre todos os métodos. Como era esperado, os algoritmos SWAP e MMR praticamente recuperaram os mesmos elementos que o algoritmo exaustivo para $\lambda<0.3$, porém para valores mais altos de $\lambda$, MMR recupera apenas dois elementos idênticos ao do conjunto $R_{r}$, enquanto SWAP recupera somente um elemento. Ainda é possível perceber na mesma figura, que o algoritmo $k$-NN não retorna os mesmos elementos que o algoritmo exaustivo quando o valor de $\lambda$ é incrementado. Assim, $D_{M}$ é capaz de distinguir entre um algoritmo que utiliza a propriedade de diversidade para escolher os elementos do conjunto de resultado de outro que não utiliza, por exemplo, o $k$-NN. Ainda sobre a Figura 8.5 (c), o método $D_{M}$ considerou os resultados do algoritmo FM similares ao do algoritmo $k$-NN, isto é resultados indesejados. Tais resultados também eram esperados, pois a definição de diversidade do algoritmo FM consiste em selecionar elementos que estejam separados uns dos outros por uma distância de separação, o que é diferente da definição 
de diversidade do algoritmo que forneceu o conjunto de resultado de referência. Por outro lado, o algoritmo GNE se provou superior em relação a todos os algoritmos avaliados e, inclusive selecionou pelo menos 4 dos 5 elementos pertencentes ao conjunto de referência. Portanto, $D_{M}$ foi capaz de identificar a superioridade do algoritmo GNE em relação aos demais algoritmos.

A Figura 8.5 (d) apresenta os resultados para o método $D E_{M}$, visando ressaltar a distância entre os elementos recuperados de um algoritmo específico em relação aos elementos do conjunto de resultados $R_{r}$. Como pode ser visto, o algoritmo GNE possui o menor erro de dissimilaridade, indicando que GNE é capaz de escolher elementos muito similares àqueles selecionados pelo algoritmo exaustivo. Para $\lambda \leq 3$, o algoritmo $k$-NN obteve, praticamente, o mesmo erro de dissimilaridade que os algoritmos de diversificação, indicando que para valores de $\lambda$ que favorecem a similaridade, tais algoritmos não alteram substancialmente as respostas do $k$-NN em conjuntos de baixa dimensionalidade. O algoritmo FM obteve um erro menor de dissimilaridade em comparação com o $k$-NN quando $\lambda$ é maior que 0.5 , indicando melhor qualidade na escolha dos elementos, aumentando a capacidade de distinção entre algoritmos de diversificação. Portanto, é possível concluir que considerar apenas a avaliação do conjunto de resultados de maneira binária não é suficiente para garantir a qualidade de um algoritmo.

A Figura 8.5(e) apresenta os resultados para o métido $D i F_{M}$, objetivando comparar os resultados dos algoritmos avaliados com base nos vetores de características de diversidade. As características extraídas, novamente, indicam que o algoritmo GNE é o melhor algoritmo para replicar a seleção dos elementos do conjunto $R_{r}$, seguido do algoritmo MMR. No entanto, na Figura 8.5(e) ambos o GNE e o MMR são considerados equivalentes quando $\lambda \leq 0.5$, revelando uma situação oposta do que foi mostrado com os métodos $D E_{M}$ e $D_{M}$, em que tais algoritmos só foram considerados equivalentes para $\lambda \leq 0.3$. Este resultado mostra que, apesar dos algoritmos escolherem elementos distintos, a distribuição de distância entre os elementos no conjunto de resultado do GNE e MMR são equivalentes.Em relação ao algoritmo SWAP, os resultados foram atenuados, porém mantendo o posto de terceiro melhor algoritmo. Por fim, as características extraídas foram capazes de distinguir entre os resultados do algoritmo FM do $k$-NN, mostrando que, de fato, há diferença entre a distribuição de distância desses algoritmos.

\section{Experimentos com o conjunto de dados Aloi}

O segundo conjunto de experimentos visou a avaliação dos métodos em dados de alta dimensionalidade. O conjunto de dados Aloi foi utilizado, sendo que foram extraídas 144 características utilizando o extrator de momentos estatísticos de cor (STRICKER, 1995). A distância de separação para o algoritmo FM foi definida como: $\mathrm{FM}_{\text {conf } 1}=0.5$ e $\mathrm{FM}_{\text {conf } 2}=1.0$.

As Figuras 8.6(a) e (b) mostram os resultados para os métodos de função objetivo $(\mathcal{F})$ e gap. É possível perceber que todos os algoritmos apresentaram, novamente, valores muito similares, porém as diferenças se mostraram mais evidentes quando $\lambda \geq 0.7$.

A Figura 8.6(c) ilustra os resultados para o método $D_{M}$. Embora o algoritmo SWAP tenha alcançado melhor valor de $\mathcal{F}$ quando comparado com o $k$-NN na Figura 8.6(a), quando analisado pelo $D_{M}$, SWAP apresentou os mesmos resultados que o $k$-NN, possuindo, exatamente, o mesmo valor para $\lambda=0.5$. Novamente, GNE foi o melhor algoritmo, porém a diferença para o conjunto de resultado ideal foi maior. Para a distância de separação 1.0, o algoritmo FM obteve a mesmo valor que o GNE, sendo melhor que os resultados alcançados pelo MMR. Em resumo, em comparação com o conjunto de resultados exaustivos, todos os 

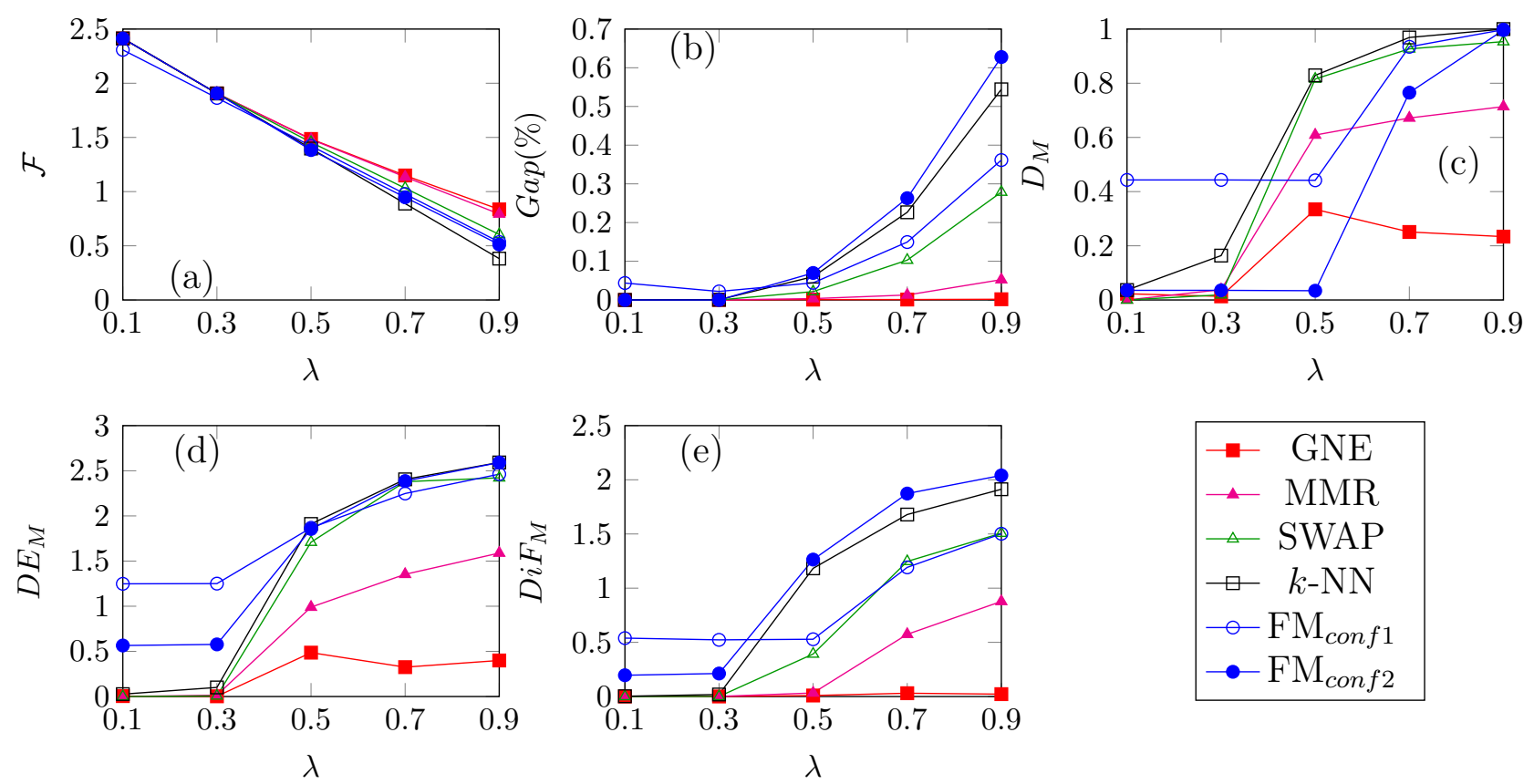

Figura 8.6: Comparação dos cinco métodos de avaliação de diversificação sobre o conjunto de dados Alo $i$ variando a preferência de diversidade.

algoritmos compartilharam menos elementos para dados de alta dimensionalidade. Contudo, o método $D_{M}$ possibilitou uma melhor análise do que é possível com os métodos de avaliação existentes.

A Figura 8.6(d) apresenta os resultados para o método $D E_{M}$. Para $\lambda \geq 0.5$, os algoritmos SWAP, FM (todas as configurações) e o $k$-NN possuem erro de dissimilaridade muito próximos quando comparados com o algoritmo exaustivo. Analisando este resultado em conjunto com os apresentados na Figura 8.6(c), é possível inferir que, apesar de escolherem elementos diferentes daqueles do conjunto de resultados $R_{r}$, esses algoritmos permaneceram com o mesmo erro de dissimilaridade, indicando uma possível existência de pequenos grupos (cluster em torno dos elementos selecionados no conjunto de resultados de referência.

A Figura 8.6(e) mostra os resultados do método $D i F_{M}$. Considerando apenas as características de diversidade, o algoritmo de FM para a distância de separação 1.0 obteve resultados com qualidade inferior ao do algoritmo $k$-NN. Tal dissimilaridade pode ser explicada pelo fato de que FM seleciona elementos que estão igualmente distantes um dos outros, o que não é assegurado para os algoritmos testados, incluindo o algoritmo exaustivo.

\section{Experimentos com o conjunto de dados Nasa}

O terceiro experimentou avaliou os métodos em dados em média dimensionalidade. Assim, o conjunto de dados Nasa que possui 20 dimensões foi utilizado. A distância de separação para o algoritmo FM foi definida como: $\mathrm{FM}_{\text {conf } 1}=0.5$ e $\mathrm{FM}_{\text {conf } 2}=1.0$.

A Figura 8.7 apresenta os resultados. Como pode ser visto, todos os métodos de avaliação propostos foram capazes de distinquir razoavelmente bem os algoritmos GNE, MMR e SWAP. A Figura 8.7 (c) mostra que o algoritmo FM e $k$-NN apresentam qualidade similar considerando o método $D_{M}$. Uma possível razão para isso é que a distância de separação não definida corretamente para melhorar a distribuição dos elementos no espaço de busca delimitado. Essa suposição é confirmada pelos resultado da Figura 8.7 (d), pois o FM e o $k$-NN apresentaram, praticamente, o mesmo erro de dissimilaridade para o conjunto de 

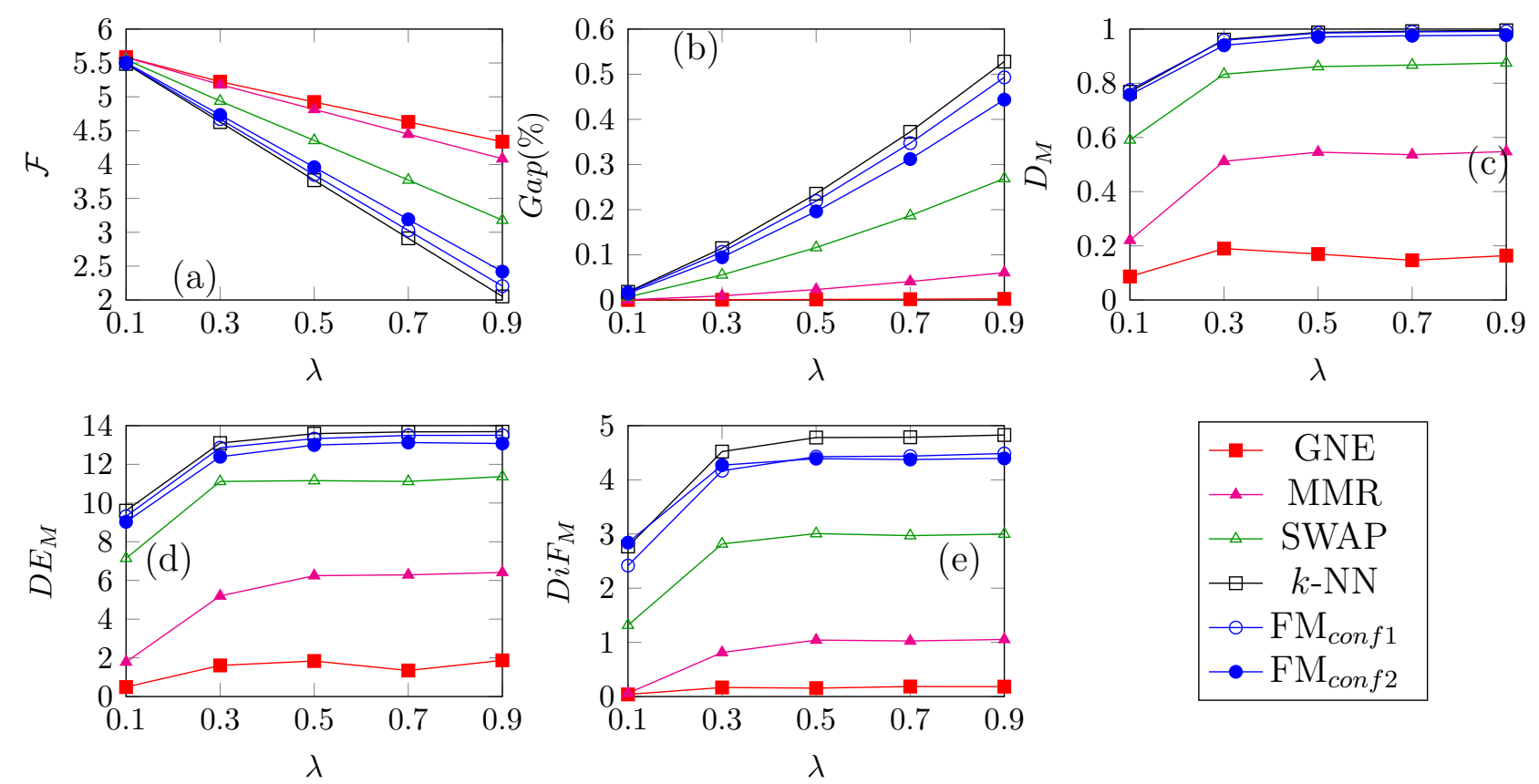

Figura 8.7: Comparação dos cinco métodos de avaliação de diversificação sobre o conjunto de dados Nasa variando a preferência de diversidade.

resultados de referência, mostrando que o algoritmo FM selecionou elementos próximos daqueles escolhidos pelo $k$-NN. Em relação aos resultados do método $D i F_{M}$ (Figura 8.7 (e)), FM continuou apresentando o mesmo comportamento que o $k$-NN, o que já era esperado devido aos resultados mostrados nas Figuras 8.7 (c) e (d). Este novo resultado confirma nossa suposição de que a distância de separação não foi definida corretamente para alterar a resposta do $k$-NN. Como foi imposto um mesmo espaço de busca para todos os algoritmos, valores maiores de distância de separação recuperavam elementos fora dos 200 elementos considerados pelo algoritmo exaustivo.

\section{Experimentos com o conjunto de dados Faces}

O último experimento visou avaliar os métodos em conjuntos com dados em altíssimas dimensões, utilizando o conjunto de dados Faces que possui 761 dimensões. A distância de separação para o algoritmo FM foi definida como: $\mathrm{FM}_{\text {conf } 1}=0.3$ e $\mathrm{FM}_{\text {conf } 2}=0.6$. A Figura 8.8 apresenta os resultados. Novamente, os resultados do algoritmo FM foram exatamente iguais aos do $k$-NN para todos os métodos avaliados, reforçando nossa suposição que a distância de separação foi insuficiente para induzir a diversidade na resposta do $k$-NN. As Figuras 8.8 (c), (d) e (e) mostram que todos os métodos de avaliação propostos apresentaram com maior clareza a diferença entre as abordagens de construção dos resultados dos algoritmos testados, indicando que a estratégia de construção de resultado por troca de elementos é mais sensitiva as variações de dimensionalidade dentre aquelas que foram testadas, pois mesmo apresentando melhores resultados, foi a única que manteve comportamento similar ao do $k$-NN com o aumento da preferência por diversidade. Em relação ao método $D i F_{M}$, a Figura 8.8 (e) mostra que o FM e o $k$-NN possuem a mesma distribuição de distância entre os elementos. Além disso, MMR e GNE apresentaram a mesma qualidade quando $\lambda \leq 0.3$, mostrando, novamente, que apesar de escolherem elementos distintos (Figuras 8.8(c) and (d)), a distribuição de distância entre os elementos do conjunto de resultados foi similar. 

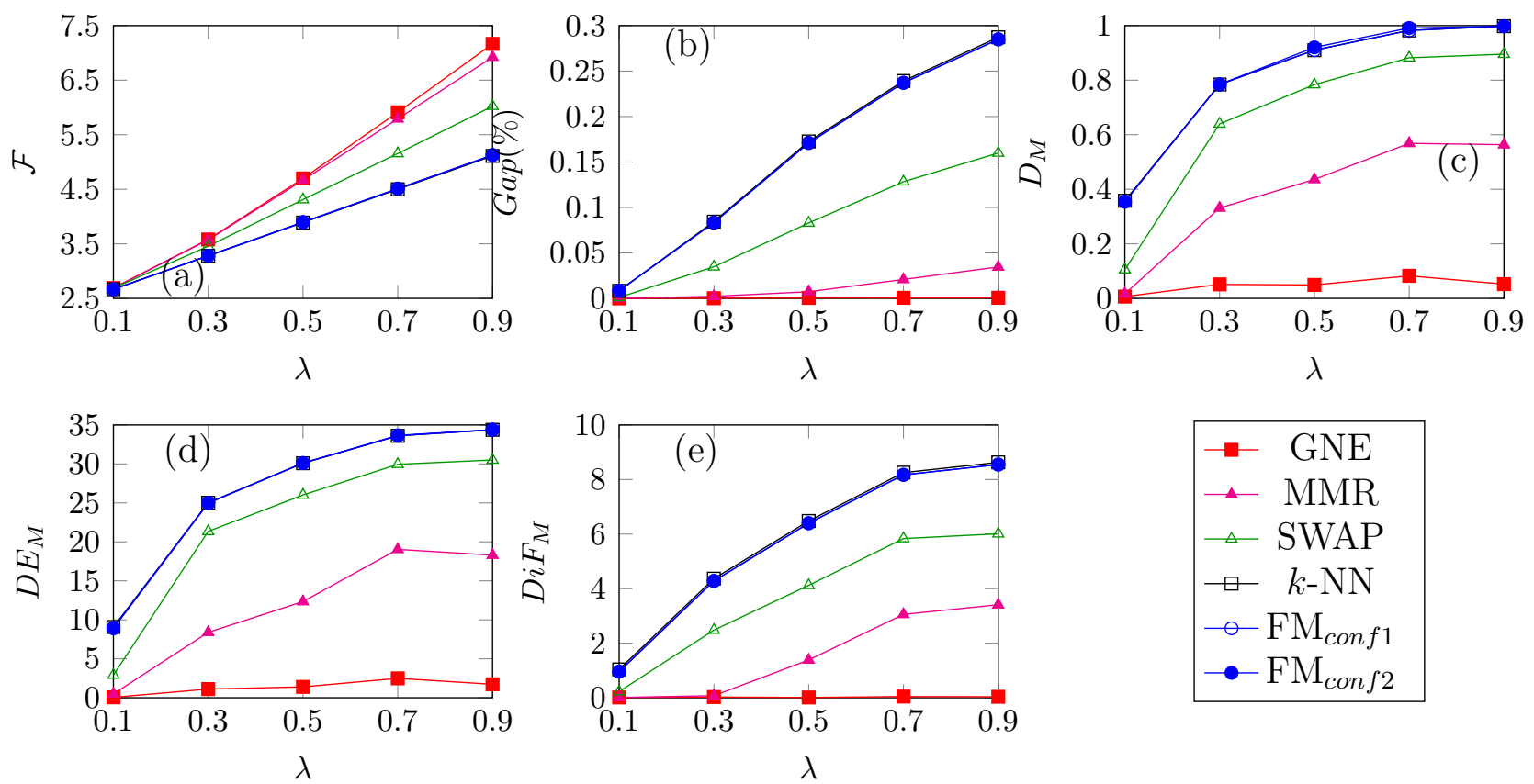

Figura 8.8: Comparação dos cinco métodos de avaliação de diversificação sobre o conjunto de dados Faces variando a preferência de diversidade.

\subsubsection{Análise de Características de Diversidade}

As características de diversidade propostas para o extrator de métricas de diversidade $\mathfrak{L}$ foram avaliadas para cada conjunto de resultado gerado pelos algoritmos testados,sendo comparadas com os resultados obtidos pelo algoritmo de $k$-NN (sem diversificação). O objetivo é mostrar quais características se transformam no processo de diversificação para cada algoritmo avaliado. Para avaliar essa informação, foi considerado a razão de cada característica extraída por cada algoritmo testado pelo o valor correspondente da característica do algoritmo $k$-NN.

De maneira análoga à seção anterior, foi utilizado um conjunto de testes compostos por 100 elementos escolhidos aleatoriamente para serem utilizados como elementos centrais de busca. Para cada conjunto de dados, o parâmetro $\lambda$ foi novamente variado entre 0.1 até 0.9 para verificar a diferença na transformação das características quando a preferência por diversidade é incrementada. Devido ao alto custo para a execução do algoritmo exaustivo, o espaço de busca ficou restrito aos 200 elementos mais próximos do elemento central de busca e foram realizadas buscas pelos cinco vizinhos diversos mais próximos $(k=5)$. Nesta seção, os resultados do algoritmo FM foram omitidos devido a definição de diversidade (distância de separação) é diferente das abordagens de otimização, pois as comparações de características são diretamente dependentes das características extraídas representarem a definição de diversidade.

A Figura 8.9 mostra a razão de cada característica de diversidade extraída comparada com as extraídas do resultado do algoritmo de $k$-NN para o conjunto de dados Nasa que possui 20 dimensões, utilizando três valores de preferência de diversidade $(\lambda)[0.1,0.5,0.9]$. A Figura 8.9(a) mostra os resultados para a situação em que a preferência de diversidade favorece a similaridade $(\lambda=0.1)$. Como pode ser visto, todos os algoritmos modificaram as mesmas características. O aumento do valor das características de distância mínima $(\mathrm{mD})$, desvio padrão de similaridade (SDS), desvio padrão de diversidade (SDD) e distância média de 
$-\mathrm{GNE} \backsim \mathrm{MMR} \backsim \mathrm{SWAP} \backsim-$ Exaustivo
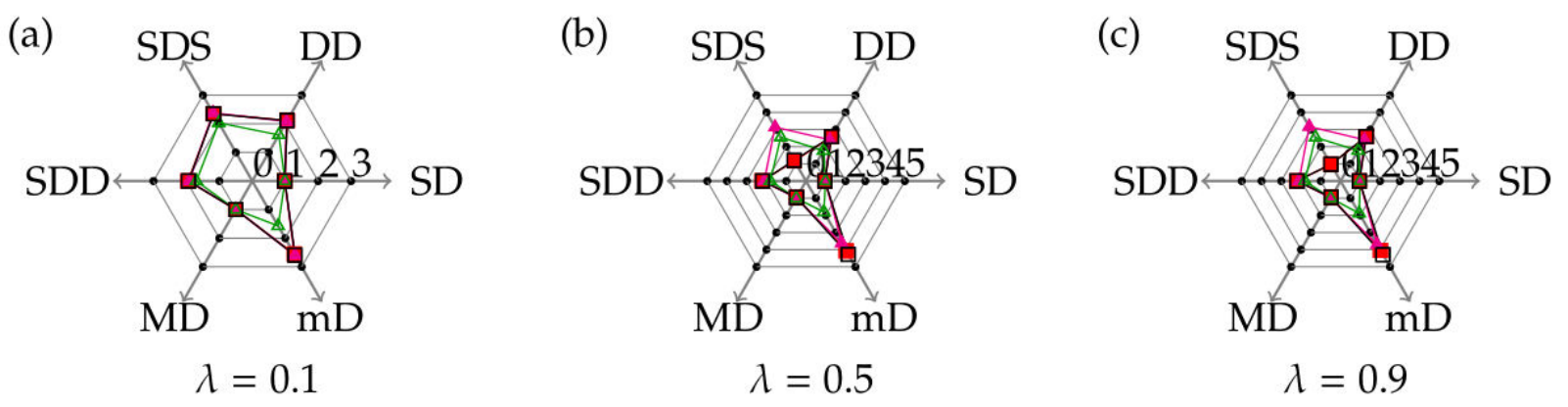

Figura 8.9: Gráficos em Radar para análise das características de diversidade no conjunto de dados Nasa. SD é a abreviação da característica AvgSimDist, DD para a característica AvgDivDist, SDS para a característica SDSimDist, SDD para a característica SDDivDist, MD para a característica MaxDist e, por fim, $\mathrm{mD}$ é a abreviação da característica MinDist.

diversidade (DD) sugere que, para valores de $\lambda$, os algoritmos realizam apenas a modificação do par de elementos mais próximo do elemento central de busca. No entanto, os elementos ainda continuam muito similares ao elemento de busca, pois a característica de distância média de similaridade (SD) possui o mesmo valor do conjunto de resposta do $k$-NN.

A Figura 8.9(b) mostra os resultados quando o compromisso de diversidade é balanceado $(\lambda=0.5)$. Como era esperado, todos os algoritmos continuaram a aumentar o valor das características mD, DD e SDD. É importante destacar que o GNE foi o único algoritmo que modificou todas as características de maneira similar ao algoritmo exaustivo. O algoritmo MMR modifica as características de diversidade de maneira similar ao comportamento do GNE, porém MMR aumenta a característica de desvio padrão de similaridade (SDS), o que é esperado, pois o MMR sempre inicia o processo de diversificação escolhendo o elemento mais similar ao elemento central de busca para, posteriormente, selecionar os elementos mais diversos do conjunto (estratégia de construção incremental). Os resultados do SWAP mostram que o compromisso com a similaridade é mantido, mesmo que a preferência de diversidade beneficie ambas propriedades, a similidade e a diversidade. $\mathrm{O}$ algoritmo aumentou um pouco o valor da característica de distância mínima $(\mathrm{mD})$, porém as características de similaridade praticamente não foram modificadas.

A Figura 8.9(c) ilustra os resultados quando a preferência de diversidade é definida para beneficiar a diversidade $(\lambda=0.9)$. Como era previsto, ambos os algoritmos GNE e o exaustivo reduziram consistentemente a importante das características de similaridade em favor da diversidade. É interessante ressaltar que as características desvio padrão de similaridade (SDS), distância máxima (MD) e distância média de similaridade (SD) foram muito reduzidas, indicando que tais algoritmos selecionam elementos mais afastados do centro de busca devido a alta probabilidade destes maximizarem as medidas de diversidade. Por outro lado, ambos os algoritmos, MMR e SWAP aumentaram o desvio padrão de similaridade (SDS), revelando que eles sacrificam a medida de diversidade para manter a similaridade em relação ao elemento de busca, independentemente da preferência por diversidade informada pelo usuário.

A Figura 8.10 (a) apresenta os resultados para o conjunto de dados Faces, que possui 761 dimensões, com preferência de diversidade ajustada para $\lambda=0.1$. Para dados em alta di- 


$$
\because \mathrm{GNE} \leadsto \mathrm{MMR} \triangle \mathrm{SWAP} \backsim-\text { Exaustivo }
$$
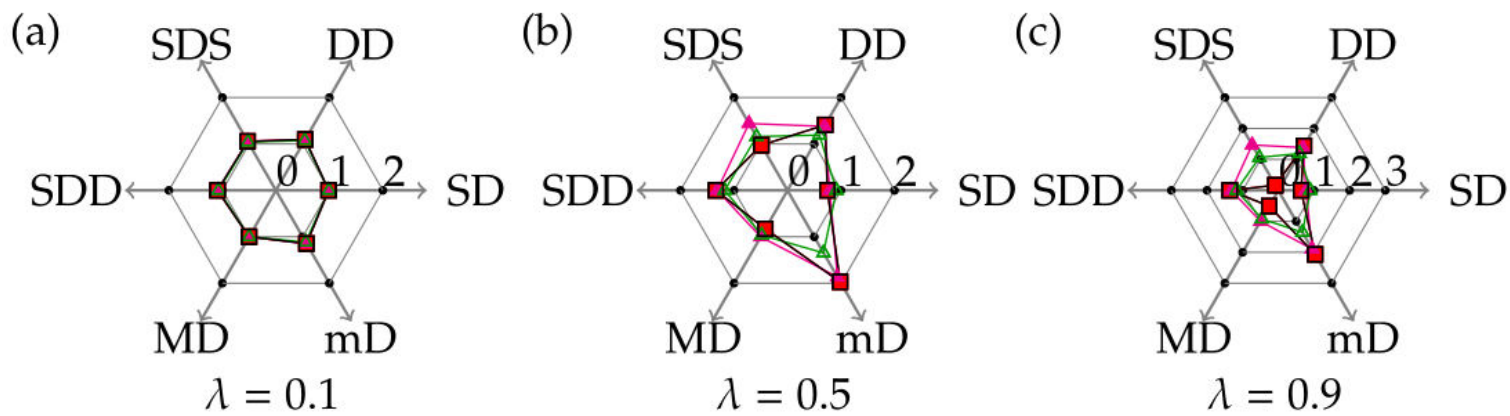

Figura 8.10: Gráficos em Radar para análise das características de diversidade no conjunto de dados Faces. SD é a abreviação da característica AvgSimDist, DD para a característica AvgDivDist, SDS para a característica SDSimDist, SDD para a característica SDDivDist, MD para a característica MaxDist e, por fim, $\mathrm{mD}$ é a abreviação da característica MinDist.

mensionalidade, todos os algoritmos mantiveram o comportamento de alteração de todas as características daquelas modificadas pelo $k$-NN, apresentando comportamento diferente do que ocorreu com dados em menor dimensão (Figure 8.10(a)). As Figuras 8.10(b) e (c) mostram os resultados para as preferências de diversidade $\lambda=0.5$ e $\lambda=0.9$, respectivamente. Como pode ser visto, os resultados são muito similares aos reportados para o conjunto de dados Nasa (Figura 8.9), indicando que, para esses valores de preferência de diversidade, os algoritmos tendem a modificar as mesmas características, independentemente da dimensionalidade do conjunto de dados. Resultados similares também foram alcançados para os conjuntos de dados U.S Cities e Aloi, porém os mesmos foram omitidos por uma questão de concisão.

\subsection{Considerações Finais}

Este capítulo apresentou a proposta de novos métodos de avaliação à qualidade da diversificação dos conjuntos de resultados dos algoritmos baseados em conteúdo. Os novos métodos consideram várias análises estatísticas obtidas por diferentes estratégias para medir a diversidade de conjuntos de resultados. Além disso, foi proposto um de extrator de características de diversidade utilizando apenas as relações de distância entre os elementos dos conjuntos de resultados avaliados. A definição de um espaço de resposta permite a comparação de vários conjuntos de resultados, a escolha de novas propriedades adequadas para o tipo de diversidade desejada para um conjunto de dados e possibilita desenvolver diretrizes para julgar qual o algoritmo de diversificação é o mais apropriado para um dado tipo de busca. Foram apresentados outros dois métodos de avaliação para a comparação direta entre os elementos dos conjuntos de dados para avaliar a precisão das respostas geradas pelos algoritmos de diversificação baseados na distância entre os elementos. Por fim, foram apresentados experimentos utilizando conjunto de dados reais, os quais confirmaram que os novos métodos de avaliação são capazes de fornecer informações adicionais sobre o processo de diversificação dos algoritmos existentes, indicando como os mesmos são comparados entre si, qual algoritmo apresenta comportamento mais próximo de um algoritmo com resposta exata, porém com custo computacional muito alto (por exemplo, o algoritmo exaustivo). Mais importante, os 
novos métodos de avaliação de diversificação complementam as informações fornecidas por outras métricas da literatura, aumentando a quantidade de informação disponível para a definição de uma plataforma de avaliação que possa indicar o benefício obtido quando a propriedade de diversidade é inserida em cada algoritmo avaliado.

O próximo capítulo apresenta a última frente de trabalho desta tese, um método para integração dos conceitos de buscas por similaridade com diversidade e as técnicas de mineração visual de dados, visando a a definição de um protótipo de sistema de recuperação de imagens por conteúdo que coloca o usuário em um papel mais ativo no processo de recuperação das imagens. Além disso, as técnicas de visualização são utilizadas para facilitar o entendimento de como a propriedade de diversidade é aplicada em conjuntos de dados de imagens. 


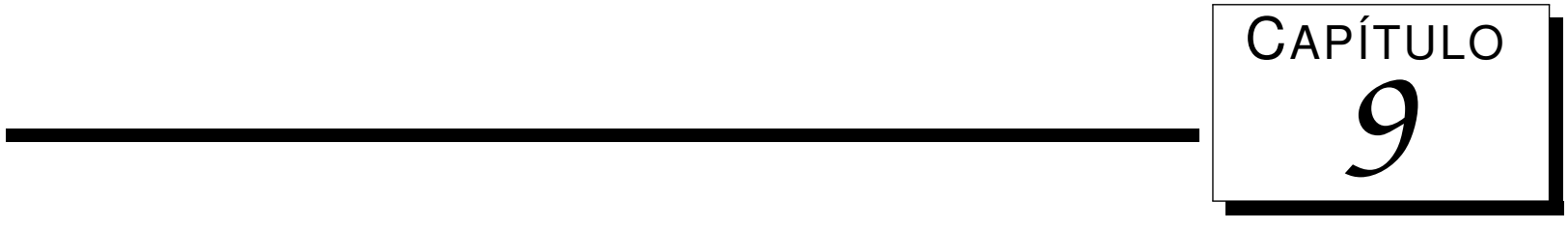

\section{O Método DiVI e o Protótipo VikS}

Os sistemas de recuperação de imagem baseados em conteúdo (CBIR) recuperam imagens que são similares a uma dada imagem de busca utilizando o conteúdo visual da imagem em vez de usar dados tradicionais (texto ou atributos numéricos anotados na imagem). Cada imagem pode ser associada a várias características visuais tais como cor, forma e textura. Tipicamente, os sistemas CBIR representam cada imagem como um vetor de característica, numa representação numérica que sumariza as características visuais que é obtida automaticamente por algoritmos de processamento de imagens. No entanto, nem sempre as imagens que são percebidas como similares pelos usuários possuem vetores de características similares e vice-versa. Essa diferença entre a representação numérica dos algoritmos de processamento de imagem e a cognição humana é chamada de lacuna semântica (semantic gap).

Assim, pesquisadores e desenvolvedores de sistemas CBIR vêm realizando estudos que mostram que a inclusão do usuário no processo de recuperação das imagens é uma maneira de reduzir a lacuna semântica de tais sistemas (GALLAS; BARHOUMI; ZAGROUBA, 2014). Uma abordagem comumente utilizada é chamada de realimentação de relevância (Relevance Feedback - RF). De modo geral, essa abordagem requisita que os usuários forneçam para o sistema notas sobre os resultados das buscas, que por sua vez são utilizadas para ajustar a definição de similaridade do sistema e apresentar novos resultados. Contudo, essa abordagem requer a utilização de muitos recursos computacionais e a habilidade do usuário para ajustar apropriadamente o sistema, o que nem sempre pode ser possível.

No capítulo 3 foram apresentadas outras maneiras para incluir o usuário no processo de recuperação e melhorar a expressividade das buscas, respectivamente, por meio das técnicas de mineração visual de dados e pela inclusão da propriedade de diversidade. No entanto, no melhor do nosso conhecimento, não há relatos na literatura sobre sistemas CBIR que utilizam técnicas de mineração visual com objetivo de auxiliar os usuários a interagir com o sistema. Além disso, os poucos protótipos que possibilitam a utilização de buscas com diversidade não fornecem informação suficiente para entender como essa propriedade é aplicada no conjunto de dados de imagens.

Neste capítulo será apresentado o método visualmente interativo e de diversidade (Diversity and Visually-Interactive - DiVI), uma abordagem para integrar os conceitos de diversidade e 
mineração visual de dados nos sistemas CBIR. O método emprega projeções multidimensionais para visualização do espaço de busca definido pelas características extraídas das imagens do conjunto de dados. Possibilita a interação com as visualizações apresentadas dos resultados, aumentando o entendimento sobre como são selecionados os elementos, incluindo como a diversidade é empregada na resposta. Além disso, o método possibilita a modificação da posição dos elementos de acordo com o interesse do usuário, aumentando a participação no processo de recuperação.

Em resumo, este capítulo apresenta as seguintes contribuições:

- Um método de integração dos conceitos de mineração visual de dados às buscas por similaridade com diversidade;

- Um protótipo de sistema CBIR que implementa o método DiVI para buscas em conjuntos de imagens;

O restante deste capítulo é estruturado da seguinte maneira. A Seção 9.1 apresenta o método DiVI para a integração das técnicas de mineração visual de dados e buscas por similaridades em sistemas CBIR. A Seção 9.2 apresenta o protótipo que implementa DiVI para buscas em conjuntos de imagens. A Seção 9.3 apresenta um estudo de caso realizado para avaliar o protótipo desenvolvido. Por fim, a Seção 9.4 apresenta as considerações finais deste capítulo.

\subsection{O Método DiVI}

Visando reduzir a lacuna semântica nos sistemas CBIR, o método visualmente interativo e de diversidade (Diversity and Visually-Interactive - DiVI) combina os conceitos de diversidade e as técnicas de Mineração Visual de Dados (MVD) para melhorar a eficiência dos resultados e as informações disponíveis sobre o processo como um todo. O método tem por objetivo incluir o usuário no processo de recuperação, permitindo a modificação do espaço de busca após a representação das imagens, possibilitando o usuário deslocar elementos de acordo com sua percepção, isto é, colocando elementos considerados similares próximos uns dos outros e afastando aqueles não tão similares no espaço de características. Assim, DiVI possibilita induzir a percepção intuitiva do usuário sobre a similaridade dos elementos que, em certos casos, não é possível alcançar com a avaliação das características extraídas automaticamente. Além disso, o usuário pode expressar a sua preferência por resultados diversos, reduzindo o esforço de análise quando as imagens são demasiadamente similares e as técnicas de visualizações fornecem informações para compreender a seleção dos elementos diversos.

Uma visão geral do método DiVI integrado a sistema CBIR utilizando as técnicas de mineração visual de dados (setas contínuas) ou não (setas pontilhadas) é apresentada na Figura 9.1. Logo no início, o usuário fornece os parâmetros usuais, como a imagem de busca e o número desejado $k$ de imagens a serem recuperadas. Em seguida, ambas as imagens do conjunto de dados e de busca são analisadas com base nas características visuais de cor, textura ou forma no módulo de extração de características (Feature Extractor Module - FEM). Os vetores de características extraídos são armazenados na base de dados de características. É importante ressaltar que essa primeira etapa de representação das imagens é realizada do mesmo modo que um sistema CBIR tradicional. 


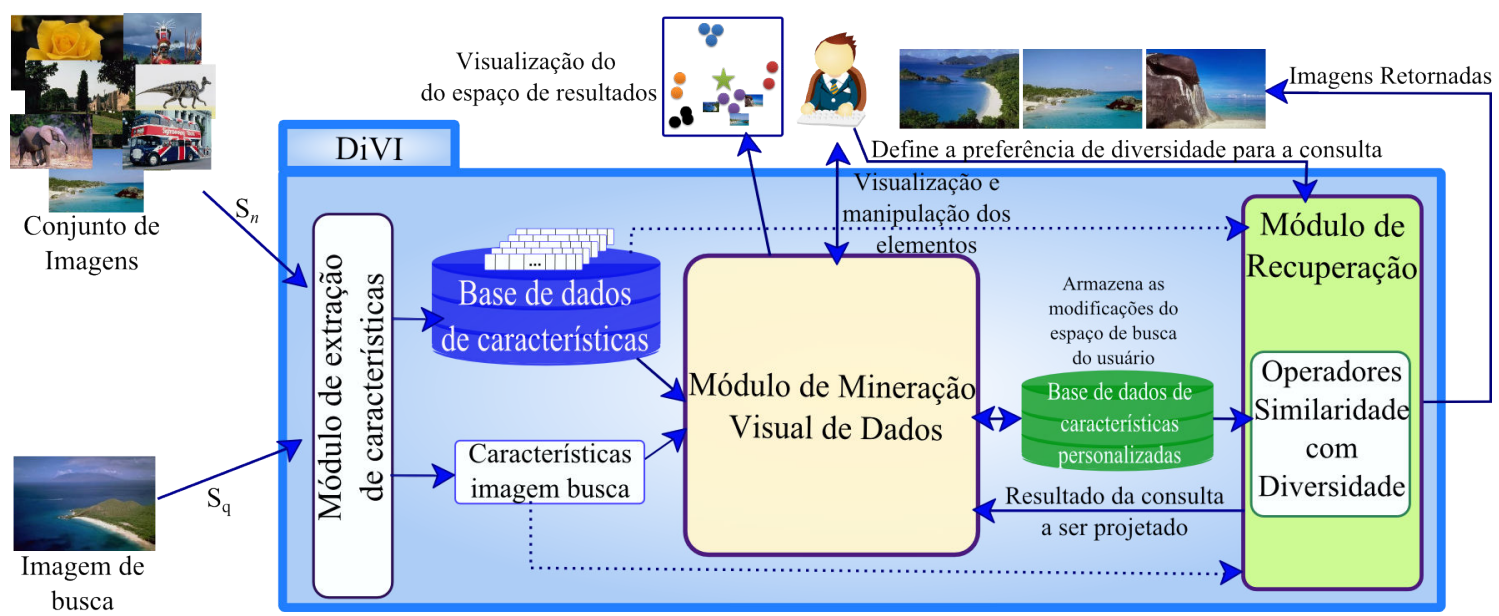

Figura 9.1: Pipeline do método DiVI.

Quando o usuário não utiliza as técnicas de MVD para interagir com o sistema, as características armazenadas na base de dados são enviadas para o módulo de recuperação, que possui operadores de similaridade com diversidade. Assim, o usuário pode informar também qual é a sua preferência por diversidade $(\lambda)$ à busca, como é ilustrado na Figura 9.1 (seguindo o fluxo das setas pontilhadas). Por outro lado, quando o módulo MVD é ativado, uma projeção inicial do espaço de busca é gerada, e o usuário pode manipular os elementos e inserir sua percepção sobre similaridade (seguindo o fluxo das setas contínuas na Figura 9.1). Visando reduzir tanto a complexidade e o esforço do usuário nessa etapa, amostras que representam cada categoria das imagens do conjunto de dados (chamadas de pontos de controle - PC) juntamente com a projeção da imagem de busca são pre-selecionadas utilizando a técnica FASTMAP (descrita na Seção 3.6). O usuário manipula as projeções dos PC e da imagem de busca, ajustando e posicionando esses elementos no espaço projetado de acordo com sua vontade. As modificações realizadas no espaço de busca são armazenadas na base de dados de características personalizadas para serem utilizadas em outras seções do usuário.

A base de dados de características personalizadas envia os vetores de características para o módulo de recuperação, realizando a busca sobre o espaço de busca distorcido pelo usuário. Uma nova projeção multidimensional é gerada utilizando a técnica LAMP, tendo como referência as distorções realizadas no espaço original de busca armazenadas na base de dados de características personalizadas e o resultado da busca retornado pelo módulo de recuperação. A comparação entre o espaço original e o espaço distorcido pelo usuário auxilia no entendimento sobre o processo de busca. A seguir são detalhados o modelo de diversidade e as técnicas de MVD aplicadas ao processo de busca de DiVI.

\section{Busca por Similaridade com Diversidade}

O modelo de diversidade escolhido para o método DiVI foi o baseado em um problema de otimização de critério duplo. A intuição é utilizar um modelo que permite aos usuários definir qual o percentual de diversidade deve ser aplicado em uma busca. Formalmente, considere-se $S=\left\{s_{1}, \ldots, s_{n}\right\}$ um conjunto de dados com $n$ imagens; $s_{q}$ uma imagem de busca e $S^{\prime}$ um subconjunto de candidatos com $m$ imagens obtido por uma busca por abrangência $R_{q}$ com limiar de similaridade máximo $\epsilon_{q}$ para a imagem de busca; $\lambda(0 \leq \lambda \leq 1)$ é o parâmetro de balanceamento entre a similaridade e a diversidade, chamado de preferência de diversidade; 
e $k$ é o número de imagens desejadas no resultado. Assim, a diversidade para uma busca por uma imagem $s_{q}$ com um conjunto de resultado $R$ é dada por:

$$
R=\operatorname{argmax}_{S^{\prime} \subseteq S, k=\left|S^{\prime}\right|} \mathcal{F}\left(s_{q}, S^{\prime}\right),
$$

em que a função objetivo $\mathcal{F}\left(s_{q}, S^{\prime}\right)$ para cada conjunto de candidato $S^{\prime}$ é definida como:

$$
\mathcal{F}\left(s_{q}, S^{\prime}\right)=(k-1)(1-\lambda) \cdot \operatorname{sim}\left(s_{q}, S^{\prime}\right)+2 \lambda \cdot \operatorname{div}\left(S^{\prime}\right) .
$$

É importante ressaltar que existem dois casos especiais para o parâmetro de preferência de diversidade $\lambda$ em (9.2). Quando $\lambda=0$, o conjunto de resultado depende apenas da imagem de busca $s_{q}$, possibilitando ao usuário recuperar as imagens mais similares para a imagem dada $s_{q}$. No segundo caso, quando $\lambda=1$, a similaridade para $s_{q}$ não possui qualquer influência no resultado final, possibilitando ao usuário receber as imagens mais diversas do subconjunto de candidatos $S^{\prime}$. Assim, o usuário pode controlar o parâmetro $\lambda$ variando entre respostas com apenas similaridade e/ou apenas diversidade.

A similaridade é representada pela Equação (9.3) que mensura a distância entre a imagem de busca e as outras do conjunto de imagens.

$$
\operatorname{sim}\left(s_{q}, S^{\prime}\right)=\sum_{i=1}^{k} \delta_{\text {sim }}\left(q, s_{i}\right), s_{i} \in S^{\prime},
$$

A função de distância $\delta_{\text {sim }}\left(s_{q}, s_{i}\right)$ é monotonicamente crescente, isto é, valores mais altos indicam que as imagem $s_{i} \in S^{\prime}$ é mais similar para a imagem de busca $s_{q}$. A diversidade é definida pela Equação (9.4), que calcula a distância entre todas as imagens do subconjunto utilizando a função de distância $\delta_{\text {div }}\left(s_{i}, s_{j}\right)$.

$$
\operatorname{div}\left(S^{\prime}\right)=\sum_{i=1}^{k-1} \sum_{j=i+1}^{k} \delta_{d i v}\left(s_{i}, s_{j}\right), s_{i}, s_{j} \in S^{\prime}
$$

\section{Técnicas de Mineração Visual de Dados}

Técnicas de mineração visual de dados foram utilizadas para fornecer visualizações e maneiras de interação com as imagens do conjunto de dados, a critério do usuário. As projeções multidimensionais fornecidas pelo FASTMAP são usadas na fase de projeção inicial com as amostras do conjunto de imagem (pontos de controle) juntamente com a imagem de busca. Nesta fase, o usuário pode manipular e ajustar o posicionamento das imagens no espaço de busca. A Figura 9.2 mostra exemplos de como é possível manipular as imagens no módulo de MVD, sendo que estrelas representam a imagem de busca e cada círculo representa uma imagem do conjunto de dados. Figure 9.2 (a) ilustra uma projeção inicial sem a manipulação do usuário. O usuário manipula a projeção ao movimentar um círculo ou uma estrela para qualquer parte da projeção. A Figura 9.2(b) ilustra uma projeção após o usuário realizar a manipulação do espaço. As cores indicam a classe de cada imagem. Essa informação é recuperada dos metadados associados. Para facilitar esse processo, o usuário pode solicitar uma miniatura da imagem projetada no espaço. 
Após a manipulação do espaço de busca, uma projeção final é calculada com todas as imagens do conjunto de dados. A informação relacionada ao posicionamento de cada imagem do espaço de projeção manipulado é utilizada para realizar a busca por similaridade com diversidade de acordo com os parâmetros informados pelo usuário. As modificações no espaço de busca, os resultados da busca no espaço original de características são utilizados para fornecer novas visualizações. Para evidenciar as vantagens da orientação do usuário no processo de busca, recursos adicionais podem ser mostrados para destacar os fatores envolvidos neste processo, como ilustrado na Figura 9.3. No espaço de projeção, é possível requisitar: a visualização dos centroides de cada classe do conjunto de dados (Figura 9.3(a)); os pontos de controle utilizados para calcular a projeção final (Figura 9.3(b)); os resultados no espaço de projeção/distorção (Figura 9.3(c)) e os resultados no espaço $n$-dimensional de características (Figure 9.3(d)).

O DiVI promove a redução da lacuna semântica através de uma participação mais ativa do usuário no processo de busca, tornando possível verificar quais as imagens foram consideradas na busca, bem como a proximidade (similaridade) em que elas estão posicionados no espaço de busca. Além disso, o usuário pode modificar a preferência de diversidade e ver como as imagens são selecionadas no espaço projetado para cada resultado de busca, melhorando sua compreensão do espaço de dados e da propriedade de diversidade na busca por similaridade.

\subsection{O protótipo VikS}

O protótipo de vizinhos diversos mais próximos visualmente interativo (Visually Interactive $k$ Diverse Neighbor System - VikS ) tem por objetivo implementar o método DiVI num sistema CBIR para possibilitar que usuários interajam com as respostas das buscas por similaridade com diversidade.

Com o objetivo de fornecer portabilidade, o framework ViKS foi codificado em Java EE. A interface principal do protótipo é apresentada na Figura 9.4. Os usuários podem realizar buscas com similaridade e diversidade, ajustar os parâmetros de diversificação e interagir com o

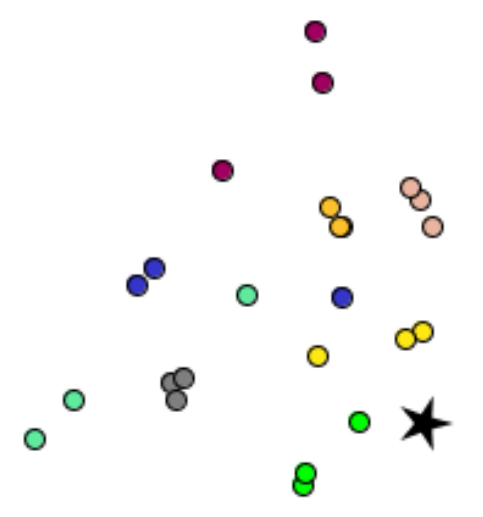

(a) Projeção inicial sem a manipulação do usuário.

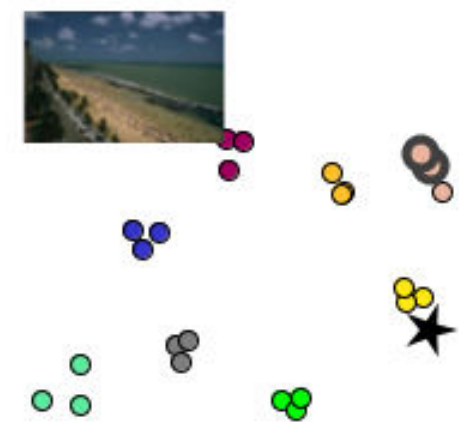

(b) Projeção inicial após a manipulação do usuário com visualização de miniatura.

Figura 9.2: Exemplos de manipulação de instâncias na projeção inicial no módulo de MVD. 


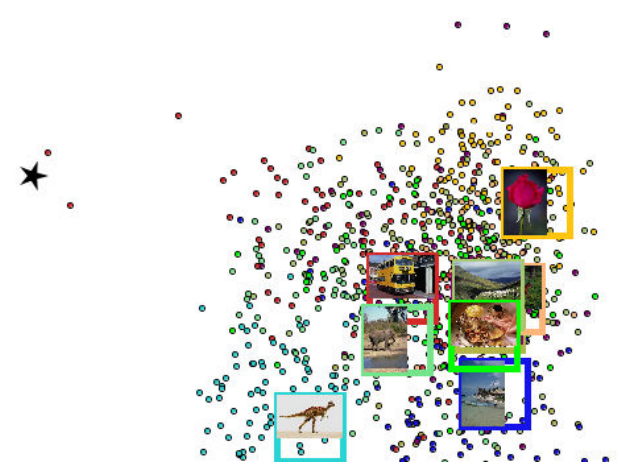

(a) Visualização dos centroides de cada classe/categoria.

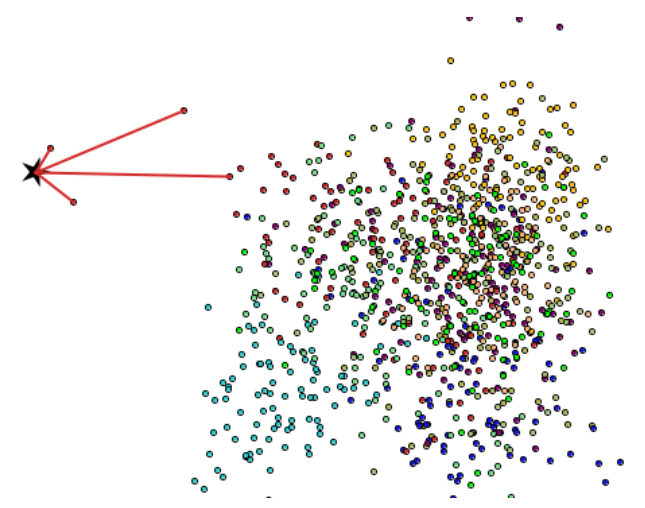

(c) Resultados no espaço de projeção, destacados pelas linhas ligando a imagem de busca (estrela).

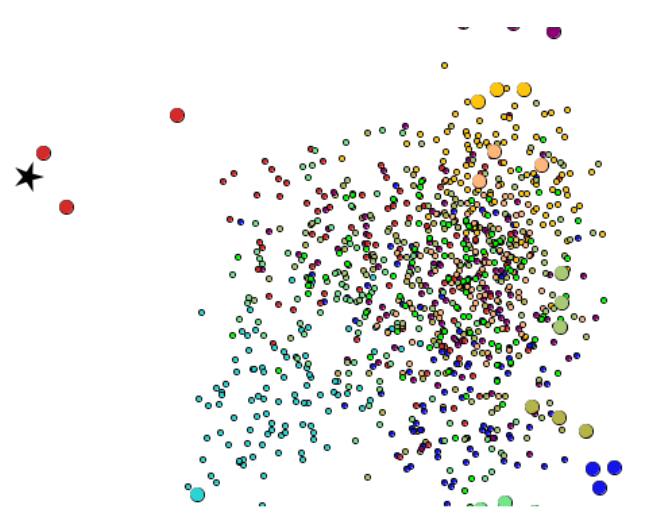

(b) Pontos de controle representados pelos círculos em destaque.

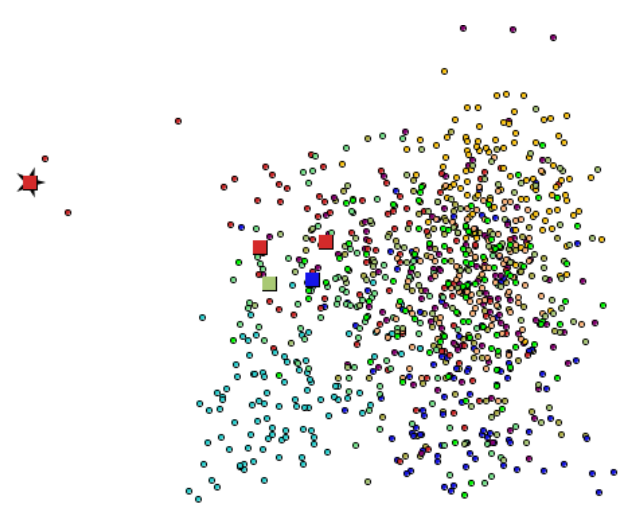

(d) Resultados no espaço $n$-dimensional, representados pelos quadrados.

Figura 9.3: Técnicas de visualização e interação utilizadas na projeção final.

espaço de busca realizando manipulação do posicionamento das imagens, a seu critério. Para permitir uma experiência de download e execução fácil, dois conjuntos de dados de imagens reais foram pré-carregados no protótipo: MRIBalan (BALAN et al., 2005) e Faces (VIEIRA et al., 2011b). O primeiro é composto por 704 imagens de ressonância magnética obtidas do Hospital das Clinicas de Ribeirão Preto da Universidade de São Paulo (USP). O extrator de características utilizado foi o método proposto por Balan et al. (2005). O conjunto Faces é uma coleção de 300 imagens da face de 30 pessoas com variações no posicionamento da cabeça. O extrator de características utilizado foi o de histogramas de níveis de cinza. Para ambos os conjuntos de dados, os vetores de características são comparados utilizado a função de distância $L_{2}$ em todas as dimensões.

A seguinte descrição do protótipo utiliza a Figura 9.4 como base para cada característica apresentada. Ao iniciar o protótipo, é apresentado um painel onde o usuário deve configurar as opções de busca, selecionando o conjunto de dados (Passo 1), a imagem de busca (Passo 2) e o algoritmo de diversidade que deve ser executado (Passo 3). Foram implementados os seguintes algoritmos da literatura no protótipo VikS: Greedy with Marginal Contribution (GMC), Greedy Randomized with Neighborhood Expansion (GNE), Maximal Marginal Relevance (MMR), SWAP, Max-Sum Dispersion (MSD), MOTLEY e uma versão paralelizada do algoritmo exaustivo de diversificação (OPD). Conforme foi apresentado no capítulo3, esses algoritmos se diferem pela estratégia de construção de resultado, o que impacta diretamente no tempo de execução e na qualidade dos resultados. 


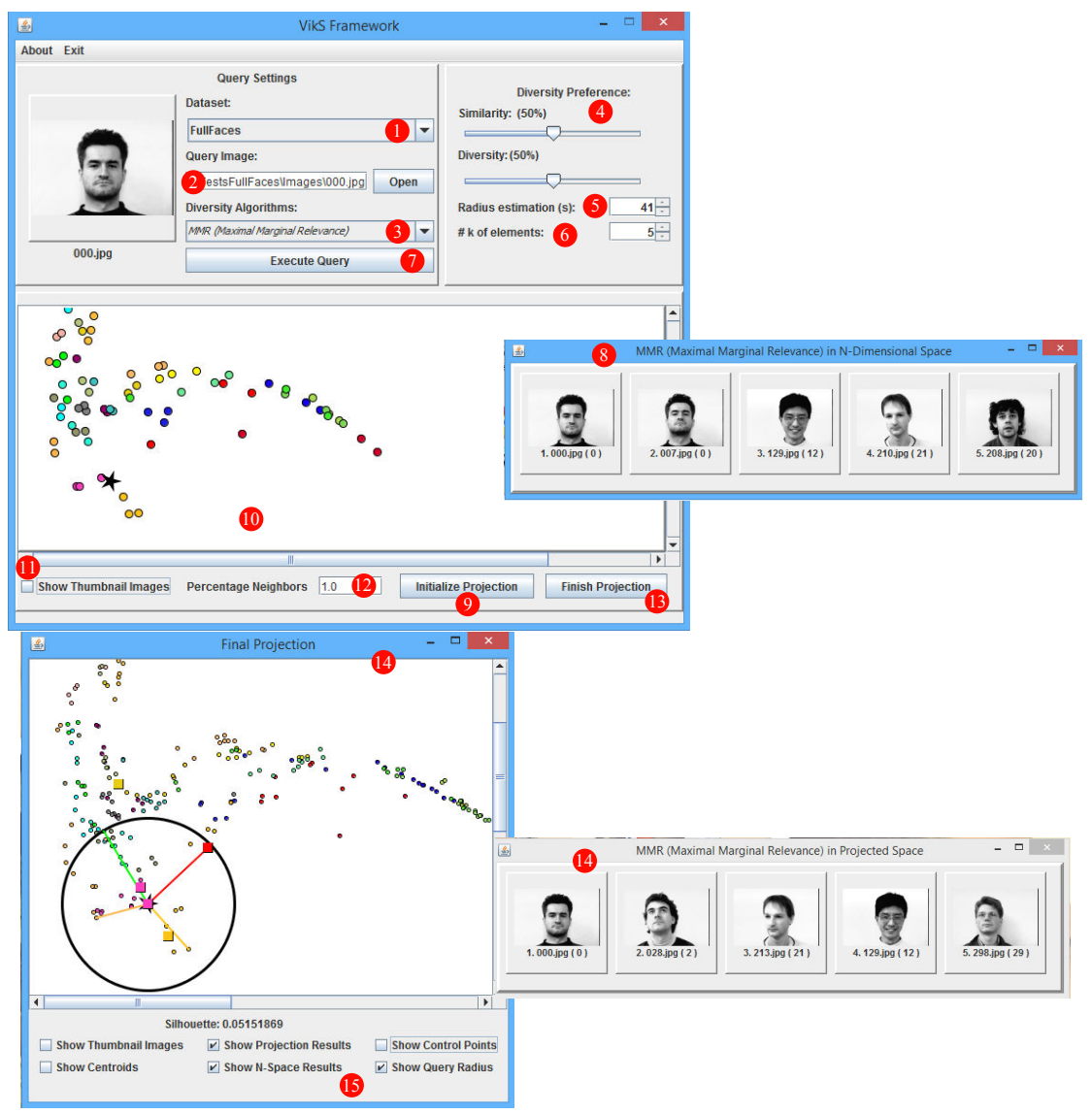

Figura 9.4: Interface do Protótipo VikS.

Em seguida, o usuário define sua preferência de diversidade nos resultados, começando com apenas similaridade até resultados somente com diversidade (Passo 4). É necessário informar a quantidade de elementos que devem fazer parte do conjunto de candidatos (Passo 5) e o número $k$ de elementos que devem ser retornados (Passo 6). Neste estágio, o usuário pode submeter a busca ao protótipo (Passo 7) utilizando as características extraídas automaticamente, utilizando o espaço $n$-dimensional sem fornecer qualquer informação adicional. Os resultados da busca são apresentados em uma janela de resultados (Passo 8).

Outra opção antes de seguir com a busca é ativar o módulo de MVD, clicando no botão de inicializar a projeção Initialize Projection (Passo 9), que habilita a janela para manipulação dos elementos e mostra a projeção inicial do espaço de busca com os pontos de controle e a imagem de busca (Passo 10). O usuário pode ajustar a visualização aumentando ou diminuindo o foco nos elementos. As cores indicam a qual classe uma determinada imagem pertence, e o usuário pode solicitar a visualização de miniaturas das imagens marcando a opção no protótipo (Passo 11) bem como definir o número de vizinhos que devem ser utilizados para selecionar os pontos de controla da projeção (Passo 12), que é definido com valor padrão de $1.0 \%$ dos vizinhos.

Ao final da manipulação dos elementos (Passo 10), é possível re-submeter a busca utilizando a nova distribuição das imagens (Passo 13). Por fim, VikS apresenta o resultado final e o espaço projetado (Passo 14), que pode também ser ajustado com aumento ou redução do foco das imagens. É possível também destacar os fatores envolvidos no processo de busca (Passo 15) mostrando os resultados no espaço $n$-dimensional de características, o limiar máximo de similaridade, os centroides de classe e as miniaturas das imagens. A indicação de cores para 
as diferentes classes do conjunto de dados deve ser fornecida juntamente com as imagens no formato de metadados.

VikS é o primeiro protótipo a possibilitar que diferentes algoritmos de diversificação sejam comparados com o apoio de técnicas de mineração visual de dados para visualizar e interagir com os resultados, fornecendo mais informações sobre como a diversidade é tratada nas buscas por similaridade e como os algoritmos se diferem uns dos outros.

\subsection{Experimentos}

Esta seção apresenta os resultados experimentais da utilização do protótipo VikS. Para realizar um estudo de caso, o conjunto de imagens Corel (WANG; LI; WIEDERHOLD, 2001) foi também pré-carregado no protótipo. O conjunto consiste de 1.000 imagens de diferentes cenas e objetos classificados em 10 categorias diferentes: África; Praia; Prédios; Ônibus; Dinossauros; Elefantes; Flores; Cavalos; Montanhas e comida. O extrator de característica utilizado foi o MPEG-7 Color Layout definido no padrão ISO/IEC 15938 (Interface de descrição de conteúdo multimídia). A comparação dos vetores de características foi realizado com a função de distância $L_{2}$.

A ideia do experimento foi avaliar a abrangência dos resultados encontrados pelo nosso método DiVI utilizando o protótipo VikS, bem como os benefícios da adição de técnicas MVD para um sistema CBIR. Para isso, o protótipo foi apresentado para sete especialistas em CBIR para avaliação. Foram executadas buscas por similaridade com e sem diversidade utilizando as características extraídas automaticamente pelo protótipo e utilizando o módulo de MVD para definir características personalizadas. Os especialistas afirmaram que VikS é realmente capaz de apresentar mais informações sobre as relações entre as imagens, podendo melhorar a precisão média, mesmo quando os resultados são subjetivos, tornando a descrição da imagem mais personalizada para cada usuário.

Para avaliar nossa proposta, pedimos aos especialistas que realizassem buscas pelas 5 imagens mais similares para a imagem de busca dada sobre o conjunto Corel, utilizando VikS. Um exemplo das buscas é mostrado na Figura 9.5, a imagem de busca foi inicialmente classificada como sendo da categoria ônibus (rótulo 4). Os resultados utilizando apenas as características

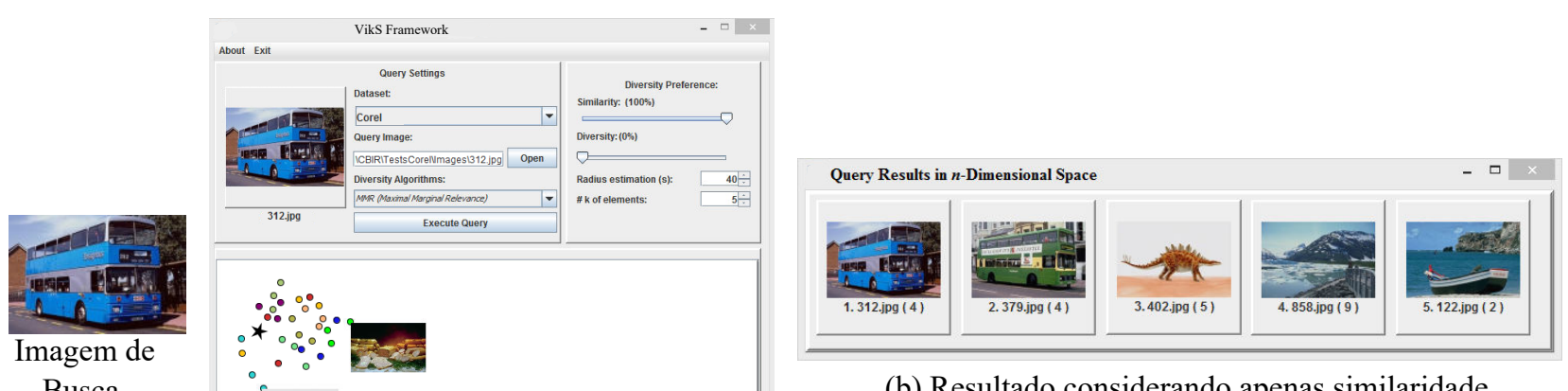

(b) Resultado considerando apenas similaridade no espaço $n$-dimensional.

Figura 9.5: Resultados (apenas similaridade) para o conjunto de dados Corel no espaço $n$ dimensional (características extraídas) com o módulo de MVD ativado. 


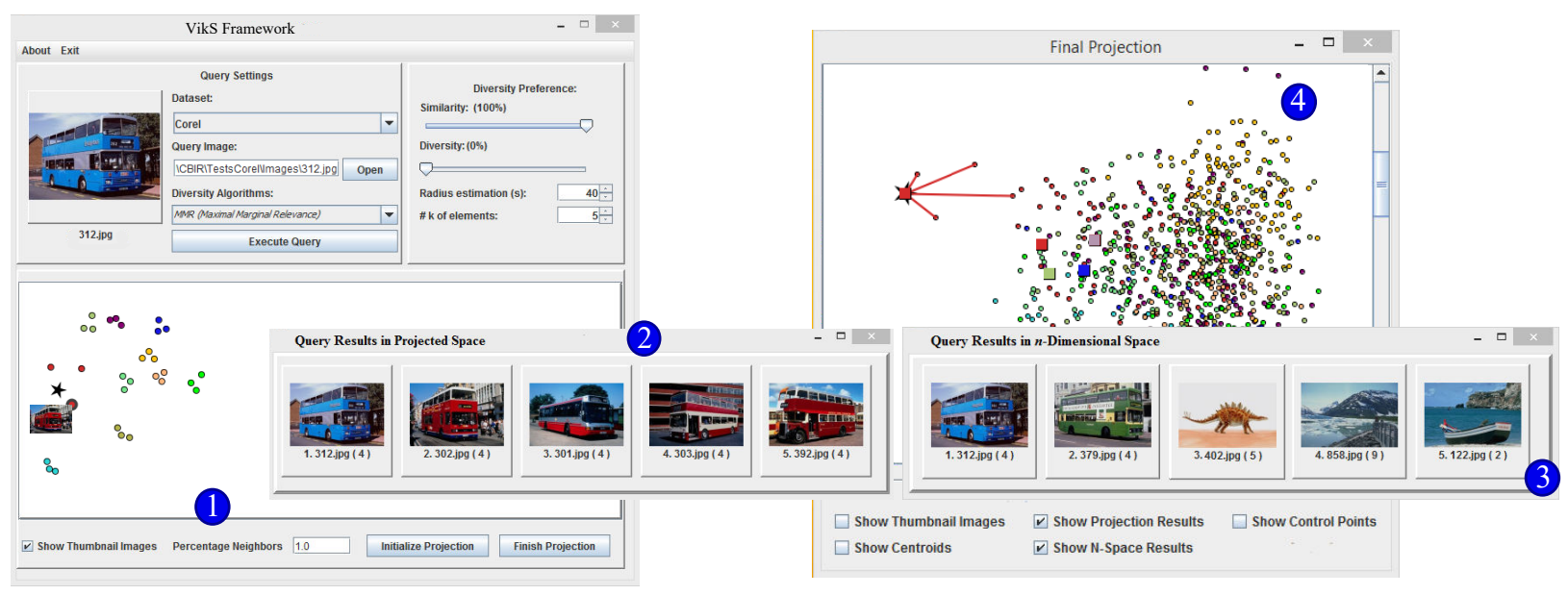

Figura 9.6: Projeção final gerada para o conjunto de dados Corel com os resultados de ambos os espaços $n$-dimensional e o de distorção do usuário.

extraídas das imagens para uma busca considerando apenas a similaridade são ilustrados na Figura 9.5 (b). Como pode ser visto, apenas duas imagens pertencem a mesma categoria da imagem de busca (rótulo 4 entre parenteses), e o restante pertence a categorias diferentes (rótulos 5, 9 e 2), resultando em uma precisão de 40\% da busca. A Figura 9.5 (a) mostra a interface gráfica de usuário (GUI) responsável por apresentar a projeção inicial do espaço de busca para o usuário, mostrando miniaturas das imagens na projeção. Como pode ser visto, as classes das imagens estão misturadas no espaço de pesquisa.

Como os resultados da busca utilizando as características visuais apresentaram imagens de categorias diferentes mesmo para uma busca por similaridade, é possível concluir que o extrator utilizado não é adequado para representar as imagens da classe de busca. Assim, o usuário pode incluir sua opinião sobre similaridade, manipulando o espaço de busca o utilizando o módulo de MVD (Figura 9.6 (1)). É importante ressaltar que as categorias das imagens estão melhores agrupadas após a manipulação do espaço. Os resultados da busca no espaço $n$-dimensional e na projeção final são apresentados na Figura 9.6 (2), (3) e (4), respectivamente. Pela da análise dos resultados, pode-se ver que cada imagem obtida é consistente com a categoria da imagem de busca (precisão de 100\%). A visualização do espaço de busca mostra as diferenças entre a busca no espaço $n$-dimensional original (quadrado nas instâncias projetadas) e aquela realizada no espaço de distorção do usuário (linha reta das instâncias projetadas para a imagem de busca na Figura 9.6 (4)). Após a interação do usuário, as modificações no espaço de busca são armazenadas na base de dados de características personalizadas e podem ser usadas para executar novas buscas.

Apesar dos resultados para a imagem de busca apresentados na janela (2) da Figura 9.6 atingirem 100\% de precisão, geralmente o usuário está interessado numa busca mais exploratória com imagens não tão homogêneas no resultado, apresentando algum tipo de diversidade. A Figura 9.7 mostra o resultado para uma busca considerando $40 \%$ de diversidade, mostrando diferentes imagens da categoria de ônibus. É importante destacar que, as considerações de diversidade aumentam a expressividade do processo de recuperação considerando o relacionamento entre as imagens no resultado, em vez de apenas considerar a similaridade para a imagem de busca. 


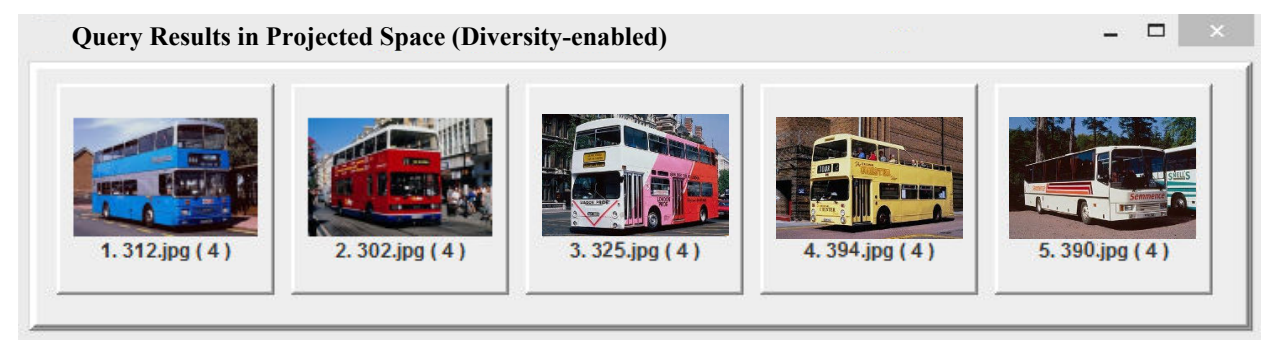

Figura 9.7: Resultado para uma busca com 40\% de Diversidade no conjunto de dados Corel utilizando as modificações armazenadas na base de dados de característica personalizadas.

\subsection{Considerações Finais}

Este capítulo apresentou o método DiVI para melhorar a qualidade dos sistemas CBIR, combinando buscas com diversidade e técnicas de mineração de visual de dados. Os resultados são obtidos de acordo com as necessidades do usuário, que utiliza técnicas de visualização e interação para participar mais ativamente do processo de busca, permitindo uma melhor compreensão dos resultados e da relação entre as imagens, categorias e as características extraídas para representa as imagens. Também foi apresentado o protótipo VikS para implementar o método DiVI, sendo este o primeiro protótipo a integrar as buscas por similaridade com diversidade com técnicas de interação e visualização, aumentando a compreensão da propriedade de diversidade nas buscas aos $k$-vizinhos mais próximos. A avaliação empírica do protótipo indicou que o método oferece resultados promissores para a análise de conjuntos de imagens. Além disso, o protótipo aumenta a aplicabilidade da diversidade e ajuda na tarefa de reduzir a lacuna semântica em sistemas CBIR. 


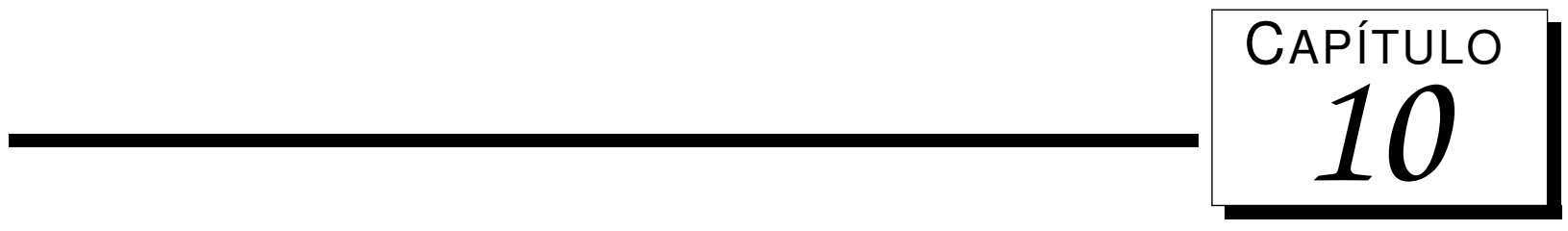

\section{Conclusão}

Com a evolução das aplicações e dos dispositivos móveis, vem se tornando necessário cada vez mais fornecer técnicas para armazenar, organizar, recuperar e analisar dados mais complexos, como exemplo, informações geo-referenciadas e dados multimídia (imagens, áudio e vídeo). Além da complexidade dos novos tipos de dados, o ritmo de produção também vem aumentando bastante, inclusive em escalas que vão à ordem dos milhares de Petabytes, desafiando tanto a eficiência quanto a eficácia dos operadores de buscas dos sistemas gerenciadores de base de dados de tais aplicações. Existe uma divisão entre os trabalhos de pesquisa que buscam aumentar a eficiência necessária para lidar com a imensa quantidade de dados dos sistemas big data, e os que buscam oferecer novos operadores de busca para tais sistemas. A maioria dos trabalhos recentes buscam melhorar a eficiência por meio da indexação e utilizando de arquiteturas paralelas, enquanto os novos operadores de busca disponíveis na literatura não levam em conta o volume de dados e a grande maioria não é escalável.

Esta tese de doutorado teve como objetivo principal propor variações dos operadores de busca para atender as necessidades de buscas por similaridade em enormes volumes de dados, considerando fatores do espaço de busca dos dados, tal como alta dimensionalidade e a densidade no local da busca. Em especial, foi considerado a inclusão da propriedade de diversidade, que vem sendo estudada como uma solução para aumentar a relevância dos resultados nas áreas de recuperação de informação e sistemas de recomendação. Assim, a tese teve o foco na definição de operações de busca por similaridade com diversidade com o intuito de aumentar a expressividade e o valor agregado dos elementos na resposta. Em consequência, tornou-se necessário definir um modelo de diversidade que pudesse ser integrado aos critérios de comparação e aos operadores de busca, bem como métodos de avaliação adequados para a recuperação de dados por conteúdo em sistemas gerenciadores de base de dados. As contribuições deste trabalho de doutorado colaboraram com o avanço no estado-da-arte na área de base de dados, apresentando um base teórica para uma nova classe de operadores de busca por similaridade que visam atender as necessidades de se recuperar dados em enormes volumes de dados. 


\subsection{Principais Contribuições}

As contribuições desta tese foram desenvolvidas como variantes dos operadores de busca por similaridade para lidar com espaços de alta dimensionalidade e densidade de dados visando melhorar a qualidade (eficácia) do resultado, porém sem aumentos significativos no desempenho de recuperação (eficiência). Resumidamente, as principais contribuições do presente trabalho de doutorado são descritas a seguir:

- A definição de um modelo de diversificação de resultados, chamado de Diversificação de Resultados baseado em Influência (Result Diversification based on Influence RDI), que realiza uma estimativa automática sobre qual deve ser o tamanho mínimo para a distância de separação, que em nossa proposta é definida adaptativamente, isto é, a medida que os elementos incluídos na resposta ficam cada vez mais distantes do elemento central de busca, a distância mínima exigida entre os elementos também aumenta, imitando a percepção intuitiva de que dois elementos distintos parecem mais similares um do outro à medida que se afastam do observador em questão. Este é o primeiro modelo de diversificação de resultados que possui essa propriedade, e portanto a única até agora que permite incluir diversidade em consultas por similaridade em um SGBD. O modelo RDI possui as seguintes características: independência de parâmetros, de domínio de dados e de operador de busca;

- A definição de uma técnica para implementar o modelo RDI nos operadores de buscas aos $k$-vizinhos mais próximos e por abrangência, chamada de Melhores Resultados com Diversificação baseada em Influência (Better Results with Influence Diversification - BRID). Também foi apresentada uma definição de método de avaliação de diversidade com base no conceito RDI, recuperando a qualidade da resposta baseandose no grau de sobreposição de influência dos elementos;

- A definição do operador de junção diversificada, uma operação binária que recebe dois conjuntos de dados como entrada e combina os elementos atendendo o critério de similaridade, porém garantindo também uma resposta com menor cardinalidade e diversificada. Assim, foi apresentada uma nova aplicação da diversificação de resultados, mostrando que o modelo de RDI é consistente e genérico o suficiente para ser utilizado em operadores de busca seja unários ou binários. Esta definição foi a primeira na literatura a incorporar diversidade em um operador de busca binário. Com isso abriu-se a possibilidade de tratar junções - que é um operador notoriamente caro para processar relações de grande cardinalidade - mesmo frente a big data;

- A definição de uma plataforma de avaliação para substituição das estratégias utilizadas na fase de filtragem de candidatos dos algoritmos baseados em otimização. Foram definidas diferentes técnicas para geração de conjunto de candidatos. Especificamente, foi ilustrado como que o modelo de RDI pode realizar uma amostragem do conjunto de dados, resultando em um conjunto de candidatos de menor cardinalidade capaz de reduzir os custos de execução dos algoritmos sem comprometer a qualidade final da resposta diversificada. Essa contribuição mostrou que é possível utilizar o conceito de diversificação já no primeiro passo de seleção de candidatos de qualquer método de diversificação por otimização, introduzindo uma nova frente de pesquisa para melhorar tais métodos. Um resultado importante neste caso foi ter conseguido fazer o algoritmo que apresenta o melhor resultado, mas que é em geral ordens de grandeza mais lento, executar em tempo comparável aos demais, sem perda de sua qualidade; 
- A definição de um conjunto de métodos para medir a precisão dos algoritmos de diversificação de resultados, com base no uso de várias análises estatísticas obtidas de diferentes estratégias para medir a diversidade de conjuntos de resultados. Foram apresentados três novos métodos de avaliação de diversidade, sendo que dois desses comparam conjuntos de resultados utilizando apenas os elementos e a relação de distância entre os conjuntos avaliados. O terceiro método utiliza a definição proposta de "espaço de resposta", no qual cada elemento é uma possível solução de busca. Tal espaço permite a comparação de buscas e a definição de propriedades que permitem desenvolver diretrizes para escolher qual é o algoritmo de buscas por similaridade com diversidade mais adequado para um dado conjunto de dados. O principal resultado desta contribuição foi apresentar o conceito e a formalização de "espaços de resposta", o que permitiu modelar e comparar diferentes algoritmos de diversificação, mesmo que sejam baseados em técnicas distintas;

- A definição de uma técnica de agrupamentos de dados relativo ao elemento central de busca, possibilitando ao usuário visualizar e navegar iterativamente pelos grupos de elementos muitos similares, começando por um elemento representativo, acelerando o processo de navegação e análise de um espaço de busca. Esta contribuição permite reduzir drasticamente o esforço de obter dados que atendam ao interesse do usuário ao definir uma consulta que resulta numa coleção de dados que usualmente somente seriam obtidos pela execução de inúmeras consultas tradicionais. Com isso, esta contribuição foi também a primeira na literatura a incorporar o conceito de diversificação aos operadores de agrupamento. Com isso, esta tese apresentou contribuições para todos os três operadores básicos da álgebra relacional que incorporam critérios de comparação em sua definição: Seleção, Junção e Agrupamento;

- A definição do método visualmente interativo e de diversidade (Diversity and Visually-Interactive - DiVI), uma abordagem para integrar os conceitos de diversidade e mineração visual de dados nos sistemas de recuperação baseado em conteúdo (CBIR). O método emprega projeções multidimensionais para visualização do espaço de busca definido pelas características extraídas das imagens do conjunto de dados. Visualizações são utilizadas para a apresentação dos resultados, aumentando o entendimento sobre como são selecionados os elementos, incluindo como a diversidade é empregada na resposta. Além disso, o método ainda possibilita a modificação da posição dos elementos de acordo com o interesse do usuário, aumentando a participação no processo de recuperação. A definição de um protótipo de sistema recuperação por conteúdo de imagens (VikS), que implementa o método DiVI e os algoritmos existentes de diversidade. Está contribuição foi desenvolvida em parceria com a Universidade Federal de São Carlos (UFSCar).

\subsection{Contribuições Complementares}

Além das contribuições principais citadas, o projeto de doutorado também alcançou contribuições complementares, derivadas de contribuições de outros membros do grupo de pesquisa, sendo possível aproveitar os resultados para o desenvolvimento da linha principal deste projeto e também repassar os aprendizados do projeto para os demais. Essas colaborações resultaram na publicação em co-autoria de resultados cujo desenvolvimento principal 
foi feita em outros projetos de pesquisa em andamento no GBdI. A seguir são listadas as contribuições complementares mais relevantes:

- Colaboração no desenvolvimento de uma abordagem para remover a ambiguidade do operador de busca por similaridade $k$-NN quando o mesmo é integrado em um Sistema Gerenciador de Base de Dados. A ambiguidade se dá pelo fato que um elemento complexo pode ser aceito como um valor de tupla, assim um elemento complexo pode assumir valores iguais em tuplas distintas. Assim o operador $k$-NN pode retornar um número $m$ maior que $k$ solicitado. Portanto, em situações práticas, torna-se importante expressar o operador em relação à contagem de $k$ tuplas ou $k$ elementos complexos distintos.

- Colaboração no desenvolvimento de um novo conjunto de operadores binários que possuem como uma de suas etapas o processo de ordenação das tuplas, chamados de junção ampla (wide-joins). A dependência de ordenação desse conjunto de operações permitiu explorar outro tipo de predicado muito útil, mas ainda não considerado nas buscas por similaridade estudadas na literatura: a negação. O principal problema em realizar a negação dos operadores de similaridade é que, ao fazê-lo, a cardinalidade da resposta é o complemento do operador, sendo muito grande a quantidade de elementos para serem analisados.

- Colaboração no desenvolvimento de uma abordagem para detecção de imagens quasi duplicatas utilizando os operadores de junção ampla (wide-joins) para lidar com autorelacionamentos e apresentar um operador físico de execução mais otimizado que os métodos existentes da literatura.

- Colaboração no desenvolvimento de uma análise sobre técnicas de mineração de dados aplicadas em sistemas de apoio ao diagnóstico (Computer-Aided Diagnosis - CAD) para lesões de úlcera. A abordagem buscou determinar a influência e as implicações das características de cor e textura extraídas automaticamente por descritores de imagem na fase de classificação das imagens no CAD desenvolvido.

- Colaboração no desenvolvimento de um método de comparação de similaridade para imagens segmentadas de lesões de úlcera por meio da contagem dos rótulos classificados. O método teve por objetivo aumentar a precisão na recuperação das imagens ao balancear a influência de cada lesão rotulada na imagem segmentada.

\subsection{Publicações}

Os trabalhos a seguir contêm as contribuições principais e complementares geradas durante o período de doutoramento:

\section{- Principais contribuições:}

1. TRAINA, A. J. M. ; BEDO, M. V. N. ; SANTOS, LUCIO F. D. ; CARVALHO, L. O. ; PEDROSA, G. V. ; COSTA, A. F. ; TRAINA JR., C. . "Making Content-Based Medical Image Retrieval Systems worth for Computer-Aided Diagnosis: From Theory to Application". Em: Marques, P. M. A.; Mencattini, A.; 
Salmeri, M.; Rangayyan, R. M.. (Org.). Medical Image Analysis and Informatics: Computer-aided Diagnosis and Therapy. 1ed.: CRC Press, 2017, v. 1, p. 1-48. (Aceito para publicação)

2. SANTOS, LUCIO F. D.; CARVALHO, L. O. ; BEDO, M. V. N. ; TRAINA, A. J. M. e Traina Jr., C.. . "When Similarity is Not Enough, Ask for Diversity: Grouping Elements Based on Influence". Em ISM: Proceedings of the 18th IEEE International Symposium on Multimedia, San Jose, 2016. p. 26-29.

3. SANTOS, LUCIO F. D.; DIAS, R. L. ; RIBEIRO, M. X. ; TRAINA, A. J. M. e TRAINA JR., C. . "Combining Diversity Queries and Visual Mining to Improve Content-Based Image Retrieval Systems: The DiVI Method". Em ISM: Proceedings of the 17th IEEE International Symposium on Multimedia, 2015. p. 357-362.

4. SANTOS, LUCIO F. D. ; CARVALHO, L. O. ; Oliveira, W. D. ; TRAINA, A. J. M. e TRAINA JR., C. . "Diversity in Similarity Joins". Em SISAP: The 8th International Conference on Similarity Search and Applications, 2015, Glasgow. Lecture Notes in Computer Science, 2015. v. 9371. p. 42-53.

5. SANTOS, LUCIO F. D. ; OLIVEIRA, W. D.; CARVALHO, L. O.; FERREIRA, M. R. P.; TRAINA, A. J. M. e TRAINA JR., C.."Combine-and-Conquer: Improving the Diversity in Similarity Search Through Influence Sampling". Em SAC: Proceedings of the Symposium on Applied Computing, 2015, Salamanca, Spain, p. 994-999.

6. SANTOS, LUCIO F. D. ; DIAS, R. L. ; FERREIRA, MONICA R. P. ; RIBEIRO, M. X. ; TRAINA, A. J. M. e TRAINA JR., C. . "Have You Met VikS? A Novel Framework for Visual Diversity Search Analysis". Em SBBD: Simpósio Brasileiro de Banco de Dados, 2014, Curitiba. Anais do XXIX Simpósio Brasileiro de Banco de Dados - Sessão de Demos., 2014, p. 209-214. (Best Paper Award)

7. SANTOS, LUCIO F. D.; BEDO, M. V. N.; PONCIANO-SILVA, M.; TRAINA, A. J. M. e TRAINA JR., C. "Being similar is not enough: How to bridge usability gaps trough diversity in medical images". Em CBMS: Proceedings of 27th IEEE Symposium on Computer-Based Medical Systems, 2014, p. 287-293.

8. SANTOS, LUCIO F. D.; OLIVEIRA, W. D.; FERREIRA, M. R. P.; CORDEIRO, R. L. F.; TRAINA, A. J. M. e TRAINA JR., C. "Evaluating the diversification of similarity query results". Journal of Information and Data Management, v. 4, n. 3, 2013, p. 188-203.

9. SANTOS, LUCIO. F. D.; OLIVEIRA, W. D.; FERREIRA, M. R. P.; TRAINA, A. J. M. e TRAINA JR., C. "Parameter-free and domain-independent similarity search with diversity". Em SSDBM: Proceedings of the 25th International Conference on Scientific and Statistical Database Management. New York, NY, USA: ACM, 2013. (SSDBM), p.5:1-5:12.

\section{- Contribuições complementares:}

10. CARVAlHO, L. O. ; SANTOS, LUCIO F. D. ; OlIVEIRA, WILliAN D. ; TRAINA, A. J. M. e TRAINA JR., C. . "Efficient Self-similarity Range Widejoins Fostering Near-duplicate Image Detection in Emergency Scenarios". Em ICEIS: Proceedings of the 18th International Conference on Enterprise Information Systems, Rome, 2016. v. 1. p. 81-91. (Best Paper Award) 
11. BLANCO, GUSTAVO ; BEDO, M. V. N. ; CAZZOLATO, M. T. ; SANTOS, LUCIO F. D. ; JORGE, A. E. S. ; Traina Jr., C.. ; AZEVEDO-MARQUES, PAULO MAZZONCINI e TRAINA, A. J. M. . "A Label-Scaled Similarity Measure for Content-Based Image Retrieval". Em ISM: Proceedings of the 18th International Symposium on Multimedia, San Jose, 2016. p. 20-25.

12. CARVAlHO, L. O. ; SANTOS, LUCIO F. D. ; Oliveira, W. D. ; TRAINA, A. J. M. e TRAINA JR., C. . "Self Similarity Wide-Joins for Near-Duplicate Image Detection". Em ISM: Proceedings of the 17th IEEE International Symposium on Multimedia, 2015, p. 237-240.

13. CARVAlHO, L. O. ; SANTOS, LUCIO F. D. ; Oliveira, W. D. ; TRAINA, A. J. M. e TRAINA JR., C. "Similarity Joins and Beyond: an Extended Set of Binary Operators with Order.". Em SISAP: The 8th International Conference on Similarity Search And Applications, 2015, Glasgow. Lecture Notes in Computer Science, 2015. v. 9371. p. 29-41.

14. BEDO, MARCOS V. N. ; SANTOS, LUCIO F. D. ; OLIVEIRA, WILLIAN D. ; BLANCO, GUSTAVO ; TRAINA, A. J. M. ; FRADE, MARCO A. C. ; AZEVEDO-MARQUES PAULO M. e TRAINA JR., C. . "Color and Texture Influence on Computer-Aided Diagnosis of Dermatological Ulcers". Em CBMS: Proceedings of 28th IEEE Symposium on Computer-Based Medical Systems, São Carlos - 2015, p.109-114.

15. PIERRO, G. V. ; FERREIRA, MONICA R. P. ; SANTOS, LUCIO F. D. ; OLIVEIRA, WILLIAN D. ; TRAINA, A. J. M. e TRAINA JR., C. . "Embedding k-Nearest Neighbor Queries into Relational Database Management Systems". Journal of Information and Data Management - JIDM, v. 5, 2014, p. 252-265.

\subsection{Trabalhos Futuros}

As contribuições apresentadas nesta tese apontaram para a necessidade de novos estudos, tanto para aprimorar as técnicas desenvolvidas quanto estender as soluções para novos domínios de dados. A seguir são apresentadas algumas sugestões de tópicos que devem ser abordados em estudos futuros:

- Explorar a possibilidade de parametrizar a técnica RDI, de maneira que se possa configurar tanto as condições de navegação de um domínio de dados quanto cada consulta em particular. Esse estudo é particularmente importante para definir um padrão de busca sobre um domínio de dados que tenha mais de uma função de distância definida.

- Explorar as propriedades algébricas dos operadores de similaridade com diversidade baseada em influência em relação aos operadores tradicionais e por similaridade para possibilitar a otimização de planos de acesso que usem essas operações em SGBDs;

- Definir uma extensão para a linguagem $S Q L$ para implementar as operações de diversidade em SGBDs com suporte a operadores de similaridade;

- Desenvolver técnicas para estimativas de seletividade e raio de cobertura para os conjuntos de resultados em consultas por similaridade com diversidade; 
- Investigar aplicações para a utilização da técnica BRID com outras estratégias para a escolha dos elementos dominantes, por exemplo, a escolha de elementos dominantes de forma aleatória e pelos elementos mais distantes do elemento central de busca para implementar algoritmos de detecção de outliers e sumarizadores;

- Explorar a propriedade de diversidade nos operadores de junção pelos $k$-vizinhos mais próximos para aplicações em classificadores baseados em instâncias (instance-based learning);

- Investigar a propriedade de diversidade nos operadores de junção pelos $k$-pares mais próximos e ampla (wide-joins) para definição de um operador de junção com visão holística em relação a todos os elementos de dois conjuntos de dados;

- Implementar os operadores de junção diversificada considerando as mesmas estratégias utilizadas para os operadores de junção tradicional e por similaridade em SGBDS, por exemplo, junções baseadas em laços aninhados indexados, tabelas hash e por divisão e conquista (quick join);

- Investigar um novo conceito, que pode ser chamado de diversificação de pares ordenados resultantes de junção, para investigar a diversificação dos elementos que aparecem nos pares das respostas de junção considerando ambas as relações envolvidas;

- Explorar novas propriedades no "espaço de resposta" para avaliar conjuntos de resultados de algoritmos que utilizam a estratégia de diversificação baseada em distância de separação, por exemplo, o método de avaliação de sobreposição e índices de validação de partições de algoritmo de agrupamento de dados;

- Estender o conceito de "espaço de resposta" para respostas de junções;

- Investigar outras técnicas para a escolha dos representantes na técnica de agrupamento relativo baseado em influência, por exemplo, pode-se realizar a busca de um medoide ou que maximize uma função de agregação de todas as distâncias do grupo ao elemento central de busca;

- Implementar novas técnicas de visualização, algoritmos de diversificação e métodos de avaliação de qualidade no protótipo VikS para possibilitar a comparação de diferentes definições de diversidade por meio de estratégias de visualização e interação. 



\section{Referências Bibliográficas}

ABID, A.; HUSSAIN, N.; ABID, K.; AHMAD, F.; FAROOQ, M. S.; FAROOQ, U.; KHAN, S. A.; KHAN, Y. D.; NAEEM, M. A.; SABIR, N. A survey on search results diversification techniques. Neural Computing and Applications, v. 27, n. 5, p. 1207-1229, 2016.

AGRAWAL, R.; GOLLAPUDI, S.; HALVERSON, A.; IEONG, S. Diversifying search results. In: Proceedings of the ACM International Conference on Web Search and Data Mining (WSDM). New York, USA: ACM, 2009. p. 5-14.

AMAGATA, D.; HARA, T. Diversified set monitoring over distributed data streams. In: Proceedings of the ACM International Conference on Distributed and Eventbased Systems (DEBS). New York, USA: ACM, 2016. p. 1-12.

ANGEL, A.; KOUDAS, N. Efficient diversity-aware search. In: Proceedings of the ACM International Conference on Management of Data (SIGMOD). Athens, Greece: ACM, 2011. p. 781-792.

ARANTES, A. S.; VIEIRA, M. R.; JR., C. T.; TRAINA, A. J. M. Operadores de seleção por similaridade para sistemas de gerenciamento de bases de dados relacionais. In: Simpósio Brasileiro de Bancos de Dados (SBBD). Manaus, AM: SBC, 2003. p. 341-35.

. Efficient algorithms to execute complex similarity queries in RDBMS. Journal of the Brazilian Computer Society, v. 9, p. 5-24, 2004.

AUGSTEN, N.; BOHLEN, M. H. Similarity joins in relational database systems. Synthesis Lectures on Data Management, v. 5, n. 5, p. 1-124, 2013.

BALAN, A.; TRAINA, A. J. M.; TRAINA, A.; AZEVEDO-MARQUES, P. Fractal analysis of image textures for indexing and retrieval by content. In: Proceedings of The IEEE International Symposium on Computer-Based Medical Systems (CBMS). Dublin, IE: IEEE, 2005. p. 581-586.

BEYER, K. S.; GOLDSTEIN, J.; RAMAKRISHNAN, R.; SHAFT, U. When is "nearest neighbor" meaningful? In: Proceedings of the International Conference on Database Theory (ICDT). London, UK: Springer-Verlag, 1999. p. 217-235.

BOHM, C.; KREBS, F. High performance data mining using the nearest neighbor join. In: Proceedings of the IEEE International Conference on Data Mining (ICDM). New York, USA: IEEE, 2002. p. 43-50. 
BORKAR, V.; CAREY, M. J.; LI, C. Inside "big data management": ogres, onions, or parfaits? In: Proceedings of the International Conference on Extending Database Technology (EDBT). New York, USA: ACM, 2012. p. 3-14.

BOZKAYA, T.; OZSOYOGLU, M. Distance-based indexing for high-dimensional metric spaces. SIGMOD Rec., v. 26, n. 2, p. 357-368, 1997.

BRISABOA, N. R.; FARINA, A.; PEDREIRA, O.; REYES, N. Similarity search using sparse pivots for efficient multimedia information retrieval. In: Proceedings of the IEEE International Symposium on Multimedia (ISM). Washington, DC, USA: IEEE Computer Society, 2006. p. 881-888.

BUDIKOVA, P.; BATKO, M.; ZEZULA, P. Query language for complex similarity queries. In: Proceedings of the East European Conference on Advances in Databases and Information Systems: 16th East European Conference (ADBIS 2012). Berlin, Heidelberg: Springer Berlin Heidelberg, 2012. p. 85-98.

CAPANNINI, G.; NARDINI, F. M.; PEREGO, R.; SILVESTRI, F. Efficient diversification of web search results. Proceedings of the VLDB Endowment, v. 4, n. 7, p. 451-459, 2011.

CARBONELL, J.; GOLDSTEIN, J. The use of mmr, diversity-based reranking for reordering documents and producing summaries. In: Proceedings of the International ACM Conference on Research and development in information retrieval (SIGIR). New York, USA: ACM, 1998. p. 335-336.

CARVAlHO, L. O.; SANTOS, L. F. D.; OLIVEIRA, W. D.; TRAINA, A. J. M.; TRAINA JR., C. Self similarity wide-joins for near-duplicate image detection. In: Proceedings of IEEE International symposium on Multimedia (ISM). Miami, USA: IEEE, 2015. p. $237-240$.

CARVAlHO, L. O.; SANTOS, L. F. D.; OliveIRA, W. D.; TRAINA, A. J. M.; JR., C. T. Efficient self-similarity range wide-joins fostering near-duplicate image detection in emergency scenarios. In: Proceedings of the International Conference on Enterprise Information Systems (ICEIS). Rome, Italy: SciTePress, 2016. p. 81-91.

CATAllo, I.; CICERI, E.; FRATERnAli, P.; MARTINENGHI, D.; TAGLIASACCHI, M. Top-k diversity queries over bounded regions. ACM Trans. Database Syst., v. 38, n. 2, p. 10:1-10:44, 2013.

CHAKRABARTI, K.; ORTEGA-BINDERBERGER, M.; MEHROTRA, S.; PORKAEW, K. Evaluating refined queries in top-k retrieval systems. IEEE Trans. on Knowl. and Data Eng., v. 16, n. 2, p. 256-270, February 2004.

CHANG, F.; DEAN, J.; GHEMAWAT, S.; HSIEH, W. C.; WALLACH, D. A.; BURROWS, M.; CHANDRA, T.; FIKES, A.; GRUBER, R. E. Bigtable: A distributed storage system for structured data. ACM Trans. Comput. Syst., v. 26, n. 2, p. 4:1-4:26, 2008.

CHAUDHURI, S. What next?: a half-dozen data management research goals for big data and the cloud. In: PODS. New York, USA: ACM, 2012. p. 1-4.

CHEEMA, M.; LIN, X.; WANG, W.; ZHANG, W.; PEI, J. Probabilistic reverse nearest neighbor queries on uncertain data. Knowledge and Data Engineering, IEEE Transactions on, v. 22, n. 4, p. 550-564, 2010. 
CHEN, L.; GAO, Y.; LI, X.; JENSEN, C. S.; CHEN, G. Efficient metric indexing for similarity search and similarity joins. IEEE Trans. Knowl. Data Eng., v. 29, n. 3, p. 556-571, 2017.

CHEN, Z.; LI, T. Addressing diverse user preferences in sql-query-result navigation. In: Proceedings of the ACM international conference on Management of data (SIGMOD). New York, USA: ACM, 2007. p. 641-652.

CIACCIA, P.; PATELLA, M.; ZEZULA, P. M-tree: An efficient access method for similarity search in metric spaces. In: Proceedings of the International Conference on Very Large Data Bases (VLDB). San Francisco, USA: Morgan Kaufmann Publishers Inc., 1997. p. 426-435.

ClARKE, C. L.; KOLlA, M.; CORMACK, G. V.; VECHTOMOVA, O.; ASHKAN, A.; BüTTCHER, S.; MACKINNON, I. Novelty and diversity in information retrieval evaluation. In: Proceedings of the International ACM conference on Research and development in information retrieval (SIGIR). New York, USA: ACM, 2008. p. 659-666.

CUZZOCREA, A.; SONG, I.-Y.; DAVIS, K. C. Analytics over large-scale multidimensional data: the big data revolution! In: Proceedings of the ACM International workshop on Data Warehousing and OLAP (DOLAP). New York, USA: ACM, 2011. p. 101-104.

DATTA, R.; JOSHI, D.; LI, J.; WANG, J. Z. Image retrieval: Ideas, influences and trends of the new age. ACM Computing Surveys, v. 40, n. 2, p. 5.1-5.60, 2008.

DEAN, J.; GHEMAWAT, S. Mapreduce: Simplified data processing on large clusters. In: Proceedings of the Conference on Symposium on Opearting Systems Design \& Implementation (OSDI). Berkeley, USA: USENIX Association, 2004. p. 10-10.

Mapreduce: Simplified data processing on large clusters. Commun. ACM, v. 51, n. 1, p. 107-113, 2008.

DECANDIA, G.; HASTORUN, D.; JAMPANI, M.; KAKULAPATI, G.; LAKSHMAN, A.; PILCHIN, A.; SIVASUBRAMANIAN, S.; VOSSHALL, P.; VOGELS, W. Dynamo: Amazon's highly available key-value store. SIGOPS Oper. Syst. Rev., v. 41, n. 6, p. 205-220, 2007.

DENG, K.; XU, H.; SADIQ, S.; LU, Y.; FUNG, G. P. C.; SHEN, H. T. Processing group nearest group query. In: . Los Alamitos, CA, USA: IEEE Computer Society, 2009. p. 11441147.

DESERNO, T. M.; ANTANI, S.; LONG, R. Ontology of gaps in content-based image retrieval. Journal of digital imaging : the official journal of the Society for Computer Applications in Radiology, v. 22, n. 2, p. 202-15, 2009.

DIAS, R. L.; BUENO, R.; RIBEIRO, M. X. Reducing the complexity of k-nearest diverse neighbor queries in medical image datasets through fractal analysis. In: Proceedings of IEEE Symposium on Computer-Based Medical Systems (CBMS). New York, USA: IEEE, 2013. p. 101-106.

DING, X.; LIAN, X.; CHEN, L.; JIN, H. Continuous monitoring of skylines over uncertain data streams. Inf. Sci., Elsevier Science Inc., New York, USA, v. 184, n. 1, p. 196-214, 2012. 
DOU, Z.; HU, S.; CHEN, K.; SONG, R.; WEN, J. Multi-dimensional search result diversification. In: Proceedings of the ACM international conference on Web search and data mining. Washington, USA: ACM, 2011. p. 475-484.

DROSOU, M.; PITOURA, E. Search result diversification. ACM SIGMOD Record, ACM, v. 39, n. 1, p. 41-47, 2010. ISSN 0163-5808.

DisC diversity: Result diversification based on dissimilarity and coverage. PVLDB, v. 6, n. 1, p. 13-24, 2012.

Poikilo: A tool for evaluating the results of diversification models and algorithms.

Proc. VLDB Endow., v. 6, n. 12, p. 1246-1249, 2013.

Diverse set selection over dynamic data. IEEE Trans. on Knowl. and Data Eng., v. 26, n. 5, p. 1102-1116, 2014.

Multiple radii disc diversity: Result diversification based on dissimilarity and coverage. ACM Trans. Database Syst., v. 40, n. 1, p. 4:1-4:43, 2015.

ELER, D. M.; NAKAZAKI, M. Y.; PAULOVICH, F. V.; SANTOS, D. P.; ANDERY, G. F.; OLIVEIRA, M. C. F.; NETO, J. B.; MINGHIM, R. Visual analysis of image collections. The Visual Computer, v. 25, n. 10, p. 923-937, 2009.

EMRICH, T.; KRIEGEL, H.-P.; KRÖGER, P.; NIEDERMAYER, J.; RENZ, M.; ZÜFLE, A. On reverse-k-nearest-neighbor joins. GeoInformatica, v. 19, n. 2, p. 299-330, 2015.

FALOUTSOS, C.; LIN, K.-I. Fastmap: a fast algorithm for indexing, data-mining and visualization of traditional and multimedia datasets. SIGMOD Rec., v. 24, n. 2, p. 163-174, 1995.

FEGARAS, L.; LI, C.; GUPTA, U. An optimization framework for map-reduce queries. In: Proceedings of the International Conference on Extending Database Technology (EDBT). New York, USA: ACM, 2012. p. 26-37.

FEO, T. a. Greedy Randomized Adaptive Search Procedures. Journal of Global Optimization, v. 68, n. 2, p. 93-133, 1995.

FRATERNALI, P.; MARTINENGHI, D.; TAGLIASACCHI, M. Top-k bounded diversification. In: Proceedings of the ACM International Conference on Management of Data (SIGMOD). New York, USA: ACM, 2012. p. 421-432.

GAGAUDAKIS, G.; ROSIN, P. Using cbir and pathfinder networks for image database visualisation. In: Proceedings of the International Conference on Pattern Recognition (ICPR). Barcelona, Spain: IEEE Comput. Soc, 2000. p. 1052-1055.

GALLAS, A.; BARHOUMI, W.; ZAGROUBA, E. Negative relevance feedback for improving retrieval in large-scale image collections. In: Proceedings of IEEE International Symposium on Multimedia (ISM). Taichung, Taiwan: IEEE, 2014. p. 1-8.

GIL-COSTA, V.; SANTOS, R. L. T.; MACDONALD, C.; OUNIS, I. Sparse spatial selection for novelty-based search result diversification. In: Proceedings of the International conference on String processing and information retrieval (SPIRE). Berlin, Heidelberg: Springer-Verlag, 2011. p. 344-355. 
GOLLAPUDI, S.; SHARMA, A. An axiomatic approach for result diversification. In: Proceedings of the International conference on World wide web (WWW). New York, USA: ACM, 2009. p. 381-390.

GUI, S.; RICE, A. P.; CHEN, R.; WU, L.; LIU, J.; MIAO, H. A scalable algorithm for structure identification of complex gene regulatory network from temporal expression data. BMC Bioinformatics, v. 18, n. 1, p. 74:1-74:13, 2017.

HALL, M. W.; KIRBY, R. M.; LI, F.; MEYER, M. D.; PASCUCCI, V.; PHILLIPS, J. M.; RICCI, R.; MERWE, J. E. van der; VENKATASUBRAMANIAN, S. Rethinking abstractions for big data: Why, where, how, and what. CoRR, abs/1306.3295, 2013.

HE, X.; CAI, D.; HAN, J. Learning a maximum margin subspace for image retrieval. IEEE Transactions on Knowledge and Data Engineering, v. 20, p. 189-201, 2008.

HONG, C.; ZHU, J. Hypergraph-based multi-example ranking with sparse representation for transductive learning image retrieval. Neurocomput., v. 101, p. 94-103, 2013.

HU, H.; LEE, D. L. Range nearest-neighbor query. IEEE Trans. on Knowl. and Data Eng., v. 18, n. 1, p. 78-91, 2006.

HU, Q. G. G. An interactive image feature visualization system for supporting cbir study. Image Analysis and Recognition, v. 5627, n. 1, p. 239-247, 2009.

HUANG, Y. Location-based aggregate queries for heterogeneous neighboring objects. IEEE Access, v. 5, n. 1, p. 4887-4899, 2017.

ISLAM, M. S.; LIU, C.; ZHOU, R. Flexiq: A flexible interactive querying framework by exploiting the skyline operator. Journal of Systems and Software, v. 97, n. 1, p. 97-117, 2014 .

JACOBS, A. The pathologies of big data. Commun. ACM, ACM, New York, USA, v. 52, n. 8, p. 36-44, 2009.

JACOX, E. H.; SAMET, H. Spatial join techniques. ACM Trans. Database Syst., v. 32, n. $1,2007$.

JAIN, A.; SARDA, P.; HARITSA, J. Providing diversity in k-nearest neighbor query results. In: Advances in Knowledge Discovery and Data Mining. [S.l.]: Springer Berlin / Heidelberg, 2004, (Lecture Notes in Computer Science, v. 3056).

JOIA, P.; PAUlOVICH, F. V.; COIMBRA, D.; CUMINATO, J. A.; NONATO, L. G. Local affine multidimensional projection. IEEE TVCG, v. 17, n. 12, p. 2563-2571, 2011.

KARIM, S.; HARRIS, M.; ARIF, M. Navigational pattern based relevance feedback using user profile in CBIR. Int. Arab J. Inf. Technol., v. 13, n. 6A, p. 867-872, 2016.

KASTER, D. S.; OLIVEIRA, W. D.; BUEnO, R.; TRAINA, A. J. M.; JR, C. T. Nearest neighbor queries with counting aggregate-based conditions. Journal of Information and Data Management, v. 2, n. 3, p. 401-416, 2011.

KATAYAMA, N.; SATOH, S. Distinctiveness-sensitive nearest-neighbor search for efficient similarity retrieval of multimedia information. In: Proceedings of the IEEE International Conference on Data Engineering (ICDE). Heidelberg, Germany: IEEE Computer Society, 2001. p. 493-502. 
KEIM, D. A. et al. Information visualization and visual data mining. IEEE TVCG, v. 8, n. 1, p. 1-8, 2002.

KHAN, H. A.; DROSOU, M.; SHARAF, M. A. Scalable diversification of multiple search results. In: Proceedings of the ACM International Conference on Information \& Knowledge Management (CIKM). New York, USA: ACM, 2013. p. 775-780.

KORN, F.; MUTHUKRISHNAN, S. Influence sets based on reverse nearest neighbor queries. SIGMOD Rec., v. 29, n. 2, p. 201-212, 2000.

KORN, F.; SIDIROPOUlOS, N.; FALOUTSOS, C.; SIEGEL, E.; PROTOPAPAS, Z. Fast nearest neighbor search in medical image databases. In: Proceedings of the International Conference on Very Large Data Bases (VLDB). San Francisco, USA: Morgan Kaufmann Publishers Inc., 1996. p. 215-226.

LEUKEN, R. H. V.; GARCIA, L.; OLIVARES, X.; ZWOL, R. van. Visual diversification of image search results. In: Proceedings of the International conference on World wide web (WWW). New York, USA: ACM, 2009. p. 341-350.

LEVENSHTEIN, V. I. Binary codes capable of correcting deletions, insertions, and reversals. Cybernetics and Control Theory, v. 10, n. 8, p. 707-710, 1966.

LI, J.; YAN, Y.; LEMIRE, D. Scaling up web service composition with the skyline operator. In: Proceedings of the International Conference on Web Services (ICWS). San Francisco, USA: IEEE, 2016. p. 147-154.

LI, Y.; LI, F.; YI, K.; YAO, B.; WANG, M. Flexible aggregate similarity search. In: Proceedings of the ACM International Conference on Management of Data (SIGMOD). New York, USA: ACM, 2011. p. 1009-1020.

LIMA L. ELON. Espaços Métricos. 3. ed. [S.1.]: Instituto Nacional de Matemática Pura e Aplicada, 1993.

LIU, W.; SHEN, Y.; WANG, P. An efficient mapreduce algorithm for similarity join in metric spaces. The Journal of Supercomputing, v. 72, n. 3, p. 1179-1200, 2016.

LIU, Y.; DUBE, P.; GRAY, S. C. Run-time performance optimization of a bigdata query language. In: Proceedings of the ACM/SPEC International Conference on Performance Engineering (ICPE). New York, USA: ACM, 2014. p. 239-246.

LOUKIDES, M. What is data science? O`Reilly radar, 2010. Disponível em: <http://radar.oreilly.com/2010/06/what-is-data-science.html>.

LU, J.; LU, Y.; CONG, G. Reverse spatial and textual k nearest neighbor search. In: Proceedings of the ACM International Conference on Management of Data (SIGMOD). Athens, Greece: ACM, 2011. p. 349-360.

MADDEN, S. From databases to big data. Internet Computing, IEEE, v. 16, n. 3, p. 4-6, 2012.

MAO, Y.; SHEN, H.; SUN, C. Diversification of web search results through social interest mining. In: Proceedings of the Hawaii International Conference on System Sciences (HICSS). Washington, USA: IEEE Computer Society, 2012. p. 3581-3590. 
MCNEE, S. M.; RIEDL, J.; KONSTAN, J. A. Being accurate is not enough: how accuracy metrics have hurt recommender systems. In: Extended abstracts on Human factors in computing systems (CHI). New York, USA: ACM, 2006. p. 1097-1101.

MOISE, D.; SHESTAKOV, D.; GUDMUNDSSON, G.; AMSALEG, L. Indexing and searching 100m images with map-reduce. In: Proceedings of the ACM Conference on International Conference on Multimedia Retrieval (ICMR). New York, USA: ACM, 2013. p. 17-24.

MÜLLER, H.; DESELAERS, T.; DESERNO, T.; CRAMER, J. K.; KIM, E.; HERSH, W. Overview of the imageclefmed 2007 medical retrieval and medical annotation tasks. In: Advances in Multilingual and Multimodal Information Retrieval. [S.l.]: Springer Berlin Heidelberg, 2008, (Lecture Notes in Computer Science, v. 5152). p. 472-491.

NEGI, S.; JAJU, A.; CHAUDHURY, S. Search result diversification in flickr. In: Proceedings of the International Conference on Communication Systems and Networks (COMSNETS). [S.l.: s.n.], 2016. p. 1-6.

NEVEOL, A.; DESERnO, T. M.; DARMONI, S. J.; GOLD, M. O.; ARONSON, A. R. Natural language processing versus content-based image analysis for medical document retrieval. Journal of the American Society for Information Science and Technology (JASIST), v. 60, n. 1, p. 123-134, 2009.

OZSOY, M. G.; ONAL, K. D.; ALTINGOVDE, I. S. Result diversification for tweet search. In: Proceedings of the International conference on Web Information Systems Engineering (WISE). Thessaloniki, Greece: Springer International Publishing, 2014. p. 78-89.

PAPADIAS, D.; SHEN, Q.; TAO, Y.; MOURATIDIS, K. Group nearest neighbor queries. In: . Los Alamitos, CA, USA: IEEE Computer Society, 2004. p. 301.

PAPADIMITRIOU, S.; SUN, J. Disco: Distributed co-clustering with map-reduce: A case study towards petabyte-scale end-to-end mining. In: Proceedings of the IEEE International Conference on Data Mining (ICDM). New York, USA: IEEE, 2008. p. 512-521.

PLANT, W.; SCHAEFER, G. Interactive exploration of large remote image databases. In: Proceedings of the ACM International Conference on Multimedia (MM). New York, USA: ACM, 2012. p. 1305-1306.

RAZENTE, H. Adequando consultas por similaridade para reduzir a descontinuidade semântica na recuperação de imagens por conteúdo. Tese (Tese de Doutorado em Ciências de Computação e Matemática Computacional) — Instituto de Ciências Matemáticas e de Computação, Universidade de São Paulo, 2009.

RAZENTE, H. L.; BARIONI, M. C. N.; TRAinA, A. J. M.; FAlOUTSOS, C.; JR., C. T. A novel optimization approach to efficiently process aggregate similarity queries in metric access methods. In: Proceeding of the ACM conference on Information and knowledge management (CIKM). New York, USA: ACM, 2008. p. 193-202.

RESENDE, M. G. Greedy randomized adaptive search procedures. p. 1460-1469, 2009.

SAFAR, M.; EL-AMIN, D.; TANIAR, D. Optimized skyline queries on road networks using nearest neighbors. Personal Ubiquitous Comput., v. 15, n. 8, p. 845-856, 2011. 
SAMET, H. Foundations of Multidimensional and Metric Data Structures (The Morgan Kaufmann Series in Computer Graphics and Geometric Modeling). San Francisco, USA: Morgan Kaufmann Publishers Inc., 2005.

SANTOS, L. F. D.; BEDO, M. V. N.; PONCIANO-SILVA, M.; TRAINA, A. J. M.; JR., C. T. Being similar is not enough: How to bridge usability gaps trough diversity in medical images. In: Proceedings of IEEE Symposium on Computer-Based Medical Systems (CBMS). New York, USA: IEEE, 2014. p. 287-293.

SANTOS, L. F. D.; OLIVEIRA, W. D.; FERREIRA, M. R. P.; TRAINA, A. J. M.; JR., C. T. Parameter-free and domain-independent similarity search with diversity. In: Proceedings of the International Conference on Scientific and Statistical Database Management (SSDBM). New York, USA: ACM, 2013. p. 5:1-5:12.

SANTOS, R. L.; MACDONALD, C.; OUNIS, I. Exploiting query reformulations for web search result diversification. In: Proceedings of the International conference on World wide web (WWW). New York, USA: ACM, 2010. p. 881-890.

SANTOS, R. L. T.; MACDONALD, C.; OUNIS, I. Aggregated search result diversification. In: Proceedings of the International conference on Advances in information retrieval theory (ICTIR). Berlin, Heidelberg: Springer-Verlag, 2011. p. 250-261.

Search result diversification. Foundations and Trends in Information Retrieval, v. 9, n. 1, p. 1-90, 2015.

SCHADT, E. E.; LINDERMAN, M. D.; SORENSON, J.; LEE, L.; NOLAN, G. P. Computational solutions to large-scale data management and analysis. Nature Reviews Genetics, v. 11, p. $647-657,2010$.

SILVA, Y. N.; AREF, W. G.; ALI, M. H. Similarity group-by. In: Proceedings of the IEEE International Conference on Data Engineering (ICDE). Shanghai, China: IEEE Computer Society, 2009. p. $904-915$.

The similarity join database operator. In: Proceedings of the IEEE International Conference on Data Engineering (ICDE). Long Beach, California, USA: IEEE Computer Society, 2010. p. 892-903.

SILVA, Y. N.; AREF, W. G.; LARSON, P.-Å.; PEARSON, S.; ALI, M. H. Similarity queries: their conceptual evaluation, transformations, and processing. VLDB J., v. 22, n. 3, p. 395420, 2013.

SILVA, Y. N.; AREF, W. G.; LARSON, P.-A.; PEARSON, S. S.; ALI, M. H. Similarity queries: their conceptual evaluation, transformations, and processing. The International Journal on Very Large Databases, v. 22, n. 3, p. 395-420, 2013.

SILVA, Y. N.; REED, J. M. Exploiting mapreduce-based similarity joins. In: Proceedings of the ACM International Conference on Management of Data (SIGMOD). New York, USA: ACM, 2012. p. 693-696.

SKOPAL, T.; DOHNAL, V.; BATKO, M.; ZEZULA, P. Distinct nearest neighbors queries for similarity search in very large multimedia databases. In: Proceedings of the International Workshop on Web Information and Data Management (WIDM). Hong Kong, China: ACM, 2009. p. 11-14. 
SMYTH, B.; MCCLAVE, P. Similarity vs. diversity. In: Proceedings of the International Conference on Case-Based Reasoning: Case-Based Reasoning Research and Development. Vancouver, Canada: Springer, 2001. p. 347-361.

STRICKER, M. O. M. A. Similarity of color images. In: Proceedings of the International Conference on Storage and Retrieval for Image and Video Databases (SPIE). San Jose, CA, USA: SPIE, 1995. p. 381-392.

SURATANEE, A.; PLAIMAS, K. Identification of inflammatory bowel disease-related proteins using a reverse k-nearest neighbor search. J. Bioinformatics and Computational Biology, v. 12, n. 4, p. 1450017, 2014.

TANG, M.; TAHBOUB, R. Y.; AREF, W. G.; ATALLAH, M. J.; MALLUHI, Q. M.; OUZZANI, M.; SILVA, Y. N. Similarity group-by operators for multi-dimensional relational data. IEEE Transactions on Knowledge and Data Engineering, v. 28, n. 2, p. 510-523, 2016.

TAO, Y.; YIU, M. L.; MAMOULIS, N. Reverse nearest neighbor search in metric spaces. IEEE Transactions on Knowledge and Data Engineering, v. 18, p. 1239-1252, 2006.

TEODORO, G.; VALLE, E.; MARIANO, N.; TORRES, R.; MEIRA JR., W. Adaptive parallel approximate similarity search for responsive multimedia retrieval. In: Proceedings of the ACM International Conference on Information and Knowledge Management (CIKM). New York, USA: ACM, 2011. p. 495-504.

TRAINA JR., C.; TRAINA, A. J.; FALOUTSOS, C.; SEEGER, B. Fast indexing and visualization of metric data sets using slim-trees. IEEE Transactions on Knowledge and Data Engineering, v. 14, p. 244-260, 2002.

VEE, E.; SRIVASTAVA, U.; SHANMUGASUNDARAM, J.; BHAT, P.; YAHIA, S. Efficient computation of diverse query results. In: Proceedings of the IEEE Intenational Conference on Data Engineering (ICDE). New York, USA: IEEE, 2008. p. 228 -236.

VENKATESWARAN, J.; KAHVECI, T.; JERMAINE, C.; LACHWANI, D. Reference-based indexing for metric spaces with costly distance measures. The VLDB Journal, v. 17, n. 5, p. 1231-1251, 2008.

VERNICA, R.; CAREY, M. J.; LI, C. Efficient parallel set-similarity joins using mapreduce. In: Proceedings of the ACM International Conference on Management of Data (SIGMOD). New York, USA: ACM, 2010. p. 495-506.

VIEIRA, M.; RAZENTE, H.; BARIONI, M.; HADJIELEFTHERIOU, M.; SRIVASTAVA, D.; TRAINA, C.; TSOTRAS, V. On query result diversification. In: Proceedings of the IEEE International Conference on Data Engineering (ICDE). New York, USA: IEEE, 2011. p. $1163-1174$.

VIEIRA, M. R.; RAZENTE, H. L.; BARIONI, M. C. N.; HADJIELEFTHERIOU, M.; SRIVASTAVA, D.; JR., C. T.; TSOTRAS, V. J. Divdb: A system for diversifying query results. PVLDB, v. 4, n. 12, p. 1395-1398, 2011.

WANG, J. Z.; LI, J.; WIEDERHOLD, G. Simplicity: Semantics-sensitive integrated matching for picture libraries. IEEE TPAMI, v. 23, n. 9, p. 947-963, 2001. 
WANG, W.; ZHU, K.; YING, L.; TAN, J.; ZHANG, L. Maptask scheduling in mapreduce with data locality: Throughput and heavy-traffic optimality. IEEE/ACM Transactions on Networking, v. 24, n. 1, p. 190-203, 2016.

WELTER, P.; FISCHER, B.; GUNTHER, R. W.; LEHMANN), T. M. Deserno (n. Generic integration of content-based image retrieval in computer-aided diagnosis. Computer Methods and Programs in Biomedicine, v. 108, n. 2, p. 589-599, 2012.

WILSON, D. R.; MARTINEZ, T. R. Improved heterogeneous distance functions. Journal of Artificial Intelligence Research, v. 6, p. 1-34, 1997.

WU, L. Flickr distance: A relationship measure for visual concepts. IEEE Transactions on Pattern Analysis and Machine Intelligence, v. 34, n. 5, p. 863-875, 2012.

XIAO, C.; WANG, W.; LIN, X.; SHANG, H. Top-k set similarity joins. In: Proceedings of the IEEE International Conference on Data Engineering (ICDE). Shanghai, China: IEEE Computer Society, 2009. p. 916-927.

YAO, B.; LI, F.; KUMAR, P. Reverse furthest neighbors in spatial databases. In: . Los Alamitos, CA, USA: IEEE Computer Society, 2009. p. 664-675.

K nearest neighbor queries and knn-joins in large relational databases (almost) for free. In: LI, F.; KUMAR, P. (Ed.). International Conference on Data Engineering. Long Beach, CA, USA: IEEE Computer Society, 2010. p. 4-15.

YIANILOS, P. N. Data structures and algorithms for nearest neighbor search in general metric spaces. In: Proceedings of the ACM-SIAM Symposium on Discrete algorithms (SODA). Philadelphia, USA: Society for Industrial and Applied Mathematics, 1993. p. 311321.

YU, C.; LAKSHMANAN, L.; AMER-YAHIA, S. Recommendation diversification using explanations. In: Proceedings of the IEEE International Conference on Data Engineering (ICDE). New York, USA: IEEE, 2009. p. 1299 -1302.

ZEZUla, P.; AMATO, G.; DOHnAL, V.; BATKO, M. Similarity Search: The Metric Space Approach. New York, USA: Springer New York, 2006. (Advances in Database Systems).

ZHANG, W.; LIN, X.; ZHANG, Y.; WANG, W.; ZHU, G.; YU, J. X. Probabilistic skyline operator over sliding windows. Information Systems, v. 38, n. 8, p. 1212-1233, 2013.

ZHANG, W.; ZHAN, L.; ZHANG, Y.; CHEEMA, M. A.; LIN, X. Efficient top-k similarity join processing over multi-valued objects. World Wide Web, v. 17, n. 3, p. 285-309, 2014.

ZHOU, T.; KUSCSIK, Z.; LIU, J.; MEDO, M. Solving the apparent diversity-accuracy dilemma of recommender systems. In: . Washington, USA: [s.n.], 2010. p. 4511-4515.

ZIEGLER, C.; LAUSEN, G.; SCHMIDT-THIEME, L. Taxonomy-driven computation of product recommendations. In: Proceedings of the ACM international conference on Information and knowledge management (CIKM). New York, USA: ACM, 2004. p. 406-415.

ZIEGLER, C.-N.; MCNEE, S. M.; KONSTAN, J. A.; LAUSEN, G. Improving recommendation lists through topic diversification. In: Proceedings of the International conference on World Wide Web (WWW). New York, USA: ACM, 2005. p. 22-32. 


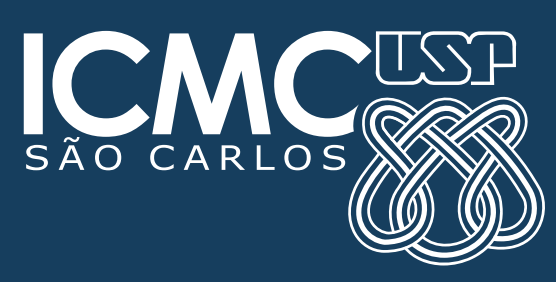

